\title{
El despliegue del Estado en el poblamiento de la Montaña del Quindío y la fundación de Santa Rosa de Cabal. 1840-1845
}

Alonso Molina Corrales
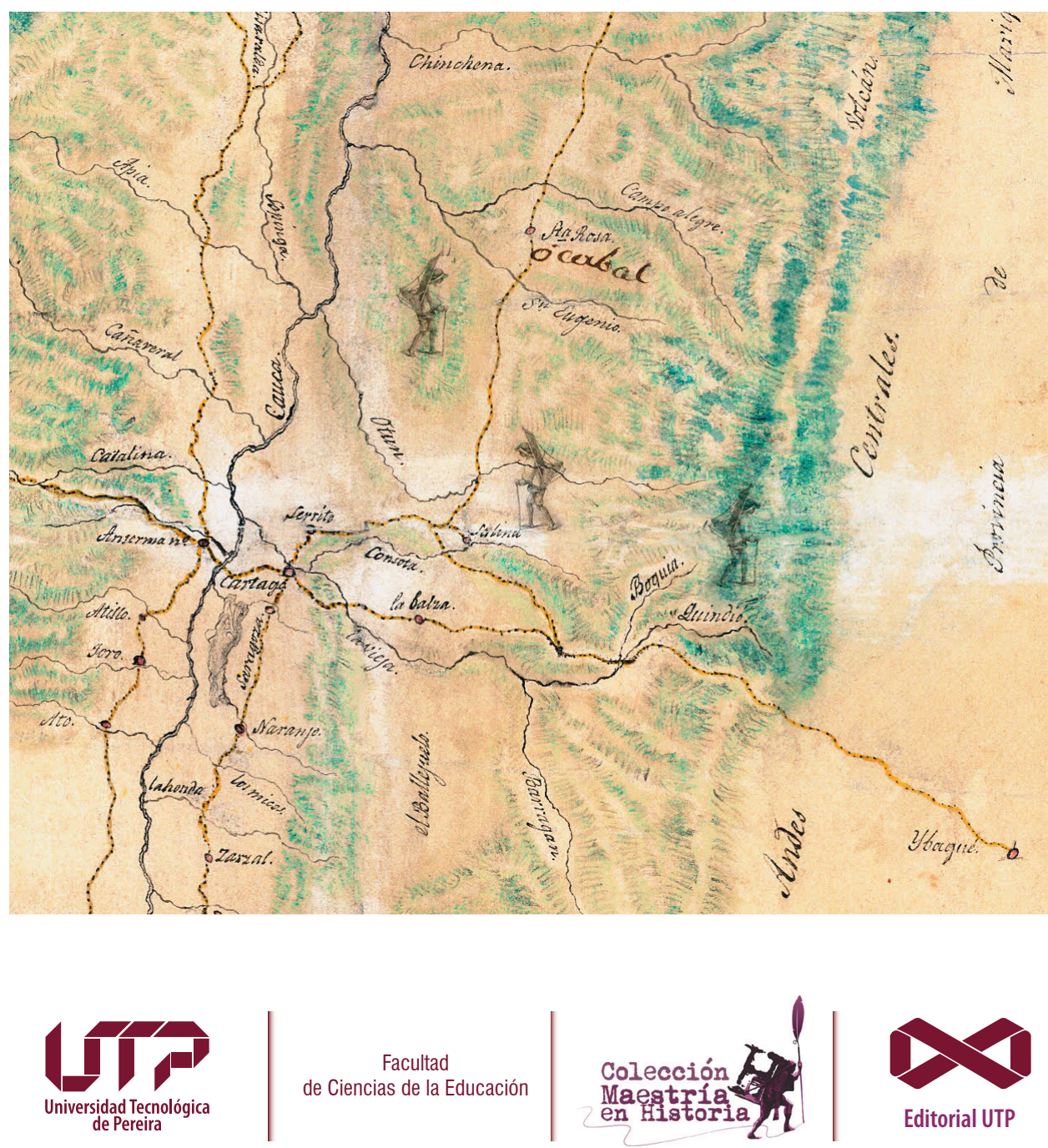


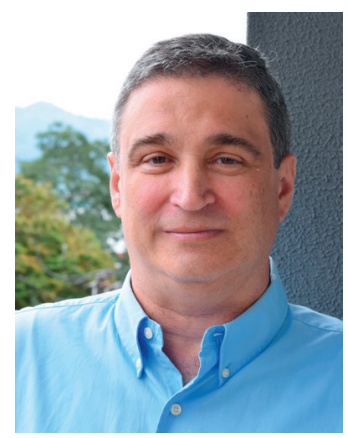

Alonso Molina Corrales, Guadalajara de Buga, 1965

Magister en Historia de la Universidad Tecnológica de Pereira. Abogado y Especialista en Derecho Administrativo de la Universidad Libre, seccional Pereira. Comunicador Social-Periodista de la Universidad Jorge Tadeo Lozano. Docente auxiliar transitorio, adscrito a la Facultad de Ciencias de la Educación de la Universidad Tecnológica de Pereira. Coautor del libro "La Historia pasa por el Rialto", 1997. Autor del libro "Desde las Termópilas. Periodismo para la Memoria", 2009. Miembro del Grupo de Investigación "Políticas, sociabilidades representaciones histórico - educativas."

alonsomolinacorrales@utp.edu.co 


\section{EL DESPLIEGUE DEL ESTADO EN EL POBLAMIENTO DE LA MONTAÑA DEL QUINDIO Y LA FUNDACIÓN DE SANTA ROSA DE CABAL 1840-1845}

\section{Alonso Molina Corrales}

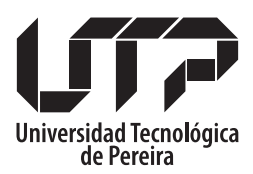

Facultad de Ciencias de la Educación Maestría en Historia 


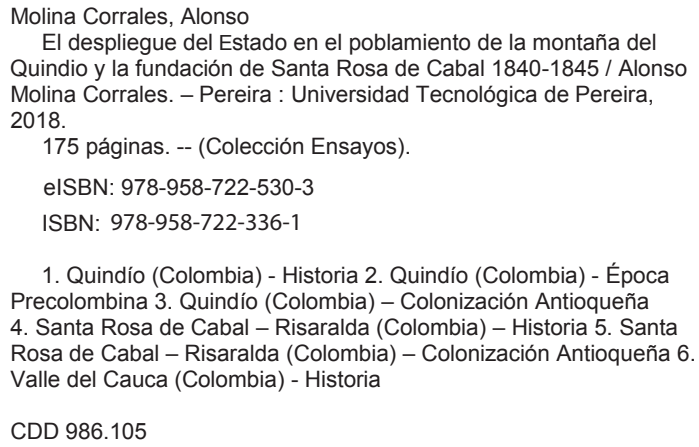

(C)Alonso Molina Corrales, 2019

CCUniversidad Tecnológica de Pereira, 2019

Primera edición

eISBN: 978-958-722-530-3

ISBN: 978-958-722-336-1

\section{Ensayo:}

El despliegue del Estado en el poblamiento de la Montaña del Quindío y la Fundación de Santa Rosa de Cabal Universidad Tecnológica de Pereira

Vicerrectoría de Investigaciones, Innovación y Extensión

Editorial Universidad Tecnológica de Pereira

\section{Coordinador editorial:}

Luis Miguel Vargas Valencia

luismvargas@utp.edu.co

Tel: 3137381

Edificio 9 Biblioteca central “Jorge Roa Martínez" 9/N1/110

Cra 27 No. 10-02 Los Álamos

Pereira, Colombia

www.utp.edu.co

\section{Montaje y producción:}

Universidad Tecnológica de Pereira

Centro de Recursos Informáticos y Educativos CRIE

\section{Impresión y acabados:}

Publiprint

Dosquebradas

Imagen portada: Detalle carta corográfica de la provincia del Cauca en 1843, elaborada por Gabriel Ambrosio de la Roche. 


Para quien no ha estado ahora y para quien siempre estará. En memoria de mi padre, Gerardo José Molina Cabal. 

AGRADECIMIENTOS

Este trabajo que hoy tiene en sus manos, no hubiera sido posible, sin la ayuda de muchas personas e instituciones. En primer lugar, la Maestría en Historia de la Universidad Tecnológica de Pereira y su cuerpo de docentes; entre los que debo destacar, por su apoyo en este esfuerzo, a Gustavo Guarín y Jhon Jaime Correa, quienes fueron sus directores mientras cursé las materias e hice la tesis; a los historiadores Sebastían Martínez Botero y Jaime Eduardo Londoño Motta, quienes me dirigieron en diversos momentos de la investigación, y a los profesores Sonia Milena Jaimes Peñaloza y a Carlos Alfonso Victoria Mena, siempre apoyando y dando ideas. También a los maestros Víctor Zuluaga Gómez, Ricardo De los Ríos Tobón y Albeiro Valencia Llano por sus opiniones e inspiración. Igualmente, resalto la ayuda del historiador Alonso Valencia Llano que me facilitó consultar fondos de algunos archivos históricos.

Del mismo modo, expreso mi gratitud al Archivo General de la Nación y a su equipo, entre los que debo destacar el respaldo de Mauricio Tovar. Igual al Archivo Central del Cauca y sus funcionarias que me orientaron con acierto, y al Archivo Histórico de Cartago, a su planta de personal y en especial a su directora Betty Valencia, que me abrió las puertas de la Casa del Virrey para investigar y hacer uso de su lector de microfilm para consultar miles de documentos. Cada ocho días Betty me recibía en la vieja casona, para que, con la ayuda vital de Cora Orozco, transcribiera los documentos que le darían peso histórico a la investigación que hoy presento.

También le doy las gracias a mi esposa Nohelia, por su apoyo y por la comprensión en las ausencias que demandó este trabajo. 



\section{CONTENIDO}

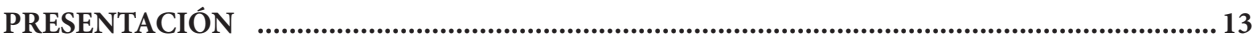

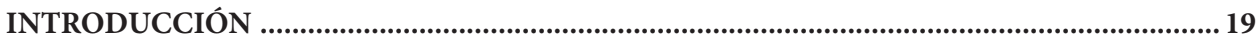

CAPÍTULO I

CONCLUSIONES DE UN BALANCE HISTORIOGRAFICO SOBRE FRONTERA,

COLONIZACIÓN ESTATAL, EL POBLAMIENTO DE LA MONTAÑA

DEL QUINDÍO Y LA FUNDACIÓN DE SANTA ROSA DE CABAL............................................ 25

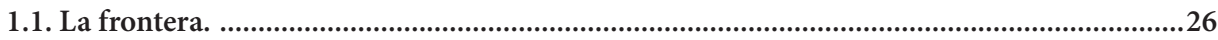

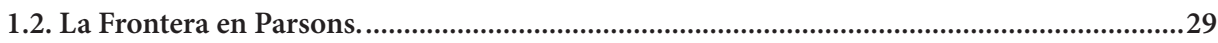

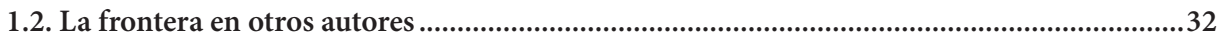

1.3. Nuevas jerarquías urbanas, nuevas fronteras. ……………………….....................................36

1.4. Una frontera que se expande y mueve su centro de impulsión................................................38

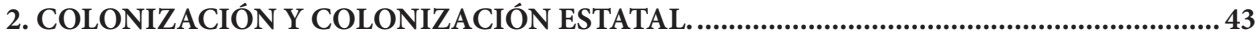

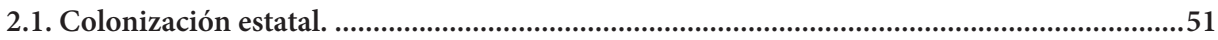

3. EL CAMINO DEL QUINDÍO Y LA FUNDACIÓN DE SANTA ROSA DE CABAL. .................59

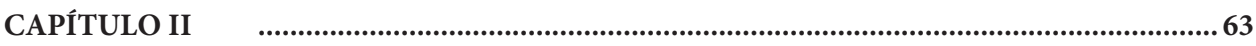

LA FRONTERA Y LA COLONIZACIÓN ESTATAL EN EL POBLAMIENTO

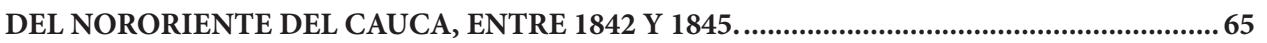

1. DEFINICIONES DE FRONTERA Y SU PRESENCIA EN EL

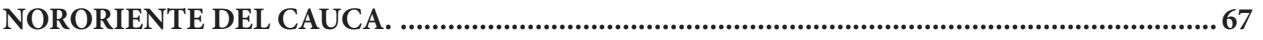

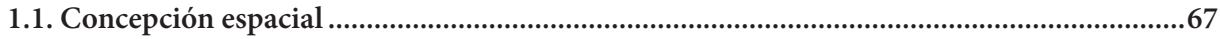

1.2. Concepción socio cultural.........................................................................................................69

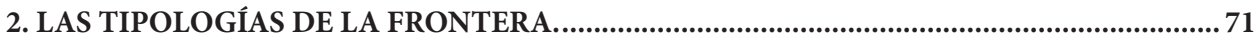

\section{DEFINICIONES DE COLONIZACIÓN ESTATAL Y SUS MANIFESTACIONES EN EL}

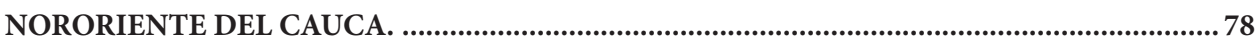

3.1. Las normas generales de la colonización estatal....................................................................... 81

3.2. Normas para la Montaña del Quindío y Santa Rosa de Cabal..............................................84

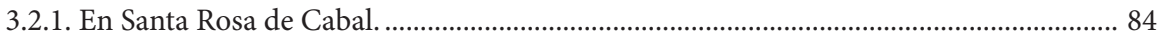

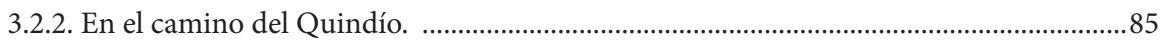

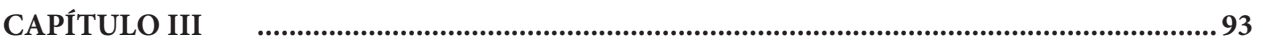

LA PROVINCIA DEL CAUCA Y SU FRONTERA NORORIENTAL, COMO ESCENARIOS PARA LA CONSTITUCIÓN DEL ESTADO, ENTRE 1842 Y 1845............................................. 95 
1.1. Los políticos aristocráticos caucanos........................................................................................98

2. EL PAPEL DE LA PROVINCIA DEL CAUCA EN LA CONSTRUCCIÓN DEL ESTADO

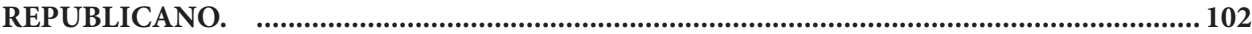

2.1. La penetración en la periferia territorial: Provincia del Cauca. ............................................103

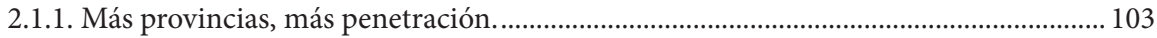

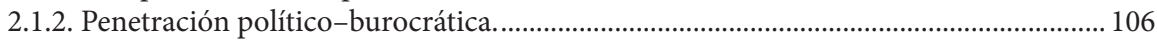

2.1.3. El camino del Quindío y la fundación de Santa Rosa de Cabal en la penetración de la

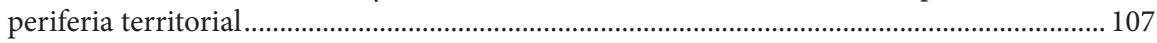

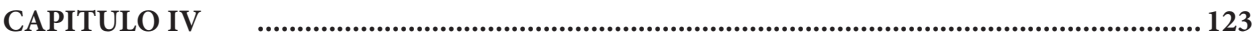

LA PRESENCIA DEL ESTADO COMO MODELADOR DE UNA REGIÓN............................... 125

1. NORMAS QUE ORIGINAN EL POBLAMIENTO DE LA MONTAÑA DEL QUINDÍO....... 126

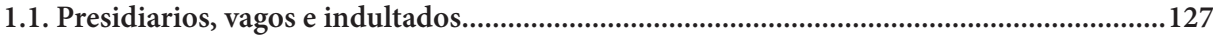

1.2. Presidio y camino: Las normas y su aplicación en la Montaña del Quindío........................137

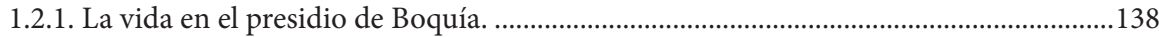

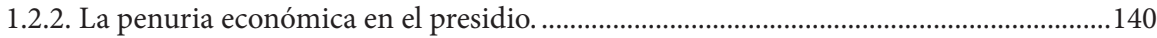

2. DECISIONES DESDE EL CAUCA: LA REAPERTURA DEL CAMINO DEL QUINDÍO...... 153

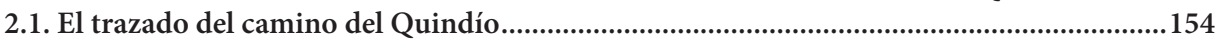

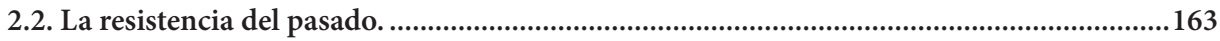

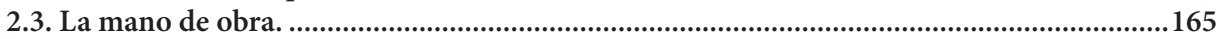

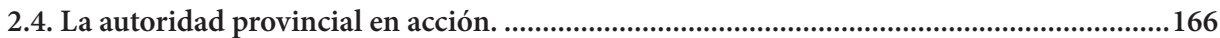

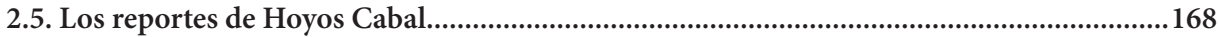

2.6. Una población en la Montaña del Quindío.........................................................................171

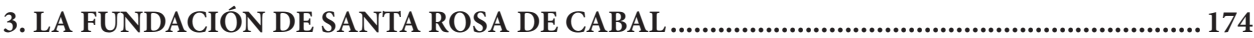

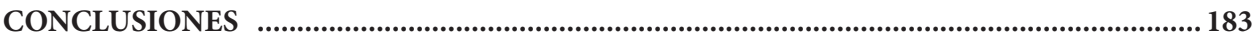

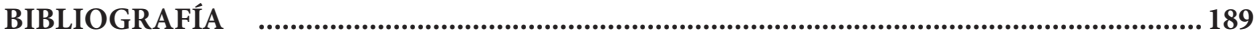

SITIOS WEB. 


\section{LISTA DE CUADROS}

Cuadro 1. Caucanos aristócratas en cuadro sinóptico de abogados de la Nueva Granada. FEBRERO 25 DE 1843

Cuadro 2. Censo de hijos de esclavos. Provincia del Cauca - 1843211....................................... 117

Cuadro 3. Presidio del Tercer Distrito, Boquía, Provincia del Cauca ....................................... 131

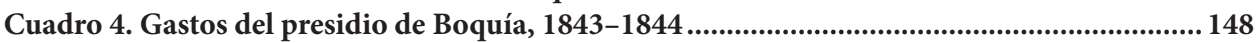

Cuadro 5. Reos de Boquía internados en el hospital, 1843-1844 ............................................... 149

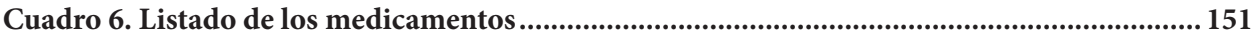

Cuadro 7. Gastos obras de desmonte del Camino del Quindío entre el

$1^{\circ}$ de agosto de 1844 y el 31 de enero de 1845 170

\section{LISTA DE MAPAS}

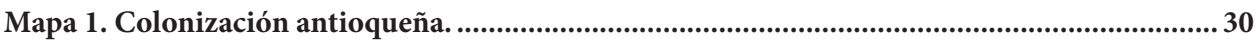

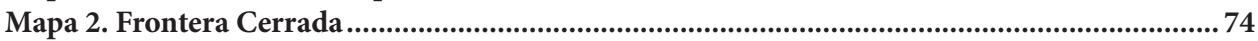

Mapa 3. Carta Corográfica de la Nueva Provincia del Cauca ....................................................... 105

Mapa 4. Zona de influencia del Camino del Quindío .................................................................... 162

Mapa 5. Croquis que ilustra la conveniencia de fundar a Santa Rosa de Cabal .......................... 180 



\section{PRESENTACIÓN}

La obra El despliegue del Estado en el poblamiento de la montaña del Quindío y la fundación de Santa Rosa de Cabal, 1840 - 1845; es una perfecta muestra de los propósitos que se ha trazado la maestría en Historia de la Universidad Tecnológica de Pereira. Tanto su contenido como todo el trasegar que significó ponerla en circulación, son la síntesis de la evolución que ha tenido la historia profesional en un escenario local como el de la ciudad de Pereira y su región más próxima. El lector podría sorprenderse por estas palabras, por ello esta presentación consistirá, de manera muy concreta, en explicarlas.

La ciudad de Pereira carece de una tradición humanística que haya logrado coagular la disciplina de la historia en estos territorios. Las instituciones de formación superior locales han fomentado mayormente el cultivo de las ciencias "útiles", lo cual ha conllevado a que apenas hace muy pocos años se iniciara una tradición académica en las disciplinas que se ocupan de entender las problemáticas sociales. Así, el conocimiento y estudio de la historia quedó vinculada a los letrados aldeanos que se preocuparon por dejar memorias, apostillas, apuntes y comentarios sobre el pasado local. Cronistas, publicistas y comunicadores han sido los elegidos para construir y transmitir la memoria histórica pereirana.

Esta condición creó una confusión entre los pereiranos que han considerado que quienes pueden escribir y son publicados, tienen el poder mágico del conocimiento. 
Si está escrito es porque es verdad, y si es verdad no precisa de refutación o puesta en cuestionamiento. El letrado aldeano pasó a ser una suerte de semi-dios que se dedicaba a elegir cuáles hechos deben ser recordados y cuáles no, pero además lo hacía en sus "ratos libres", pues ninguna institución o persona estaría dispuesta mantener una tarea de tan evidente poca "utilidad".

El inevitable contacto de las comunidades con corrientes de otras latitudes ha iniciado un cambio en estos comportamientos parroquiales. El siglo XXI llegó a Pereira con transformaciones de las que el propio autor de esta obra ha sido parte. La puesta en cuestionamiento de los referentes tradicionales del pasado local precisaban divulgarse para ser valorados y tomados como punto de partida y no como punto de llegada. En ejercicio de la dirección del Instituto Municipal de Cultura, Alonso Molina Corrales impulsó la reedición en el año 2002 de estas obras agrupadas bajo el título de "Colección Clásicos Pereiranos". Este hecho, que para cualquier ciudad parecería un tema más en la agenda cultural, para Pereira fue, a mi juicio, el detonante de un proceso que aún continúa madurando y que hoy nos permite tener en nuestras manos un trabajo de historia profesional como el presente libro.

La "Colección Clásicos Pereiranos" logró introducir un debate sobre el pasado local. La simple selección de los textos que debían ser reeditados permitió a los editores repensar lo que se sabía sobre el pasado de Pereira más allá de la tradicional mitología fundacional que pasaba de boca en boca como en el juego infantil del "teléfono roto". La colección coincidió además con varios hechos relevantes para la historiografía de Pereira. La formalización de la Academia Pereira de Historia; el terremoto de 1999 que permitió exploraciones arqueológicas; y la llegada de historiadores profesionales de otras regiones como Álvaro Acevedo Tarazona y Jhon Jaime Correa Ramírez quienes tomaron como propia la causa y empezaron a publicar de manera asidua sobre la ciudad.

En la coyuntura de cambio de siglo habían aparecido trabajos publicados sobre historia local como el de Gustavo Guarín Medina, Carlos Bravo Molina y Juan Velásquez Garzón titulado Gestión Política del Concejo de Pereira a través de la historia, 1867-1998 (CMP, 1998). Así mismo el historiador Víctor Zuluaga Gómez publicó hacia el 2004 un trabajo titulado La nueva historia de Pereira: fundación (UTP, 2004), cuyo impacto condujo a un interesante debate entre su autor y otros miembros de la Academia como Emilio Gutiérrez Días y Alvaro Acevedo Tarazona a propósito de la titularidad de las tierras de la familia Pereira. La discusión propuesta por Zuluaga Gómez logró extenderse hacia la importancia de los mitos 
fundacionales y la aparición de una historia más rigurosa que involucrara pruebas documentales y que permitiera pensar que el pasado no es estático. Ese mismo año se llevó a cabo el traspaso del Archivo Notarial en manos del notario Daniel Trujillo, al cuidado de la Academia Pereirana de Historia que ya contaba con nueva sede en el Centro Cultural Lucy Tejada y que pretendía ser el punto de partida para la creación de un archivo histórico para la ciudad.

Todos esos hechos fueron abonando el terreno para que desde la universidad se iniciara el proceso de creación de un postgrado en Historia, escenario que permitiría la producción de nueva historiografía regional, pero sobre todo que posibilitara la incursión de la historia profesional a la ciudad gracias a la formación de un cuerpo crítico de personas que divulguen la importancia de la pluralidad de miradas y de la construcción crítica de referentes sobre el pasado colectivo.

Uno de los riesgos con que se contó para la apertura de la Maestría en Historia, fue la ausencia de un pregrado en esta disciplina. Lastimosamente la universidad pública no cuenta con la posibilidad de abrir nuevos programas de pregrado, y aún menos en áreas de conocimiento humanístico que se consideran poco rentables a los ojos del sistema de autofinanciación a los que han sido conducidos estos centros de enseñanza superior. Pero el reto fue superado, desde el año de 2011 bajo la dirección del profesor Gustavo Guarín Medina se dio inicio a la Maestría en Historia; a partir del 2014 tomó las riendas el profesor Jhon Jaime Correa y apenas en siete años de funcionamiento (2011-2018), la maestría ya cuenta con 11 cohortes y un buen número de egresados que están apostándole a la historia en múltiples escenarios.

Adicional a lo anterior se ha concebido a la Maestría en Historia no solo como un escenario de formación sino como un motor de múltiples procesos. Espacios de debate académico como los Coloquios Regionales de Historia; plataformas de circulación del conocimiento como Ciencia Nueva, Revista en Historia y Política, y la Colección Maestría en Historia; programas de historia pública como las estrategias de utilización de redes sociales y de otras narrativas como las Microhistorias de Ciudad en asocio con el medio digital La cebra que habla; pero sobre todo el énfasis en construir una nueva historia crítica y polifónica sobre la ciudad y la región.

Esta tarea ha significado plantear problemas que se estudien con el rigor y disciplina de la historia profesional que además lleguen a convertirse en representaciones escritas fundamentadas en fuentes y que circulen en el mayor ámbito posible para ser puestas en debate y aportar al conocimiento del territorio común que habitamos. Esta es la misma consigna que desde 1775 se impuso el filósofo Immanuel Kant 
al decir que si bien el papel del científico es adquirir conocimientos, su tarea solo se vuelve honorable en la medida en que transmite sus conocimientos a sus conciudadanos. En consecuencia a esto no se trata de acumular un conocimiento erudito presentado en el lenguaje de los especialistas, sino el de comunicarlo para permitir que la comunidad tenga mejores referentes históricos.

El trabajo de Alonso Molina Corrales ha cumplido con todos estos propósitos. Este libro desde mi punto de vista simboliza un hito no solo para su autor, sino para la historiografía escrita desde Pereira. El itinerario que cumplió antes de salir a la luz pública fue el deseado para cualquier publicación de esta naturaleza. Se inició desde el reposado y riguroso debate con otros autores inscribiéndose en una línea que desde hace años viene ganando fuerza y que podríamos identificar como el revisionismo de los estudios sobre la colonización antioqueña que inauguró el historiador Jaime E. Londoño con su trabajo sobre la obra James J. Parsons, al que podríamos añadir los textos de Luis Javier Ortiz y Oscar Almario ${ }^{1}$ así como el libro Policromías de una región editado por Alexander Betancourt Mendieta en el 2008, entre otros. Desde allí se diseñó un proyecto que intentaba llenar un vacío historiográfico e innovar con nuevos referentes documentales. Molina Corrales entre las dificultades en materia de acceso a la información primaria logró levantar un edificio sobre unos pilares que yo llamaría las fuentes de la colonización antioqueña mirada desde el sur. He ahí la relevancia del trabajo y su aporte al conocimiento regional. Además, el rigor empleado para la crítica de fuentes y la sistematización en el procesamiento de las mismas, le permitieron no solo convertirse en un historiador profesional, sino ser el primer egresado en publicar en la Colección Maestría en Historia que al largo plazo tal vez sea el proyecto más importante gestado por este programa de formación postgradual.

Son varios los aportes que nos deja el libro El despliegue del Estado en el poblamiento de la montaña del Quindío y la fundación de Santa Rosa de Cabal, 1840 - 1845 al estado de la cuestión de los estudios regionales. Por un lado, el propio título de la obra anticipa un problema que es central al hablar del siglo XIX en el centro occidente del país. Se trata del "despliegue" que realiza el proyecto del EstadoNación colombiano en estas tierras de frontera. Molina Corrales logra demostrar que en efecto el Estado tenía un proyecto coherente que pretendía poner en marcha en aquellos territorios que se mantenían excluidos del mismo por diversos factores. La idea de integrarlos desde diferentes estrategias bajo las naturales resistencias de algunos actores sociales y con las mismas precariedades de las limitaciones con las

$1 \quad$ Publicado con dos títulos: Caldas una región nueva moderna y nacional (UNAL, 2007); y Caldas una región antigua y nueva, tradicional y moderna, local y nacional. (UNAL, 2015). 
que contaba por esos años, son bastante significativas. El rol que cumple para la Nación el camino del Quindío y por ende el presidio de Boquía, es un aspecto que sin lugar a dudas hay que destacar y que el autor hace con la maestría del historiador que es consciente que sin fuentes no hay historia.

En igual medida este libro demuestra que las unidades territoriales regionales tuvieron un papel muy significativo para la construcción de la Nación en el siglo XIX. El Cauca, primero como provincia y luego como Estado Soberano, tuvo conciencia de la existencia de una frontera porosa al norte de su jurisdicción, por eso se ocupó de poblar y equipar con la insitucionalidad disponible estos territorios que culturalmente se habían integrado al sur de Antioquia por vía del factor humano que los estaba poblando. Pero en lo que otros autores habían encontrado conflicto y resistencia, Molina Corrales nos muestra alternativas de mediación y estrategias de consolidación. Según el autor para el Cauca los colonos antioqueños más que un invasor, eran el vehículo de la consolidación del Estado en la frontera norte y en ello la entrega de tierras y la creación de centros urbanos cumplen un papel central.

Adicional a lo anterior, Molina Corrales se vale de herramientas conceptuales para vincularse a los estudios de frontera y mostrar que la región que se estaba fraguando en el centro occidente colombiano durante el siglo XIX no podía obedecer a otra realidad que a la de esta idea que ya nos había anticipado autores como Ricardo de los Ríos Tobón (otro miembro de la Maestría en Historia). Autores como Carlos E. Reboratti y Juan Maiguashca son por primera vez convidados a la interpretación de esta territorialidad para reconocer en ella los matices y variantes de las regiones de frontera. El uso adecuado de conceptos, junto a un mesurado diálogo con fuentes primarias, es uno de los logros más significativos del trabajo de Molina Corrales. No se puede dejar de mencionar otro de los aportes que tiene la obra desde el punto de vista de la información cartográfica. La lectura de este tipo de fuentes siempre ha significado un reto para el historiador regional, la cual en la mayor parte de los casos se convierte en un ornamento del texto pues no se logra extraer de ella ninguna información. Este no es el caso de la presente obra que presenta nueva información visual, a la que se suma la elaboración de tablas, esquemas y gráficos que ayudan a entender de una mejor manera la realidad espacial que en el siglo XIX se definía como "la montaña del Quindío".

En suma, son muchas cosas que podría seguir mencionando sobre el libro. Pero solo una desearía que quede que muy clara en la memoria de los lectores. Este libro simboliza el fin y el principio de un proceso. El fin, porque su autor es el resultado de un esfuerzo de formación de historiadores profesionales en Pereira, y un principio 
porque desde trabajos como este se debe construir y perpetuar una tradición que consolide la ciencia histórica en Pereira y su región.

En el epitafio de Marc Bloch, connotado historiador francés e inspirador de múltiples generaciones de historiadores profesionales de todo el mundo, se puede leer la siguiente frase en latín: Dilexit veritatem. Esta idea sigue siendo el propósito de todo aquel que ingresa a los senderos de la historia profesional, el presente libro no es la excepción. La comparación de fuentes y evidencias, el rigor sistemático, la disciplina y el esfuerzo crítico por "separar lo que es verdad de la mentira", es la fuerza que impulsa el trabajo de Alonso Molina Corrales como historiador. Sólo me queda por exaltar la labor que viene haciendo en diferentes frentes en pro de la historia profesional; auguro una brillante trayectoria en este campo y aspiro a que continúe trabajando y produciendo este tipo de ejercicios investigativos que lleguen hasta el clímax que trabajos de esta naturaleza deben tener, la publicación de sus resultados.

Sebastián Martínez Botero. PhD.

Pereira, septiembre de 2018. 


\section{INTRODUCCIÓN}

Siempre me llamó la atención que una población fundada por antioqueños, en medio de la colonización antioqueña como Santa Rosa de Cabal, llevara uno de los apellidos más caucanos. Después, mis lecturas de diletante me hicieron saber que el territorio ocupado por ese asentamiento pertenecía en el momento de su fundación al Cauca y que el gobierno de ese ente territorial -no definido en términos constitucionales y legales- agenció asentamientos como ese y el de Cartagoviejo, en desarrollo de una estrategia de contensión militar y comercial contra sus vecinos de Antioquia: conservadores y católicos.

Al tiempo, cayó en mis manos el libro de Enrique Valencia sobre Santa Rosa de Cabal, en el que visibiliza el papel jugado por las autoridades caucanas en la fundación de ese municipio y en particular, el desempeñado por el bugueño Jorge Juan Hoyos Cabal, Gobernador del Cauca; una provincia que no tenía nada que ver con la representación que tenemos del Gran Cauca decimonónico dirigido por las mismas familias de siempre desde Popayán. ¿Un caucano con el ombligo enterrado en Buga, alentando la venida de paisas a estas tierras?

Ahí sí fue mayor mi confusión. El Cauca no era el Cauca y su capital tampoco era Popayán. El gobierno de esa provincia atrayendo antioqueños a su frontera, cuando era de común recibo decir que "antioqueño, ni grande, ni pequeño", y los paisas llegando a colonizar las soledades de la orilla oriental del gran río, en cumplimiento de un plan y unos objetivos muy diferentes a la espontánea pulsión de la pobrecía en procura de conseguir un pedazo de tierra para su maíz. 
Convertí mi confusión en propósito de un trabajo de investigación; una pesquisa que se decanta con el paso de los cursos, las lecturas y la búsqueda de documentos en diferentes archivos históricos, hasta llegar a la pregunta: ¿Cuál fue el papel del Estado nacional y territorial, en el poblamiento de la frontera nororiental de la provincia del Cauca, entre 1840 y 1845 ?

El interrogante también es mutante, fruto de hibridar las discusiones teóricas sobre frontera y las diversas formas de colonización, con los frutos intelectuales de la "revuelta" contra el mito democrático de la colonización antioqueña y su carácter hegemónicamente paisa y la visibilización de una institucionalidad territorial encubierta por una historia al servicio del Estado nación o de causas políticas, ideológicas y teórico disciplinares propias y ajenas.

Del mismo modo, la delimitación temporal es el resultado de lo que se encuentra en la indagación bibliográfica y documental, pues del interés por conocer los detalles de la fundación de Santa Rosa de Cabal, se pasa a una mirada más amplia que incluye en un solo lustro (1840-1845) la oficialización de ese asentamiento, la reapertura del camino del Quindío y el establecimiento del presidio de Boquía; agenciados por un mismo gobierno en lo nacional y en lo territorial y por los mismos dirigentes, en procura de integrar las regiones e incorporar amplias zonas de frontera a la producción, en medio del fenómeno migratorio interno más relevante de nuestra historia.

Así se establece el objetivo general de la investigación que es establecer el papel del Estado nacional y territorial, en el poblamiento de la frontera nororiental de la provincia del Cauca, compuesta por la llamada Montaña del Quindío y el territorio comprendido entre los ríos La Vieja y Chinchiná durante quinquenio 1840-1845, a través del estudio de la reapertura del Camino del Quindío, el asentamiento del presidio de Boquía y la fundación de Santa Rosa de Cabal.

De esta manera el presente trabajo se enmarca dentro de la historia regional, consultando y comparando fuentes primarias y secundarias, para abordar conceptos como colonización estatal, frontera, penetración ideológico normativa y periferia territorial. Para dar respuesta a la pregunta se acomete en primer lugar, un balance historiográfico que se recoge en forma suscinta en el primer capítulo que da cuenta de la forma como investigadores sociales e historiadores han tratado el tema de la frontera y la colonización estatal, en relación con la reapertura del camino del Quindío, el asentamiento del presidio de Boquía y la fundación de Santa Rosa de Cabal. 
El segundo capítulo tiene como objetivo identificar las formas en las que el Estado interviene en el poblamiento del nororiente de la provincia del Cauca dentro del lapso establecido, y para ello se revisan primero teorías acerca de la frontera y la colonización estatal, para luego contrastarlas con las afirmaciones de algunos historiadores y con la documentación recuperada en archivo.

El siguiente capítulo tiene como objetivo revisar el papel del Estado central y territorial en el poblamiento de la frontera nororiental de la provincia del Cauca, como una forma de penetrar en lo material, en lo normativo, en lo político e ideológico, las periferias territorial y social para la consolidación del proyecto republicano de las élites aristocráticas al mando de la nueva república a nivel nacional y provincial.

El cuarto y último acápite tiene como objetivo enseñar la penetración del Estado republicano en la provincia del Cauca y el impacto que muchas de esas decisiones tuvieron en la forma como se pobló ese territorio; alejadas de la versión generalizada sobre el papel preponderante y exclusivo de los pobladores antioqueños.

Los documentos consultados son básicamente la correspondencia oficial entre el gobernador de la provincia del Cauca y el secretario del interior y relaciones exteriores de la República de la Nueva Granada, en relación con las obras de reapertura del camino del Quindío y su poblamiento, el asentamiento del presidio de Boquía y la fundación de Santa Rosa de Cabal.

Otros son las normas recogidas en la Gaceta de la Nueva Granada, el diario oficial de la época y por la célebre Recopilación Granadina de Lino de Pombo; muy útiles para conocer la urdimbre normativa que soportó el proceso de la colonización de todas las fronteras internas de la nación y en particular, de la que separaba al Cauca de Antioquia y de la que era llamada comunmente como la montaña del Quindío. Pese a las indagaciones en la Biblioteca Nacional de Colombia y en otros archivos regionales, no se pudo encontrar dentro del período estudiado otras fuentes períodicas y las normas expedidas en relación con los acontecimientos por la Cámara provincial del Cauca, no fueron halladas en los repositorios consultados.

Todo lo anterior ayuda a constituir un texto que resignifica el papel del Estado en el proceso de la colonización de las vertientes en la mitad del siglo XIX, así como el valor que esa periferia tuvo para la consolidación de la nueva institucionalidad post colonial; al tiempo que invita a revisar la forma como generalmente se ha calificado el quehacer público antes de la revolución liberal de los cincuenta, inclinada casi siempre a ver proyectada la "inercia" del régimen virreinal en las dos primeras décadas de la república neogranadina. 
También, el trabajo es una reflexión sobre la forma como el fenómeno de la colonización ha sido relatado. Más allá de la impronta antioqueña, es claro que el radar de los investigadores e historiadores del tema no capta las realidades políticas administrativas de la época y asumen que el ordenamiento territorial en el siglo XIX fue algo estático - Antioquia es la misma en todo momento y el Cauca también- y donde, además, no se logran mostrar los frutos de la agencia humana en medio de la avalancha de acontecimientos.

Develar la vida política de esas comunidades locales y de los entes territoriales a los que pertenecían, será una tarea enriquecedora para la historia local y una oportunidad de relatar sucesos más detallados y próximos en provecho de la densidad de datos que se puede encontrar. 
CAPÍTULO UNO 



\section{Conclusiones de un balance historiográfico sobre frontera, colonización estatal, el poblamiento de la montaña del Quindío y la Fundación de Santa Rosa de Cabal}

El propósito de este primer capítulo es presentar algunas conclusiones de un extenso balance historiográfico ${ }^{2}$, adelantado para establecer qué se ha escrito sobre los fenómenos asociados a frontera y colonización estatal en el nororiente de la provincia del Cauca entre 1840 y 1845 , y que tienen como estudios de caso la fundación de Santa Rosa de Cabal, el presidio de Boquía y la apertura de los caminos para comunicar a Cartago con el sur de Antioquia y el Tolima.

Esta revisión bibliográfica ${ }^{3}$ aporta elementos que ayudan a establecer si el poblamiento

2 Alonso Molina Corrales, «El poblamiento del nororiente de la provincia del Cauca entre 1840 y 1845. Estudio de casos: el camino del Quindío, el presidio de Boquía y la fundación de Santa Rosa de Cabal» (Tesis de maestría, Universidad Tecnológica de Pereira, 2016), http://repositorio.utp.edu.co/dspace/ handle/11059/7586

3 Para la lectura de los trabajos, se conformaron tres grupos de obras. El primero, integrado por textos de Antonio García Nossa, James P. Parsons, Hermes Tovar, Fabio Zambrano, Eduardo Santa, Catherine Le Grand, Jacques April y Roberto Luis Jaramillo, debido a la visión general que aportan sobre el fenómeno colonizador y la forma como unos y otros contemporizan o marcan distancia con James P. Parsons, el pionero sobre ese tema en el ámbito nacional e internacional y que planteó una forma de interpretarlo con una enorme acogida inicial dentro del mundo académico colombiano. El segundo grupo está compuesto por trabajos con enfoque de historia regional, de los autores extranjeros Keith H. Christie y Nancy P. Appelbaum; los nacionales Albeiro Valencia Llano, Ricardo de los Ríos Tobón, Luís Javier Ortiz y Oscar Almario, que aportan una mirada comprensiva del fenómeno de construcción, y el de Alonso Valencia Llano sobre los empresarios y políticos caucanos que inaugura una mirada desde el sur al proceso de colonización de las vertientes cordilleranas del occidente de Colombia. Inscritos también dentro de la postura de la 
del nororiente de la provincia del Cauca, al promediar el siglo XIX, se ubica sin salvedades dentro del conocido fenómeno de la colonización antioqueña descrito por James P. Parsons, con trazos cosmogónicos y de un enorme poder generalizador, o entraña otros componentes y categorías diferentes -como lo son enfoques diversos sobre la frontera y la colonización estatal-, que pasan inadvertidos o minimizados. Del mismo modo, permite establecer cómo son tratados, en ese acervo documental secundario, los sucesos que sirven de estudio de caso.

\subsection{La frontera}

El interés por entender el tema de la fundación de Santa Rosa de Cabal y luego lo referente al camino del Quindío y el presidio de Boquía, como parte del establecimiento o surgimiento de fronteras con diferentes características, surge por la invitación del historiador vallecaucano Jaime Eduardo Londoño Motta a incorporar a la investigación el concepto de frontera; ausente, dice él, de los trabajos sobre colonización del occidente de Colombia, por la mecánica aplicación del modelo de colonización propuesto por el geógrafo norteamericano James P. Parsons.

La obra de James P. Parsons, "La Colonización Antioqueña en el Occidente de Colombia", ha inspirado las investigaciones posteriores sobre los procesos de colonización de vertiente en los territorios que corresponden actualmente a los departamentos de Antioquia, Caldas, Risaralda, Quindío, Valle del Cauca y Cauca, entre finales de la Colonia hasta el primer cuarto del siglo XX; al tiempo que es la razón de una discusión sobre lo benéfico o perjudicial de esa influencia para la misma producción historiografía, con adeptos que explícita o implícitamente acogen el modelo aplicado por el geógrafo y con detractores con disímiles posturas y niveles de confrontación.

historia regional, se revisó el trabajo de historiadores y cronistas interesados en la conformación del actual Quindío, como son Alfonso Valencia Zapata, Jaime Lopera, Olga Cadena Corrales y José Manuel Perez Bravo. Un tercer grupo de trabajo son los que hablan sobre el camino del Quindío y sobre Santa Rosa de Cabal, conformando un conjunto de obras que aportan a la historia regional, pero con un enfoque más limitado y en muchos casos con entronques con la historia ambiental o política y donde un buen número se podrían clasificar en el género de la crónica. Las obras analizadas sobre el camino del Quindío son las de Álvaro Hernando Camargo, Jaime José Grisales, Larry Larrichio y Víctor Zuluaga Gómez, enfocados en el significado de todo orden que tuvo esa obra de infraestructura. Las referentes a Santa Rosa de Cabal son las de José María Restrepo M., Presbitero Diego M. Gómez, Juan Bautista López O. Luís Enrique Valencia R. y Francisco Gómez Valderrama. de Antioquia, 1950). Publicada por primera vez en castellano en 1950, con traducción del entonces presidente de la Academia Colombiana de Historia, el médico Emilio Robledo y gracias a la iniciativa de importantes empresas colombianas. 
Por su parte, en su obra "El Modelo de Colonización Antioqueña de James Parsons.

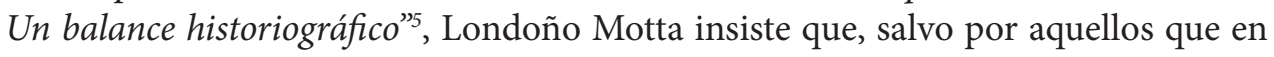
años más recientes han asumido una postura crítica frente al "mito antioqueño parsoniano", sobre la construcción de una sociedad democrática de campesinos arrebatandole tierra a la selva para generar riqueza; la historiografía nacional ha sido sometida, por ausencia de un análisis historiográfico, a las corrientes provenientes de Europa y Estados Unidos, lo que genera una recepción pasiva y mecánica del modelo de colonización propuesto por Parsons y en consecuencia, la incapacidad de remontar lo dicho por éste ${ }^{6}$. En esta misma medida, se repite su discurso y lo nuevo sólo busca llenar los vacíos temáticos, cubrir tópicos no abordados por el geógrafo en relación con el poblamiento de los paisas.

Una de las razones de ese patronazgo intelectual se origina en no haber tenido en cuenta en las investigaciones y publicaciones sobre la colonización antioqueña, el concepto articulador de la frontera de la obra de Parsons:

Esta noción no es explícita en el texto de Parsons; es implícita y está asociada con la propuesta esbozada por Frederick Jackson Turner ${ }^{[7]}$ para analizar el caso del desplazamiento hacia el Oeste en los Estados Unidos. El olvido, el desconocimiento, el no tener en cuenta este concepto, impidió a los historiadores colombianos apropiarse directamente de una categoría para el análisis de determinados procesos históricos. En su lugar se produjo una apropiación indirecta y mecánica, mediada por la lectura y aplicación de la propuesta de Turner efectuada por Parsons. La historiografía colombiana no se apropió de un concepto sino de un modelo ${ }^{8}$.

Parsons le da el mismo significado a la noción de frontera turneriana y al concepto de colonización, con lo cual la primera es la incorporación de los espacios vacíos o no integrados, lo que ha dado lugar a que los historiadores colombianos omitan las

5 Jaime Londonoño, «El Modelo de Colonización Antioqueña de James Parsons. Un balance historiográfico». Revista Frontera de la historia 7 (2002): 187-226.

6 Jaime Londoño, «El Modelo de Colonización Antioqueña de James Parsons»,189.

$7 \quad$ Frederick Jackson Turner nació el 14 de noviembre de 1861 y murió el 14 de marzo de 1932. Investigador y profesor de historia de las Universidades de Wisconsin y Harvard, se convirtió en uno de los historiadores más influentes del siglo XX en Estados Unidos de Ámerica y en otras latitudes. Su tesis sobre la influencia de la expansión de la frontera oeste de norteamérica, en la consolidación de las instituciones y la democracia de ese país, determinó toda una corriente que determinó la forma como se enseñó y escribió sobre esa disciplina. Aunque no publicó mucho, su obra más importante fue "La Importancia de la Frontera en la Historia de Ámerica”, que a su vez influyó en la interpretación que hizo James J. Turner del fenómeno de la colonización antioqueña en el occidente colombiano. 
particularidades de los procesos estudiados, al asumir que la ocupación y explotación de las tierras de los actuales departamentos de Risaralda, Quindío y las estribaciones cordilleranas del Valle del Cauca fue obra exclusiva de los antioqueños:

La aplicación de estas premisas a los estudios relativos a la frontera norte del Suroccidente colombiano ha reducidolaslabores deinvestigación a rutinas mecánicas. La repetición reiterada de esta práctica ha hecho invisible las particularidades de los procesos analizados. Así por ejemplo, la llegada de colonos de diferentes regiones del país, la participación de los empresarios caucanos y las políticas de colonización, efectuadas por las élites del Gran Cauca en el siglo XIX y por los dirigentes del Valle del Cauca en el siglo XX, no han abierto la opción de plantear nuevos problemas y de formular otras temáticas de análisis9.

Londoño concluye que el modelo de colonización propuesto por James P. Parsons no lograr explicar los procesos de frontera y colonización de lo que él llama el norte del suroccidente colombiano, y que como Parsons lo tomó de Frederick Jackson Turner, el que éste aplica para entender la expansión de los Estados Unidos de América hacia el oeste, tampoco sirve para nuestro caso porque termina siendo reduccionista ${ }^{10}$. También plantea que la historiografía colombiana está obligada a buscar otro modelo para estudiar los procesos de frontera y colonización del norte del suroccidente colombiano, que a mediados del siglo diecinueve correspondía a la frontera septentrional de la provincia del Cauca. El autor propone el modelo de Richard Morse denominado "Patrón de Archipiélago":

Después de las guerras de emancipación, en las primeras décadas del siglo XIX, se produjo una eclosión de estados nacionales y, por tanto, de procesos de delimitación territorial entre ellos; paralelamente al interior de los nuevos paises, los espacios que habían permanecido "desploblados" durante el período colonial comenzaron a ser colonizados emergiendo un sinnúmero de fronteras. La ocupación de estas áreas se efectuó desde las antiguas fundaciones ocurridas bajo la dominación española, mediante un proceso de desplazamiento centrífugo, que posibilitó el llenado de las zonas que permanecían "desocupadas" entre dos núcleos urbanos ${ }^{11}$.

Jaime Londoño, «El Modelo de Colonización Antioqueña de James Parsons»,192.

10 Jaime Londoño Motta reconoce en su texto que las glosas al modelo de Turner vienen de tiempo atrás y referencia autores como Víctor Andrés Belaunde y Silvio Zavala. 


\subsection{La Frontera en Parsons}

Al leer el libro "La Colonización Antioqueña en el Occidente de Colombia", se encuentra que el tratamiento de Parsons al tema de frontera, es una referencia implícita a lo planteado por Turner ${ }^{12}$, ya que califica los territorios objeto de la colonización antioqueña como tierras vacías, y les da el tratamiento de fronteras originales y tradicionales de Antioquia, ampliadas hacia el sur por una serie de fenómenos que el autor enumera.

El modelo de frontera de Turner predica que aquella es el límite entre el territorio ocupado y las tierras abiertas a la expansión. Literalmente dice que la frontera "es la línea móvil que señala el límite de la colonización con la naturaleza salvaje, sin conquistar". Esa postura es reiterada por Parsons en diferentes espacios académicos y textos, como cuando en una publicación de 1977 describe la zona de expansión de Antioquia hacia el sur como un espacio en blanco en el mapa, y posteriormente dice que el escenario donde se evidencian las cualidades paisas es una frontera móvil ${ }^{13}$.

Sin embargo, se puede calificar como una aproximación a una propuesta propia de modelo para explicar el fenómeno de la colonización antioqueña dentro de una frontera, la incorporación de un mapa denominado "Colonización Antioqueña", en el cual ubica y sectoriza los poblados fundados por los antioqueños entre $1795 \mathrm{y}$ 1850 , entre 1850 y 1900 y después de 1900, que, según él, constituyen en el plano tres lóbulos separados (Ver Mapa 1).

Los lóbulos parecen unas islas pertenecientes a un mismo archipiélago $-\dot{\imath}$ el de Morse? -, y lo que separa sus componentes no implica que no hubiera interacción entre ellas; por el contrario, es la evidencia del papel de trampolín que juega cada asentamiento en el propósito de controlar una frontera que tampoco se puede afirmar que estaba en ese momento histórico completamente vacía. Esa traza en el mapa no tiene relación alguna con la línea móvil que separa lo civilizado de lo desierto y es un planteamiento más cercano a otras tesis contemporáneas o posteriores al propio Parsons.

12 Frederick Jackson Turner lanzó la frontera como uno de los más influyentes modelos explicativos de la historiografía estadounidense y latinoamerina, gracias a su ensayo "La importancia de la frontera en la historia de América”. Su práctica como docente de historia en la Universidad de Wisconsin, tuvo los mismos efectos que su postura frente al tema de la frontera, pues introdujo a la práctica investigativa, métodos interdisciplinarios y cuantitativos con los que impactó en la formación de una pléyade de historiadores norteamericanos.

13 James J. Parsons. La Geografía como exploración y descubrimiento. Traducido de Annals of the Assocation of American Geographers, Vol. 67, No 1, marzo de 1977, pp. 1-16. Versión española de Dr. H. F. Rucinque en: Trimestre Geográfico, Vol. 1, marzo 1980. En: Las regiones tropicales americanas: visión geográfica de James J. Parsons. Bogotá: Fondo FEN Colombia, 1992, p. 27. 
El despliegue del Estado en el poblamiento de la Montaña del Quindío y la fundación de Santa Rosa de Cabal, $1840-1845$

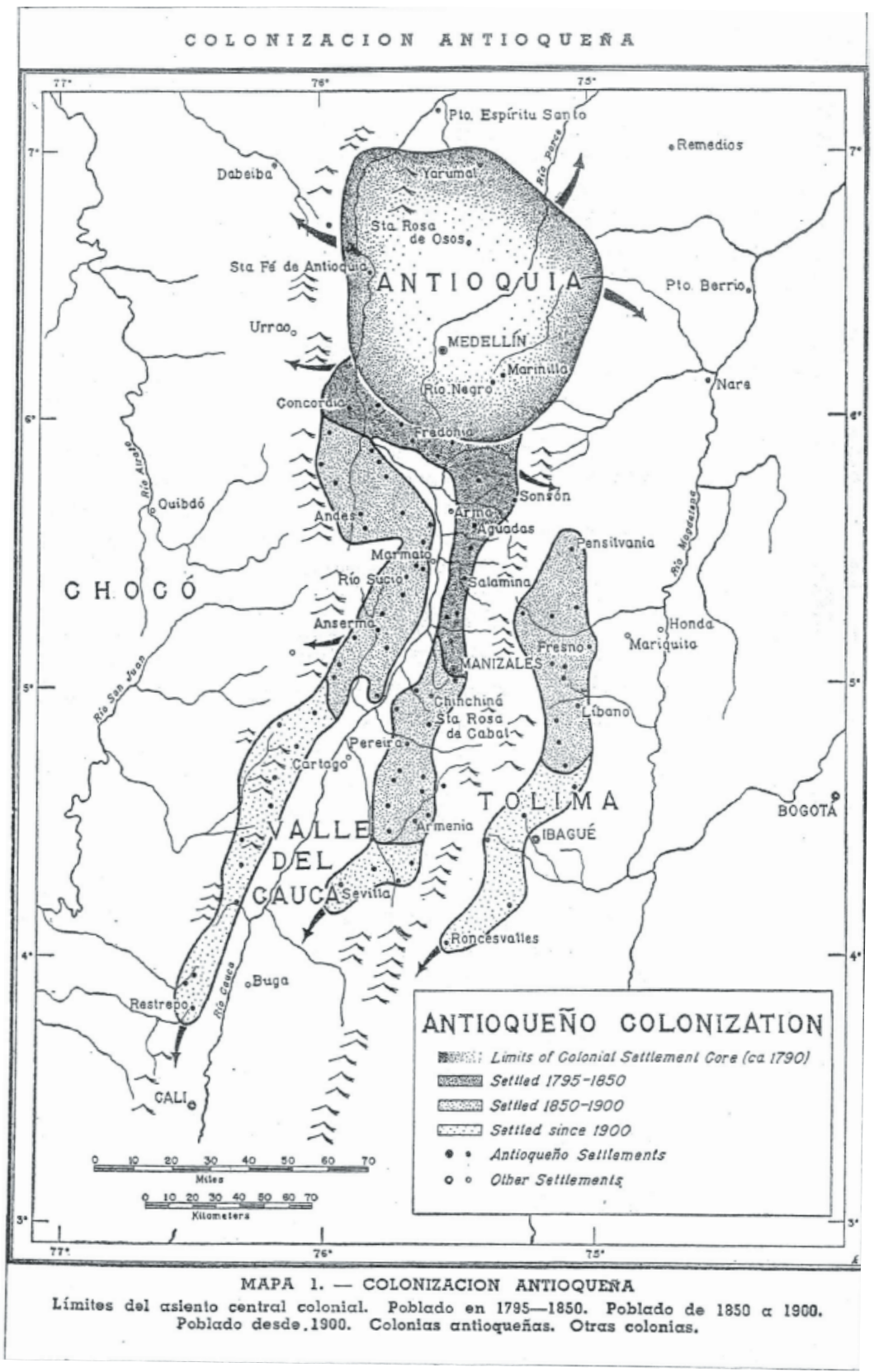

Mapa 1. Colonización antioqueña ${ }^{14}$

14 James Parsons, La Colonización Antioqueña en el Occidente de Colombia, 8. 
La línea turneriana no explica lo acontecido porque oculta las particularidades de un proceso más complejo, la injerencia del Estado nacional y territorial y sus instituciones -en el caso que nos ocupa, la República de la Nueva Granada y la provincia del Cauca-, el papel de otros grupos poblacionales y la razón de la posterior y masiva presencia antioqueña en los mencionados territorios. Vacios que Londoño Motta expone en su crítica a la recepción de la obra de Parsons, que en las décadas recientes ha sido duramente golpeada, más por lo afirmado en cuanto a la "sociedad democrática", que por el tratamiento de la frontera.

En un suceso digno de encomio, por lo que representa de honestidad profesional; cuarenta años después de su viaje investigativo por Antioquia, James J. Parsons regresa a Colombia, y en Manizales, durante un evento organizado por Fiducal, hace una dura crítica a la forma como abordó la investigación que desembocó en su libro "La Colonización Antioqueña en el Occidente de Colombia":

En retrospectiva, y a la luz de lo que otros han escrito más tarde, mi interpretación de la historia antioqueña fue algo idealizada y precipitada. Me equivoqué en varios puntos y me faltaron otros. Por ejemplo, pasé por alto los comentarios sobre los antioqueños de sociólogos como Luis López de Mesa y Alejandro López. No hice uso de fuentes documentales de los archivos municipales ni de los libros de las parroquias. Dejé a un lado casi todo lo relativo a la religión, a la iglesia y también a la política. Jorge Villegas y otros han mostrado que eran algo románticas mis presunciones acerca de la "sociedad democrática" de pequeños propietarios o colonos y las virtudes sencillas de la vida campesina tradicional ("la vida maicera") de estas montañas. Parece, por ejemplo, que el acceso libre a la tierra para peones era bastante raro. El papel de los capitalistas y patrones y la especulación en tierras tuvo más énfasis del que recibió. El hecho es que las leyes draconianas contra la vagancia obligaron a hombres sin empleo a emigrar a la frontera como peones. Finalmente, nunca me metí propiamente en el programa más grande de geografía, como es la ecología total o ecológica de una región con el impacto tan frecuentemente destructivo ${ }^{15}$."

15 Joaquín Molano, ed., Las regiones tropicales americanas: visión geográfica de James Parsons. (Bogotá: Fondo FEN, 1992), 135. 


\subsection{La frontera en otros autores}

Lo planteado por Jaime Londoño Motta sobre la recepción de la obra de Parsons fue cuestionado por uno de los jurados en la sustentación de la tesis que le permitió alcanzar la Maestría de Historia en la Universidad Industrial de Santander. El historiador Oscar Almario García, en compañía de su colega Luís Javier Ortiz, toman el concepto dado por el primero al trabajo de grado de Londoño y redactan el ensayo "Las Percepciones historiográficas de la "Colonización Antioqueña", que sirve de introducción al texto "Caldas: una región nueva, moderna y nacional" ${ }^{16} \mathrm{y}$ en el que plantean que para 1980, "estaba en plena evolución un modelo alternativo al de Jame J. Parsons”, para entender la construcción de la región caldense y ponen como ejemplo el trabajo de Ricardo de los Ríos Tobón y el de ellos mismos.

El ensayo de Ricardo de los Ríos Tobón titulado "Orígenes y colonización hasta 1850 "17, delimita una región caldense -superior a las de las líneas políticas administrativas- de tal forma que configura las fronteras internas intervenidas por el proceso colonizador, y bosqueja un modelo de frontera cercano al del patrón de archipiélago, insumo principal del que posteriormente proponen Luís Javier Ortiz y Óscar Almario.

Sin mencionar un interés en el debate académico sobre la frontera, el autor se suma tácitamente a quienes no comparten la frontera turneriana -una línea móvil que separa lo civilizado de lo inexplorado e inculto- y ve, más bien, muchas de ellas alrededor de centros de impulsión necesitados de los recursos que promete la "terra incógnita".

El bosquejo de lo que es el Gran Caldas, en términos superiores a los estrechos límites político-administrativos -lo cultural, lo social y económico-, que hace Ricardo de los Ríos Tobón, es al mismo tiempo el mapa de la expansión del fenómeno colonizador colombiano y, por tanto, es la proyección de las fronteras que fueron incorporadas a la vida económica del nuevo país, entendidas como lo que rodeaba los centros de impulsión de las migraciones.

Del mismo modo, sugiere las fronteras cuando propone unas flechas o direcciones que tomó el fenómeno colonizador desde finales del siglo XVIII. Primera ruta, entre el río Cauca y la Cordillera Central, desde Medellín hasta el extremo sur del

16 Ortiz, Luis Javier y Óscar Almario García, Caldas: Una región nueva, moderna y nacional. (Medellín: Universidad Nacional de Colombia Sede Medellín, 1990). 
Quindío. Segunda Ruta, entre el río Cauca y la Cordillera Occidental, llegando casi hasta los farallones de Cali. Tercera ruta, desde Sonsón hasta la cabecera del Saldaña, por las laderas orientales o tolimenses de la Cordillera Central ${ }^{18}$.

Alimentada por la postura anterior, la obra "Caldas: una región nueva, moderna y nacional” de Luís Javier Ortiz y Oscar Almario, pretende establecer cómo emerge Caldas ante los ojos de generaciones de estudiosos sociales, con sus particulares maneras de interpretar la realidad, "al hilo de los acontecimientos".

Con el objeto de avanzar aún más en la comprensión de las relaciones regiónnación-Estado, se impone una discusión sobre los conceptos de colonización, frontera y región, para proponer un modelo alternativo que permita comprender la construcción de la región caldense en el siglo XIX y que supera lo aceptado como el legado de Turner, vía Parsons. Ese modelo habla de países y se basa en lo propuesto en su momento por Ricardo de los Ríos Tobón, cuando identificó unas regiones supra frontera político administrativas, que incidieron en la construcción de la región caldense. Con lo planteado, Almario y Ortiz se sintonizan con el modelo de patrón de archipiélago ofrecido como alternativa para entender la frontera. Cada país entraña su propia frontera -con sus conflictos, territorios y poblamientos- que se expande desde un centro de impulsión, con el propósito de satisfacer necesidades de abastecimiento, reducir la presión demográfica e insertarse en el mercado agro exportador.

Los países son: El norte caldense o el sur antioqueño, compuesto por zonas medias de montaña entre el oriente de Antioquia y el páramo del Ruiz, hacia las vertientes occidentales de la cordillera Central cayendo al río Cauca y al Chinchiná. El del centro, que comprende a Antioquia vs. Cauca y tuvo como ejes a Pereira, San Francisco (Chinchiná), Aldea de Santa María, Santa Rosa de Cabal, localidades cercanas y el valle bajo del río Risaralda y del Cañaveral del Carmen. El del oriente, que corresponde a las cuencas de los ríos La Miel y el Magadalena, y las hoy poblaciones caldenses de Pensilvania, Marulanda, Manzanares, Marquetalia, Samaná, La Victoria y La Dorada. El del occidente, que va de Anserma por Quinchía hasta Marmato. El del Quindío, que va "desde las tierras de Filandia al norte hasta Génova sobre la cordillera del Barragán; La Tebaida, Montenegro y Quimbaya hasta el río La Vieja; y Salento hasta las márgenes del río Otún" ${ }^{19}$.

Al culminar el ensayo, Ortiz y Almario, afirman que:

18 Ricardo de los Ríos Tobón. Orígenes y colonización hasta 1850,113.

19 Ortiz, Luis Javier y Óscar Almario García, Caldas: Una región nueva, moderna y nacional, 25. 
Con base en De los Ríos (1986) y nuestro propio trabajo (Almario y Ortiz, 1998: II), se pueden concluir dos asuntos sustanciales: primero, que el modelo de Parsons parece funcionar basicamente para el sur antioqueño o norte caldense pero no para el resto de los países que se configuran en la región; segundo, que el modelo de subregiones o de paises coincide en lo fundamental con lo propuesto por Londoño sobre el patrón de archipielago ${ }^{20}$.

Una mención especial merece Hermes Tovar Pinzón, quien propone un modelo explicativo distinto en torno a la frontera en su obra "Que nos tengan en cuenta. Colonos, empresarios y aldeas: Colombia 1800-1900” en la que las plantea como: "materialidad de espacios marginales, incorporados a economías regionales, nacionales y mundiales, y como forjadora de leyendas y expresiones culturales propias"21. Tovar concluye que las fronteras son más que una línea que separa lo civilizado de lo salvaje: "Toda frontera es, en esencia, un mundo de invenciones, de novedades y de intereses que se mezclan: la fuerza, el poder, la avaricia, la miseria y la impotencia en el remolino de su historia. La frontera es también odio y amor, miedo y coraje, vanidad y orgullo, frustración y éxito"22.

El debate que intentan plantear Ortíz y Almario sobre lo dicho por Londoño en cuanto a Parsons y la frontera, induce a pensar en que esa temática es de vivo interés para los investigadores sociales y los historiadores en particular; pero no es así. Salvo los autores mencionados anteriormente, encontramos trabajos que no se interesan por abordar el concepto de frontera, otros que en forma implícita asumen la línea móvil de Turner y otros que, sin mencionarlo dentro de sus propósitos, aportan a la construcción de un modelo explicativo alternativo.

Así ocurre con Roberto Luis Jaramillo, cuando afirma que cada concesión colonial y republicana y cada pueblo de indios, interactúan durante la colonización, atrayéndose y repeliéndose, y al decir que Sonsón y Salamina pronto abrirían comunicación y comercio entre el occidente y el oriente y en especial con la zona minera de Marmato y Supía ${ }^{23}$; pues lleva a recordar el patrón de archipielago y el simil de la frontera con una válvula de escape a las tensiones sociales, económicas y políticas.

20 Ortiz, Luis Javier y Óscar Almario García, Caldas, 22.

21 Hermes Tovar Pinzón, Que nos tengan en cuenta. Colonos, empresarios y aldeas: Colombia 1800-1900. (Bogotá: Tercer Mundo Editores, 1995), 15. 
El urbanista francés Jacques April en su libro "La Ciudad Colombiana. Siglo XIX y Siglo XX" ${ }^{24}$, Fabio Zambrano y Olivier Bernard "con "Ciudad y Territorio. El proceso de poblamiento en Colombia" 25 y Nancy P. Appelbaum en su obra "Dos plazas y una nación: raza y colonización en Riosucio, Caldas, 1846-1948” valoran la frontera en relación con el cambio de paradigma sobre el poblamiento y el surgimiento de nuevas regiones que trajo consigo la república.

\section{Afirma April:}

En el siglo XIX será el de la sustitución gradual del modelo español por un nuevo modo de poblamiento territorial expansivo y productor de excedentes exportables, por el surgimiento de tipos genuinos de poblados y ciudades, la conformación de nuevas unidades laborales y territoriales de producción, como la plantación; de gestión, como son las comarcas y las subregiones, con sus respectivos mallajes urbanos; la aniquilación correlativa del sistema urbano heredado del siglo XVIII ${ }^{26}$.

Con la República, en contraposición con el modelo colonial español que busca a toda costa "la absoluta fijación de la población" 27 , se incentiva la circulación de la población: "Es por medio de la libertad de circulación -a veces vuelta obligaciónque opera entre 1830 y 1930, más o menos, una prodigiosa dilatación del territorio nacional "útil": se decupla en un siglo el espacio del poblamiento colonial español"28. En ese orden de ideas, se puede decir que, al menos en Colombia, hay dos tipos de fronteras, de acuerdo con el período histórico: la frontera colonial y la frontera republicana. La primera es la línea artificial, que como veremos más adelante pretende separar la "república de blancos" de la "República de indios", pero que, como en la época del oidor Mon y Velarde, también puede ser mirada como un espacio para el poblamiento, aunque por razones muy distintas a las que mueven la frontera republicana. Esta última se abre por la presión de un modelo introducido como la fórmula del desarrollo; una válvula de escape contra la miseria. La del siglo XVIII en Antioquia es una salida al hacinamiento y la pobreza en los valles de Aburrá y Rionegro.

\footnotetext{
24 Jacques April, La ciudad colombiana. Siglo XIX y Siglo XX. (Bogotá: Banco Popular, 1992)

25 Zambrano, Fabio y Olivier Bernard, Ciudad y territorio. El proceso de poblamiento en Colombia. (Bogotá: Academia de Historia de Bogotá e Instituto Francés de Estudios Andinos, 1993).

26 Jacques April, La ciudad colombiana, 65.

27 La historia regional colonial recoge los intentos de los gobernantes españoles por reducir a los indios y a los libres de todos los colores en poblados.

28 Jacques April, La ciudad colombiana, 66.
} 
En la obra de Fabio Zambrano y Olivier Bernard "Ciudad y Territorio. El proceso de poblamiento en Colombia", la ciudad es la más acabada consecuencia de los procesos de poblamiento: "El Estado crea la ciudad y sobre la ciudad el Estado toma lugar. En nuestro caso, igual que en el resto de Hispanoamérica, España dominó los espacios conquistados fundando ciudades" ${ }^{\prime 2}$. Estas ciudades coloniales, con su propio sistema de jerarquías urbanas, frente al que se impuso al llegar la república, le permite a Zambrano y Bernard aportar elementos para entender el fenómeno de la frontera en Colombia. Según estos autores, los ibéricos planteaban una frontera entre el campo y lo urbano, con base en un sistema de jerarquías urbanas, sustentado en el principio de privilegio de ciudades, villas, parroquias y lugares -repúblicas de blancos- y el campo -republica de indios-, hasta que empezó a hacer crisis en el Siglo XVIII, "en gran parte a causa del poblamiento al margen del control de las autoridades coloniales"30, y colapsó junto con el dominio de Fernando VII.

\subsection{Nuevas jerarquías urbanas, nuevas fronteras}

Con la llegada de la independencia y la instauración de la república, y el consiguiente agotamiento del sistema de jerarquías urbanas de la Colonia, se impulsaron grandes cambios en la interacción urbana, que los autores señalan como elementos explicativos del fenómeno decimonónico de la frontera colombiana, con nuevas jerarquías urbanas y nuevas fronteras internas. Los cambios en la jerarquía urbana que resaltan los autores; la supremacía del complejo urbano de la cordillera Oriental y su decadencia y el ascenso de los valles interandinos occidentales como asentamientos de una nueva red de ciudades, tienen implícita la visibilización de fronteras, procesos migratorios (colonización) y fundación de poblaciones ${ }^{31}$.

Pero estas fronteras no eran nuevas. El gran vacío entre Cali y Medellín era una frontera que aguardaba ser incorporada a la vida productiva; estaba ahí, como en el caso del sur de Antioquia y el norte del Cauca, muy cerca de los asentamientos mineros de la margen occidental del Río Cauca, un inmenso territorio "virgen":

Durante la Colonia se establecieron diversos asentamientos ubicados en los márgenes de la sub región (montaña cafetera), como Marmato, Supía y Mistrató; pero solo hasta principios del siglo XIX se inició la colonización de estas montañas de Caldas y Quindío. Desde finales del siglo XVIII, los

Zambrano, Fabio y Olivier Bernard, Ciudad y territorio,13.

30 Zambrano, Fabio y Olivier Bernard, Ciudad y territorio,62.

31 Zambrano, Fabio y Olivier Bernard, Ciudad y territorio, 65. 
pobladores de La Ceja, Abejorral y Sonsón habían proyectado ocupar las tierras al sur del río Arma... Puede afirmarse que esta subregión actuó como una especie de frontera interior de las dos regiones limítrofes, Antioquia y Cauca $^{32}$.

La problemática de la frontera decimonónica como resultado del cambio sufrido por las regiones constitutivas del Virreinato de la Nueva Granada al llegar la república, es también identificado por Nancy P. Appelbaum en su obra "Dos plazas y una nación: raza y colonización en Riosucio, Caldas, 1846-1948"33, en la cual atribuye el surgimiento de la región cafetera al esfuerzo por trazar un mapa con regiones categorizadas desde la perspectiva racial.

Al hablar de la región o de las regiones, la autora dice que en el Siglo XIX la nueva república se perfila hacia un país de regiones, que alcanza su punto culminante expresado en la consolidación del Estado-nación, con la introducción del federalismo:

El proceso de consolidación del Estado-nación también lo fue de su división. El federalismo reflejó y reforzó las emergentes animosidades e identidades regionales, aunque los límites geográficos entre los Estados no siempre coincidían con los inestables e indistintos límites de las entidades raciales ${ }^{34}$.

Esos límites surgían de la vinculación del concepto de raza al proceso de creación, diferenciación y consolidación de las regiones y en la caracterización de la frontera entre Cauca y Antioquia. Las fronteras raciales, aunque no las denomina así Appelbaum, son las delimitaciones que emergen al caracterizar regiones de acuerdo con el grupo étnico asentado en el territorio y que están asociadas también con el clima y la geografía:

Varios de los intelectuales de la élite de mediados del siglo atribuyeron las diferencias culturales y raciales al clima y la topografía. Los geógrafos Agustín Codazzi y Felipe Pérez de la Comisión Corográfica lamentaban la desnudez, la falta de amor por el trabajo y la poca ambición por las comodidades

Zambrano, Fabio y Olivier Bernard, Ciudad y territorio, 149.

33 Nancy P. Appelbaum, Dos plazas y una nación: raza y colonización en Riosucio, Caldas, 1846-1948. (Bogotá: Universidad de los Andes, Universidad del Rosario e ICANH, 2007). 
materiales que ellos percibían entre los negros e indígenas de las zonas bajas del Valle del Cauca y la costa del Pacífico ${ }^{35}$.

La visión racialista estuvo vinculada a la visión que las autoridades de la provincia del Cauca tenían sobre el poblamiento de su frontera nororiental, de clima templado, montañosa y disponible para ser ocupada por familias que quisieran trabajar la tierra.

\subsection{Una frontera que se expande y mueve su centro de impulsión}

Otro planteamiento sintonizado con el patrón de archipiélago, las fronteras internas y el papel de trampolín de los asentamientos de frontera, es el que hace el historiador quindiano Jaime Lopera Gutiérrez ${ }^{36}$,en su texto: "La colonización del Quindío. Apuntes para una monografía del Quindío y Calarcá” ${ }^{37}$.

Luego de anotar que el Quindío durante los siglos XVI y XVII es "terra incógnita", como si se hubiera instalado allí un gran vacío colonial, el historiador avanza en el planteamiento que tiene que ver con el tipo de frontera que es el norte del Cauca durante la colonización antioqueña, muy cercano al patrón de archipiélago teorizado por Morse:

El oriente antioqueño es, para nosotros, la semilla del cambio colonizador. Una idea en obra negra sugiere un proceso centrífugo que movilizó desde allá a los colonizadores... El descongelamiento de todo ese proceso comenzó en Sonsón, asociado a la pobreza y a la presión demográfica ${ }^{38}$.

Advierte el historiador que la frontera va corriendo su centro de impulsión a medida que avanza la acción colonizadora, de manera que cada población consolidada es el trampolín desde el cual se da el próximo salto explorador:

Salamina queda atrás como centro de irrigación colonizadora. Con Aguadas, Pácora y Riosucio -fundadas antes de 1827- se va articulando la influencia

Nancy P. Appelbaum, Dos plazas y una nación, 70.

36 Jaime Lopera Gutiérrez nació en Calarcá en 1936, es historiador, periodista, escritor y un exponente de la historia regional y en especial de la historia del Quindío. También ha ocupado altos cargos públicos, debido a su incursión en la política. Es columnista del diario económico Portafolio y La Crónica del Quindío. 
colonizadora hacia el oriente y el occidente. Santa Rosa y Pereira sirven de punto de arranque a otra ola expedicionaria. Salento es, por otra parte, una estación intermedia entre Cartago e Ibagué, establecida en 1843 como colonia penitenciaria para los trabajadores de la vía del Quindío ${ }^{39}$.

Otro tanto ocurre con la obra "Empresarios y políticos en el Estado Soberano del Cauca 1860-1895" 4 , del historiador Alonso Valencia Llano, que ayuda a imaginar cómo era la frontera nororiental de la provincia del Cauca, cuando habla de las del Estado Soberano del Cauca, en el decenio sesenta del siglo XIX. Una frontera que no es la que separa lo civilizado de lo salvaje y que conecta núcleos de poblamiento y actividad comercial separados hasta la época de la colonia.

Como frontera interna, define Alonso Valencia Llano, la que separa al Cauca de Antioquia y que no es sinónimo de soledad, ni de inactividad económica; como tampoco la línea que separa lo civilizado de la barbarie. Era el Quindío. El autor dice que para 1860 el Cauca ya tenía relaciones comerciales con Antioquia y referencia los avances hechos en el Quindío para comunicar a los dos territorios e, incluso, poblar el norte caucano con paisas ${ }^{41}$. Las obras del camino del Quindío, el asentamiento de una población donde se estableció el presidio del tercer distrito, la concesión de las obras del llamado Camino del Privilegio y la fundación de Santa Rosa de Cabal, son las actividades que reseña.

En el capítulo quinto, donde habla de las relaciones económicas y de producción, Valencia Llano referencia la subregión del Quindío como la frontera minera y de colonización:

Estaba compuesta por las municipalidades de Quindío (Cartago), Toro, San Juan y Atrato e integraba zonas fundamentales para la economía caucana: la de colonización que separaba a Cauca y a Antioquia y los distritos mineros del Chocó, Supía, Marmato, Anserma y Riosucio: algunos distritos como Cartago y Toro tenían también tierras sobre la suela plana del valle del Cauca. La economía estaba dominada por la extracción de oro, pero también se producía una buena cantidad de alimentos y de ganado que pastaba en las tierras planas del valle que correspondían a los municipios de Cartago y

\footnotetext{
39 Jaime Lopera Gutiérrez, La colonización del Quindío, 61.

40 Alonso Valencia Llano, Empresarios y políticos en el Estado Soberano del Cauca 1860-1895. (Cali: Universidad del Valle, 1993). 
Toro. Desde el punto de vista comercial el dominio estaba en Cartago desde donde se distribuían alimentos, artesanías y aguardientes producidos en las otras subregiones caucanas y que se destinaban al consumo de la zona de colonización, los distritos mineros y el vecino Estado de Antioquia ${ }^{42}$.

El ámbito señalado por Valencia Llano es el de una frontera que se expande desde un centro de impulsión que es Cartago hacía los nuevos asentamientos del sur de Antioquia, la zona minera de Marmato, el Chocó e Ibagué, como si se tratara del avance hacia las islas del archipiélago al que se refiere Morse.

Otros autores reconocen, sin ser el objeto de sus preocupaciones investigativas, que la frontera asume características relacionadas con las necesidades sociales de la comunidad que se desplaza, la forma de explotar sus recursos, la clase de mano de obra que lo anterior exige, las actividades económicas generadas y la infraestructura que se debe proveer. La mayoría acepta, por ejemplo, que la frontera sobre la cual se volcaron los colonizadores antioqueños, fue una especie de válvula de seguridad que operó para quitarle presión a una compleja situación social y económica. La obra de Albeiro Valencia Llano, "Colonización. Fundaciones y conflictos agrarios" ${ }^{4}$, habla inicialmente de la frontera conflicto, fruto de "la naturaleza no igualitaria de la frontera agrícola desde el río Arma hasta Manizales y en los actuales departamentos de Risaralda y del Quindío, lo mismo que en el norte del Valle"44; luego aborda la frontera agrícola -abastecedora- pensada por el Oidor Mon y Velarde, y que debía ser poblada por quienes quisieran explotarla y producir los bienes de consumo que necesitaba la minería para poder ser rentable, y termina con el concepto de frontera como válvula de seguridad para resolver la compleja problemática social de la Antioquia del siglo XVIII, que supera en mucho las dificultades de su minería.

Los siguientes factores en su conjunto, constituían en ese entonces, un obstáculo para el desarrollo económico y social y generaron las presiones que llevaron a miles de personas a afrontar los riesgos de la empresa colonizadora hacia tierras abandonadas, de títulos dudosos o del Estado:

Las presiones más fuertes sobre emigración manifestadas en Antioquia se hicieron latentes en las zonas de mayor concentración de la tierra y

Alonso Valencia Llano, Empresarios y políticos, 171.

Albeiro Valencia Llano, Colonización. Fundaciones y conflictos agrarios. (Manizales: Artes gráficas Tizan, 2001), 414.

\section{Albeiro Valencia Llano, Colonización,368.}


donde existía baja productividad agrícola, especialmente en las tierras altas, densamente pobladas y donde los recursos económicos de las clases dirigentes eran orientados hacia el comercio, actividad ésta con poca incorporación de fuerza de trabajo. El monopolio ejercido sobre la mejor tierra, más productiva, con fácil acceso geográfico y que hubiese servido para producir alimentos, atraer el exceso de fuerza de trabajo de las zonas altas y satisfacer las necesidades de la minería, fue uno de los principales obstáculos para el desarrollo económico y social de la región. Ante ese estado de cosas la población sobrante debía aceptar los términos de contratación ofrecidos por los terratenientes o convertirse en mazamorreros independientes o vagabundear ${ }^{45}$.

La otra alternativa era emigrar a sitios no incorporados a la producción agrícola, para abrir parcelas en compañía de sus familias. Ese camino fue seguido por miles de familias, dando inicio al proceso de incorporación de amplios territorios inexplotados a la producción, llamado la Colonización Antioqueña. En ese momento, la frontera funciona como una válvula de seguridad.

En mayor o menor medida, todos listan elementos articuladores útiles para moverse en la intersección ofrecida por los difuminados límites entre frontera y colonización, que carácterizan los discursos de la historiografía nacional. La fonda y los caminos, por ejemplo, son introducidos como categorías necesarias para comprender lo sucedido en la colonización antioqueña. Están presentes en el texto de Jacques April; en el Antonio García Nossa, "Geografía Económica de Caldas" y en "Colonización Antioqueña. Una empresa de caminos" ${ }^{46}$, de Eduardo Santa.

Los casos referenciados en la bibliografía que aborda en forma implícita o explícita el problema de la frontera, llevan a concluir que el patrón de archipiélago es el apropiado para entender el ámbito espacial donde se desplegó el fenómeno de la colonización de las vertientes de las cordilleras central y occidental.

El estudio de la fundación de Santa Rosa de Cabal valida la propuesta, ya que el asentamiento se establece a medio camino entre Cartago, Cartago viejo -hoy Pereira y que nunca estuvo desahabitado- y el pueblo antioqueño de Neira. Cartago viejo es el nombre que se le daba al sitio que durante más de ciento cincuenta años ocupó la población española de San Jorge de Cartago, fundada por el conquistador Jorge

45 Albeiro Valencia Llano, Colonización, 8.

46 Eduardo Santa, Colonización antioqueña. Una empresa de caminos. (Bogotá: TM Editores, 1993). 
Robledo en el siglo XVI, y que luego de ser trasladada a orillas del río La Vieja se mantuvo como referente, porque continuó siendo habitada por labriegos y luego se consolidó como cruce de caminos y sitio de intercambio comercial, hasta el punto de ser el embrión de la ciudad de Pereira ${ }^{47}$.

Lo mismo ocurre con Neira; fundada por colonos antioqueños en 1842, fue la población del sur oriente de Antioquia más cercana a la frontera con la provincia del Cauca y, por tanto, necesitada de un enlace comercial con el cantón de Cartago. Otro ejemplo es la consolidación de Salamina, asociado en gran medida a su interacción mercantil con la zona minera de Marmato, centro urbano fundado en la margen izquierda del Río Cauca por los españoles para la explotación del oro entre 1536 y 1539. La relación de Salamina y Marmato, o lo que a mitad del siglo XIX se llamaba el distrito norte, con sus minas, es estrecha. Las poblaciones que como Salamina se fundaron en el marco de la colonización antioqueña, en la margen derecha del río Cauca -como fue Arma en su momento-, sirvieron como estaciones entre los campos auríferos y los centros urbanos importantes, como centros de abastecimiento de alimentos, herramientas y lugares de residencia de las familias de empresarios del oro.

Así las cosas, en lo que tiene que ver con el asunto de la frontera, se debe reiterar que no ha sido un tema del interés de los científicos sociales, ni de los historiadores en particular. Sin embargo, los avances en la formulación de un modelo explicativo post-Parsons por los autores referidos, implica una nueva senda en el enfoque del modelo de colonización, cuya exploración y profundización que deben ser señaladas por la comunidad académica como indispensables para el entendimiento de un fenómeno actual en el suroriente del país. que cuando se fundó Pereira, el sitio que hoy ocupa Pereira ya estaba poblado. El cuadro sobre la llegada del séquito del Padre Cañarte a Cartago Viejo el 30 de agosto de 1863 -fecha aceptada como la de la fundación de Perera-, y que pintó Jesús María Ormaza, uno de los acompañantes del presbítero, demuestra que el territorio ya estaba poblado. Al lado y lado de lo que hoy es la calle 19 o Calle de la Fundación, se ven varias casas y ranchos. 


\section{Colonización y colonización estatal}

Otro de los propósitos del balance historiográfico adelantado, fue rastrear el tratamiento que se le ha dado al concepto de colonización estatal, tras revisar el posicionamiento asumido por los autores frente al fenómeno de la denominada colonización antioqueña y en particular, frente a la versión pionera construida por James P. Parsons en su obra "La Colonización Antioqueña en el Occidente de Colombia”.

A pesar de que en sus textos recoge evidencia de la función que tuvo el Estado en el proceso de poblamiento que implicó la denominada colonización antioqueña $\mathrm{y}$ en particular, el desempeñado por las autoridades virreinales, primero, y las neogranadinas y caucanas después, en lo que tiene que ver con la ocupación de lo que para la mitad del siglo XIX se denominaba la Montaña del Quindío -frontera nororiental de la provincia del Cauca-, Parsons no hace un reconocimiento a ningún otro actor que no sea el proveniente de Antioquia, ni a otro estamento diferente al campesinado paisa sin tierra y, quizás, al empresario visionario, quienes se volcaron planificada o "espontáneamente", según el caso, a las vertientes al sur de Rionegro y Sonsón.

El autor, por ejemplo, apenas menciona el carácter caucano de la fundación de Pereira en 1863. A pesar de calificarla como la "única colonia próspera de origen no antioqueño", no profundiza en la tramoya que determinó que la élite de Cartago oficializara un asentamiento que existía de hecho, quizás desde que los españoles decidieron trasladar la fundación robledana a la vega del río La Vieja.

Las mencionadas categorías de colonización estatal, colonización empresarial, con las tensiones por la tierra que esta implica, o colonización de otro origen poblacional, no están insertas en el modelo parsoniano, pese a que referencia el paso del Oidor Mon y Velarde por las tierras de Antioquia, sus medidas para impulsar la fundación de nuevas poblaciones y las políticas adoptadas desde el comienzo de la República por sus autoridades con relación a la adjudicación de los baldíos, con el fin de crear una capa de pequeños y medianos propietarios agrarios; así como las decisiones políticas relacionadas con la dotación de caminos para impulsar la actividad comercial entre diferentes provincias. En algún momento afirma que la del Quindío fue una "empresa provechosa para unos pocos terratenientes en grande", mientras que en lo que llama el norte - sur y sur oriente de Antioquia- "predominó fue una especie de comunidad socialista" ${ }^{38}$.

48 Joaquín Molano, ed., Las regiones tropicales americanas, 83 
Justamente, lo relacionado con la implantación de un modelo social democrático e igualitario en el Occidente de Colombia por cuenta de los colonos antioqueños, es la tesis más controvertida de las planteadas por James Parsons y muchas de las argumentaciones que sustentan las críticas fueron aceptadas por el propio geógrafo estadounidense, tal como lo vimos anteriormente ${ }^{49}$.

Con excepción de Eduardo Santa ${ }^{50}$, la totalidad de los autores de los trabajos revisados para la investigación, desestiman que la colonización antioqueña haya construido una sociedad igualitaria y democrática de pequeños campesinos. Sus obras muestran matices que en últimas desembocan en mostrar una visión más conflictiva de la colonización y en especial de la colonización antioqueña.

Antonio García Nossa, por ejemplo, aunque avala la afirmación de Parsons sobre la sociedad que construyó la colonización antioqueña ${ }^{51}$, no pasa por alto el conflicto que en esa misma región se vivió por la posesión y dominio de la tierra:

Hay un primer tropiezo grave: el de las adjudicaciones y el de los extensos territorios sin desmontar, que reivindican los herederos de quienes los habían obtenido por Capitulaciones Reales. Casi 7 municipios, desde el río Pozo hasta Chinchiná, pertenecen a un solo propietario. Entonces se inicia la lucha entre colonos y terratenientes ${ }^{52}$.

Roberto Luis Jaramillo en su ensayo sobre "La Colonización Antioqueña", pone de manifiesto no sólo el carácter conflictivo del escenario de frontera, sino también el de las intencionalidades que determinan los desplazamientos hacia las tierras incultas. Recuerda cómo la colonización de la montaña de Sonsón tuvo tensiones entre quienes querían una colonia para pobres y mestizos y los que deseaban ver esos baldíos poblados por ricos y blancos ${ }^{53}$. Jaramillo, aunque reconoce que la antioqueña es la colonización más significativa y estudiada, aclara que hay otros procesos colonizadores donde, al igual que la "paisa", el título de propiedad no fue un premio caído del cielo ${ }^{54}$.

Joaquín Molano, ed., Las regiones tropicales americanas, 135.

Eduardo Santa, La Colonización Antioqueña: Una empresa de Caminos. (Bogotá: TM Editores, 1993).

Antonio García Nossa, Geografía Económica de Caldas. (Bogotá: Banco de la República, 1978), 37.

García Nossa, Geografía Económica de Caldas, 35.

Roberto Luís Jaramillo, La Colonización Antioqueña. (Bogotá: Suramericana, 1988), 184.

Jaramillo, La Colonización Antioqueña, 186 - 187. 
Por su parte, Catherine LeGrand en su obra "Colonización y protesta campesina en Colombia 1850-1950"55, muy pronto rompe fuego contra lo que ella misma llama el "mito demócrático" y para eso se sustenta en estudios que recalcan el papel decisivo que jugaron los comerciantes y especuladores territoriales en la dirección de la colonización y el provecho que sacaron de ellas. Y agrega:

El avance de la colonización y la formación de grandes propiedades no fueron, como se ha supuesto, fenómenos contradictorios: más aún, entre 1850 y 1930 la adjudicación de baldíos contribuyó directamente a la consolidación de grandes propiedades en las regiones más económicamente productivas del país.

A renglón seguido, desestima la democratización del acceso a la tierra que se predica como un atributo de la colonización antioqueña:

Pero lo que más claramente se destaca es la concentración en la tenencia de la tierra. Más de las tres cuartas partes de todo el territorio otorgado a particulares, compañías y poblaciones desde 1827 hasta 1931 se repartieron en concesiones de 1.001 hectáreas o más. Estas cifras respaldan la hipótesis que la privatización de los baldíos reforzó el predominio de la gran hacienda en el campo colombiano. Tan solo se le concedió el 5 por ciento de la tierra a las poblaciones antioqueñas sobre las cuales tanto se ha escrito y solo otro 4 por ciento está representado en parcelas inferiores a 100 hectáreas. Ciertamente, las grandes concesiones eran más frecuentes en áreas ganaderas que en zonas cafeteras, pero incluso en el departamento de Caldas, corazón de la llamada frontera democrática del café, casi el 30 por ciento de la tierra adjudicada correspondíó a predios de más de 1.000 hectáreas ${ }^{57}$.

Al identificar dos etapas del fenómeno colonizador, LeGrand está dibujando de cuerpo entero las causas más obvias de un poblamiento conflictivo. En la primera de aquellas, se da el desplazamiento de las familias a la tierra virgen a cultivar la tierras y darle valor; en la segunda, llega el empresario interesado en formar grandes propiedades, tras aprovecharse de las mejoras del colono y de volverlo su peón y

55 Catherine Legrand, Colonización y protesta campesina en Colombia 1850-1950. (Bogotá: Universidad Nacional de Colombia, 1988)

56 Legrand, Colonización, 17-18.

57 LeGrand, Colonización, 78-79. 
arrendatario, por cualquier método ${ }^{58}$. En la primera etapa, la frontera es refugio que acoge a quienes deben abandonar su lugar de origen, huyendo de la guerra, buscando sobrevivir después de la manumisión y del desmonte de los resguardos indígenas, $\mathrm{o}$ para redimir a sus familias de la miseria secular. Detrás de ellos, en lo que la autora identifica como la segunda etapa, llegan los empresarios: "individuos de estratos medio y alto", comerciantes, abogados, terratenientes o políticos pertenecientes a familias importantes, así como otros sectores en ascenso, profesionales de provincia, caciques políticos, tenderos y prestamistas.

El conflicto entre unos y otros reside en que los empresarios territoriales, como los llama LeGrand, se interesan por las tierras ya ocupadas y mejoradas por las familias de colonos y por la mano de obra capacitada que estos núcleos pueden ofrecer. No miran las tierras vírgenes, que son las que los dirigentes colombianos aprecian como el espacio con oportunidades para todos. Entonces la frontera pasa a ser el escenario del conflicto y este se expresaba según las condiciones económicas, sociales y políticas que tuviera cada sector para lograr su propósito. Por eso, los hechos y circunstancias que configuran una frontera no son iguales en ningún caso y de ahí lo nocivo de mirar el fenómeno a través del lente de la experiencia antioqueña.

Jacques April percibe las contradicciones que implica la voluntad de incorporar la economía nacional a la mundial, a través del modelo agro exportador y las estructuras sobrevivientes del régimen colonial español; así como la entrega de las tierras realengas a los extranjeros, en desarrollo de los tratados de amistad y libre comercio con naciones de Europa y Norte América: "Esta contradicción entre pujanza de fuerzas productivas nuevas enfrentadas a relaciones viejas, se resuelve parcialmente con la colonización popular de nuevas tierras: las laderas de vertientes de las tres cordilleras" 59 .

Para el autor es claro que la colonización se hace y es al mismo tiempo expresión de múltiples conflictos, de corte clasista, que superan el carácter regional del importante fenómeno social:

Este período que se inicia en 1810-1820 y concluye hacia 1930 está interferido por violentos conflictos clasistas, las llamadas guerras civiles se traducen en pillaje, expoliaciones, despojos, migraciones y éxodos, los cuales tienen un doble efecto contradictorio... en ciertas regiones que provocan un vacío

LeGrand, Colonización, 18. 
demográfico y el consiguiente estancamiento productivo, pero en otras llegan migrantes y un amplio abanico de conflictos de clase se convierten en el motor del desenvolvimiento territorial. Suscitan unas fuertes corrientes migratorias, las cuales se dirigen hacia las montañas, las cordilleras, o sea a los baldíos de vertientes ${ }^{60}$.

Algo relevante de April en la obra analizada, es que califica la colonización como un fenómeno de clase, en tanto se "fusionan los tres componentes étnicos (el campesinado mestizo, las variadas corrientes de aborígenes y el numeroso proletariado negro) bajo prácticas sociales del mismo proceso de trabajo en las selvas inhóspitas, hasta generar el embrión de una nueva sociedad agraria"61.

Por eso considera que "más que de una determinada región, la colonización procede de un sector social específico: el campesinado sin tierras propias o suficientes, el cual existía en numerosas regiones. Con lo anterior se verifica el carácter inminentemente clasista y la magnitud nacional de la gran gesta popular" ${ }^{2}$.

A su vez, Hermes Tovar Pinzón, en "Que nos tengan en cuenta. Colonos, empresarios y aldeas: Colombia 1800-1900"63, nos introduce en el tema de un proceso colonizador conflictivo, debido a los ajustes entre las realidades jurídicas y las situaciones de hecho en materia de tenencias de tierra, a la amplitud de los baldíos y al uso que el legislador y los gobiernos le van dando a esos globos de terreno: "la documentación sobre baldíos para el siglo XIX revela el interés de la sociedad por deslindar y titular" ${ }^{64}$.

Tovar Pinzón precisa que el fenómeno migratorio estuvo presente en la mayor parte del territorio nacional, matizado por la forma como actuaron los empresarios en el proceso colonizador. Según el autor, los siguientes eran los comportamientos de estos personajes de la frontera:

1. Controlar colonos fundando pueblos.

2. Oposición a las aldeas.

3. Disputando espacios a los cultivadores primitivos.

60 April, La ciudad colombiana, 67.

61 April, La ciudad colombiana, 68.

62 April, La ciudad colombiana, 69.

63 Tovar Pinzón, Que nos tengan en cuenta.

64 Tovar Pinzón, Que nos tengan en cuenta, 19. 
4. Venden parcelas y valorizan la frontera al fundar economías de subsistencias $\mathrm{y}$ fortalecer grupos mediados de empresarios.

5. Promueven la fundación de pueblos con gentes humildes, para proveer de mano de obra las nuevas haciendas.

6. Fundaban campamentos en las selvas, para la explotación de materias primas como la tagua, la quina y el caucho. Estos asentamientos duraban lo que tardara en extraerse la materia prima demanda por el mercado exportador; por eso, estos empresarios no traían pobladores sino trabajadores, que se iban con el trasteo del campamento.

En cada una de estas conductas subyace el ejercicio de la coerción, para lograr los propósitos. En lo que corresponde a la colonización antioqueña, las asimetrías de sus resultados según la época y el territorio, nos enseñan que ni siquiera la gesta paisa, tan cantada y puesta como ejemplo virtuoso, fue uniforme en su desarrollo y en sus consecuencias.

A su vez, Albeiro Valencia Llano expone que, si la frontera fue el escenario del conflicto, este no fue de un solo tipo. Múltiples intereses confluyeron en esa coyuntura de la historia y fueron diversas clases de colonización que se hicieron presentes en distintos períodos y regiones, o de manera coetánea; así como actores de variada procedencia interactuaron y se enfrentaron en procura de sacar adelante sus intereses.

Gracias su enfoque de historia regional, se pueden conocer los detalles de este período histórico para encontrar coincidencias y aciertos entre lo que narra el historiador y lo resaltado por otros autores, en desarrollo de paneos generales sobre la colonización de vertientes en los siglos XIX y XX. Coincidencias y aciertos que no se agotan con la referencia al conflicto en la frontera, sino que se hacen presentes con el papel de los empresarios, de los colonos y del Estado. Sin ellos no se podría avanzar en la comprensión del fenómeno social tratado.

La forma como intervienen los empresarios, los colonos y el Estado, permite caracterizar el tipo de colonización que se desarrolla y también el grado de conflictividad de los procesos de poblamiento. Valencia Llano describe el conflicto que enfrenta a los titulares de las concesiones con los campesinos que descuajaban la montaña para sembrar y establecer potreros esperando ser adjudicatarios:

Dueños de las grandes concesiones desarrollaron la táctica de fundar colonias para valorizar sus tierras y vendieron lotes a colonos pobladores. Mientras 
tanto el gobierno republicano reconoció los derechos del cultivador de baldíos. Así, de acuerdo con la Ley del 20 de abril de 1848 se perfiló la idea de que quien desmontaba tierras adquiría derechos sobre ellas ${ }^{65}$.

En el fondo, de acuerdo a lo dicho por el historiador, había un conflicto entre lo que los intereses de los empresarios que impulsaban el poblamiento de las fronteras internas y el campesinado que de manera espontánea acudía a las vertientes cordilleranas:

Eran profundas las diferencias entre comerciantes-terratenientes y latifundistas, cuyos títulos de propiedad se remontaban a la colonia. Estos últimos esperaban obtener beneficios de la tierra por la presión del crecimiento demográfico que facilitaba la venta de lotes a inmigrantes; por tanto, no estaban interesados en invertir capital para desarrollar la producción. Por el contrario, la élite tenía interés en aumentar la producción con el fin de obtener alimentos más baratos para la minería, buscando, además, la fundación de poblaciones para impulsar el desarrollo de la ganadería, lo que favorecía la migración de mano de obra hacia el sur de Antioquia y engendraba la alianza entre comerciantes y colonos, contra los obstáculos puestos al proceso de colonización por los herederos de las concesiones coloniales ${ }^{66}$.

Sobre ese antagonismo tercia el historiador Keith H. Christie en su obra "Oligarcas, campesinos y política en Colombia: Aspectos de la historia socio-política de la frontera antioqueña". Luego de referenciar la forma gradual en que la versión rosa de Parsons es objeto de cuestionamientos, debido a las cifras que hablan sobre el ínfimo beneficio de los campesinos pobres a la hora de distribución de los baldíos y al hecho de que los protagonistas de los procesos de poblamiento no podían ser ejemplos de la gran movilidad social ascendente, en tanto eran parte de o representaban a poderosas familias antioqueñas ${ }^{67}$, el autor afronta la tarea de explicar que los concesionarios o los empresarios territoriales no podían ser comparados con los latifundistas latinoamericanos que Parsons usa como ejemplo:

Se ha puntualizado que los comerciantes ricos no sólo cultivaban las tierras de la frontera para su propio beneficio, sino que poseían enormes concesiones

\footnotetext{
65 Valencia Llano, Colonización, 369.

66 Valencia Llano, Colonización, 7.

67 Keith H. Christie, Oligarcas, campesinos y politica en Colombia: Aspectos de la historia socio-politica de la frontera antioqueña (Bogotá: Universidad Nacional de Colombia, 1986) 25.
} 
de tierra, partes de las cuales eran consideradas por ellos como tierras para ser vendidas a eventuales colonos con un pingüe provecho. Este tipo de propietarios no podrían ser considerados latifundistas en el sentido más estricto del término ${ }^{68}$.

Lo innovador en Christie, es que aunque dice que los nuevos asentamientos fueron impulsados por comerciantes de las mejores familias de Antioquia; que utilizaron los bonos de deuda pública expedidos por el gobierno para adquirir grandes extensiones de terrenos y que esa actividad colonizadora era sólo parte de un portafolio mucho más grande de inversiones, no se les puede llamar latifundistas, al menos en el sentido clásico latinoamericano, pues no deseaban conservar para siempre esos enormes globos de tierra:

Estos comerciantes no pensaban quedarse de manera permanente con las concesiones de tierras adquiridas. Abrieron rudimentarios caminos y fundaron pequeños pueblos con el fin de vender tierras con buena ganancia, a los eventuales colonos. En este sentido fueron claramente unos inversionistas en propiedad raíz ${ }^{69}$.

Para el efecto, pone de ejemplo a las concesiones Villegas y Aranzazu: “(...) Hasta donde puede establecerse, lejos de ser un representante de la clásica lucha entre latifundistas y colonos, Villegas estaba deseoso de vender la tierra en disputa" ${ }^{\prime \prime}$. Continúa afirmando el autor:

El mismo espíritu comercial aparece aún más claramente en la concesión Aranzazu(...) Tampoco en este caso el origen de las disputas fue la negativa de la Compañía a realizar cualquier venta de tierra(...) se debió al deseo de obtener el mejor precio posible para la tierra y no al interés en bloquear las ventas ${ }^{71}$.

Christie adhiere al grupo de los que cree que la frontera igualitaria durante la colonización antioqueña hace parte de un mito, cuya refutación no implica reconocer que fue variada la condición de quienes se beneficiaron con el reparto de las tierras; aunque la ventaja siempre la tuvieron las familias mejor relacionadas:

68 Christie, Oligarcas, campesinos y política en Colombia, 24.

69 Christie, Oligarcas, campesinos y política en Colombia, 31.

$70 \quad$ Christie, Oligarcas, campesinos y política en Colombia, 31.

71 Christie, Oligarcas, campesinos y política en Colombia, 32. 
Las familias oligárquicas, pues, permanecieron activas e importantes en la frontera a lo largo del período colonizador. Sin embargo, a pesar de esta continuidad, el retrato aquí bosquejado es complejo. Familias pobres y modestas lograron prosperar, pese a la presencia de las mejores familias. No obstante, aunque hubo alguna posibilidad de movilidad social, las oportunidades frecuentemente estaban circunscritas a la minoría. Las mejores familias determinaron la vida social y política de la frontera ${ }^{72}$.

En síntesis, casi la totalidad de los trabajos revisados en el balance historiográfico coinciden en que la colonización antioqueña fue un escenario de confrontación, donde midieron fuerza los múltiples intereses y sectores que modelaban la realidad de la joven república y especial, la de sus fronteras internas. Del mismo modo, se reconoce en forma generalizada la supremacía de las élites tradicionales y de los grupos sociales en ascenso, al momento de acceder al dominio de la tierra. De mejor forma no lo ha podido definir Catehrin LeGrand, al hablar de cómo los empresarios territoriales suceden a los colonizadores espontáneos en el control de la tierra, con todo lo conflictivo que eso implica.

\subsection{Colonización estatal}

Aparecen entonces dos sectores protagónicos en el proceso de poblamiento de las vertientes de las cordilleras: los campesinos sin tierra que descuajan los montes para sembrar y asentar a sus familias y los empresarios territoriales; sector compuesto por un conglomerado de diversa condición y origen, que va desde el concesionario realengo, hasta el profesional liberal de clase media, que ha ido a la frontera a buscar un lugar en el mundo, pasando por el potentado inversionista inmobiliario. Los primeros lideran una colonización denominada espontánea, con las características que desde Parsons se le dio a la colonización antioqueña, y los segundos son los gestores de una colonización planificada de carácter empresarial.

Sin embargo, al recalibrar el sentido del balance historiográfico en el marco de una investigación que rastrea el despliegue del Estado en la frontera nororiental de la provincia del Cauca entre 1840 y 1845 , asociado a sucesos como la apertura del camino del Quindío y la fundación de Santa Rosa de Cabal, la categoría de colonización estatal -modalidad de la planificada- aparece como un elemento esencial del debate sobre la naturaleza de la colonización antioqueña y en particular, sobre el tipo de poblamiento del territorio que separaba a Cartago del sur de Antioquia y de Ibagué.

Christie, Oligarcas, campesinos y politica en Colombia, 47. 
En busca de responder a estas preguntas, exploramos en los trabajos incluidos en el balance bibliográfico y encontramos que todos de alguna forma - explícita o implícita-, abordan el tema e incluyen la colonización estatal como una categoría de sus clasificaciones; pero no alcanzan a decir cuáles etapas o casos de este importante fenómeno social se pueden clasificar como tal.

Antonio García habla del tanteo que implicó los primeros desplazamientos colonizadores de la segunda mitad del siglo XVIII y el paso firme de la colonización entre 1840 y 1870, que llama de desbordamiento y que evidencia ya la planificación de una colonización dirigida ${ }^{73}$. Del mismo modo, la mención de la fundación de Manizales como ciudad estratégica desde lo geográfico y militar, habla de objetivos más ambiciosos que los perseguidos por los colonos que espontáneamente buscan tierras para cultivar ${ }^{74}$.

Las élites antioqueñas, dice Roberto Luis Jaramillo, se habían preparado para la empresa de la colonización, aprovechando las normas expedidas por el Rey de España en 1754 y 1780 y la riqueza alcanzada en la actividad minera. Sin embargo, el autor no se atreve a hablar de una colonización planeada como la única modalidad del fenómeno social antioqueño:

La colonización antioqueña revistió en sus primeros períodos dos modalidades: la espontánea y la planeada; hacia donde los campesinos pobres y futuros colonos apuntaban espontáneamente, allí mismo las élites compraban calculadamente los terrenos. Unos y otros colonizaron con distintos esfuerzos, los primeros para subsistir y los segundos para invertir en una empresa prevista, calculada y lucrativa (a veces estos patricios, desde sus posiciones burocráticas, señalaron hacia dónde se deberían dirigir los colonos o los vagos expulsables) $)^{75}$.

Lo anterior le da oportunidad a Jaramillo para decir que "No en todos los casos los colonos marcharon espontáneamente" 76 , y a continuación, a manera de ejemplo, dice que utilizando las normas coloniales contra "vagos y malentretenidos", el cabildo de Rionegro impulsó una colonización forzoza hacia el sur, en las tierras calientes del Buey y Arma. Para redondear recuerda que:

\footnotetext{
73 García Nossa, Geografía Económica de Caldas, 39.

74 García Nossa, Geografía Económica de Caldas, 186.

75 Jaramillo, La Colonización Antioqueña, 186.

76 Jaramillo, La Colonización Antioqueña, 190.
} 
Veinticinco años más tarde, ya avanzada la colonización hacia el sur, se ventilaba en el mismo cabildo el proyecto de acabar con vagos y ladrones, formando una población en Sabanalarga, camino de Herbeo: con esos colonos forzados se dieron los primeros pasos para la fundación de Salamina ${ }^{77}$.

A manera de ilustración, el autor dice:

Vagos eran los que no tenían rentas, ni bienes, ni sueldo, ni oficio, ni beneficio, ni ocupación; ser hijo travieso o jornalero sin estabilidad en una finca ajena constituía vagancia. Ser pobre o desadaptado social era delito ${ }^{78}$.

Ahora bien, Catherine LeGrand le da en su trabajo un peso muy importante a lo que llama la colonización espontánea:

Durante el período de crecimiento de las exportaciones, el campo colombiano era un campo en movimiento. A medida que aumentaba la atracción de las fronteras, indígenas, ex-esclavos, arrendatarios, artesanos y pequeños propietarios emigraron de regiones que habían sido pobladas por mucho tiempo hacia tierras de dominio público. La colonización espontánea de los baldíos contribuyó significativamente al desplazamiento económico y demográfico de la Cordillera Oriental hacia el occidente y, en menor medida, hacia la costa Atlántica, que tuvo lugar entre 1850 y $1930^{79}$.

Al proponer la mirada general de la colonización que revisamos, Jacques April habla de unas modalidades y entre ellas lista en tercera posición la colonización estatal, que da como resultado la fundación de pueblos de origen institucional. Sobre la primera dice: "La colonización estatal, con intervención oficial e institucional y con motivaciones esencialmente políticas; reformista por esencia actúa en un marco legal y administrativo apoyada en leyes" 80 .

En cuanto a los pueblos de origen institucional, afirma que estos, a diferencia de los originados en la acción popular, trazados por los mismos pobladores, y de los surgidos por la acción especulativa empresarial que se piensan desde los despachos de ingenieros y geómetras; son planeados desde la administración central de

\footnotetext{
77 Jaramillo, La Colonización Antioqueña, 191.

78 Jaramillo, La Colonización Antioqueña, 191.

79 LeGrand, Colonización, 59.

80 April, La ciudad colombiana, 70.
} 
Bogotá. El autor afirma que este tipo de caso "opera en el marco de unas tímidas políticas agrarias estatales de principios de siglo XX. Políticas geográficamente muy localizadas, limitadas a unas zonas marginadas del país, y que tendrían poco éxito"81.

Fabio Zambrano y Olivier Bernard son los únicos en resaltar la presencia estatal en lo que, para efectos de este trabajo, hemos llamado el norte de la provincia del Cauca y en relación con el presidio de Boquía y el camino del Quindío:

En el poblamiento de la parte sur (sur de Antioquia) tuvieron mucha influencia el llamado camino del Quindío y la colonia penal de Boquía, lugares donde hubo presencia estatal diferente de la simple titulación. El proceso migratorio a Salento fue estimulado y propiciado por el Estado, con el propósito de ampliar la frontera agrícola y de desarrollar el sistema vial. En 1843 se estableció un presidio en Boquia, para el mantenimiento del camino del Quindío. Además, se otorgaban 20 hectáreas de baldíos a quienes se instalaban en las montañas del Quindío cercanas al camino, por lo cual atrajo pobladores de diversos lugares del país ${ }^{82}$.

Para Eduardo Santa lo ocurrido, como ya se dijo, es el resultado de un "movimiento humano" de considerables propociones, que fue interpretado por los gobernantes de la mitad del siglo XIX, que le dieron respaldo legal; es decir, privilegia el carácter espontáneo y heróico de la colonización antioqueña.

Por su parte, Hermes Tovar Pinzón habla del proceso de ocupación de tierras baldías que promovía el Estado, por medio de la entrega de globos de terreno a los extranjeros, a los acreedores de bonos de deuda pública y a los empresarios interesados en la construcción de nuevos caminos:

Mientras el Estado intentaba inducir los procesos de ocupación de tierras baldías, grupos de gentes comenzaron a moverse por el territorio nacional, sobre todo después de la Independencia, para ocupar tierras baldías, en un proceso menos artificial que aquel que promovía el Estado... Así, un soterrado mundo de colonos, de trabajadores, de familias humildes, de gentes ansiosas por consolidar su seguridad familiar, recorría el país bajo el signo de su propia esperanza, mientras que otros iban andando paralelamente con los agrimensores, con los señores de las concesiones, con los proyectos de 
desarrollo y ampliación de las fronteras y con los dueños de la inmigración extranjera ${ }^{83}$.

El esfuerzo del Estado, ante el fracaso de poblamiento con extranjeros y el desbordamiento de los colonos, se debió reorientar paulatinamente. Dice Tovar Pinzón:

El interés fiscal dejaba de ser fundamental en la concesión de baldíos para dar paso a consideraciones de orden social y económico. Las nuevas disposiciones no solo buscaron beneficiar a las gentes acomodadas, o con ciertos recursos económicos, sino a cultivadores tradicionales que habían llegado antes que estos señores a las zonas de baldíos ${ }^{84}$.

El autor dice que a pesar del esfuerzo de algunos en calificar la colonización antioqueña como dirigida, la evidencia matiza esa afirmación: "los hechos parecen demostrar que durante el siglo XIX no todo fue drigido, sino que, por el contrario, casi todos estos movimientos se mostraron en un alto grado espontáneos". A renglón seguido compara dos coyunturas importantes dentro del proceso de colonización en la frontera Antioqueño-caucana. Las acciones de los habitantes de Arma y la consecuente fundación de Pácora, fueron adelantadas como parte de una estrategia de defensa de intereses jurídicos, por tanto, fueron dirigidas; mientras que el desplazamiento de colonos hacia el sur del río Chinchiná y las fundaciones de Salamina, Neira y Manizales, en contra de los esfuerzos de los concesionarios por controlar, fue espontáneo.

Con su mirada desde el sur, Alonso Valencia Llano en su obra "Empresarios y Políticos en el Estado Soberano del Cauca 1860-1895", habla de que las condiciones demográficas de esa división político administrativa, le presentaba un gran reto a las élites caucanas empeñadas en activar la economía. A finales del siglo XVIII y a lo largo del siglo XIX, los imperativos del Cauca son diferentes a los de Antioquia, donde uno de sus problemas es la explosión demográfica, la concentración de la tierra cultivable en pocas manos y una economía basada en actividades de baja absorción de mano de obra. El Cauca, por el contrario, no tenía con quien poblar.

Esto obligó a desarrollar políticas tendientes a llevar población que explotara las riquezas de las selvas, lo que se dio en dos estrategias: la primera consistía

Tovar Pinzón, Que nos tengan en cuenta, 55.

84 Tovar Pinzón, Que nos tengan en cuenta, 55. 
en poblar las zonas de frontera con delincuentes originando la colonia penal de Boquía en la municipalidad del Quindío y, la segunda, en la atracción de población de otros Estados como en el caso de los colonizadores antioqueños a quienes se les daba la ciudadanía caucana por una vecindad mayor a seis meses y la propiedad de los lotes que beneficiaran. En pocas palabras, sólo se orientaba la colonización del Quindío, una frontera interna que separaba a Antioquia y Cauca en la parte nororiental del Estado ${ }^{85}$.

De acuerdo a los planteamientos de Valencia Llano se puede decir que en la frontera norte del Cauca la colonización combinó el poblamiento espontáneo con el inducido por los gobiernos (colonización estatal):

Las primeras referencias que tenemos acerca de la colonización de los territorios que separaban al Cauca de Antioquia se remontaban al año 1840 cuando se sabía de la existencia de algunas familias antioqueñas en el sitio de Buriticá. Luego, en 1842 se encontraba en la zona la tercera sección del Presidio de Panamá arreglando el camino del Quindío ${ }^{86}$.

Esa política de poblamiento con reos se proyectó en el tiempo:

Posteriormente, en 1847, delincuentes de Cali y Palmira eran enviados a que purgaran sus penas en sitios aislados de la frontera del Quindío buscando colonizar y controlar una población negra bastante levantisca. Esta política continuó durante los años cincuenta y gracias a ella se fortaleció la colonia penal de Boquía, aunque no impidió que la criminalidad, secuela de las guerras civiles y de desórdenes sociales generados a partir de la liberación de los esclavos, campeara en el Valle ${ }^{87}$.

Mientras tanto, riadas de campesinos sin tierra buscaban en los pliegues del Quindío la fortuna, sin orden ni concierto:

Aparte de este proceso colonizador orientado por el Gobierno Nacional y los de las provincias de la antigua Gobernación de Popayán, en la zona del Quindío se presentó a partir de los años cincuenta otro proceso de

Alonso Valencia Llano, Empresarios y Políticos en el Estado Soberano del Cauca 1860-1895 (Cali: Universidad del Valle, 1996), 52.

Valencia Llano, Empresarios y Políticos, 53.

Valencia Llano, Empresarios y Políticos, 54. 
colonización, esta vez espontáneo, por colonos antioqueños que llegaban a "tumbar monte" y a construir pequeñas unidades productivas huyendo de las persecusiones de la empresa colonizadora "González, Salazar y Cía", o atraídos por leyendas de tesoros, por las minas de oro y por la supuesta existencia de grandes caucheras ${ }^{88}$.

En su obra "Caldas: una región nueva, moderna y nacional", Oscar Almario y Luís Javier Ortiz dicen que la presencia del Estado en la constitución de lo que ellos definen como el país del Quindío, se manifiesta por medio de "la distribución de tierras a las colonias y en la fundación de Salento" ${ }^{\prime \prime}$, y a renglón seguido muestran cómo dos de los ejes corresponden, justamente, a la actividad del gobierno de la Nueva Granada y del Cauca por abrir y mantener el camino del Quindío y poblar los territorios aledaños a las vías:

2. Este último (la fundación de Salento) se convirtió en eje decisivo en la construcción de la región y en la consolidación del camino del Quindío. 3. Dicho camino fue decisivo para la apertura del nuevo país y para establecer comunicación entre el Magdalena y el Cauca, Ibagué y Cartago, el centro y el occidente del país ${ }^{90}$.

Lo anterior le atribuye a la acción estatal un gran papel, al menos en lo que tiene que ver con el proceso de colonización del Quindío, que para entonces incluía toda la frontera nororiental del Cauca, entre el río que lleva ese nombre y la cordillera Central. Es decir, cuando se hablaba del Quindío a mediados del siglo XIX, se incluían los territorios que hoy ocupa el municipio de Santa Rosa de Cabal.

Con la misma intención de rastrear el manejo del concepto de colonzación estatal, encontramos entre los autores dedicados a historiar el proceso de poblamiento de la montaña del Quindío a Jaime Lopera y Olga Cadena Corrales, que resaltan el papel jugado por el Estado.

Jaime Lopera Gutiérrez, afirma que el proceso migratorio que dio como resultado la fundación de Salento y su consolidación como trampolín de la colonización hacia el resto del territorio del Quindío, fue fomentado conscientemente por las autoridades de la Nueva Granada y el Cauca, en desarrollo de su política de poblamiento de las fronteras internas, la incorporación de los baldíos a la producción nacional y la integración de las regiones por medio de caminos:

\footnotetext{
88 Valencia Llano, Empresarios y Políticos, 54.

89 Ortiz, Luis Javier y Óscar Almario García, Caldas, 27.

90 Ortiz, Luis Javier y Óscar Almario García, Caldas, 124.
} 
El proceso migratorio a Salento - una avanzada en el camino cordilleranofue estimulado y propiciado por el Estado, cuyos propósitos de ampliar la frontera agrícola y de desarrollar el sistema vial del país se aseguraba mediante el poblamiento. Criterio diferente al de otros asentamientos originados en espontáneas movilizaciones, en ondas expansivas del espíritu migratorio en el que la acción del Estado solo se cristalizaba con posterioridad al asentamiento cada vez que "sus moradores a través de la Junta Pobladora solicitaban la legalización de los baldíos o se les nombraba un alcalde o corregidor". En términos generales, el proceso de colonización también fue un movimiento poblacional: algunos contaron con el apoyo del Estado y su desplazamiento fue dirigido; en otros, las condiciones de pobreza determinaron una movilización espontánea ${ }^{91}$.

El autor identifica lo que él mismo llama "peculiaridades" en el proceso de poblamiento del Quindío, que lo introducen dentro de la categoría de colonización estatal. La reapertura del Camino, la extensión de una línea de telégrafo, el nombramiento de funcionarios para atraer familias y el establecimiento del presidio en Boquía, convertido luego en poblado y centro de impulsión de la colonización, son esas pecualiaridades ${ }^{92}$.

La obra de Olga Cadena Corrales que lleva por título "Procesos de colonización

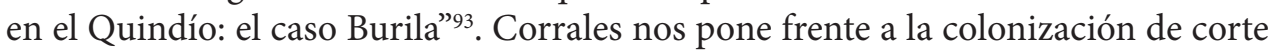
estatal. Al dar cuenta de lo que se conocía de la región hasta 1884, la autora dice:

En el norte el proceso de colonización había comenzado décadas atrás, ligado con la política oficial, tendiente a poblar los territorios adyacentes a los caminos nacionales; en este caso al camino del Quindío, que unía a la capital de la república con Popayán y el Océano Pacífico a través de Buenaventura”.

Según la tesista, fue la preocupación por la unidad nacional surgida luego de la Independencia, la que incentivó la apertura y mantenimiento de los caminos, "así como la colonización de las zonas aledañas" ${ }^{\prime 4}$.

\footnotetext{
91 Lopera Gutiérrez, La colonización del Quindío, 66.

92 Lopera Gutiérrez, La colonización del Quindío, 65.

93 Olga Cadena Corrales, «Procesos de colonización en el Quindío: El Caso Burila» (Tesis de Maestría, Universidad Nacional de Colombia, 1988). 
A renglón seguido, menciona la iniciativa del presidente de la época, General Pedro Alcántara Herrán, en el sentido de crear una colonia penal con presos de Panamá, Antioquia y Cauca, para hacer los trabajos de apertura y mantenimiento del camino del Quindío: "se construyó en un punto estratégico del camino, con el nombre de Boquía"95.

Cadena Corrales reconoce dos etapas en el desarrollo de la colonización estatal en el Quindío, que tienen que ver con la distribución de baldíos. En cuanto a la donación de tierras se refiere, la colonización estatal en el Quindío presenta dos momentos: “...

1. En un principio se ofrecían tierras, ganado y herramientas a quienes vinieran a poblar los territorios adyacentes al camino del Quindío, comprometiéndose a mantener en buen estado la vía. Para reforzar esta política el gobierno creó la colonia penal (...) 2. El segundo momento de la colonización lo constituye la creación de Nueva Salento y su posterior donación de tierras como nueva colonia. Este poblado sería cabeza de distrito durante muchos años y es el momento culminante de la colonización oficial dirigida sobre todo por el Estado del Cauca" ${ }^{\prime 96}$.

Luego de revisar y reseñar lo más importante de los abordajes de las obras incluidas en el balance historiográfico, en relación con la colonización estatal, se debe decir que aunque el papel del Estado, con sus normas y las acciones emprendidas en las fronteras internas para incorporarlas a la vida nacional son registrada por los autores y que en el caso del poblamiento de la montaña del Quindío y el nororiente de la provincia del Cauca algunos de ellos lo califican como definitiva; no se menciona

\section{El Camino del Quindío y la fundación de Santa Rosa de Cabal}

Los sucesos que sirven de estudios de caso son tratados con mayor detenimiento por los autores de trabajos relacionados con la construcción del camino del Quindío, el poblamiento de esa montaña y la fundación de Santa Rosa de Cabal.

\footnotetext{
95 Cadena Corrales, «Procesos de colonización en el Quindío», 15.

96 Cadena Corrales, «Procesos de colonización en el Quindío». 16- 17.
} 
"El Camino del Quindío en la conformación de la región”, de Jaime José Grisales Otálvaro"; el ensayo "El Camino del Quindío y la cambiante biodiversidad en la Provincia Quimbaya", de Álvaro Hernando Camargo"; la obra "Origen y desarrollo del Camino del Quindío" de Jesús Arango Cano"; el ensayo "La arquitectura del paisaje topográfico-ecológico y adaptación cultural en el Eje Cafetero", del historiador norteamericano Larry Vito Larrichio ${ }^{100}$, y el libro "El Camino del Quindío y las guerras civiles. Cartago, Boquía, Salento, Ibagué", del historiador Víctor Zuluaga Gómez ${ }^{101}$, dan a conocer diversos aspectos de lo que coinciden en calificar como un importante y -la mayoría de las veces- malogrado esfuerzo del Estado colonial y republicano por conectar los valles interandinos de los ríos Cauca y Magdalena e incorporar esos territorios a la economía.

El foco se cierra en los hechos que determinaron el poblamiento de la Montaña del Quindío o la fundación de alguno de sus asentamientos, en las obras Alfonso Valencia Zapata titulada "Quindío histórico. Monografía de Armenia"102, y de los ya mencionados Jaime Lopera Gutiérrez con "La colonización del Quindío. Apuntes para una monografía del Quindío y Calarcá," y Olga Cadena Corrales, con "Procesos de colonización en el Quindío: El Caso Burila”.

En tono de crónica la mayoría de las veces, la lupa que registra Santa Rosa de Cabal, es muy sensible al papel jugado por Fermín López, reconocido como su fundador, pero mucho más famoso por el sentido que el acervo bibliográfico le ha dado a su vida y a su decisión de asentarse finalmente en las vegas del río San Eugenio. Dan a conocer la vida y obra del colonizador y su supuesto enfrentamiento con Juan de

97 Jaime José Grisales Otálvaro, El Camino del Quindío en la conformación de la región. En: Historia de Nuestra Región. La Historia del Quindío. La Crónica. Armenia (s.f.)

98 Álvaro Hernando Camargo Bonilla. El Camino del Quindío y la cambiante biodiversidad en la provincia Quimbaya, en Ensayos de Historia Quindiana. Volumen 2. (Armenia: Centro de Publicaciones de la Universidad del Quindío, 2011) Jesús Arango Cano, Origen y desarrollo del Camino del Quindío. (Armenia: Óptima Gráfica Ltda., 2003).

100 Larry Vito Larrichio, «La arquitectura del paisaje topográfico-ecológico y adaptación cultural en el Eje Cafetero", en Policromías de una región. Procesos históricos y construcción del pasado local en el Eje Caferero, ed. Alexander Betancourt Mendieta (Pereira: Red Alma Mater y Coordinación de Ciencias Sociales y humanidades de la Universidad Autónoma de San Luís Potosí, 2008)

101 Víctor Zuluaga Gómez, El camino del Quindío y las guerras civiles. Cartago, Boquía, Salento, Ibagué. (Pereira: Gráficas Buda, 2010).

102 Alfonso Valencia Zapata, Quindío histórico. Monografía de Armenia. (Armenia: Imprenta departamental de Caldas,1963). 
Dios Aranzazu y su concesión. En esta línea se ubican José María Restrepo M. ${ }^{103}$, el presbítero Diego M. Gómez ${ }^{104}$ y Juan Bautista López $\mathrm{O}^{105}$.

Las otras dos obras sobre Santa Rosa de Cabal se edifican por la consulta de fuentes primarias y secundarias, como un esfuerzo por aportar un verdadero discurso histórico alrededor de la fundación de esa población.

"Historia de Santa Rosa de Cabal106", así se titula la obra de Luis Enrique Valencia R., que en dos volúmenes, es la primera en el ámbito santarrosano con pretensiones de texto histórico comprensivo de toda la evolución de la población. No en vano, es considerado por muchos el trabajo más serio que se ha escrito sobre la historia de Santa Rosa de Cabal.

Con un lenguaje ameno, el autor en el primer volumen de la obra denominado La Historia de la Ciudad, lleva al lector desde la época precolombina hasta la segunda mitad del siglo XIX, cuando se consolida Santa Rosa de Cabal, pasando por la saga de su fundador Fermín López y las acciones gubernamentales que determinaron el acceso de los colonos a los baldíos, después de 1844. Ese esfuerzo se lleva los seis primeros capítulos del primer volumen. Los otros están dedicados al crecimiento del caserío, cómo era la vida diaria y la visibilización de ciertos personajes.

La obra "Historia de Santa Rosa de Cabal"107 le fue encargada a Francisco Gómez Valderrama, por parte de la administración municipal, para conmemorar el Sesquicentenario de la fundación del municipio, con una publicación que tratara sobre su historia y planteara hipótesis sobre el futuro.

El texto no referencia fuentes primarias. Se sustenta en fuentes secundarias, especialmente de historiadores regionales y locales. No lista textos teóricos metodológicos. Hay que recordar que no pretende pasar por historiador. Cita

103 José M. Restrepo, «El explorador manizaleño Fermín López» en Archivo Historial. Manizales, ed. Imprenta departamental, 1923, 2a Ed. Col. Órgano del Centro de Estudios Históricos de Manizales. "Obras Históricas" № 3 (Manizales: Academia Caldense de Historia, 2006), 151-154.

104 Diego M. Gómez, Apuntes para la historia de Santa Rosa de Cabal. (Pereira: Tipografía Santander, 1926).

105 Juan Bautista López, «Biografía de Fermín López», en: Santa Rosa: Primer Centenario, ed. Rafael Lema Echeverry (1944)

106 Luis Enrique Valencia R., Historia de Santa Rosa de Cabal. Volumen I. (Manizales: Imprenta Departamental de Caldas, 1984).

107 Francisco Gómez Valderrama, Historia de Santa Rosa de Cabal. (Pereira: Editorial Papiro, 1994). 
documentos, pero no hace referencias de pie de página o de final de capítulo y no es claro al decir dónde reposan esos documentos.

Redactado de manera legible, la obra se divide en seis partes, de las cuales cinco tratan de la historia de Santa Rosa de Cabal. El primer capítulo se denomina "La Gesta de los Fundadores" y habla de Fermín López; se ocupa de la fundación de la aldea, la forma como se entregaron los baldíos y de los primeros años de la ciudad. El segundo capítulo tiene que ver con la historia de Santa Rosa de Cabal durante la segunda mitad del siglo XIX y el comienzo del siglo XX.

El tercer capítulo se refiere al acendrado catolicismo de la urbe, que la ha llevado a entregar a muchos de sus hijos como sacerdotes. El cuarto es el devenir de la población en las primeras décadas del siglo XX, mientras que el quinto son los acontecimientos del resto de la centuria.

Al rastrear la forma como los investigadores sociales y los historiadores han tratado los sucesos como la apertura del camino del Quindío, el establecimiento del presidio de Boquía y la fundación de Santa Rosa de Cabal, se concluye que los trabajos dedicados a una mirada general del fenómeno de la Colonización Antioqueña e incluso muchos de los clasificados como de historia regional, no los abordan o los referencian de manera superficial. Lo importante, es que su mención se asocia a entender que el Estado jugó un papel en el poblamiento del nororiente de la Provincia del Cauca, en desarrollo de una actividad que se insiste en llamar colonización estatal.

Del mismo modo, esa conclusión les da razón a los historiadores que detectan un mayor interés y detalle en la pesquisa de los hechos que desembocaron en la fundación de Salamina, Neira y Manizales, en medio del violento enfretamiento entre los agentes de las concesiones de origen colonial y los campesinos en busca de oportunidades. Ese mismo entusiasmo se manifiesta cuando se trata el papel de Burila en el poblamiento del Quindío en la segunda mitad del siglo XIX, por las agudas diferencias y acusaciones sobre la conducta de esos empresarios.

También puede ser la expresión de lo inadecuado que ha sido aplicar el modelo de frontera móvil traído por Parsons, al análisis del proceso de poblamiento al sur del río Chinchiná, por cuanto implica la invisibilización de elementos demográficos, políticos, económicos, sociales, culturales e institucionales, que hacen diferente de la antioqueña, la colonización del suroriente de la provincia del Cauca. 
CAPÍTULO DOS 



\section{La frontera y la colonización estatal en el poblamiento del nororiente del Cauca, entre 1840 y 1845}

Este capítulo tiene como objetivo establecer, a la luz de expertos en la materia, que clase de frontera era la que separaba el nororiente de la provincia del Cauca y el sur de la de Antioquia y que tipo de colonización se adelantó entre la rivera oriental del río Cauca y la cordillera Central, con manifestaciones como el proceso de reapertura del Camino del Quindío, el establecimiento del presidio de Boquía y la fundación de Santa Rosa de Cabal.

En procura de lo anterior, se revisan las definiciones y modelos explicativos de la frontera y la colonización estatal, con el propósito de ponerlos a hablar entre ellos, con las afirmaciones de algunas de las obras estudiadas y con la evidencia documental aportada por el rastreo de fuentes primarias.

Una de las dificultades que ofrece el hecho de tratar como conceptos equivalentes la frontera, la colonización y el poblamiento, es que esconde la historia particular de cada uno de ellos, "en su largo y tortuoso proceso de conformación"108.

108 Jaime Londoño Mota, «La frontera: un concepto en construcción» en Fronteras, Territorio y Metáforas. Comp. Clara Inés García (Medellín: Hombre Nuevo Editores, Instituto de Estudios Generales Universidad de Antioquia (s.f.)), 61. 
Ese ocultamiento -que es teórico disciplinar, pues impide ver las particularidades que cada concepto incorpora en su formación- tiene también connotaciones históricas en la medida en que una mirada reduccionista de la frontera y de la colonización -la traída por James J. Parsons-, permitió por décadas que la primera fuera el espacio vacío e inculto incorporado a la economía nacional por una colonización con "apellido" único -antioqueña- y en tono épico.

Cuando se habla de la colonización de vertiente en lo que hoy corresponde a Risaralda, Quindío y el norte del Valle del Cauca, las motivaciones del proceso poblacional vivido allí y los sucesos que conforman sus hitos, son abordados en términos generales como parte de la colonización antioqueña, sin considerar las particularidades políticas e institucionales de cada una de las etapas que conforman el fenómeno migratorio en el siglo XIX, ni las características de los actores y territorios. Todo estaba explicado con la línea móvil que separaba lo civilizado de la barbarie, la necesidad de tierras para los marginados de Antioquia y la contextura moral y cultural de los antioqueños. Sin matices sobre frontera y colonización, esta y aquella eran una sola.

Así las cosas, el Camino del Quindío, salvo algunos enfoques de historiadores regionales y locales, es tan solo un episodio anecdótico sobre las penurias de los viajeros que se atrevían a transitarlo; el establecimiento del presidio del Quindío, apenas es la antesala de Salento, y la fundación de Santa Rosa de Cabal, la consecuencia ineludible de la expedición antioqueña que lideró Fermín López.

Para superar eso, con la ayuda de Jaime Londoño Mota y Carlos Reboratti, se rastrearán la vigencia y pertinencia de definiciones y modelos explicativos sobre frontera y colonización estatal, en el decorado de los acontecimientos relacionados con el poblamiento del nororiente de la provincia del Cauca y en particular con el camino del Quindío, el presidio de Boquía y la fundación de Santa Rosa de Cabal.

Transitando por esa ruta reflexiva, se pretende determinar en qué clases de frontera se pueden clasificar la reapertura del camino del Quindío, el establecimiento del presidio de Boquía y la fundación de Santa Rosa de Cabal. 


\section{Definiciones de frontera y su presencia en el nororiente del Cauca}

Jaime Londoño Mota en el ensayo "La frontera: un concepto en construcción”; luego de hacer una revisión de lo planteado por Frederik Jackson Turner sobre la frontera, su recepción en América Latina, las críticas recibidas y las propuestas alternativas a su modelo; recomienda como conclusión, avanzar en el estudio de la concepción que llama socio cultural; que como su nombre indica, hace énfasis en los aspectos sociales y culturales. Su contraparte, la concepción espacial, es "construida desde la geografía, privilegia el espacio en calidad de factor determinante" de ese concepto ${ }^{109}$.

\subsection{Concepción espacial}

La concepción espacial mira la frontera como un espacio, con lo cual se apartan de Turner y acentúan su análisis en aspectos económicos tales como la tierra, la producción y la población. El carácter de espacio que le da a la frontera y sus variantes, bien podría servir para caracterizar el territorio objeto de la actividad colonizadora en el nororiente del Cauca, por cuanto había zonas aparentemente marginadas como la del actual asentamiento de Santa Rosa de Cabal y otras intervenidas en forma transitoria, como las aledañas al camino del Quindío ${ }^{110}$.

Esa concepción, al apuntalar su reflexión en factores económicos como la tierra, la produción y la población, establece un diálogo entre la frontera y lo que Londoño califica como conceptos similares, tales como colonización, poblamiento, territorio y tierras nuevas, para proponer así esquemas más comprensivos y explicativos de la ocupación y la integración de una frontera. De esta manera, la tarea de deslindar este último concepto queda aplazada, para dar paso a una mirada más integradora que permite superar, en el caso de Colombia, la descripción de las rutas de penetración de los colonizadores y la narración de los conflictos por la tierra, como intereses únicos de la historiografía del poblamiento.

A esta corriente pertenece a Carlos E. Reboratti, quien propone un modelo explicativo del desarrollo de la frontera compuesto por cuatro fases: a. Frontera potencial; b. Apertura de la frontera; c. Expansión de la frontera, y d. Integración de la frontera.

109 Londoño Mota, «La frontera», 75.

110 Londoño Mota, «La frontera», 76. 
Dos de las características de la frontera potencial, son el paso de frentes extractivos por la tierra libre de ocupación y la existencia de instalaciones aisladas con fines de seguridad o al servicio de la investigación científica.

En la montaña del Quindío, entre 1840 y 1845, se pueden rastrear las dos: El gobernador de la Provincia del Cauca, Jorge Juan Hoyos Cabal, habla de un frente extractivo, al remitirle desde Cartago a Mariano Ospina Rodríguez, Secretario del Interior de la República de la Nueva Granada, la solicitud de fundación de una población y la consiguiente adjudicación de baldíos, firmada por Fermín López y sus asociados el 12 de julio de 1843:

Actualmente acaba de hacer López una entrada a la alta cordillera, i ha descubierto pastales i en ellos ganado vacuno resto probablemente del que de esta especie se puso allí hace más de cincuenta años por varios particulares" ${ }^{111}$.

Igualmente, el señor Alfonso Gómez dijo en Cartago al ser citado por el Gobernador del Cauca a una diligencia el 3 de agosto de 1844 para certificar la condición de baldíos de las tierras solicitadas por Fermín López y sus asociados, que como habitante de ese cantón sabía que esos terrenos

han permanecido desconocidos hasta hace poco tiempo, que algunas personas han hecho rocerías en ellas i pedido permiso para poblar, i que antes de este tiempo solo ha habido que algunos pocos individuos han emprendido buscar minas por entre esos terrenos incultos ${ }^{112}$.

El 11 de julio del mismo año, desde Cartago, Hoyos informa sobre el valor y la forma de pago de la construcción de una casa en Boquía que sirva de albergue y almacén para los reos, en vista de la ausencia de cualquier otra instalación a lo largo del camino del Quindío. ${ }^{13}$

En su "Geografía e historia de la provincia del Quindío. Departamento del Cauca. 1892”, Heliodoro Peña Piñeiro dice:

111 Archivo General de la Nación, (1843). Bogotá, Sección República. Fondo Gobernaciones Varias. Rollo 86., f. 642 .

112 Archivo General de la Nación, (1844). Bogotá, Sección República. Fondo Gobernaciones Varias. Rollo 94., f. 46.

113 Archivo General de la Nación, (1843). Bogotá, Sección República. Fondo Gobernaciones Varias. Rollo 86., f. 629. 
En el año de 1843 se encontraba la tercera sección del presidio de Panamá ocupada en componer el camino del Quindío, la parte comprendida entre El Roble y el que ocupa hoy Pereira; y no encontrándose en el gran trayecto de Cartago a Ibagué ni una sola casa para hospedaje, para los que atravesaban tan extensas y solitarias selvas, dio orden el señor Jorge Juan Hoyos, entonces Gobernador de la Provincia, para que se construyese una casa en Boquía como lugar de depósito y escala de los viajeros ${ }^{114}$.

La combinación del recurso tierra con los excedentes demográficos y la producción, que caracterizan la seguna fase que Reboratti llama la apertura de la frontera, también se dan en la montaña del Quindío. Las familias antioqueñas que guiadas por Fermín López se asientan en inmediaciones del río San Eugenio en 1842, tal como lo afirman Juan Bautista López y Diego María Gómez en sus textos sobre Santa Rosa de Cabal y su fundador, empiezan a hacer sus primeras rocerías, mientras se preparan para abastecer el mercado de Cartago con diversos productos, gracias a la variedad de climas. Así se lo hacen saber al gobernador en una representación del 12 de julio de 1843:

Aunque nosotros no contamos con capital para emprender, nos creemos capaces de edificar nuestras casas i formar las labranzas para nuestra subsistencia i prosperidad, encontrando en la variedad de climas que hai desde el río Chinchiná hasta el Otún, un aliciente para las cementeras de trigo, papa, yuca, plátano i mais (sic), la primera de las cuales nos da frutos vendibles en la ciudad de Cartago, a donde podemos ir en dos días con carga, número que se disminuirá luego de que perfeccionemos el camino, que ahora nos sirve apenas en estado de trocha ${ }^{115}$.

Las fases de expansión y de integración de la frontera no hacen parte de esta investigación, debido a su delimitación temporal.

\subsection{Concepción socio cultural}

La concepción sociocultural se sustenta en su crítica a Turner por la trascendencia que le otorga al medio ambiente en la conformación de la "nacionalidad norteamericana" y el énfasis en los aspectos espaciales y económicos. Sus preocupaciones estriban en

114 Heliodoro Peña Piñeiro, Geografía e historia de la Provincia del Quindío (Departamento del Cauca) 1892. $2^{\text {a }}$ edición. (Pereira: Instituto de Cultura de Pereira, 2003)

115 Archivo General de la Nación, (1843). Bogotá, Sección República. Fondo Gobernaciones Varias. Rollo 86. F. 642 . 
la heterogeneidad del entorno físico de la frontera y la forma como influye en los aspectos culturales, la necesidad de estudiar las sociedades ubicadas a cada lado de la frontera y la revisión sobre el verdadero impacto del medio ambiente en los patrones culturales de los colonizadores.

Lo último está sintonizado con una observación recogida por Roberto Luis Jaramillo:

Si se miran las primeras estadísticas de Sonsón, Aguadas o Salamina, se verá una sociedad esclavista en decadencia, pero señorial en otros aspectos: los blancos de Rionegro residentes en las colonias no poseían esclavos, pero sí numerosísimos sirvientes que tenían la calidad de libertos... Patricios y plebeyos, transplantados a las nuevas tierras, lograron reproducir las condiciones de sus lugares de origen"116.

Del mismo modo, se articula a lo dicho por O. Lattimore, citado por Londoño Mota, en el sentido de que cada sociedad modela la frontera a su imagen y semejanza. Lo imaginado por la élite caucana conservadora para su frontera nororiental al promediar el siglo XIX, era una sociedad laboriosa con familias blancas y católicas; es decir, con antioqueños. Realmente el imaginario es el de los estratos altos de la sociedad central.

De lo anterior hay múltiples evidencias documentales sobre el interés del gobierno caucano por poblar con antioqueños las soledades entre los ríos La Vieja y Chinchiná y el río Cauca y la cordillera Central. Al hablar de la conveniencia de autorizar la fundación de Santa Rosa en la vega del San Eugenio, el gobernador de la provincia del Cauca Jorge Juan Hoyos Cabal, le dice al Secretario del Interior, Mariano Ospina Rodríguez en julio de 1843:

Yo juzgo importante esta población como lo he manifestado ya; la posibilidad de llevar a efecto la empresa se deduce de la experiencia, acerca del modo como se han formado otras de las poblaciones de las nuevas. El carácter laborioso i constitución robusta de los habitantes de la provincia de Antioquia (de donde son los habitantes) son una garantía adicional para el buen éxito de la población ${ }^{117}$.

Esa concepción sociocultural del tema de frontera, con sus líneas de investigación y con sus interrogantes, agenció la aparición de corrientes como la de la Nueva

116 Jaramillo, La Colonización Antioqueña, 194.

117 Archivo General de la Nación, (1843). Bogotá, Sección República. Fondo Gobernaciones Varias. Rollo 86., f. 642 . 
Historia del Oeste y la irrupción de historiadores e investigadores sociales, prestos a adelantar definiciones sobre el concepto de frontera:

- David Weber y Jane Rausch: La frontera es una zona de encuentro entre dos o más culturas.

- David Weber: "la frontera representa tanto un entorno humano como uno geográfico. Ya no se considera la frontera como una línea entre la 'civilización y la barbarie' sino como la interacción entre dos culturas diferentes. La naturaleza de estas culturas interactivas -ambas culturas la del invasor y del invadido- se combinan con el entorno físico para producir una dinámica que es única en el tiempo y en el espacio".

- José de Souza Martins: La frontera es "un lugar de alteridad y lo que caracteriza a la situación de frontera es el conflicto social donde se 'desencuentran diferentes temporalidades históricas, pues cada uno de los grupos está situado diversamente en el tiempo de la historia"118.

Las anteriores definiciones coinciden en la frontera como espacio de encuentro, interacción y conflicto. Con relación a la fundación de Santa Rosa de Cabal, la frontera como espacio de encuentro es amplia. Mientras en el territorio explorado por Fermín López no existen asentamientos humanos, Cartagoviejo, con sus labriegos de distintos orígenes, su tambo y su contadero de ganado, es el lugar en que se materializa ese cara a cara cultural y la antesala al mercado de la nueva Cartago.

Sin embargo, cuando el presidente Pedro Alcántara Herrán ordena fundar entre los ríos Otún y Chinchiná una población con el nombre de Cabal ${ }^{119}$, en respuesta a las peticiones de los antioqueños allí asentados y que habían bautizado el lugar con el nombre de Santa Rosa, se visibiliza, como se verá más adelante, un conflicto entre dos temporalidades históricas y dos imaginarios, tal como lo define José de Souza Martins. Los antioqueños y su religiosidad y los caucanos con sus aspiraciones y su adhesión a los valores de la Ilustración que encarna la memoria del prócer bugueño José María Cabal.

\section{Las tipologías de la frontera}

Jaime Londoño Mota reseña igualmente que la irrupción de las nuevas posturas frente al tema de frontera, permitió decantar las tipologías propuestas por Frederick

118 Londoño Mota, «La frontera», 80.

119 Gaceta De La Nueva Granada. No 700 del $1^{\circ}$ de septiembre de 1844. 
Turner y otros investigadores de acuerdo con la ocupación del pionero y del colonizador que se internaba hacia el oeste estadounidense más y más: frontera del minero, frontera del trampero, del ranchero, del agricultor, frontera indígena, frontera cimarrona, etc.

En la medida en que el radar percibía nuevos y complejos elementos involucrados en la conformación y establecimiento de la frontera, las tipologías se ampliaron y acogieron aspectos como:

Las relaciones sociales imperantes en su interior, por la cantidad de tierras disponibles para colonizar, por los tipos de ocupación, por la dinámica interna de la colonización y por las fuerzas o factores generadores del desplazamiento de los colonizadores hacia la zona fronteriza ${ }^{120}$.

Encontramos así las fronteras de inclusión y de exclusión, "asociadas a la asimilación de los inmigrantes y de los ocupantes de la zona incorporada o, a la selección y al rechazo de los colonizadores, sin importar si están recién llegados o son pobladores establecidos con anterioridad". En el caso del poblamiento de la frontera limitada por los ríos Cauca y la cordillera Central y entre La Vieja y Chinchiná, dentro del régimen de temporalidad de la investigación, se evidencia que estaba en marcha todo un proceso de atracción de pobladores a esas soledades y que se preferían a las familias antioqueñas, por el enfoque racialista ${ }^{121}$.

Podemos decir que la frontera nororiental del Cauca es de inclusión. La autoridad caucana promueve la creación de la población de Cabal, interesada en tener un asentamiento antioqueño para conectar a Cartago con Neira y Salamina, y sabe que esa decisión generará una corriente migratoria paisa hacia el norte de la provincia, que apoyará con su mano de obra antioqueña la apertura del camino del Quindío.

Así se lo expresa Hoyos Cabal a Mariano Ospina Rodríguez en una comunicación del 3 de abril de 1844:

Antes he manifestado a usted la conveniencia de fomentar en aquel punto una población o caserío, que sirva de apoyo para la apertura del camino que desde Cartagoviejo conduce por Neira i Salamina al centro de la provincia de Antioquia i ahora renuevo a usted mis súplicas a fin de que por su parte

120 Londoño Mota, «La frontera», 81.

121 Nancy P. Appelbaum, Dos plazas y una nación, 95. 
se empeñe en obtener del P.E. (puede ser las iniciales de Poder Ejecutivo o Presidente del Estado) la concesión de tierras valdías (sic) con tal útil objeto.La afluencia de personas acia (sic) aquel sitio, producirá entre otras ventajas, la de obtener buenos peones que trabajarán gustosos en los ulteriores trabajos necesarios para la conservación del camino del Quindío ${ }^{122}$.

Otra tipología es la de las fronteras abiertas y cerradas. Dice Londoño que se refiere esta clasificación a la disponibilidad de tierras libres para la colonización. La frontera cerrada es la compuesta por bolsones de tierras inhabitadas e incultas delimitadas en todos sus costados por los bordes habitados de antiguas poblaciones. Las abiertas, por su parte, son aquellas donde los bordes de las antiguas poblaciones solo delimitan una parte de sus costados. Londoño pone de ejemplo para esta última a la Amazonía y la Orinoquía ${ }^{123}$.

En los casos que se observan con la ayuda de los teóricos, se debe decir que la montaña del Quindío era una dilatada extensión de tierra baldía, flanqueada por las antiguas ciudades españolas de Cartago, Ibagué y Anserma, el relicto de Cartagoviejo y por las fundaciones antioqueñas de Neira y Salamina en el sur de Antioquia. (Ver mapa 2)

Por esa razón funciona muy bien el modelo de patrón de archipiélago de Richard Morse, recogido por Alistair Hennessy y que Londoño reivindica y explica:

La ocupación de estas áreas se efectuó (...) bajo el patrón de 'archipiélago': desde las antiguas fundaciones ocurridas bajo la dominación española comenzó un proceso de desplazamiento centrífugo, que posibilitó el llenado de las zonas que permanecieron 'desocupadas' entre dos núcleos urbanos ${ }^{124}$.

Esa especie de centrífuga no solo funcionó para las poblaciones hispanas. Lejos de ser el final del camino, cada población fundada durante el fenómeno colonizador, era el comienzo de otra acometida migratoria, pues los asentamientos nuevos eran como trampolines desde donde se impulsaba la ampliación de la frontera.

122 Archivo General De La Nación, (1843). Bogotá. Sección República. Fondo Gobernaciones varias. Rollo 94. F. 751 .

123 Londoño Mota, «La frontera», 82.

124 Londoño Mota, «La frontera», 74. 
El despliegue del Estado en el poblamiento de la Montaña del Quindío y la fundación de Santa Rosa de Cabal, $1840-1845$

Mapa de la frontera nororiental de la Provincia del Cauca, basado en el Mapa de 1843 de Gabriel Ambrosio De La Roche

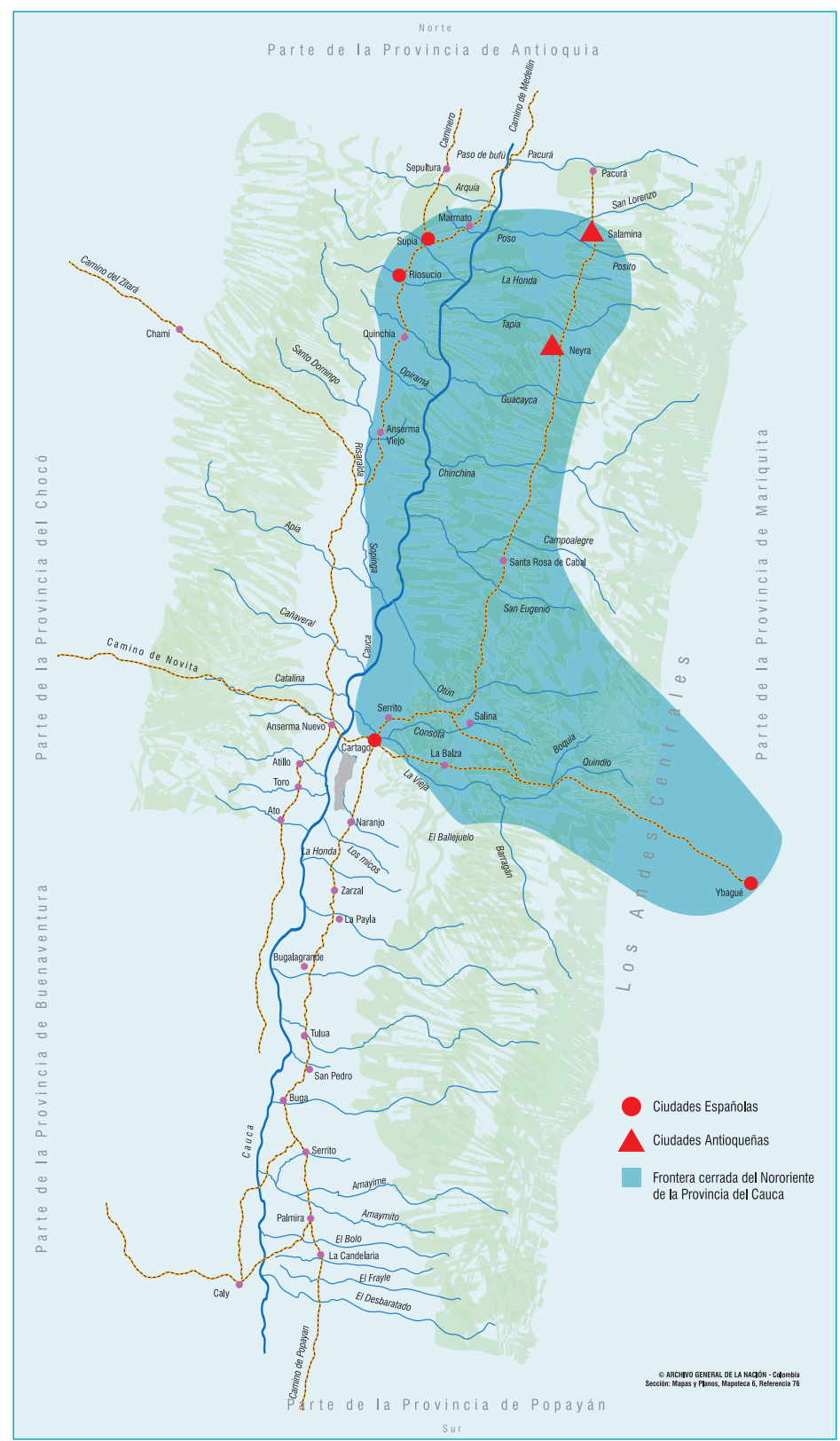

Mapa 2. Frontera cerrada 
Las características de la ocupación del territorio arrojan otra tipología: frontera vacía, frontera hueca y frontera sólida. La primera es propia de la colonización empresarial para la instalación de grandes plantaciones de productos destinados a los mercados interno y exportador, explica Londoño:

En estos casos la frontera no significa una población densa, sino una producción masiva y una alta inversión. La población ocupada reside preferentemente en centros urbanos pequeños y medianos cercanos, desde los cuales se moviliza diaria o semanalmente a la zona de producción ${ }^{125}$.

La segunda es la frontera hueca, aquella que se desplaza dejando amplias áreas degradas ambientalmente o destinadas a actividades económicas mucho menos productivas, para buscar nuevas tierras útiles para una determinada explotación agrícola. El borde de la frontera tiene más dinamismo que sus áreas interiores. Sólida se le llama a la tercera clase de frontera, según las características de ocupación de su territorio. Al respecto, dice Carlos Reboratti, citado por Londoño:

Son aquellas que basan la ocupación del espacio (colonización) en el establecimiento de altas densidades de población... La actividad económica de la frontera es llevada a cabo por pequeños y medianos productores que definen una densa red de población rural y que normalmente da lugar luego a la formación de una red urbana incipente.

La fundación de Santa Rosa de Cabal contribuye a la apertura de una frontera sólida, por el carácter de pequeños y medianos productores de sus pobladores y por el volumen de inmigrantes que llegan al lugar con Fermín López y sus pioneros, y luego del anuncio de la adjudicación de los baldíos por parte del gobierno.

En lo que tiene que ver con Santa Rosa de Cabal, la representación que encabeza con su firma Fermín López ante el gobernador del Cauca el 3 de abril de 1844, es la expresión de la voluntad de un numeroso grupo de inmigrantes:

De los que representamos, cincuenta i siete somos cavesa (sic) de familia $\mathrm{i}$ muchos más somos miembros de otras parentelas, todas estando actualmente en Santa Rosa, con el deliberado (sic) ánimo de radicarse inmediatamente que V.E. nos mande hacer la designación i amparo del terreno ${ }^{126}$.

Londoño Mota, «La frontera», 82.

A.G.N. Gobernaciones varias. Rollo 94. F. 751. 
Posteriormente, el 7 de agosto de 1844, el propio gobernador Hoyos Cabal le decía al secretario del interior, luego de una inspección personal al asentamiento antioqueño:

Esta población será el punto en que venderán los habitantes del Cauca los cerdos, mulas i ganado vacuno i cacao que consuma Antioquia, i en donde comprarán lo que el comercio de aquella región le ofrezca, circunstancia que me hace esperar que después de fundada la población crecerá rápidamente. La desconfianza de obtener el permiso legal para establecerse, ha retenido hasta ahora a muchas familias de transportarse. Ciento sesenta cabezas de familia han manifestado estar prontos a venir a establecerse en la nueva población luego de que se autorice el permiso ${ }^{127}$.

La insistencia y los planteamientos de Fermín López y sus asociados y la intermediación de Hoyos Cabal rindieron sus frutos, pues el 28 de agosto de 1844, el presidente de la Nueva Granada, Pedro Alcántara Herrán, expidió el decreto concediéndole a los solicitantes la adjudicación de 12 mil fanegadas de tierras baldías para la formación de una población llamada Cabal.

Luego, en 27 de abril de 1849, el Congreso de la Nueva Granada concede 12 mil fanegadas más, para atender las necesidades de quienes llegaban con el ánimo de establecer en Santa Rosa "casa y labranza" y no habían recibido tierra de la primera adjudicación. Aún así no se pudo satisfacer la demanda y por eso, la propia Convención de Rionegro, el 29 de abril de 1863, ordenó, según explica Albeiro Valencia Llano:

Que de las tierras baldías entre el Otún y el Chinchiná, se tomara lo suficiente para que a las familias de la Aldea de María, Santa Rosa de Cabal, San Francisco y Palestina, que aún no habían recibido tierra, se les otorgara una superficie proporcional al número de miembros de la familia, en razón de cinco hectáreas por persona; pero a los veteranos de la guerra civil, sus acreedores y sus herederos legítimos, recibirían 10 hectáreas en lugar de cinco $^{128}$.

La transición entre dos o más territorios trae a la mesa como tipología, las fronteras móviles y las fronteras fluidas. Al respecto, Jaime Londoño dice, citando a Patricia Vargas:

127 Luis Enrique Valencia R., Historia de Santa Rosa de Cabal. Volumen I. (Manizales: Imprenta Departamental de Caldas, 1984), 53. 
En el primer concepto, el carácter móvil, está dado por la imposibilidad de las diferentes avanzadas de implantar el sistema social que representan (...). En el segundo, la noción fluida, está relacionada con 'zonas de amortiguación en donde dos o más sociedades tienen referencias territoriales e históricas, siendo generalmente centros comerciales"'129

La idea imperante en la Nueva Granada y en el Cauca, cuando empieza a promediar el siglo XIX, es la colonización con presos y vagos que trabajan en la reapertura del camino entre Cartago e Ibagué y que se establecían después a su vera, y con familias antioqueñas interesadas en lo mismo o que deseaban asentarse en las soledades que separan al Otún del río Chinchiná, como ocurrió con Santa Rosa de Cabal.

Los líderes caucanos proyectaron una visión de progreso para su región impulsada por los antioqueños, hasta el punto de que la acción de los facilitadores de ese tipo de poblamiento, permitió la incorporación del norte del Cauca a "Antioquia La Grande", como dice Nancy P. Appelbaum, y a la posterior irrupción de Caldas o la región cafetera.

El volumen de la migración antioqueña y la consolidación de su cultura y sus tecnologías, dan cuenta de que las "avanzadas" paisas impusieron su sistema, con la complacencia -en el lapso objeto de la investigación- de los gobernantes caucanos. Eso ocurrió con la fundación de Santa Rosa de Cabal y su posterior consolidación.

El poblamiento de los territorios aledaños al llamado Camino del Quindío es diferente -también en la época en que se enfoca la investigación-, por el origen diverso de los reos que llegaron al presidio del Tercer Distrito para trabajar en la reapertura de la vía y de los vagos que fueron concertados con el mismo propósito. Unos presidiarios provenían de Antioquia, pero los otros eran traídos del Cauca y de Panamá.

La historiadora Olga Cadena Corrales, califica la migración impulsada en el decenio de los cuarenta del siglo XIX alrededor del camino del Quindío, como una ola colonizadora no antioqueña: "en ella participaron especialmente caucanos, tolimenses y cundiboyacenses". Y agrega: "esta particularidad del encuentro y mezcla de corrientes migratorias venidas de diversas partes del país, se mantuvo en toda la colonización del Quindío. A partir de la fundación de Finlandia en 1878, la migración paisa dominó sobre las demas"130.

129 Patricia Vargas, «Los Emberas y los Cuna». En Londoño Mota, «La frontera»,83.

130 Cadena Corrales, «Procesos de colonización en el Quindío», 17. 
Sólo hasta ese año, el sistema social antioqueño se empieza a imponer. Esta conducta diversa en una y otra latitud del nororiente del Cauca, es el factor que identifica a esa frontera, en ese momento, como móvil.

La frontera fluida está presente en la intencionalidad de consolidar poblaciones que articulen la comunicación entre las provincias del Cauca y Antioquia, que comparten un límite político y entre Cartago e Ibagué, que desde el siglo XVI habían comerciado y combatido a lo largo del Camino del Quindío. En su condición de nodo de la ruta hacia Salamina, Santa Rosa de Cabal es un centro de comercio; el camino del Quindío, en sí mismo es una "comarca caminera" como la llama Álvaro Hernando Camargo Bonilla ${ }^{131}$, y un referente histórico. Todo lo anterior hace que la frontera sea una zona de amortiguación en el choque entre dos culturas como son la caucana y la antioqueña.

Finaliza Jaime Londoño mencionando que hay investigadores que establecen una distinción entre las fronteras planificadas por empresarios o entes estatales y las fronteras espontáneas; aquellas ocupadas sin obedecer a ningún plan previo. Justamente es la colonización de la frontera, dirigida desde la órbita estatal, la que se rastrea en esta investigación.

\section{Definiciones de colonización estatal y sus manifestaciones en el nororiente del Cauca}

Con la ayuda de Carlos Reboratti, se avanza en establecer definiciones sobre colonización estatal, junto con lo dicho por los historiadores del balance historiográfico. Lo anterior se busca en las representaciones que aportan las fuentes primarias consultadas sobre la reapertura del camino del Quindío, el establecimiento del presidio de Boquía y la fundación de Santa Rosa de Cabal.

Lo primero que se debe subrayar del trabajo de Carlos E. Reboratti es que no habla de colonización estatal, porque para él lo que merece una clasificación es la forma como es planificada la frontera por parte de empresarios o de las agencias del Estado. Cuando esto es así, sin hacer ninguna distinción, utiliza el concepto de frontera planificada y la que no es producto de la planificación, frontera espontánea:

131 Álvaro Hernando Camargo Bonilla, «El camino del Quindío y la cambiante diversidad en la Provincia Quimbaya» en Ensayos de Historia Quindiana. Volumen 2 (Armenia: Centro de Publicaciones de la Universidad del Quindío, 2011), 235. 
Podríamos hacer una distinción en las fronteras de acuerdo a cuál haya sido el grado de planificación que las definió. Desde ese punto de vista, podríamos pensar en fronteras espontáneas y planificadas, más como extremos de un continuum que como tipos claramente diferenciados, y aclarando que estamos refiriéndonos a la planificación global de la ocupación, y no de la individual ${ }^{132}$.

Sin embargo, el investigador se ocupa de la colonización, pues la reconoce como parte del universo de la frontera, junto con el frente, el pionero y la tierra nueva:

Colonización es otra palabra muy unida al tema de la frontera, si bien en sus comienzos -y en alguna medida aún hoy- era una expresión que definía tanto el asentamiento en tierras nuevas de pequeños o medianos agricultores, como la ocupación de territorio por alguna potencia extranjera, con la intención de crear dominios. En realidad, la idea en el fondo es similar: transplantar, ocupar con especies nuevas; en la América Latina de hoy colonizar significa ocupar para la agricultura, dividir la tierra.

Recuerda cómo en un principio, la colonización se entendía como la inmigración de extranjeros por medio de planes de colonización, como los que tuvo la Nueva Granada una vez se independizó de España, y la mayoría de los Estados creados en Suramérica en el primer cuarto del siglo XIX. Hermes Tovar Pinzón afirma, al referirse a las políticas poblacionales adoptadas por la Nueva Granada al comienzo de la república, que:

La convicción de encontrar las rutas del progreso en la inmigración extranjera propició la entrega de 2`386.000 hectáreas de tierras a 24 empresas y empresarios, asociados en su mayor parte con colombianos que servían de intermediarios. Estos empresarios se comprometieron a 'colonizar las tierras baldías que por los mismos contratos se le cedían ${ }^{133}$.

Sin embargo, Reboratti dice que "la idea de frontera planificada suele estar ligada a la de colonización", luego de precisar que aquella es el resultado de la organización previa de la distribución y uso de la tierra.

132 Carlos E. Reboratti, «Fronteras agrarias en América Latina», Cuadernos Críticos de Geografía Humana, $n .^{\circ}$ 87 (1990). 
Después baja el foco: "La planificación de la frontera puede ser llevada a cabo indistintamente por el Estado o por entidades privadas, con algunos casos intermedios". A la que adelanta el Estado la denomina como planificación oficial e implica:

El levantamiento cartográfico de la tierra que se va a ocupar, planifica el tipo de lotes (tamaño, forma, ubicación), y por lo general también la necesaria infraestructura de transportes y centros urbanos. El Estado instala a los colonos y a partir de allí, o bien puede mantener una especie de control sobre éstos -a través por ejemplo de la promoción de algunos productos o el control del manejo de la tierra-, o bien simplemente deja a los colonos hacer su voluntad. ${ }^{134}$

Al llegar el siglo XIX a su medio camino, el Estado neogranadino ha ensayado, con diversos propósitos, poblar con europeos y luego con familias católicas de los climas templados y fríos; antioqueños en el caso de la fundación de Santa Rosa de Cabal. Del mismo modo, como se ve en la migración promovida hacia los terrenos aledaños al camino del Quindío, con presidiarios provenientes de Antioquia, Cauca y Panamá. Ha dispuesto de sus baldíos, en desarrollo de políticas con motivaciones diversas, pero que terminan desembocando en esa oleada colonizadora abigarrada y multidireccional que se precipita al final del siglo XVIII, es imparable en el XIX y se morigera en las primeras tres décadas del XX.

$\mathrm{Al}$ respecto, Catherine LeGrand en "Colonización y protesta campesina en Colombia 1850-1950", identifica dos tendencias de la política de baldíos y les ubica su origen en la época de la colonia: 1. Fomentar el crecimiento económico rural y la colonización, y 2. Manejar los baldíos como fuente de ingresos para el Estado. En el primer caso, se otorgaban baldíos a quien quisiera explotarlos y tenían el acceso a la propiedad de los mismos, y en el segundo, se entregaban a quien pudiera pagar por ellos:

Esta tendencia predominó en Colombia en los primeros decenios después de la Independencia. Desde 1820 hasta 1870, la política de baldíos de Colombia estuvo basada en una preocupación fundamental: la de financiar a un gobierno en quiebra (...). A partir de 1830, los baldíos representaron un ingrediente esencial dentro del sistema crediticio del Estado. El Congreso colombiano emitía bonos y vales territoriales redimibles por baldíos, a fin de respaldar 
la deuda nacional y pagar a los veteranos de la Independencia. Esos bonos servían también para subsidiar la construcción de carreteras y ferrocarriles. Las compañías ferroviarias, por ejemplo, recibían por lo general de a 200 o 300 hectáreas de baldíos por cada kilómetro de carrilera concluido ${ }^{135}$.

\subsection{Las normas generales de la colonización estatal}

El hecho de que los baldíos fueron usados con diferentes propósitos por parte del Estado y que lo anterior determinó la expedición de una serie de leyes y normas por parte del Congreso y del Poder Ejecutivo, es algo en lo cual coinciden los trabajos clásicos revisados para la investigación y algunos de los inscritos en el compartimento de la historia regional.

El cuerpo normativo que así se forma, es en sí mismo una política sobre tierras y poblamiento. Pago a soldados de la Independencia, venta de baldíos a particulares para pagar deudas, adjudicación a inmigrantes europeos como estategia de problamiento y desarrollo de la agricultura y entrega de globos de terrenos baldíos a los gobiernos territoriales para que se arbitren sus propios recursos y las cedan para fundación de poblaciones, son los propósitos perseguidos por la política oficial ${ }^{136}$.

La producción de normas a lo largo de tres siglos implica un acercamiento de las autoridades respectivas a las realidades constituidas por las fronteras internas existentes en el nuevo Estado: establecer la cantidad de tierra baldía con la que se contaba y determinar la forma como esta sería distribuida, de acuerdo a las necesidades de cada coyuntura y al desarrollo de un pulso que había entre el modelo de desarrollo basado en un sistemas de grandes propiedades y el otro sustentado en las parcelas familiares ${ }^{137}$.

Eduardo Santa en su obra enumera las siguientes leyes como las expedidas por el Estado colombiano para afrontar el reto que implicaba la mejor utilización de los millones de fanegadas de baldíos que constituían las fronteras internas de la Nueva Granada:

- Ley del 29 de septiembre de 1821: cumplimiento soldados, pago deudas.

- Ley del 13 de octubre de 1821: acceso a baldíos de pobres, defensa resguardos indígenas.

135 LeGrand, Colonización y protesta, 33.

136 Santa, Colonización antioqueña, 61.

137 LeGrand, Colonización y protesta, 18. 
- Ley 11 de junio de 1823: Promueve la inmigración extranjera para poblamiento.

- Ley 29 de septiembre de 1827: Se conceden gracias y privilegios para los que quieran abrir caminos o refaccionar los antiguos.

- Constitución de 1832: cierto número fanegadas baldíos para beneficio de fondos y rentas de cada provincia (art. 166).

- Ley del 6 de mayo de 1834: colonización y poblamiento, a través del fomento al establecimiento de poblaciones y promueve acceso a las tierras a la población laboriosa que no encuentra ocupación.

- Ley del 19 de mayo de 1834: ejecutivo asignará a cada provincia número de fanegadas baldías (arts 175 y 176).

- Ley 11 de abril 11 de 1839: se disponen 2 millones de fanegadas de tierras baldías al pago de los intereses vencidos y la amortización de la deuda nacional esterior (sic).

- Ley del 3 de agosto de 1848: adjudica a cada provincia entre 15 y 20 mil fanegadas de baldíos adicionales.

Entre las incorporadas en la Recopilación Granadina ${ }^{138}$, se encuentra la que allí se denomina la "lei 1 (sic) del 19 de mayo de 1834" -el primer código de régimen político y municipal de las provincias, cantones y distritos parroquiales de la Nueva Granada-, que enumera entre las rentas provinciales, las que se deriven de las tierras baldías adjudicadas a cada provincia (art. 174). De acuerdo con la norma, el Poder Ejecutivo adjudicará a cada provincia, previo trámite de los gobernadores, "el número de fanegadas baldías" comprendidas entre los límites de la respectiva entidad territorial, "que no baje de quince mil ni esceda (sic) de veinticinco mil, atendiendo a su calidad, al sitio que ocupen, y a otras circunstancias" (art. 175). Las cámaras provinciales son las encargadas de enajenar, arrendar o disponer de los baldíos con el propósito de que el producido alimente las rentas provinciales (art. 176).

También en la mencionada recopilación está la "lei 7 del 6 de mayo de 1834"139, sobre la adjudicación y repartimiento de tierras baldías para nuevas poblaciones, gracias a la cual se establece una serie de incentivos para quienes deseen conformar asentamientos en las fronteras internas de la Nueva Granada. En la norma se establece que "el Poder Ejecutivo podrá conceder hasta doce mil fanegadas de tierras baldías para cada población” (art. $1^{\circ}$ ) y de aquellas se podrá adjudicar hasta

138 Lino De Pombo, Recopilación de leyes de la Nueva Granada. (Bogotá: Imprenta Zoilo Salazar, 1845$), 41$.

139 Lino De Pombo, Recopilación, 93. 
sesenta fanegadas a cada cabeza de familia, según las necesidades; con la condición de que solo se le hará entrega de terrenos a quienes fijen su residencia en las nuevas poblaciones (art. $2^{\circ}$ ). Los artículos $4^{\circ}$ y $8^{\circ}$ exceptúan respectivamente del pago del diezmo eclesiástico a las plantaciones y sementeras y a los productos de la agricultura y la ganadería establecidas en esos terrenos baldíos, por espacio de veinte años. Por su parte, el artículo $8^{\circ}$ de la misma Ley establece que "Los individuos que fijen su residencia en las nuevas poblaciones estarán esentos (sic) del alistamiento para servir en el ejército, por el término de doce años; i no podrán ser obligados a desempeñar empleos concejiles que no sean de su distrito parroquial".

La Recopilación da cuenta de la forma como evoluciona la política de poblamiento a lo largo de la primera mitad del siglo XIX, cuando incorpora la "lei 8 de mayo 21 de $1841^{\text {"140 }}$, que concede las mismas excepciones de la norma anterior, a las poblaciones que se funden en "las tierras desiertas de propiedad de particulares", y la "lei 9 de marzo 12 de 1842, que dispone separar una porción de los terrenos adjudicados a una nueva población, para que sean vendidos y el producido sirva para financiar los gastos de agrimensura y repartimiento de los baldíos.

Con el mismo espíritu favorable al poblamiento y a la incorporación de los baldíos a la producción nacional, ya el Congreso había expedido la Ley de mayo 5 de 1834, codificada en la Recopilación Granadina como la "Ley 11", exonerando del pago de diezmo a las nuevas plantaciones de cacao, café y añil ${ }^{141}$.

La Recopilación Granadina incluye una Ley, la 11 del 11 de abril de 1839, con la cual se autoriza al Poder Ejecutivo arreglar la deuda "esterior" y se incorpora para el pago de la misma, dos millones de fanegadas de tierras baldías. Aunque la decisión corresponde a la etapa en que los baldíos eran mirados como una salida al déficit fiscal, más que una frontera interna por incorporar, el hecho de que se hable de volúmenes de terreno y se tomen decisiones sobre aquellos, implica un ejercicio de planificación y disposición de ese recurso, en los términos expuestos por Reboratti al hablar de la frontera planificada por un ente oficial. El Estado entiende las implicaciones de entregar baldíos para el pago de intereses vencidos o la amortización de la deuda externa, pues en la ley citada regula la forma como se enajenarán los terrenos e introduce restricciones sobre las cantidades que se deban ceder en cada provincia y en zonas aledañas a costas, ríos navegables y caminos

140 Lino De Pombo, Recopilación, 93.

141 Lino De Pombo, Recopilación, 93. 
públicos; así como la relación de los pobladores con el Estado, en caso de que los baldíos sean colonizados ${ }^{142}$.

Las anteriores son las decisiones tomadas por el Estado cuando se ha impuesto la tarea de impulsar y planear el poblamiento de sus fronteras internas, tal como lo dice Reboratti. Lo importante; desde la concepción espacial de la frontera que enarbola Reboratti, donde la tierra, junto con la producción y la población, es uno de los factores económicos sobre los que se sustenta, es que la responsabilidad en la adjudicación de los baldíos es del Estado, tal como lo señala LeGrand. El Estado tiene la titularidad de esas inmensas extensiones de terrenos incultos, que en la época colonial eran calificados como realengos, por considerarlos propiedad del Rey.

El papel que juega el Estado como titular de los baldíos e impulsor de las políticas de poblamiento, a través de la expedición de las normas mencionadas anteriormente, llevan a concluir que, en los términos planteados por Reboratti, hubo una colonización estatal, más allá del origen de los flujos migratorios.

\subsection{Normas para la Montaña del Quindío y Santa Rosa de Cabal}

A esa misma conclusión se llega cuando se revisa la actividad normativa de la República de la Nueva Granada y de la provincia del Cauca, en el período temporal de la investigación. Si en alguna región se puede hablar de colonización estatal, es en la Montaña del Quindío y en Santa Rosa.

\subsubsection{En Santa Rosa de Cabal.}

Lo anterior se confirma al comparar lo ocurrido en Santa Rosa de Cabal, con lo sucedido en el suroriente de Antioquia cuando se fundaron las poblaciones de Salamina, Neira y Manizales. En el último caso, jurídicamente es claro que la entrega de la mayoría de las tierras destinadas a la apertura de fincas y al establecimiento de poblaciones, corrió por cuenta de los dueños de las conceciones Villegas y Aranzazu, otorgadas a particulares por las autoridades virreinales. Los conflictos registrados por la historiografía de la colonización antioqueña entre los concesionarios y los colonos, se debieron a que los globos de terreno adjudicados coincidían con lo que la ciudad de Arma consideraba como suyo; al no cumplimiento de las obligaciones inherentes a la adjudicación, por parte de los concesionarios; al despojo que los agentes de aquellos quisieron hacer con las mejoras de los colonos, y a las pérfidas 
movidas legales y políticas para correr linderos y apropiarse de predios ya mejorados por el trabajo de las familias campesinas asentadas.

Mientras que lo ocurrido en Santa Rosa de Cabal fue la consecuencia de una coyuntura en la que confluyen los excedentes demográficos antioqueños presionando la frontera sur de Antioquia, la disponibilidad de baldíos en el nor oriente de la provincia del Cauca, la existencia de una legislación expedida para estimular el poblamiento -Ley del 6 de mayo de 1834- y la voluntad política de los gobiernos neogranadino y caucano para que eso sucediera. En este caso, es el gobierno de la Nueva Granada quien determina la entrega de los baldíos a los colonos antioqueños y las autoridades del Cauca se encargan de su reglamentación y ejecución, pues la adjudicación es la expresión de la voluntad de sus gobernantes, de poblar ese territorio con paisas.

Investigadores como Hermes Tovar Pinzón ${ }^{143}$, y Jacques April, asi lo manifiestan:

En muchos pueblos nuevos la fundación se legaliza cuando el Estado la oficializa, obsequiando los terrenos al nuevo municipio por medio de un decreto. En Aranzazu, Salamina, Filadelfia, Neira y Manizales aquellos que escrituran las tierras son los pretendidos propietarios de la Compañía Salazar-González ${ }^{144}$.

\subsubsection{En el camino del Quindío.}

Al revisar lo acontecido en el camino del Quindío entre 1840 y 1845 , encontramos algo similar pero asociado a una necesidad estratégica de la República de la Nueva Granada: la apertura y mantenimiento de un camino.

Para eso, el Estado tiene varias herramientas: extensos territorios baldíos y la capacidad de poblar con reos y vagos o de estimular asentamientos de familias campesinas, por medio de una legislación que fomenta el poblamiento.

Con base en los cálculos aportados por Ricardo de los Ríos Tobón al proyectar el Gran Caldas más allá de los límites políticos-administrativos, podemos decir que la provincia del Cauca de la mitad del siglo XIX - la creada después de la promulgación de la Constitución Política de 1843- tenía unos cuatro mil kilómetros cuadrados de

143 Tovar Pinzón, Que nos tengan en cuenta, 14.

144 April, La ciudad colombiana, 120. 
tierras baldías en su zona nororiental, limitadas por el río Cauca al occidente, la cordillera Central al oriente, el río La Vieja al sur y el río Chinchiná al norte ${ }^{145}$.

Como se ha visto en el balance bibliográfico, los autores de muchas de las obras referenciadas dan cuenta de los esfuerzos de los gobiernos coloniales y republicanos por mantener abierto el camino del Quindío, y la forma en que muchas de esas decisiones asociaron la funcionalidad de la obra con un poblamiento útil para el mantenimiento de la vía y la atención de los viajeros.

Una de esas decisiones fue la que aparece como "lei 3" (sic) de la Recopilación Granadina, que corresponde a la expedida en mayo 27 de $1842^{146}$, sobrela composición y mejora del camino del Quindío, con gran énfasis en el poblamiento de las zonas aledañas a la vía de comunicación. Fuera de establecer que para la construcción del "camino de herradura, desde Ibagué a Cartago, por la montaña del Quindío", el Poder Ejecutivo aplicará hasta la tercera parte del producido total del derecho nacional de caminos, determina el establecimiento de tambos o posadas para el servicio de los transeúntes, por cuenta de la empresa del camino. Los encargados del mantenimiento de los tambos gozarán de una asignación anual fijada por el Poder Ejecutivo proveniente de peajes y serán beneficiados con la adjudicación de doce fanegadas de tierras baldías a cada uno y a la entrega, por primera vez, de herramientas y semillas necesarias para la explotación de los terrenos.

En el mismo artículo $2^{\circ}$ se estipula también que "si el individuo fuere casado, se le adjudicarán seis fanegadas más de tierras baldías por cada hijo que tuviere o que le nazca, con tal de que resida en el lugar en que se le hace la asignación". Adicionalmente, en el artículo $4^{\circ}$ de la misma norma, se pretende estimular el poblamiento del Quindío cuando se establece que: "A cada uno de los demás individuos que quieran establecerse en la montaña del Quindío, podrá el Poder Ejecutivo conceder veinte fanegadas de tierras baldías, con la precisa condición de establecer en ellas casa i labranza". A estos adjudicatarios la mencionada ley los relevaba del servicio militar por doce años y determinaba que el ejercicio de empleos concejiles, solo sería prestado en los distritos parroquiales que se establezcan en la misma montaña. Del mismo modo, los productos de la agricultura y la ganadería desarrollada en los terrenos baldíos estaban exentos del pago del diezmo eclesiástico hasta el año 1854.

De los Ríos Tobón, Orígenes, 140. 
En dicha norma aparecen como herramientas que el Poder Ejecutivo de la Nueva Granada aplicará para la construcción del "camino de herradura", "el presidio o los presidios que estime convenientes" 147 .

Al respecto dice Jaime Lopera Gutiérrez:

Al determinar el gobierno la creación de tres presidios (uno en Mariquita, el segundo en Cartagena y el último en el Cauca) la administración del presidente Herrán (1842) ordenó que los presos de Antioquia, Cauca y Panamá que hubieran cumplido la mitad de su tiempo de condena, fueran destinados a trabajar en el mejoramiento y conservación del Camino del Quindío ofreciéndoles como estímulo la rebaja de sus penas ${ }^{148}$.

Lo anterior lo avala Albeiro Valencia Llano cuando dice que:

Se estableció la colonia penal de Boquía con el fin de ampliar y mejorar el camino y la penitenciaría fue rodeada poco a poco por viviendas de colonos transformados rapidamente en agricultores; el gobierno otorgó herramientas y ganado además de terrenos baldíos para ser repartidos entre los colonos que iban llegando ${ }^{149}$.

También los denominados vagos tuvieron su papel en la apertura del Caminio del Quindío cuando, acordes con la clasificación de la vagancia como un problema de la policía, el gobierno del presidentre Herrán expidió el decreto del 31 de marzo de 1843, que dispone que el concierto de los vagos debía tener como destino el trabajo en el camino del Quindío ${ }^{150}$.

\subsubsection{La llave maestra.}

La norma más importante que expidió el gobierno del presidente Herrán con relación al camino del Quindío, fue el decreto del Poder Ejecutivo de julio 15 de $1842^{151}$, sobre la composición y mejora del camino del Quindío. Su importancia radica en que desencadena procesos posteriores relacionados con el poblamiento del

147 Lino De Pombo, Recopilación, 92.

148 Lopera Gutiérrez, La colonización del Quindío, 68.A

149 Valencia Llano, Colonización, 179.

150 Natalia Botero Jaramillo, «El problema de los excluidos. Las leyes contra la vagancia en Colombia durante las décadas de 1820 a 1840», Anuario Colombiano de Historia Social y de la Cultura 39, $n .^{\circ} 2$ (2012): 41-68 
nororiente del Cauca; demanda de las autoridades de esa provincia su permanente presencia en Cartago y determina quiénes y cómo ejecutarán los trabajos en cada uno de los tramos que la misma reglamentación determina.

Su contenido se ocupa de lo siguiente:

A. Divide el camino entre Ibagué y Cartago en dos partes, con el punto medio que representa la cumbre de la cordillera Central o "por el punto de camino en que se separan las aguas que se dirigen al Cauca, de las que corren al Magdalena...." El gobernador de Mariquita será el responsable de la obra entre Ibagué a la cumbre de la Cordillera y el del Cauca, desde la cumbre hasta Cartago. Está en el artículo $1^{\circ}$.

B. "Cada una de las porciones se dividirá en dos partes aproximadamente iguales, atendiendo para esto no tanto a la longitud, cuanto al tiempo que se gaste en recorrerlas por razón de la forma y naturaleza del terreno. Artículo $2^{\circ}$.

C. A cada uno de esos tramos les asigna el decreto, responsables de la ejecución de los trabajos de reapertura del camino, así: La que va de Ibagué hasta el punto medio, será construida y mejorada con el servicio personal subsidiario de los habitantes del cantón de Ibagué; la que va del punto medio hasta la cumbre de la cordillera -oriente-occidente- lo será con el trabajo del presidio del ler distrito; el tramo que baja de la cumbre hasta el punto intermedio con Cartago, será atendido por los reos del presidio del 3er distrito, y del punto intermedio hasta Cartago, por el servicio personal subsidiario de los habitantes de la mencionada población. Artículo $3^{\circ}$.

D. Ordena tres tambos o posadas en cada uno de los dos segmentos del camino, separados uno del otro por una distancia de tres leguas. Cada lugar debe ser salubre, con espacio para cultivar comida y tener dehesas para el ganado, que podrá ser comercializado, con agua y material para construir casas. Cada tambo está a cargo de un posadero, con obligaciones asignadas por el propio decreto. Artículos del $4^{\circ}$ al 16.

Merecen por su impacto, especial mención los siguientes aspectos del decreto de julio 15 de 1842: 


\section{a. Presencia permanente de los gobernadores:}

El primero se refiere a que los gobernadores de las provincias del Cauca y Mariquita debían trasladarse permanentemente a Cartago e Ibagué respectivamente, para atender personalmente la realización de los trabajos de apertura del camino, "sin desatender los demás negocios de la Gobernación, despacharán como en los casos de visita".

Hasta ese momento, la Ley 1 de mayo 19 de 1834 sobre régimen político y municipal de las provincias, cantones y distritos parroquiales, determinaba en sus artículos 32,33 y $34,{ }^{152}$ las circunstancias en que los gobernadores de las provincias de la Nueva Granada debían dejar temporalmente la capital provincial, como parte de sus funciones:

Art. 32. Visita a la provincia a lo menos en el primer año de su gobierno para informarse por sí mismo del cumplimiento que se le dé a las leyes i (sic) ordenanzas, i (sic) a las providencias dictadas en su ejecución; del desempeño i (sic) conducta de los funcionarios, oyendo las quejas que se le dirijan contra estos; del estado de la policía en sus diversos ramos, i (sic) el de las obras i (sic) establecimientos públicos particularmente de los de instrucción, beneficencia i (sic) comunicaciones; i (sic) por último de la marcha de todas las partes de la administración pública ${ }^{153}$.

Gracias al decreto de Herrán, la circulación de los gobernadores del Cauca y Mariquita por sus territorios no se reducía a la visita dispuesta por la ley en el primer año del mandato. Por el contrario, se garantizaba la presencia de los mandatarios de las dos provincias en los centros logísticos de la obra del camino del Quindío y un permanente desplazamiento, en el caso del Cauca, entre Cartago y Buga, la capital, y otros cantones más al sur como el de Palmira. Así lo evidencian los documentos encontrados en los archivos históricos, referentes al período presidencial de Herrán. La correspondencia entre el gobernador del Cauca, Jorge Juan Hoyos Cabal y el Secretario de Estado en el despacho del Interior y Relaciones Exteriores, Mariano Ospina Rodríguez, circulaba en su mayoría entre Cartago y Bogotá.

La exigencia de permanecer en Cartago permitió que el gobernador Hoyos conociera de primera mano los avances de la obra de apertura del camino del Quindío, que

152 Lino De Pombo, Recopilación, 92.

153 Lino De Pombo, Recopilación, 93. 
él mismo entregó al promediar 1845, como se verá más adelante. También facilitó que el mandatario provincial se enterara de la situación de las familias antioqueñas establecidas a orillas del río San Eugenio, que solicitaban la fundación oficial de una población. Personalmente, Hoyos Cabal inspeccionó el terreno, conoció los aspectos favorables de la fundación de un pueblo y, por tanto, impulsó la creación del poblado como parte de la estrategia para atraer mano de obra que sirviera al mantenimiento del camino del Quindío.

\section{b. La decisión de establecer poblados para fortalecer el camino del Quindío:}

Entre el artículo $17^{\circ}$ y $25^{\circ}$ del decreto de julio 15 de 1842 , el gobierno dispone lo pertinente para la fundación de poblaciones en lugares estratégicos de los dos grandes tramos en que la misma norma dividió el camino del Quindío.

Así dice el artículo $17^{\circ}$ :

Los Gobernadores de Mariquita y del Cauca, oído el informe del director del camino y después de haber hecho ejecutar los reconocimientos y observaciones que se crean convenientes, designarán cada uno en la parte del camino que le corresponda, el sitio en el que debe erigirse una nueva población, la que ha de levantarse a este lado de la montaña está a una distancia de seis a ocho leguas de Ibagué e igual distancia de Cartago la que debe crearse en el lado opuesto $^{154}$.

Lo importante es que, vía el decreto citado, los gobernadores respectivos promocionarán las nuevas poblaciones, anunciando que cada individuo recibirá 20 fanegadas de tierras baldías, gozará de exenciones en relación de pago de diezmos, servicio militar y ejercicio de funciones de empleos concejiles fuera de la población, y que recibirá herramientas e insumos para que pueda explotar los terrenos que le han sido adjudicados.

\section{c. Reúne en un solo articulado las herramientas jurídicas para ejecutar la obra:}

Si la Ley de mayo 27 de 1842, la llamada lei 3 (sic) de la Recopilación Granadina, señala qué va aplicar para la construcción del camino del Quindío; el decreto de julio 15 de 1842 desarrolla la forma como se deben utilizar esas herramientas, que ya existen en el ordenamiento jurídico neogranadino. Precisa cómo debe ser

Gaceta De La Nueva Granada, 567. 
aprovechada la composición de los vagos, la contribución del servicio personal y la mano de obra de los reos de los presidios $1^{\circ}$ y $3^{\circ}$, para los propósitos de la obra.

De esa forma, el mencionado decreto se constituye en una herramienta muy importante para los gobernadores de Mariquita y Cauca, responsables de la ejecución de los trabajos.

Estos funcionarios, como veremos en el caso del Cauca, expidieron en su órbita regulaciones para mejorar las condiciones de ejecución de la obra de apertura del Camino del Quindío, que imponía enormes retos y entrañaba grandes obstáculos. Decretos y resoluciones, redactadas e implementadas por el gobernador Jorge Juan Hoyos Cabal, con el visto bueno del Secretario de Estado del Interior y de Relaciones exteriores, completaron un corpus normativo propio de un proceso de colonización estatal. La República continuó expidiendo normas que permitieran el cumplimiento de los propósitos fijados en el decreto del 15 de julio de 1842. Una de ellas, también recogida en la Recopilación Granadina, es la lei (sic) 5 de junio 18 de 1844, que apropia fondos para la iglesia, el párroco y el culto de una nueva parroquia en la montaña del Quindío.

Aún con las precariedades que desde la actualidad se pueden advertir en el ejercicio normativo de las ramas ejecutiva y legislativa de la Nueva Granada en la mitad del siglo XIX, las leyes y decretos expedidos eran actos administrativos complejos, que exigían conocimiento de los territorios y la voluntad de planificar la forma de utilizar importantes recursos, como lo eran en su momento los baldíos; tal como lo demanda, al decir de Carlos Reboratti, la constitución de una frontera planificada desde el Estado y una colonización estatal. 

CAPÍTULO TRES 



\section{La provincia del Cauca y su frontera Nororiental, como escenarios para la constitución del Estado, entre 1840 y 1845}

La expedición de leyes, decretos ejecutivos y resoluciones, no solamente son las manifestaciones de un Estado planificando la colonización de una frontera. Estas normas y las operaciones de sus funcionarios en cuanto a la problemática del poblamiento y al resto de temas de la agenda estatal de entonces, son también la expresión de un Estado nuevo que busca consolidarse por medio de la integración de los fragmentos del viejo orden colonial español y de las entidades regionales y locales, visibilizadas o constituídas durante la guerra de independencia y los primeros años de vida republicana.

Justamente, el objetivo de éste capítulo es mostrar que la provincia del Cauca y en especial su frontera nororiental, fue un ámbito territorial y social en que el Estado Republicano central intervino para consolidarse, con el liderazgo de dirigentes "aristocráticos".

Para entender lo anterior, se busca el apoyo del historiador Juan Maiguashca, quien propone la región andina como una unidad de análisis para conocer el papel de los políticos y burócratas en la formación y desarrollo del Estado como institución republicana, y de paso identifica sus objetivos, las herramientas usadas para alcanzarlos y los ámbitos de intervención del mismo, con miras al alcance de esos propósitos ${ }^{155}$.

155 Juan Maiguashca, «Dirigentes políticos y burócratas: el Estado como institución en los países andinos, entre 1830 y 1890» en: Historia de América Andina. Creación de las repúblicas y formación de la nación. (Quito: Universidad Andina Simón Bolívar, 2003). 
Para empezar, ofrece una tipología tendiente a caracterizar el "modus operandi" de los dirigentes políticos y los burócratas. Los primeros como formuladores de políticas y los segundos como sus ejecutores y determinadores del éxito o el fracaso de los nacientes Estados andinos: "Las características básicas de esta tipología son las siguientes: "dirigentes políticos", "burócratas" y sus respectivas variantes"156.

Las variantes para el dirigente político son: los "aristocráticos", que van desde 1830 hasta 1850; los "palaciegos", entre 1850 y 1870, y los "pluto-democráticos", de 1870 a 1890. Los burócratas tuvieron dos tipos: los "neo-patrimoniales" y los "protomodernos"157. Los primeros, los neo patrimoniales, fueron el tipo de funcionarios de las tres etapas mencionadas. En este capítulo nos concentraremos en los políticos "aristocráticos".

Del mismo modo, tomando de La Palombara ${ }^{158}$ el concepto de penetración, el autor dice que el Estado andino se propuso desde el principio penetrar su entorno territorial y social, para asegurar por parte de toda la sociedad la aceptación de sus dictámenes y políticas. Hay cuatro tipos de penetración: la política-burocrática, la represiva, la normativa-ideológica y lo material.

Completa el planteamiento precisando que el contexto de poder dentro del cual funcionó el Estado andino solo podrá ser entendido si incorporan al análisis dos conceptos adicionales, como son la periferia territorial y la periferia social: "El municipio provincial y los territorios fronterizos representan un ejemplo del primero. Mientras tanto, las dimensiones de género y etnicidad ilustran el segundo de los conceptos", precisa el ecuatoriano ${ }^{159}$, para contribuir a articular su modelo interpretativo con el poblamiento de la frontera nor oriental de la provincia del Cauca.

156 Juan Maiguashca, «Dirigentes políticos», 214.

157 Maiguashca, «Dirigentes políticos», 217.

158 Joseph La Palombara es un profesor emérito de la Universidad de Yale en Ciencias políticas y gestión, citado por Oscar Oszlak en su obra La formación del Estado argentino, de acuerdo con la referencia aportada por Maiguashca. 


\section{Los políticos aristocráticos}

Entre 1840 y 1845, los dirigentes políticos neogranadinos y caucanos que impulsaron la reapertura del Camino del Quindío, el asentamiento del presidio de Boquía y la fundación de Santa Rosa de Cabal, pertenecían a la variante de aristocráticos propuesta por Maiguashca.

Estaba compuesta por parte de las élites sociales y económicas tradicionales de las poblaciones de provincia, por los líderes militares que apuntalaron su supremacía gracias al prestigio guerrero y a su capacidad de garantizar el orden, y los letrados y profesionales en ascenso gracias a los servicios prestados a estos últimos en la conducción del gobierno y en la politica. Aunque no compartían el mismo origen con las fracciones del grupo dominante con que se aliaron, los militares y letrados buscan a través de ese lazo, alcanzar la legitimidad como paradigma de una visión del mundo y un estilo aristocratizante que admiraban y deseaban adoptar ${ }^{160}$.

Coincide con esa clasificación el historiador Víctor M. Uribe-Urán, quien habla de las categorías de "aristócrata" y "provinciano", para identificar a los sectores sociales enfrentados por la supremacía en las primeras décadas de la república:

Por aristócrata me refiero al individuo cuyo estatus social y honor se debían al hecho de que su familia estaba vinculada a la alta burocracia del estado colonial o a las jerarquías eclesiásticas, o que poseía un título nobiliario o, en menor medida, habían recibido tierras reales o concesiones de trabajo tales como las encomiendas. Por lo general, esas familias eran oriundas de Cartagena, Bogotá, Tunja y Popayán, ciudades y regiones con una alta concentración de clero, burocracia estatal, nobles y encomiendas. No era exclusivamente una aristocracia de gentiles o nobles titulados en el sentido europeo, sino ante todo de individuos y familias (a veces modestamente ricas) en los altos círculos de la burocracia ${ }^{161}$.

Los provincianos tenían poder económico, pero ninguna relación con las tradicionales familias que constituían la cúpula de la sociedad colonial y que después de la Independencia lucharían por seguir en la cima. Sus fortunas se acumularon gracias al comercio, la minería y la explotación agropecuaria, en regiones como Antioquia, Huila, la costa Atlántica y lo que hoy conocemos como los "Santanderes".

160 Juan Maiguashca, «Dirigentes políticos», 219

161 Víctor M. Uribe-Urán, 28. 
Eran ricos deseosos de acceder al poder político y escalar la pirámide social, y la Independencia fue la mejor oportunidad para hacerlo.

\subsection{Los políticos aristocráticos caucanos}

Los Cabal de Buga, -por la época investigada, capital del Cauca- con el gobernador Jorge Juan Hoyos Cabal y el presidente de la Cámara Provincial del Cauca, Miguel Cabal, primos dobles; son los exponentes de esos políticos aristocráticos.

El jurista e historiador Tulio Enrique Tascón da cuenta de los vínculos de la familia Cabal con hechos de la historia de Buga a lo largo del siglo XVIII y comienzos del XIX. Al promediar esa misma centuria serán estos dos vástagos de esa misma estirpe, los que impulsen desde el Cauca la reapertura del camino del Quindío y la fundación oficial de Santa Rosa de Cabal, en memoria de su antepasado, general José María Cabal. La madre del gobernador Jorge Juan Hoyos Cabal, doña Asunción Cabal Aedo, era prima hermana del prócer mencionado ${ }^{162}$. Reporta Tascón, al dar cuenta de las actividades del cabildo de Guadalajara de Nuestra Señora de la Victoria de Buga en 1761:

Los hermanos Manuel Antonio y Cayetano Cabal otorgaron cartas dotales a favor de sus esposas, doña Margarita y doña María Teresa Barona, cada una por dos mil quinientos sesenta y tres patacones recibidos de sus suegros don Juan Barona Fernández, ya difunto, y doña Josefa Ruiz Calzado, y se hicieron cargo del censo que gravaba el fundo de El Alisal"163.

Dos hermanos se habían casado con dos hermanas, para iniciar una larga tradición endogámica: "El 25 de mayo (1768) nació el prócer de la Independencia general José María Cabal, y fue bautizado en la capilla de El Alisal ${ }^{164}$, por su tío el presbítero Juan de Barona"165. En 1770 fallece el fundador de la familia Cabal en el Cauca:

162 Enrique Valencia Ramírez, Santa Rosa de Cabal y sus fundadores. (Santa Rosa de Cabal, Alcaldía Municipal de Santa Rosa de Cabal, 1980).

163 Tulio Enrique Tascón, Historia de Buga en la Colonia. (Buga: Alcaldía de Buga, 1990), 170.

164 El Alisal, que data de 1563, es la hacienda más antigua del Valle del Cauca y desde allí se empezó a producir caña de azúcar para exportar a Panamá, cuando su tamaño sobrepasaba las tres mil hectáreas e incluía también a las haciendas de Piedechinche y El Paraiso. 
El 2 de febrero murió don José Cabal, natural de Oviedo, en Asturias... y el 18 de julio, su mujer, doña María Josefa Escobar de Santa Cruz, padres del presbítero Ignacio Cabal, de Luis (casado con María Ángela Molina), Manuel Antonio (con Margarita Barona), Cayetano (con Teresa Barona), Margarita (con Manuel Vicente Martínez), Pedro Pablo (con María Ignacia González de Aedo), María Rosalía y María Luisa Cabal, célibes ${ }^{166}$.

En la obra de Tascón, los Cabal son responsables de asuntos públicos y gestores de obras para el beneficio de la ciudad de Buga, hasta llegar al final del gobierno colonial en el Cauca con la instalación en Popayán el 26 de julio de 1811, de la Junta Superior de Gobierno de la Provincia, que preside Joaquín Caicedo y Cuero, con la vicepresidencia de José María Cabal, quien debe asumir el mando cuando el titular parte a la campaña militar contra Pasto ${ }^{167}$.

En los archivos sobre el Cauca de la época investigada, se evidencia un gran protagonismo de su gobernador, Jorge Juan Hoyos Cabal, perteneciente a la aristocracia caucana colonial; abogado integrante de una poderosa red burocráticofamiliar y representante de quienes en la provincia asumieron el mando desde el final de los treinta y la mitad de los cuarenta, en nombre de los aristócratas -en la época del presidente Márquez se denominaron ministeriales- y en detrimento de los provincianos. Al respecto, Uribe-Uran dice lo siguiente:

Entre los abogados ministeriales de la región del Cauca vale la pena destacar a los hermanos Sanclemente Domínguez (Ramón y Manuel A.), a Jorge Juan Hoyos Cabal, y a los hermanos Martínez Escobar (Francisco, Carlos, Rafael y José Vicente), todos los cuales pertenecían a las clases dominantes de Buga... Todos los abogados de Buga y Girón arriba mencionados fueron distinguidos burócratas ministeriales durante los años cuarenta y después, llegando a cargos como ministros de economía, magistrados en los tribunales de apelaciones regionales, e incluso, en el caso de Mallarino y Manuel Sanclemente, vicepresidente y presidente de Colombia respectivamente ${ }^{168}$.

Todos tenían estrechos lazos familiares y políticos en sus regiones y desde ellas apoyaron el proyecto aristocrático que se enseñoreó de la Nueva Granada y sus provincias, incluyendo la del Cauca.

\begin{tabular}{ll}
\hline 166 & Tascón, Historia de Buga, 190. \\
167 & Tascón, Historia de Buga, 354. \\
168 & Tascón, Historia de Buga, 287.
\end{tabular} 
En un cuadro sinóptico de los abogados de la Nueva Granada, fechado en Bogotá el 25 de febrero de 1843, Jorge Juan Hoyos Cabal aparece entre los profesionales del derecho del Cauca, graduado en 1835, con treinta y tres años de edad, ocupando el cargo de Gobernador y habilitado para actuar ante los tribunales del distrito judicial respectivo. Junto a él se destacan los nombres de otros jurisconsultos bugueños y cartagüeños, que se constituyeron en el soporte del régimen aristocrático y que tenían estrechos lazos familiares y económicos entre sí:

\begin{tabular}{|c|c|c|c|}
\hline NOMBRES & RECEPCIÓN & OCUPACIÓN & RESIDENCIA \\
\hline Francisco de J. Martínez & 1834 & Ejerce profesión & Buga \\
\hline Carlos Martínez & 1837 & Ejercer profesión & Buga \\
\hline Manuel A. Sanclemente & 1837 & Ejercer profesión & Buga \\
\hline Pedro V. Martínez & 1788 & Ejercer profesión & Buga \\
\hline José I. Valenzuela & 1804 & Ejercer profesión & Buga \\
\hline Jorge Juan Hoyos Cabal & 1835 & Gobernador & Buga \\
\hline Miguel Cabal & 1836 & Estudio cerrado & Buga \\
\hline Cayetano Delgado & & Estudio cerrado & Cartago \\
\hline
\end{tabular}

Cuadro 1. Caucanos aristócratas en cuadro sinóptico de abogados de la Nueva Granada. Febrero 25 de $1843^{169}$

De los mencionados en el cuadro sinóptico citado, aparecen dos abogados que ocuparon en esa época la jefatura política del cantón de Buga. Se trata de José Ignacio Valenzuela, que con 68 años ejercía su profesión para el 25 de febrero de 1843, tras haber ocupado la mencionada responsabilidad burocrática hasta el 17 de enero anterior. Lo reemplazó el jurisconsulto Ramón Sanclemente, que para la fecha de expedición del listado de abogados tenía 30 años de edad. ${ }^{170}$ Este último aparece entre los profesionales que Uribe-Urán lista del lado de los defensores del gobierno en 1840, plena guerra de los Supremos, y con investidura de congresista ${ }^{171}$.

Todos ellos colaboraron en la administración del gobernador Hoyos Cabal, que era abogado como ellos y como él, todos eran de la facción calificada como aristocrática que accedió al poder como consecuencia de los sucesos y resultados de la Guerra

\footnotetext{
169 A.G.N. Sección Colecciones. Fondo: Enrique Ortega Ricaute. Caja 1. Carpeta 2. URIBE-URÁN, Víctor M, 290.

170 A.G.N. Sección República. Fondo Gobernaciones varias. Rollo: 86. Folio: 271.

171 Víctor M. Uribe-Urán, ,290.
} 
de los Supremos. Constituían una red burocrático-familiar y elevaba su identidad corporativa ${ }^{172}$, el hecho de hacer parte de la "carrera de los honores", tal como lo habían hecho sus ascendientes en la época colonial.

Algunos, quizás, estaban en la brega política por el reconocimiento y el honor social de que habla Max Weber ${ }^{173}$, más que por la sola riqueza material. Buscaban el prestigio que aportaba el ejercicio del algún puesto público, a pesar de que durante el debate político surtido en el Congreso neogranadino, en las universidades, en los clubes literarios y asociaciones filantrópicas y en los periódicos, los aristócratas estigmatizaron la búsqueda de puestos burocráticos con el nombre de "empleomanía", una condición enfermiza atribuida a los provincianos ${ }^{174}$.

Tal como se dijo anteriormente citando a Maiguashca, los notables "aristocráticos" y "provincianos" de las provincias, como en el caso del Cauca, construyeron desde la independencia un discurso que justificaba sus actuaciones políticas e incluso la guerra $^{175}$, en el que se involucraban los temas nacionales con las reivindicaciones locales; verdaderas visiones sobre lo que esperaban hacer en su territorio, gracias a la acción de las instituciones del Estado y a los esfuerzos de ellos como dirigentes políticos y burócratas.

Para las élites aristocráticas de la entonces provincia del Cauca, la interconexión con las demás provincias y con los puertos fluviales y marítimos era esencial para el despegue económico y social, a través de las exportaciones. Era una convicción que compartía la cúpula caucana y el gobierno de la Nueva Granada y de la cual se ocupaban en sus comunicaciones, como cuando se repasa y retoca el bosquejo de algo que se debe llevar a cabo.

Una expresión de esa visión compartida de futuro son los comentarios que sobre los caminos le hace el gobernador de la provincia del Cauca, Jorge Juan Hoyos Cabal, al Secretario del Interior y Relaciones Exteriores de la Nueva Granada, Mariano Ospina Rodríguez. Luego de enumerar los proyectos camineros en ejecución más importantes de 1843, como son el camino del Quindío en el cantón de Cartago, el de Amaime a la Torre y Yunde a Palmira en el cantón del mismo nombre, y el de Supía a Caramanta y Salamina, en el cantón de Supía, el gobernador expresa:

172 Maiguashca, «Dirigentes políticos», 214.

173 Max Weber, Economía y Sociedad. Esbozo de sociología comprensiva, (Madrid: Fondo de Cultura Económica, 2002), 1058.

174 Víctor M. Uribe-Urán, 297.

175 Maiguashca, «Dirigentes políticos», 219. 
Pero aún más interesante que estas obras es la apertura de un camino a Salamina i (sic) la composición del que de Anserma Nuevo va a Nóvita hasta ponerlo en estado de transitar en caballerías. El primero facilita el transporte de mulas, de reses i (sic) cerdos a la provincia de Antioquia, i el segundo el de carne, dulce, queso i (sic) tabaco para Chocó. Este tiene además la ventaja de prometer lisonjeras esperanzas para nuestra futura esportación (sic) de frutos del país, porque recogidos estos en todo el Valle del Cauca vendrán por el río de este nombre hasta Cartago, seguirán por el espresado (sic) camino hasta encontrar confluentes del San Juan i (sic) continuarán llevando por la corriente navegable de este río hasta Chambirá, puerto en el mar Pacífico. Además, sabe usted que la línea que separa las aguas del San Juan de las del Atrato, i (sic) las de este río de las que naciendo en su orilla occidental van al Pacífico, es una serie de angostos esteros que están indicando la posibilidad de unir las aguas que tributan a uno i (sic) otro océano; i (sic) esta circunstancia hace de aquel país un punto de grande importancia geográfica que un día lo será para el comercio ${ }^{176}$.

Visiones de los representates de una aristocracia que, con todo y su "mezcla", conservó esa mirada racialista que les impidió una adecuada penetración en la periferia social, en términos de Maiguasca tal como se vio atrás; pero que hizo acuerdos o alianzas entre los impulsores del proyecto de consolidar un Estado republicano unitario en las décadas del treinta y el cuarenta en lo que había sido el virreinato de la Nueva Granada y las élites de la periferia territorial.

\section{El papel de la provincia del Cauca en la construcción del Estado republicano}

La formación del Estado republicano fue el cambio más importante de la etapa que siguió a la victoria política y militar de los insurrectos contra España. Representó la transformación del viejo orden en uno nuevo, de características distintas, sintonizadas con las ideas difundidas desde las revoluciones burguesas de Europa y América.

La tarea más importante de ese nuevo Estado republicano era su propia consolidación, por medio de la sujeción de las antiguas jurisdicciones españolas a su autoridad y al sometimiento de las ciudades y villas que pretendían mantener la autonomía ganada, gracias al papel decisivo que jugaron a favor de la causa independentista durante la guerra. 
Una tarea difícil en opinión de Maiguashca: "El municipio fue el protagonista del proceso de independencia en la América andina, entre 1810 y 1825, y fue el que se enfrentó, muchas veces con éxito, con los flamantes Estados republicanos a partir de los años treinta"177.

\subsection{La penetración en la periferia territorial: Provincia del Cauca}

En la Nueva Granada - el Estado que sucedió a la fallida Gran Colombia de Simón Bolívar -, los enfrentamientos entre las provincias y las localidades y el que pretendía ser el poder central, tuvo la temprana forma de las conflagraciones civiles, que, para la época relacionada con la investigación, lo representa la Guerra de los Supremos, que asoló varias regiones del país, incluyendo al Cauca con particular crueldad.

Esta guerra fratricida y sus resultados inciden de forma cierta en la organización posterior de la república, que endureció el centralismo y todo lo relacionado con el control del orden público, teniendo como base una nueva Constitución Política expedida en 1843. El diseño de esa carta fundamental explica las particularidades de la penetración que la Nueva Granada adelanta en sus periferias territorial y social.

La forma como afrontó el gobierno legítimo el levantamiento sucesivo de los "jefes supremos" en las diversas latitudes del territorio, la conducción de la guerra, el desenlace que salva la precaria institucionalidad y las medidas coercitivas y punitivas adoptadas después, son un buen ejemplo de lo que llamaría Maiguashca, la penetración represiva; aún contradiciendo al mismo autor, que no alcanza a valorar el hecho de que el Estado republicano neogranadino salió airoso del trance.

\subsubsection{Más provincias, más penetración.}

Otra manifestación de los esfuerzos por viabilizar la integración, que se podría enmarcar dentro de la penetración ideológico-normativa, fue organizar el territorio, que representa la periferia territorial, de una manera distinta a como estaba en la época colonial, con el objetivo de jerarquizar las ciudades y villas de acuerdo con su verdadero peso económico y social y no a los privilegios racialistas del régimen español, con sus repúblicas de blancos y sus repúblicas de indios ${ }^{178}$.

Así se entiende que del antiguo territorio de la gobernación de Popayán hayan salido las provincias de Barbacoas, Buenaventura, Pasto y Popayán, como parte de

177 Maiguashca, «Dirigentes políticos», 216.

178 Zambrano, Fabio y Olivier Bernard, Ciudad y territorio, 62. 
las dieciocho creadas por la Ley fundamental de 1831, que organizó el territorio de la Nueva Granada luego de la disolución de la Gran Colombia.

En 1835 se crea la provincia del Cauca con capital en Buga, cuyos límites según la Comisión Coreográfica del coronel Agustín Codazzi en 1855, eran los siguientes: Del cerro Caramanta por la cumbre de la cordillera Occidental hasta el paso San Miguel en el río Cimbria; seguía por la cordillera del Chamí hasta el cerro Tatamá y de este por la cresta que divide las aguas del río San Juan del Cauca hasta la cabecera de la quebrada La Cueva. De allí por su curso aguas abajo hasta el río Garrapatas y por este hasta el camino que conduce de Sipí a Roldanillo. Después el río Garrapatas siguiéndolo aguas arriba hasta la cumbre de la cordillera Occidental, llegando al páramo Mediación. Luego pasaba por la ciénaga del Gorrón hasta alcanzar la boxa de la quebrada Hato de Lemus en el río Cauca, siguiendo este último hasta la desembocadura del río Desbaratado, el cual subía hasta su cabecera en la cordillera Central. Pasando por las cumbres de esta y encontrando los páramos de Isabelilla, Fraile, Iraza, Chiche, Miraflores y Cumbara, e igualmente los nevados del Ruiz, Santa Isabel y del Quindío hasta la cabecera del río Chinchiná. Siguiendo el Chinchiná aguas abajo hasta su desembocadura en el río Cauca, se seguía por el curso de este hasta llegar a la quebrada Arquía hasta su origen en el cerro Santa Isabel, y por las cumbres de los farallones de Citará hasta el cerro de Caramanta. En términos político administrativos, la nueva provincia limitaba con las del Chocó, Antioquia, Mariquita, Popayán y Buenaventura y contenía los cantones de Buga, Anserma, Cartago, Palmira, Supía, Toro y Tuluá ${ }^{179}$.(Ver mapa 3)

De acuerdo con el censo de 1843, la provincia del Cauca tenía 60 mil 860 habitantes, ${ }^{180}$ repartidos en forma desigual en un territorio que llegaba a los 12 mil 524 kilómetros cuadrados y que concentraba la mayor parte de su población en los cantones de Buga y Palmira. El de Cartago, que incluía en su jurisdicción la frontera nor oriental -la montaña del Quindío- con sus dilatados baldíos, ocupaba el tercer lugar en materia demográfica y su cabecera listaba en el censo 5 mil ciento seis almas ${ }^{181}$.

179 Comisión Corográfica: Expediciones e Itinerario» https://es.wikipedia.org/wiki/Provincia_del_Cauca

180 Lino De Pombo, Recopilación, 465.

181 Lino De Pombo, Recopilación, 465. 


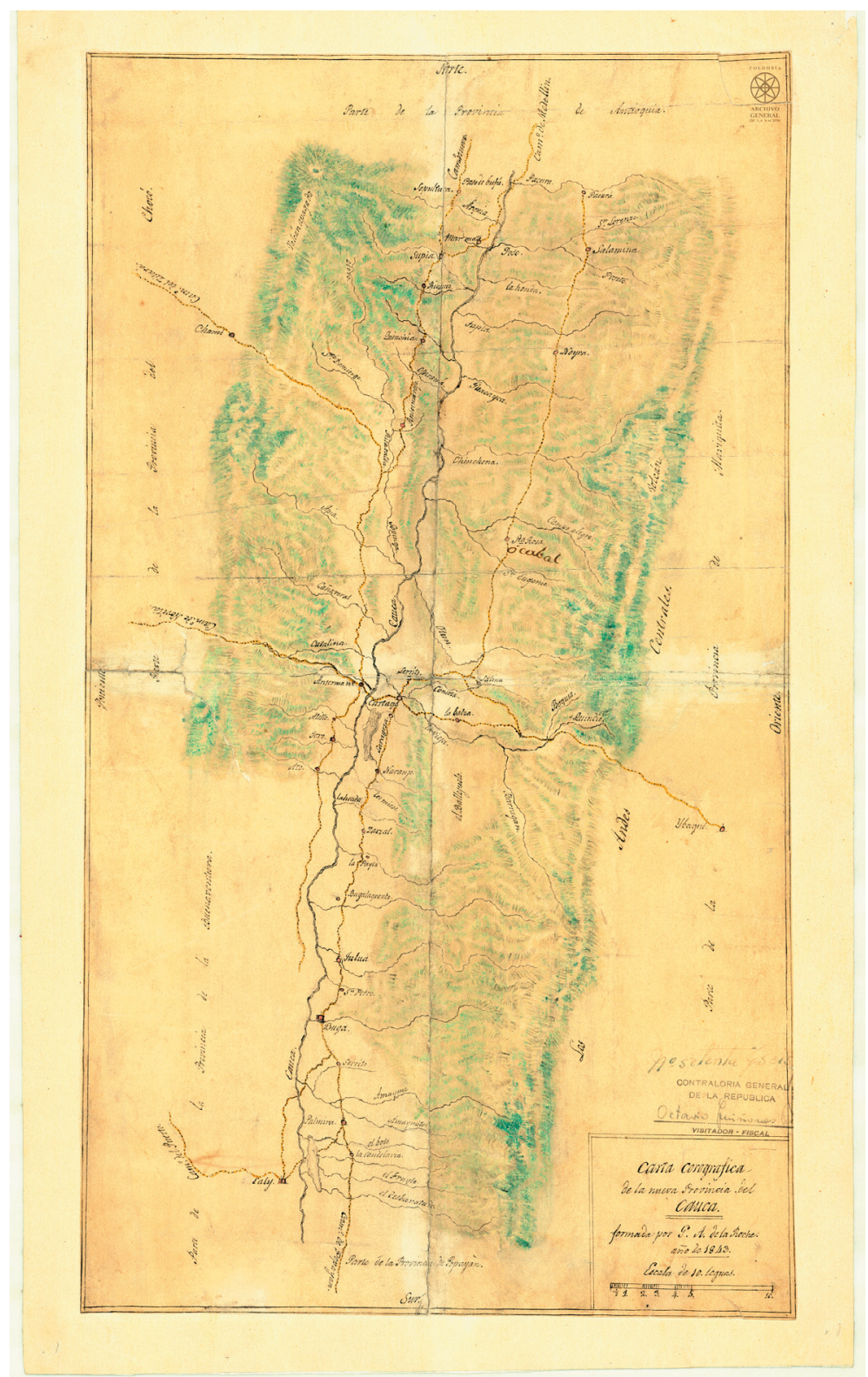

(C) ARCHIVO GENERAL DE LA NACION - Colombia

Sección: Mapas y Planos, Mapoteca 6, Referencia 76

Mapa 3. Carta Corográfica de la Nueva Provincia del Cauca, $1843 .{ }^{182 .}$

182 Este mapa elaborado por el cartógrafo francés Gabriel Ambrosio De la Roche, en 1843, es la primera representación de la provincia del Cauca y ya para entonces aparecía referenciada Santa Rosa, Cabal y el río Boquía. De la Roche, Gabriel Ambrosio. A.G.N. Mapoteca 6. Mapa 76. 
El resultado buscado por la nueva normatividad era la fractura de liderazgos territoriales enraizados en el statu quo colonial y revalidado por el poder armado alcanzado por los vástagos de esas élites y por quienes aprovecharon la carrera militar para ascender en el mundo de la política y escalar en la sociedad provincial.

Algunos, al contrario de lo afirmado por Maiguashca quien dice que en los treinta y cuarenta no aparece en los países andinos una clase de dirigentes políticos de rango nacional ${ }^{183}$; proyectan su influencia en el panorama nacional y se convierten en las cadenas de transmisión entre el interés por consolidar el Estado republicano y las aspiraciones de las élites regionales. Este es el caso del general Tomás Cipriano de Mosquera, que como se ve en la documentación aportada, sigue incidiendo en la política de las provincias que antes conformaban la Gobernación de Popayán y luego alcanza la presidencia en varias oportunidades.

\subsubsection{Penetración político-burocrática.}

Pero las regulaciones neogranadinas mencionadas como parte de la penetración ideológico-normativa son también facetas de la penetración politico-burocrática. En el numeral 4 del artículo 160 de la Constitución Política del Estado de la Nueva Granada, expedida en 1832, se le entrega a las cámaras provinciales la facultad de proponer al Poder Ejecutivo una "lista de seis individuos para que de entre ellos tomen al que haya de ser gobernador" ${ }^{\prime 184}$.

Luego de la Guerra de los Supremos, los redactores de la Constitución de 1843 despojan a las cámaras provinciales de esa facultad y les dan a los gobernadores en su artículo 131, el carácter de funcionario de "libre nombramiento i (sic) amovible a voluntad del Poder Ejecutivo", del que son ajentes (sic) políticos e inmediatos. Por eso, su contacto con la capital de la república es permanente, a través de los secretarios de Estado de cada ramo de la administración pública.

De la investigación documental se comprueba el estrecho control que, para el lapso del que se ocupa la investigación, ejercía sobre el gobernador del Cauca el Poder Ejecutivo, a través del Secretario del Despacho del Interior y Relaciones exteriores.

El mandatario del Cauca sostiene una constante comunicación epistolar con el Secretario del Interior Mariano Ospina Rodríguez, con el fin de informar sobre el

183 Maiguashca, «Dirigentes políticos», 220.

184 Carlos Restrepo Piedrahíta, Constituciones políticas nacionales de Colombia (Bogotá: Universidad Externado de Colombia, 1995), 176. 
control que hace a las arcas de los colegios y hospitales, sobre los nombramientos de sus inmediatos colaboradores, sobre sus desplazamientos por el territorio de su jurisdicción y sobre el desarrollo de las sesiones de la cámara provincial.

La orden que dá el secretario del interior al gobernador del Cauca en relación con la remisión de los informes de visita al colegio de esa provincia, a pesar de ser provincial, es la más clara expresión del carácter centralista de la institucionalidad imperante en la Nueva Granada en la década del cuarenta ${ }^{185}$.

\subsubsection{El camino del Quindío y la fundación de Santa Rosa de Cabal en la penetración de la periferia territorial.}

Ese control es más estrecho cuando se habla de la reapertura del camino del Quindío y el establecimiento del presidio de Boquía, que, como vimos en otro capítulo, exigió la expedición de normas especiales y que a la luz del modelo explicativo de Maiguashca, constituye la penetración material en la frontera, en la periferia territorial.

Una copiosa correspondencia entre Cartago, sede provisoria del mandatario provincial, y la capital de la República, muestra cómo la mayoría de las decisiones sobre el presidio y el camino eran consultadas para su aprobación al secretario del interior, ya que los trabajos se financiaban con fondos especiales del Estado.

Los formatos de vales, la confección de uniformes para presos y vagos concertados, la dotación de herramientas y medicinas, la entrada y salida de internos del presidio y los gastos para el traslado y racionamiento de los reos destinados a trabajar en el camino del Quindío, son objeto de injerencia por parte del Poder Ejecutivo, a través del Secretario del Interior y Relaciones Exteriores.

Para ejemplo puede servir la respuesta que el 20 de junio de 1843 le da Ospina Rodríguez a Hoyos Cabal, sobre unas decisiones de la Junta de Hacienda comunicadas el 5 de junio anterior, con relación a los costos de traslado de reos:

Apruébase el gasto de dos pesos (\$2) acordado el 22 de mayo último por la junta de hacienda de la provincia del Cauca, para pago de un bagaje suministrado a un presidiario que no ha podido seguir su marcha a pie de Buga a Cartago. Igualmente se aprueba los seis reales acordados el 24 del mes 
citado por dicha junta de hacienda, para raciones de los reos Miguel Palla y Pedro Antonio Paruma, prófugos del tercer distrito, conducidos de Buga a Cartago. Una y otra suma se deducirá del fondo respectivo compredido en la parte $13^{a}$. Artículo 1 de la lei del 5 de junio de 1842, teniéndose presente respecto del segundo gasto lo que dispone el artículo 84 del Decreto Ejecutivo reglamentario de los estalecimientos de castigo, expedido el 17 de abril de $1839^{186}$.

La obra del camino del Quindío ofrece facetas similares a lo que que Maigushca llama la penetración en sus diversas variedades entre 1830 y 1850 , y por eso el mencionado proyecto contribuye a que el balance del período dominado por los políticos aristocráticos y los burócratas neo patrimoniales en la Nueva Granada, difiera un poco del planteado por el mencionado autor para la generalidad de las repúblicas andinas.

El balance de Maiguashca sobre lo alcanzado por el Estado republicano en los países andinos durante las décadas del treinta y el cuarenta del siglo XIX, no es bueno: “...en general los dirigentes aristocráticos/neopatrimoniales de los años treinta y cuarenta no tuvieron recursos como para poner en práctica ninguna de los cuatro tipos de penetración que hemos identificado en la introducción..."187

Sin embargo, la voluntad del Poder Ejecutivo neogranadino de reabrir el camino del Quindío entre las provincias del Cauca y Mariquita, como un proyecto que involucraba el poblamiento de baldíos y la integración de las fronteras internas; sumado al papel jugado por las autoridades de las dos provincias y al despliege normativo, burocrático, coercitivo, logístico y económico, es una demostración de la forma como el Estado republicano penetra en su periferia territorial en lo material, lo político-burocrático, lo represivo y en lo ideológico normativo, que es donde el autor reconoce algún avance de los dirigentes aristocrático-neopatrimoniales andinos.

\subsubsection{Gobernar es poblar.}

El capítulo anterior del presente texto es una prueba de esa afirmación, pues se muestra la actividad normativa de carácter legislativo y ejecutivo en torno al aprovechamiento y colonización de los baldíos que constituyen las fronteras internas

186 A.G.N. Sección República. Fondo Gobernaciones varias. Rollo 86. Folio 514.

187 Maiguashca, «Dirigentes políticos», 224. 
de la Nueva Granada y, en particular, las decisiones y operaciones dirigidas a la reapertura del caminio del Quindío, con su estrategia de poblamiento incorporada.

Con ese cúmulo de actos y operaciones, el Estado republicano neogranadino penetra de diversas formas su periferia territorial para integrar un inmenso territorio bajo su dominio, que se expresa en el poblamiento y la construcción de vías que unan la geografía nacional, como adelantándose a la famosa frase "Gobernar es poblar", dicha por Juan Bautista Alberdi en Argentina en $1853^{188}$.

Olga Cadena Corrales y José Manuel Pérez Bravo afirman a propósito de Alberdi:

En los comienzos de la vida republicana, una de las preocupaciones centrales de los gobernantes fue la de vincular unas regiones con otras, tratar de ocupar los espacios vacíos, por lo menos en aquellos lugares considerados importantes para los planes de desarrollo y para la vinculación a los mercados externos. En ese entonces predominaba la tesis, hecha famosa por Juan Bautista Alberdi, arquitecto de la Constitución argentina de 1853, que dice: "gobernar es poblar", por lo que, desde el gobierno mismo, se impulsaron procesos migratorios y de apropiación de tierras, que dieron origen a la llamada colonización dirigida. (...) El estímulo a la ocupación de baldíos, promovido por la República como parte de un proyecto de desarrollo nacional que se propuso entregar tierra, primero a los extranjeros y luego a sus propios ciudadanos (Tovar Pinzón 1995). Entre estas medidas se encuentra la decisión del gobierno de Pedro Alcántara Herrán de construir la colonia penal de Boquía, en uno de los dos caminos oficiales que cruzaban la Cordillera Central y que unían a Bogotá con Popayán y con el puerto de Buenaventura ${ }^{189}$.

Se debe decir entonces que, al menos en la provincia del Cauca, el Estado republicano de la Nueva Granada tuvo éxito en su penetración material de la periferia territorial, pues, como veremos más adelante, en el lapso objeto de la investigación, la obra del camino del Quindío avanzó en los términos en que se había proyectado.

188 Juan Bautista Alberdi, Bases y puntos de partida para la organización política de la República de Argentina, (Buenos Aires: La Cultura Argentina, 1852).

189 Cadena Corrales, Olga y, José Manuel Pérez Bravo, «Colonización del Quindío» en Historia de nuestra región. La Historia del Quindio. (Armenia (sin más datos)), 47. 


\subsubsection{Penetración represiva.}

La penetración represiva no fue la excepción, ya que el asentamiento del presidio del 3er distrito en Boquía no solo garantizaba la mano de obra para los trabajos del Camino del Quindío, sino también proveía el castigo y el aislamiento de individuos peligrosos para el Estado; algunos acusados y condenados por participar activamente en la Guerra de los Supremos, al lado de las fuerzas rebeldes.

Una prueba del buen resultado del asentamiento del presidio en esa zona, es que mucho de sus reos, provenientes del Cauca, Panamá y Antioquia, se instalaron posteriormente allí como los primeros pobladores del Quindío. De delincuentes y rebeldes a colonos campesinos. Así lo explica Álvaro Hernando Camargo Bonilla:

En este período se consolida más la penetración colonizadora de la región en cabeza de los prisioneros de guerra empleados para el arreglo de la ruta. Una vez cumplidas sus penas, resolvían quedarse y dedicarse a la colonización de predios para la agricultura y la ganadería ${ }^{190}$.

\subsubsection{Penetración político-burocrática.}

Las dificultades para constituir una red de funcionarios que garantizaran un gobierno mínimo, las obras del camino, el asentamiento del presidio y la fundación de Santa Rosa de Cabal, obligaron a incorporar muchos individuos al servicio de ciertos destinos para garantizar la presencia estatal o para permitir el cumplimiento de los propósitos trazados.

Satisfacer esas necesidades determinó, incluso, que, indultados a cambio de trabajar en el camino del Quindío, terminaran a cargo de responsabilidades en el presidio y en las obras del camino. Entonces lo que es una manifestación de la penetración represiva, se convierte también en parte de la penetración político-burocrática. El gobernador Hoyos lo ratifica cuando le dice al secretario Ospina el 22 de marzo de 1843, que "por falta del director del presidio sin que sea aún creado, me he visto en la necesidad de encargar, en calidad de comisionado accidental de las funciones de director al señor Ciriaco del Villar, joven indultado en condiciones de servir en la apertura del Camino del Quindío, ya que ha manifestado buena conducta y es afecto"191.

190 Álvaro Camargo Bonilla, «El Camino del Quindío y la cambiante biodiversidad en la Provincia del Quindío» en Ensayos de Historia Quindiana. Volumen 2. (Armenia: (sin más datos)), 242. 
De otra parte, la fundación de Santa Rosa de Cabal es una clara muestra de la penetración político-burocrática del Estado republicano neogranadino en la periferia territorial. En el decreto del $1^{\circ}$ de septiembre de 1844, que autoriza la formación de la nueva población de Cabal, el presidente Herrán ordena al cabildo de Cartago la creación de una comisaría de policía "para proveer la conservación del buen orden"192. De la misma forma, el $1^{\circ}$ de enero de 1845, desde Cartago el Gobernador del Cauca solicita al Poder Ejecutivo de la Nueva Granada, autorizar la asignación de sueldo al presbítero Fulgencio Castillo quien ha venido promoviendo la formación de una población en el Quindío, con el objeto de que administre los sacramentos y celebre misa; al tiempo que asuma tareas de agente de la gobernación en todo lo relacionado con el establecimiento de un nuevo poblado ${ }^{193}$.

\subsubsection{Penetración normativa-ideológica en la periferia territorial del} Cauca.

Es conveniente detenerse en los resultados de la penetración ideológico-normativa delos dirigentes estatales del período queva de 1830 a 1845 , porque los mismos, según se concluye de la lectura de Maiguashca, se relacionan con los logros generales del personal aristocrático/neopatrimonial, con la consolidación del Estado republicano en la periferia territorial y por último, con los resultados de la interacción entre esa estructura de poder y la "comunidad imaginada" que ricos, pobres y sectores medios de diversas localidades, constituyeron alrededor de las ideas de independencia y república.

Para el autor, esos logros fueron la defensa del Estado republicano frente a las pretensiones del Ejército y de la Iglesia, y la instauración de un "sistema de gobierno constitucional y republicano", que por ser así propendía por el liderazgo civil como uno de sus más importantes paradigmas y que tenía a la libertad como el mayor valor $^{194}$. Lo anterior supone éxitos en la penetración normativa-ideológica.

\section{Frente a los militares:}

En lo que respecta a la Nueva Granada, el celo por imponer la autoridad de los civiles sobre los militares en los diferentes niveles territoriales del Estado, aún en

\footnotetext{
192 Gaceta De La Nueva Granada. № 700, Domingo 1º de septiembre de 1843.

193 A.G.N. Sección República. Fondo Gobernaciones varias. Tomo I. Carpeta 104. Folio 180.

194 Maiguashca, «Dirigentes políticos», 222.
} 
clara confrontación con los caudillos de la Guerra de Independencia, está presente en varias normas de la Carta Constitucional de 1832.

Al referirse a los gobernadores de las provincias, dice el artículo 152: "En todo lo perteneciente al orden y seguridad de la provincia, y a su gobierno político y económico, están subordinados al gobernador todos los funcionarios públicos de cualquier clase y denominación que sean, y que residen dentro de las mismas provincias"; mientras que el artículo 174 estipula que:

La guardia nacional en cada provincia estará a las órdenes de su respectivo gobernador, quien la llamará al servicio en los casos que determine la ley, o cuando el Poder Ejecutivo lo ordene con acuerdo del Congreso, o del Consejo de Estado en receso de aquel; o sin estos requisitos, para obrar dentro de la provincia, en caso de conmoción súbita, o de invasión exterior repentina ${ }^{195}$.

En el artículo 30 de la Ley 1 del 19 de mayo de 1834, también se subraya la potestad civil sobre la militar:

En las provincias en donde haya fuerza veterana, está siempre dicha fuerza a disposición del gobernador para conservar y restablecer la tranquilidad de la provincia, para la seguridad de las personas, bienes i (sic) derechos de los habitantes, para la prevención i (sic) persecución de los delitos, para ejecución de sus providencias i (sic) mandamientos, i (sic) para la ejecución de los demás objetos de su autoridad ${ }^{196}$.

El artículo siguiente, el 31, remata: "El gobernador en la provincia de su cargo tiene los mismos honores militares que un jeneral (sic) con mando, i (sic) se los harán cualesquiera tropas que haya en ella"197.

El poder disponer de la Guardia Nacional que le otorgaba la constitución y la ley a los gobernadores de provincia, fue aprovechado por el mandatario del Cauca en los trabajos de reapertura del Camino del Quindío, ya que era esa fuerza la que proveía la vigilancia de los reos del presidio del Tercer Distrito ubicado en Boquía con el objeto de realizar los trabajos.

195 Restrepo Piedrahíta, Constituciones políticas, 178.

196 Restrepo Piedrahíta, Constituciones políticas ,179.

197 Lino De Pombo, Recopilación, 43. 
Sin embargo, como se verá más adelante, el papel de la Guardia Nacional en su misión de vigilar a los condenados a trabajar en el camino del Quindío fue controvertido y exigió del Gobernador Hoyos toda su atención y una constante interacción con la Secretaría de Guerra y Marina.

El 20 de septiembre de 1840, el gobernador del Cauca al dar explicaciones sobre las numerosas y constantes fugas de los reos, ante el Secretario del Interior Mariano Ospina Rodríguez, dice:

Las verdaderas causas de las frecuentes fugas son: $1^{\circ}$ Que los militares no observan la disciplina con esactitud (sic). $2^{\circ}$ Por la falta de tropa ha quedado muchas veces el destacamento en poder de cabos y sarjentos (sic) que no saben ni escribir, i (sic) que viéndose solos descuidan sus deberes i (sic) no exigen vigilancia de soldados. $3^{\circ}$ Alegando siempre cansancio por la continua fatiga (Esto es, porque no se releva con frecuencia el destacamento) los soldados buscan las sombras, se separan de los reos, o duermen principalmente cuando el director no asiste, como por desgracia ha sucedido con una parte de los que han desempeñado ese destino. $4^{\circ}$ Porque rehusando siempre el soldado recibir preparado su rancho, i (sic) no dando lugar a esta reforma el estado de la disciplina, se ocupan en preparar su comida rodeado de las mujeres que los acompañan, i (sic) no en vigilar ${ }^{198}$.

\section{Frente a la Iglesia Católica:}

La lucha por la supremacía entre el nuevo Estado y la Iglesia Católica -que Maiguashca considera perdida por parte del clero entre 1830 y 1850 -, tuvo en la Nueva Granada y en el Cauca expresiones claras sobre la forma como el personal aristocrático/neopatrimonial concebía las relaciones de la institucionalidad republicana con Roma.

La documentación que hay sobre la supresión del distrito parroquial de los Cerrillos, cantón de Cartago, en 1844, así lo demuestra. Cuando en junio de 1843, a instancias del jefe político del Cantón de Cartago se empieza a discutir la supresión del distrito parroquial de los Cerrillos, el gobernador Hoyos informa al Secretario del interior que elevará consulta al "prelado diocesano", habida cuenta de que la mencionada población es también la cabecera de una parroquia de la Iglesia Católica ${ }^{199}$.

198 A.G.N. Sección República. Fondo Gobernaciones Varias. Rollo 94. Folio 139.

199 A.G.N. Sección República. Fondo Gobernaciones Varias. Rollo 86. Folio 596. 
Semanas después, el mandatario provincial cambia de parecer y le anuncia al secretario Ospina Rodríguez que:

(...) he suspendido la revisión del expediente sobre supresión de la parroquia de los Cerrillos al prelado Diocesano para oir su concepto, hasta que se haya resuelto definitivamente sobre la supresión del distrito parroquial, porque juzgo que la administración eclesiástica debe acomodarse a las decisiones territoriales que se hagan para la administración civil i (sic) no al contrario, aunque deba tener presente la división para lo eclesiástico al reformar la división para lo civil, por la conveniencia que hai (sic) de que sea una misma para una i (sic) otra administración ${ }^{200}$.

\subsubsection{El balance de la penetración normativa-ideológica en la periferia social.}

De acuerdo con Maiguashca, el Estado republicano en los países andinos también debía buscar su consolidación a través de lo que él denomina la penetración normativa-ideológica de la periferia social, conformada por dimensiones como el género y la etnicidad.

De entrada, el autor advierte que en el mencionado ámbito, la penetración del Estado republicano es mucho menor en comparación con la alcanzada en la periferia territorial ${ }^{201}$. Posteriormente, afirma que el personal aristocrático "tuvo poco éxito en la penetración de la periferia social", como consecuencia de las decisiones adoptadas frente a los indios y los esclavos.

\section{Con los indios}

La eliminación de los resguardos indígenas y la imposición de una utópica "igualdad" entre los "blancos" y los indios, que además ya no contaban con la protección brindada por las autoridades españolas hasta antes de la Independencia ${ }^{202}$, los condenó a la marginalidad.

Maiguashca explica que esa especie de bipolaridad donde los blancos y los mestizos están en el centro y en la periferia se ubican los indígenas, está presente en todos los

200 A.G.N. Sección República. Fondo Gobernaciones Varias. Rollo 86. Folio 703.

201 Maiguashca, «Dirigentes políticos», 216.

202 Maiguashca, «Dirigentes políticos», 226. 
países andinos en mayor o menor medida, de acuerdo con el carácter mayoritario o minoritario de los indios en términos demográficos.

Esto se puede confirmar con lo acontecido en la Nueva Granada, donde dice el autor la bipolaridad fue mucho menor y en ese sentido, la situación de la provincia del Cauca en el período de esta investigación lo confirma.

Al informar sobre las características del distrito parroquial de los Cerrillos, poblado por sobrevivientes de los Quimbayas, el gobernador del Cauca, Jorge Juan Hoyos Cabal le dice el 14 de febrero de 1843 al secretario del Interior de la Nueva Granada que, de acuerdo con lo informado por el jefe político del Cantón de Cartago, el asentamiento:

(...) constaba, según tradición, hasta de mil almas poco después de la conquista, y de ciento hasta el año 1809; que se componía de indígenas... que la población está reducida a cincuenta habitantes porque la han diseminado en otros distritos; que pienso que esta disminución es tambien obra de la que en jeneral (sic) ha sufrido la raza americana en esta provincia, en cuyo centro es una rareza ver un indio ${ }^{203}$.

En la misma fecha, el gobernador provincial también le informa a Bogotá que en el Cauca no hay indígenas para reducir, ni adoctrinar y por esa razón no es necesario establecer un colegio de misiones ${ }^{204}$.

Posteriormente, el 31 de mayo de 1843, el gobernador Hoyos le dice a Ospina Rodríguez al remitirle el cuadro del censo general del Cauca, que:

En esta provincia no se tiene noticia alguna de que exista en ella alguna tribu de indios herrantes. Desde que las guerras i (sic) el tiempo destruyeron la de los Pijaos, que recorría la Cordillera Central de los Andes, apareciendo sobre los poblados con espanto de sus habitantes, que hasta ahora conservan en la memoria el horror de su nombre, presentándolo a los niños como el de un objeto temible, que se recuerda en varias expresiones provinciales, ya no se oye hablar de indios sino con relación a las provincias vecinas, pues que aún los reducidos a vida social han desaparecido desde Anserma hacia el sur ${ }^{205}$. 


\section{Con los esclavos}

Para resolver la contradicción que implicaba la erección de un Estado moderno basado en los principios liberales europeos, en un país "donde todavía existían unos hombres en condición de esclavos, a quienes no se les reconocía su calidad de personas, es decir, carentes de derechos civiles y políticos" los legisladores del Congreso del Rosario de Cúcuta expidieron la Ley del 21 de julio de 1821, que ratificaba la abolición del tráfico de esclavos, la manumisión de los mismos y la libertad de vientres ${ }^{206}$. Esta última consistía en que los hijos de esclavas nacidos a partir de la publicación de esa ley, serían libres y deberían ser inscritos como tales en los registros cívicos de las municipalidades y en los libros parroquiales cuando cumplieran dieciocho años, al tiempo que los dueños de sus madres debían educarlos, vestirlos y alimentarlos hasta que llegara a la mencionada edad.

Después de veinte años de vigencia, la ley que parecía un remedo de reforma en comparación con las expectativas de los esclavos y negros de la Nueva Granada, muchos de los cuales lucharon en las filas de los ejércitos libertadores, empezó a rendir frutos, gracias a la libertad de vientres y demandó de algunas reformas que evitaran la pérdida de esa mano de obra vital para la economía del Estado republicano y en especial, para la de provincias como el $\mathrm{Cauca}^{207}$.

Los informes enviados por el gobernador Hoyos Cabal a Bogotá con relación a los esclavos y sus hijos nacidos libres, estaban motivados por una serie de normas expedidas en 1842 por el Congreso de la República, el Presidente Pedro Alcántara Herrán y su Secretario del Interior y Relaciones Exteriores, Mariano Ospina Rodríguez, para regular la inminente pérdida de la mano de obra afrodescendiente, como consecuencia de la libertad efectiva que lograrían los hijos de esclavos al llegar a los dieciocho años de edad y que estaban bajo la tutela de sus antiguos amos.

La primera de las normas es una Ley del 29 de mayo de 1842, que reglamenta la forma como los amos deben presentar a los hijos de esclavas nacidos libres en virtud de la libertad de vientres y que cumplieron la edad de dieciochos años, ante el alcalde de su distrito parroquial, para que les expida documento en que conste que gozan de plena libertad.

Después de establecer multas para los amos que no cumplan con ese deber, el artículo 4 ' dice: "Entregado que sea al joven el documento de que habla el artículo anterior, es

206 Liliana Fabiola Ruiz, «El Estado y el concierto de los hijos de los esclavos» Reflexión Política. 3, $n .^{\circ} 5$ (2001)

207 Ruiz, «El Estado», 3. 
un deber del alcalde destinarlo a oficio, arte, profesión u ocupación, concertándolo a servir con su antiguo amo o con otra persona de respeto que pueda educarlo e instruirlo: para este concierto se consultará la voluntad del joven y se oirá la voz del personero comunal, como su protector". El artículo $6^{\circ}$ dice a su turno: "Los jóvenes de que hablan los artículos anteriores que no se concertaren, o que concertados se fugaren, o que no cumplieren debidamenrte con las obligaciones de su concierto, serán, como vagos, destinados por el alcalde al ejército permanente, después de oir al personero comunal"208. Posteriormente, en 1846, se decidió también destinar a los jóvenes renuentes a formar nuevas poblaciones ${ }^{209}$.

Luego viene el decreto del 21 de junio de 1842, sobre la formación del censo anual de esclavos que arrojó, en el caso del Cauca, las estadísticas siguientes ${ }^{210}$ :

\begin{tabular}{|c|c|c|c|c|c|c|c|c|c|}
\hline \multirow{2}{*}{ Cantones } & \multicolumn{3}{|c|}{ HOMBRES } & \multicolumn{3}{c|}{ MUJERES } & \multicolumn{3}{c|}{ TOTALES } \\
\cline { 2 - 11 } & $\begin{array}{c}\text { Menores } \\
\text { de 7 } \\
\text { años }\end{array}$ & $\begin{array}{c}\text { De 7 } \\
\text { a 14 } \\
\text { años }\end{array}$ & $\begin{array}{c}\text { De 14 a } \\
\mathbf{1 8} \text { años }\end{array}$ & $\begin{array}{c}\text { Menores } \\
\text { de 7 años }\end{array}$ & $\begin{array}{c}\text { De 7 a 14 } \\
\text { años }\end{array}$ & $\begin{array}{c}\text { De 14 a } \\
\mathbf{1 8} \text { años }\end{array}$ & Hombres & Mujeres & General \\
\hline Palmira & 256 & 216 & 59 & 228 & 174 & 60 & 531 & 462 & 993 \\
\hline Buga & 243 & 237 & 52 & 233 & 234 & 69 & 532 & 536 & 1068 \\
\hline Toro & 15 & 2 & 4 & 16 & 17 & 5 & 21 & 38 & 59 \\
\hline Cartago 2 & 139 & 108 & 30 & 135 & 78 & 40 & 277 & 253 & 530 \\
\hline Supia 4 & 56 & 45 & 7 & 55 & 60 & 17 & 108 & 132 & 240 \\
\hline Totales & 809 & 703 & 180 & 755 & 653 & 232 & 1686 & 1640 & 3326 \\
\hline
\end{tabular}

Cuadro 2. Censo de hijos de esclavos. Provincia del Cauca - 1843. ${ }^{211}$

Para el 30 de julio de 1842, el presidente Herrán expide otro decreto con el cual instruyen a los curas párrocos sobre su obligación de precisar en la partida de bautismo, si el inscrito es hijo de una esclava y sobre la forma como esa información debe cruzarse con la que deben entregar bajo la gravedad del juramento los amos, sobre si tienen en su poder hijos de esclavas.

\footnotetext{
208 A.G.N. Sección República. Fondo Libros y manuscritos y leyes originales de la República. Libro No 120.

209 Ruiz, «El Estado», 3.

210 A.G.N. Fondo Negros y esclavos.

211 A.G.N. Sección República. Fondo Gobernaciones Varias. Rollo 86. Folio 401.
} 
Las mencionadas medidas se amparaban en la necesidad de que estos jóvenes libres, hijos de esclavas, pudieran aprender un oficio o arte y no caer en la vagancia, cuando pudieran gozar su libertad por haber llegado a los dieciocho años, y entrañaban el forcejeo de algunos sectores por mantener durante el mayor tiempo posible el control sobre esta población que alcanzaba su libertad gracias a la libertad de vientres, tal como lo ilustra la intentona de la Cámara Provincial del Chocó, que pidió que aquellos lo pudieran hacer al cumplir cuarenta años de edad y la de Cartagena que propuso que fuera a los cincuenta ${ }^{212}$.

\subsubsection{La visión aristocratizante.}

Para entender todo lo anterior -el magro resultado de la penetración estatal en la periferia social-, es necesario volver a Maiguashca, quien caracteriza a la dirigencia política del período en que se expiden las mencionadas normas como aristocrático, que implica una visión donde se privilegia la libertad como idea dominante y en detrimento de valores como la igualdad y la fraternidad ${ }^{213}$.

El resultado es que la penetración de la periferia social no se logra y, por el contrario, se perpetúa la marginación colonial de los indios, con el argumento de una igualdad que los despoja de sus tierras y de la protección que hasta antes de la Independencia les ofrecía la corona española.

Esa visión aristocratizante pregonaba que los indígenas y los esclavos "debían ser protegidos de sí mismos y debían aceptar la guía patriótica de las élites políticas y sus aliados" 214 , y en nombre de eso concibieron la concertación de los hijos libres de esclavas, que podían gozar de ese derecho al cumplir los dieciocho años, gracias a la libertad de vientres, para prolongar la tutela de sus amos.

Del mismo modo, condena a la exclusión a la mayor parte de la población de los países andinos y a la de la Nueva Granada en particular, cuando sujeta la realización de los derechos ciudadanos a certificar el alfabetismo o el hacer parte de un censo en relación con el patrimonio o el ingreso.

Al proponer incorporar la condición de propietarios de bienes raíces por valor neto de 20 pesos o en su defecto la de ejercer algún oficio o industria textil, a las calidades

\footnotetext{
212 Ruiz, «El Estado», 6.

213 Maiguashca, «Dirigentes políticos», 222.

214 Maiguashca, «Dirigentes políticos», 228.
} 
que debía tener todo neogranadino para ser ciudadano y poder elegir los miembros del Congreso de la República, dentro de las discusiones del Congreso Constitucional de 1842 que redactó la Constitución Política de 1843, el Secretario del Interior y de Relaciones Exteriores Mariano Ospina Rodríguez argumentaba que solo una cuarta parte de los habitantes de la Nueva Granada eran útiles e inteligentes y que sumada esa proporción a otra equivalente compuesta por elementos no tan buenos, tan solo la mitad de los habitantes merecerían la protección de leyes expedidas por el Congreso de la República:

Si mis observaciones anteriores son exactas, no hay más que la mitad de la población, que contribuye a la prosperidad pública, por esto es que la parte única que está formada por ciudadanos útiles es digna de la protección del Congreso, porque ellos solos, o solamente esta parte tiene objetos dignos de protejer (sic), mientras que en la otra parte siendo dueños de poca cosa los hombres que la constituyen, bastan las leyes municipales para formar su bienestar y su felicidad... creo que el objeto del Gobierno representativo no es otro que protejer (sic) propiedades donde ellas existan, y propagar leyes para crearlas, aumentarlas y asegurarlas, y con un código de leyes civiles toda la igualdad que tal gobierno puede dar, se había conseguido ${ }^{215}$.

Esa reflexión de Ospina es recogida en el artículo $9^{\circ}$ de la Constitución Política de 1843, cuando en su numeral 12 establece como uno de los requisitos para ser ciudadano de la Nueva Granada, la propiedad de bienes raíces ubicados en el territorio nacional con un valor libre de trescientos pesos, o tener una renta anual de ciento cincuenta pesos, y pagar cumplidamente los impuestos correspondientes a ese ingreso y ese patrimonio ${ }^{216}$. La carta política anterior, promulgada en 1832, solo listaba dentro de los requisitos para el ejecicio de la ciudadanía " 3 . Tener una subsistencia asegurada, sin sujeción a otro en calidad de sirviente doméstico, o de jornalero"217.

Al mismo tiempo, es una visión que identifica para las décadas del 40 y el 50 en la Nueva Granada, a los líderes del proyecto estatal centralista impulsado desde Bogotá, con las élites de las ciudades y villas de la periferia territorial del pretendido Estado republicano. Los intereses que juntos persiguen y los valores que desean

215 Leyes i Decretos Espedidos por el Congreso Constitucional de la Nueva Granada en el año de 1842 págs. 13 i 14. En: Geografía y censos en el siglo XIX. p. 13.

216 Constitución Politica de la República de la Nueva Granada. 1843.

217 Constitución Política del Estado de la Nueva Granada de 1832. 
representar, obran como denominadores comunes, expresados en la constitución de redes de colaboración mutua, con constraprestaciones definidas.

Es una aristocracia matizada por los elementos que ascendieron como consecuencia del conflicto bélico y las reacomodaciones que este trajo en lo económico y social. Es la clase dirigente que entre 1830 y 1850 debe afrontar la formación del Estado como institución, con la realización de tareas tan complicadas como la incorporación de las fronteras internas heredadas de la Colonia, tal como le correspondió al presidente Pedro Alcántara Herrán, a su Secretario del Interior y Relaciones Exteriores Mariano Ospina Rodríguez, y al gobernador del Cauca Jorge Juan Hoyos Cabal. Por supuesto, los aristócratas aportan al proyecto de incorporar las fronteras internas a la vida nacional y provincial, la lente del racialismo que ellos mismo creen compartida por las clases subalternas.

Lo último se evidencia en una carta enviada desde Buga el 29 de septiembre de 1843, por el coronel Pedro José Dorronsoro al general Tomás Cipriano de Mosquera, en la cual fuera de hablar de los asuntos políticos locales, le plantea las dificultades que tiene para la crianza y cuidado de una niña llamada María Engracia, que por alguna razón no expresada merece su preocupación y cariño. Dorronsoro le dice a su jefe que no la recibe en su casa porque "las gentes del pueblo en estos lugares, son enemigos de que sus hijos vivan en las casas de los blancos (que es el nombre con que nos distinguen)" Lo cerca que está la infante de la adolescencia aumenta la inquietud del soldado: "Ella es muy bonita i (sic) no ha de faltar quien trate de seducirla cuando entre en la estación de los placeres"218.

Pero aquello de la minoría de edad eterna en que asumen que están estancados los mestizos, los indios y los esclavos, es una argumentación permanente que justifica las acciones del gobierno. El 5 de julio de 1843, el gobernador de la provincia del Cauca Jorge Juan Hoyos Cabal, dice que los habitantes del distrito parroquial de Cerrillos son "decidiosos" y que "desprecian las comodidades que brinda un terreno aparentemente fértil con quiebras húmedas para cultivar el plátano, temperamento medio, i (sic) praderas ya formadas", cuando envía al Secretario del Interior y Relaciones Exteriores, Mariano Ospina Rodríguez, un informe en torno a la supresión de esa división territorial ${ }^{219}$.

Del mismo modo, Hoyos Cabal duda de las posibilidades que tiene la provincia del Cauca de poblar con su propia gente la frontera nororiental, hasta el punto

218 Archivo Central Del Cauca. Sección República. Fondo Mosquera. Carpeta 13D. Folio D9729.

219 A.G.N. Sección República. Fondo Gobernaciones varias. Rollo 94. Folio 848. 
de considerar inviable la fundación de una población en un punto estratégico del tramo que le corresponde construir del Camino del Quindío en cumplimiento de la normatividad expedida por el presidente Herrán.

Así lo hace saber el funcionario a Ospina desde Cartago, el 27 de febrero de 1824:

La población es muy escaza (sic) en esta provincia, esto porque sus habitantes son sedentarios, i (sic) se hayan adormecidos en la aparente abundancia de que gozan; tienen algunas de las orillas del Cauca i (sic) no afectan terrenos donde el plátano no crecerá robusto, i (sic) que sus bacas (sic) i marranos no encontrarán alimento fácil. No será pues posible poblar con jentes de esta provincia, mientras que de las demás solo Antioquia i (sic) el Socorro, se presentan a ofrecer pobladores ${ }^{220}$.

Esta cruzada personal del gobernador Hoyos en favor del poblamiento con antioqueños, solo se equipará a su reiterada oposición a concertar vagos para las obras del camino y el poblamiento del Quindío, pues los considera inútiles, viciosos y perezosos.

Días antes de la comunicación comentada, el funcionario le escribe desde Cartago que:

Las gobernaciones de Panamá i (sic) Popayán me han remitido en calidad de pobladores del Quindío, mujeres que, por corrompidas, insolentes e incorregibles no han podido aguantar allá. Yo me he visto precisado a recibirlas porque no queda partido que tomar, i a destinarlas en calidad de cocineras de los peones del Quindío, pero ni de esto han podido servir i (sic) han introducido el desorden entre los trabajadores.

Luego sentencia agriamente: "Cosa estraña (sic) me ha parecido que se haya podido pensar que una población que se fomenta para seguridad i comodidad del tránsito de la montaña, pueda formarse de las personas más corrompidas de la tierra"221. El artículo 29 de la Ley del 3 de mayo de 1826, expedida a instancias del gobierno de Francisco de Paula Santander, definió como vagos:

(...)a los que no tenían oficio ni beneficio, hacienda o renta; a los que teniendo algún medio de subsistencia, se dedicaran a las casas de juego, las compañías

220 A.G.N. Sección República. Fondo Gobernaciones varias. Rollo 94. Folio 639.

221 A.G.N. Sección República. Fondo Gobernaciones varias. Rollo 94. Folio 640. 
mal opinadas, tabernas, casas de prostitutas o que no desmostraran un destino y una ocupación útil; a los que pideran limosna sin tener alguna lesión suficiente que le impida trabajar o fueran muchachos huérfanos o descuidados por sus padres; a los hijos de familia mal inclinados, con malas costumbres e irrespetuosos con sus padres; a quien se entrega a la ociosidad; a los que, con el pretexto de estudiar, viven sin sujeción; a quien no es constante con su trabajo y oficio; a los forasteros y prófugos sin destino; y a los que van vendiendo mercancías de pueblo en pueblo (cuya actividad no le produjese lo necesario para mantenerse a él mismo y a su familia) ${ }^{222}$.

Es un hecho relevante la oposición de Hoyos Cabal a una política del gobierno central, sustentada con leyes y decretos, como la de utilizar vagos para la construcción de obras públicas y el establecimiento de poblaciones, ya que expresa un pulso latente y a veces explícito entre la forma de pensar de las élites de las provincias y la manera como los miembros del gobierno nacional abordan los problemas.

Con antioqueños o socorranos se debía incorporar a la vida nacional y a su economía la Montaña del Quindío, recomendaba el gobernador Hoyos Cabal; tal como posteriormente, en 1853, lo haría Alberdi al acuñar en Argentina la tesis de que "gobernar es poblar", pero con europeos, luego de un análisis del todo racialista:

Aunque pasen cien años, los rotos, los cholos o los gauchos no se convertirán en obreros ingleses... En vez de dejar esas tierras a los indios salvajes que hoy las poseen, ¿por qué no poblarlas de alemanes, ingleses y suizos?... ¿Quién conoce un caballero entre nosotros que haga alarde de ser indio neto? ¿Quién casaría a su hermano a su hija con un infanzón de la Araucanía y no mil veces con un zapatero inglés? ${ }^{223}$.

En lo que se refiere al poblamiento de las fronteras internas, lo revisado en el presente texto demuestra cómo la visión aristocratizante determina las decisiones que se tomaron en un momento para atraer a los antioqueños como colonizadores del nororiente de la provincia del Cauca y también la forma como el gobierno de esa división territorial actuó ante la necesidad de poblar las inmediaciones del camino del Quindío.

222 Jaramillo, «El problema de los excluido, 50.

223 «Juan Bautista Alberdi: Padre Constitucional Argentino», Monografías.com, acceso el 06 de marzo de 2018, http://www.monografias.com/trabajos63/juan-bautista-alberdi/juan-bautista-alberdi.shtml. 
CAPÍTULO CUATRO 



\section{La presencia del Estado como modelador de una región}

En los dos anteriores capítulos se demostró respectivamente, que el poblamiento de la frontera nororiental de la provincia del Cauca entre 1840 y 1845, fue el resultado del impulso del Estado, en lo que de acuerdo a Reboratti se define como una colonización planificada oficial o colonización estatal a secas ${ }^{224}$, y el papel jugado por el Cauca como la periferia territorial y social que debieron penetrar las élites aristocráticas y neo patrimoniales, para consolidar su proyecto de Estado republicano unitario después de la Independencia ${ }^{225}$.

El objetivo general de este capítulo es visibilizar algunas formas de penetración del Estado neogranadino en el territorio de la República y en la provincia del Cauca, que invitan a revisar las generalizaciones sobre la supuesta ausencia de la institucionalidad en el tercer y cuarto decenio del siglo XIX y el carácter exclusivamente antioqueño del poblamiento de la Montaña del Quindío en el mismo lapso, y que también modelan el territorio en cuestión y contribuyen en doble vía a la construcción de un nuevo ordenamiento estatal.

Se busca lo anterior, por medio del alcance de los siguientes objetivos específicos:

- Revisar las decisiones que el Estado central neogranadino adoptó para conservar el orden público y cómo las mismas, expresadas en leyes y decretos,

224 Reboratti, «Fronteras agrarias»

225 Maiguashca, «Dirigentes políticos». 
determinaron el origen de los primeros pobladores de la denominada Montaña del Quindío.

- Mostrar la implementación de las normas nacionales en el ámbito de lo local, la forma como fue administrado el presidio de Boquía y dirigida la obra de reapertura del camino del Quindío, así como la solución de los problemas que debieron enfrentar las autoridades caucanas en el día a día.

- Describir la forma como los colonos antioqueños y las autoridades neogranadinas y caucanas interactuaron hasta lograr la fundación oficial de Santa Rosa de Cabal, por medio de la revisión de las representaciones y la correspondencia oficial.

\section{Normas que originan el poblamiento de la montaña del Quindío}

La confluencia de los esfuerzos normativos y administrativos del Estado central y el territorial, gracias a la comunión de intereses y proyectos de las élites dominantes en la década de los cuarenta del siglo XIX, contribuyó a la consolidación de un orden institucional republicano en la Nueva Granada. El poblamiento de la frontera nororiental del Cauca de entonces, es la mayor expresión de esa sinergia y la reapertura del Camino del Quindío, el establecimiento del presidio de Boquía y la fundación de Santa Rosa de Cabal, el modo de lograrla.

En desarrollo de lo que Maiguashca llama la penetración represiva y material del Estado neogranadino, el presidente Pedro Alcántara Herrán decide darle impulso a la reapertura del camino del Quindío, con la implementación de herramientas presupuestales y la utilización de recursos tales como el servicio personal obligatorio y la utilización de reos condenados a presidio, indultados y vagos concertados como mano de obra.

Desde el punto de vista de la colonización de los territorios baldíos del nororiente de la provincia del Cauca, lo anterior es importante, en tanto autores de muchas procedencias académicas y políticas reconocen en el establecimiento del presidio del tercer distrito en el sitio de Boquía, la semilla del poblamiento de la montaña del Quindío ${ }^{226}$. 
La presencia de quienes fueron llevados forzadamente para trabajar en la apertura del camino entre Cartago e Ibagué, es la primera en la zona durante el siglo XIX, junto con la de los atraídos por diversas prebendas ofrecidas para encargarse de los tambos o abrir fincas a lo largo de la "provincia caminera" para brindar seguridad a los viajeros ${ }^{227}$. Responder quiénes eran, por qué estaban condenados y de dónde venían los presidiarios, los indultados y los vagos que confluyeron en Boquía en la década de los cuarenta, sirve para develar la verdad sobre la supremacía de la población antioqueña y la forma como funcionaban el Estado central y el territorial.

\subsection{Presidiarios, vagos e indultados}

El artículo 18 del Código Penal de junio 27 de 1837, divide las penas en corporales y en no corporales, determinando que las primeras son en orden de severidad, la muerte, la de trabajos forzados, la de presidio, la de reclusión en una casa de trabajo, la de vergüenza pública, la de prisión, la de expulsión del territorio de la República, la de confinamiento en un distrito parroquial, cantón o provincia determinada y la de destierro de un lugar o distrito determinado ${ }^{228}$. A lo largo de todo el articulado se describen los delitos que hacen merecedor a quien incurra en uno de ellos, a cualquiera de las mencionadas penas corporales.

Posteriormente, el 4 de mayo de 1838 el Congreso de la República expide una ley que determina que cada una de las penas de trabajos forzados, presidio, reclusión y prisión, tendrá un establecimiento de castigo, cuya creación y ubicación son del resorte del Poder Ejecutivo. Del mismo modo, la ley autoriza la creación de distritos compuestos por varias provincias para establecer y sostener un presidio o una casa de reclusión, como el compuesto por Cauca, Antioquia, Chocó y Panamá e identificado como el tercero. ${ }^{229}$

La pena corporal de presidio consistía en realizar "trabajos de obras públicas todos los días a escepción (sic) de los festivos, por nueve horas diarias por lo menos, i (sic) podrá eximírseles del trabajo sino por un impedimento físico suficientemente comprobado”. Parte de la pena era llevar como única prisión, un grillete $^{230}$.

227 En el capítulo 3 se mencionan las normas expedidas para fomentar el poblamiento de las zonas aledañas al camino del Quindío.

228 Lino De Pombo, Recopilación, 174.

229 Lino De Pombo, Recopilación, 228.

230 Lino De Pombo, Recopilación, 176. 
De acuerdo con lo anterior, para la época de la investigación, iban a pagar la pena de presidio y, en este caso, podían ser remitidos al presidio del tercer distrito ubicado inicialmente en Panamá y luego en el sitio de Boquía en la provincia del Cauca, los que incurrieran en las siguientes conductas:

1. Fraude electoral, falsificación de billetes para el sufragio, cambio de los nombres de los sufragantes en los registros y sustracción de los votos para modificar los resultados (Art. 177).

2. Planeación de tumultos y vías de hecho para impedir el ejercicio de los derechos políticos en uno o varios cantones (Art. 183).

3. Incitar, sin éxito, a potencias extranjeras para que declaren la guerra contra la República de la Nueva Granada o sus aliadas (Art. 211).

4. Entregar, aprovechando el descuido o la negligencia del responsable, planos o diseños de fortificaciones, puertos o arsenales, a agentes de una nación extrajera, neutral o aliada (Art. 224).

5. Promover y dirigir motines (Art. 255).

6. Levantar sin facultad o legitimidad algún cuerpo de tropa armada, llamar a las armas a alguna parte de la guardia nacional o reclutar soldados o gentes para que se armen (Art. 262).

7. Apoderarse del mando de algún cuerpo de tropas, flota, escuadra, buque de guerra o puesto militar (Art. 263).

8. El que utilizando armas se resistiese o impidiere la ejecución de una ley, acto de justicia, reglamento u otra provindencia de autoridad pública (Art. 265).

9. Ser miembro de una cuadrilla de malhechores (Art. 279).

10. Quienes suministren armas, municiones u otros elementos o les den acogida a las cuadrillas de malhechores (Art. 280).

11. El que atente contra la vida de empleado o funcionario que no ejerza jurisdicción ni autoridad, pero que esté en cumplimiento de sus funciones (Art. 287).

12. El que impida al Presidente o al Vicepresidente de la República, Secretarios de Estado, tribunales o jueces, o cualquier otra autoridad con autoridad pública civil, militar o elcesiástica, en el libre ejercicio de sus funciones (Art. 302).

13. El que con amenazas o algún tipo de fuerza obligue al Presidente o al Vicepresidente de la República, Secretarios de Estado, tribunales o jueces, o cualquier otra autoridad con autoridad pública civil, militar o elcesiástica, de hacer algo, así sea justo (Art. 303). 
14. Los funcionarios públicos y las personas particulares que causaren daño a la salud pública, como consecuencia de la exhumación de un cadáver recién enterrado o que no lleve más de dieciocho meses de sepultado, por motivos diferentes a una diligencia judicial (Art. 349).

15. Los que cercenen las monedas de cobre u otro metal de circulación legal en la Nueva Granada o que de cualquier otro modo disminuyan su valor; así como el que las introduzca, expenda o circule a sabiendas de que han sido modificadas (Arts. 363, 364 y 365).

16. Los que cometieren falsedad en letras de cambio, conocimientos, pólizas, facturas, libros u otros instrumentos de comercio (Art. 391).

17. Los que cometieren falsedad en documento privado (Art. .95).

18. Los que malintencionadamente sustrajesen o destruyeren expedientes judiciales, libros y protocolos donde se asienten actas, acuerdos o registros u otro tipo de documentos custodiados en oficina u otro depósito público (Art. 415).

19. El que abra sin autorización o sin ser el otorgante, testamento o instrumento cerrado (Art. 417).

20. El que abra lo cerrado o rompa sellos, o destruya o sustraiga lo que está dentro de habitación, escotilla, o cámara de buque o caja, sellada por las autoridades para la custodia de su contenido (Art. 418).

21. El que finga ser funcionario o empleado público, civil, militar o eclesiástico, o agente de gobierno o comisionado y ejerciere como tal (Art. 424).

22. Los peritos o testigos que bajo la gravedad del juramente declaren falsamente en negocio civil (Art. 427).

23. El que mate a otro para evitar algún peligro, ultraje, violencia o deshonra grave contra él o los miembros de su familia (Art. 633).

24. El que, por medio de alimentos, bebidas o golpes, procure el aborto a alguna mujer sin su consentimiento (Art. 662).

25. La mujer embarazada que consiente el aborto, así sea en grado de tentativa (Art. 665).

26. El que de manera intencional maltrate a otro, hasta lisiar alguno de sus órganos, hasta generar la pérdida del mismo, enfermedad permanente e incapacidad (Art. 669).

27. El hombre soltero que rapte a mujer soltera menor de edad con su consentimiento (Art. 711).

28. El que fuerze a firmar testamento, entregar títulos o adquirir obligaciones en menoscabo de terceros (Art. 714).

29. El que cambie a un niño o que habiendo fallecido aquel, lo subrogue con otro (Art. 752). 
30. El que robe sin fuerza o violencia ropas, alhajas $\mathrm{u}$ otro tipo de elementos (Art. 801).

31. El que se introduzca a casa o lugar habitado sin escalar o forzar la entrada (Art. 812).

32. Quien con autorización o sin ella, organice una rifa y se quede con el premio o con el dinero recogido (Art. 850).

33. El que, al vender, cambiar o empeñar algo engañe o que al entregar la cosa la cambie por otra de menor valor (Art. 851).

34. El criado o doméstico que, abusando del conocimiento de las cosas de su amo, le cause daño por sí o por terceras personas (Art. 865).

Una variada gama de delitos determinó entonces, que personas de diversa condición y origen llegaran a Boquía, lugar donde se estableció la primera construcción que debía servir de albergue y depósito para los miembros del presidio del tercer distrito, que recibía reos provenientes de Antioquia, Panamá y del territorio correspondiente a la antigua gobernación de Popayán, y que para la época se había dividido en las provincias de Pasto, Buenventura, Popayán, Chocó y Cauca.

De todas esas regiones llegaban reos a purgar sus penas en el presidio de Boquía, junto con sus familias constituidas o sus concubinas de ocasión. Muchos al terminar sus condenas, se quedaban por las raíces de su entorno familiar o porque accesoria a la pena de presidio, pesaban también las de confinamiento y destierro. Esos, según los historiadores y cronistas, fueron los primeros pobladores del Quindío durante el siglo XIX.

Determinar su origen ayuda a saber qué tan prominente fue la influencia antioqueña en la población del Quindío en el decenio del cuarenta. Una revisión del número y origen de los reos llegados al presidio entre diciembre de 1843 y diciembre de 1844, es una herramienta útil para tal propósito.(Ver cuadro 3)

De acuerdo con el cuadro y el carácter fundador que la historiografía le da al establecimiento del presidio del tercer distrito en el sitio de Boquía, se debe decir que el componente antioqueño era minoritario, frente al volumen de individuos provenientes de otras provincias y en particular, frente al número de caucanos (29), que podrían ser más, si se asume que también son de ese territorio los que se reputan como de la misma provincia. 


\begin{tabular}{|c|c|}
\hline Lugar de Origen & Total \\
\hline Chocó & 2 \\
\hline Antioquia & 16 \\
\hline Cauca & 29 \\
\hline Buenaventura & 7 \\
\hline Panamá & 10 \\
\hline Pasto & 5 \\
\hline Misma Provincia & 10 \\
\hline Popayán & 7 \\
\hline Reincorporados & 1 \\
\hline Total & 87 \\
\hline
\end{tabular}

Cuadro 3. Presidio del Tercer Distrito, Boquía, Provincia del Cauca. ${ }^{231}$ CUADRO DE ALTAS (Ingreso de reos). Diciembre de 1843- diciembre de 1844.

Se confirma entonces lo planteado por la historiadora Olga Cadena, al manifestar que para la primera etapa de colonización del Quindío, el elemento antioqueño era minoritario y que solo en la década del setenta, la tendencia cambió con la fundación de Filandia ${ }^{232}$.

Es claro además, luego de la revisión documental, que los presidiarios y en particular los que iban para el tercer distrito en el sitio de Boquía, no gozaban -al menos en el lapso de esta investigación- de los beneficios planteados por cronistas e historiadores, entre los que se destaca Jorge Santos Forero, quien en 1930 dijo que el gobierno enviaba a la mencionada colonia penal a quienes habían completado la mitad de la condena y habían observado buena conducta ${ }^{233}$.

También contribuyeron al poblamiento del Quindío en el decenio del cuarenta, quienes se acogieron a los indultos ofrecidos por el Congreso de la República y el Poder Ejecutivo durante el transcurso de la Guerra de los Supremos, dentro del marco de las normas expedidas para la recuperación del orden público y la seguridad ciudadana.

231 Archivo General de la Nación. Sección República. Fondo Gobernaciones varias. Rollo 86, folio 521. Rollo 94. Folios 10, 12, 55, 155, 210, 283, 310, 319, 620, 675, 761, 899, 521.

232 Cadena Corrales, «Procesos de colonización en el Quindío».

233 Jorge Santos Forero, Armenia. Libro Histórico. Sociedad de Mejoras Públicas de Armenia (Manizales: Tipografía Cervantes, 1930), 89. 
La rama legislativa expide el 16 de abril de 1841, una ley que le permite a los gobernadores, entre otras muchas facultades, "separar del territorio de su mando" a quienes sean sospechosos de hacer parte o colaborar con la sublevación y sus caudillos ${ }^{234}$.

Cuando esta confrontación civil se extiende por casi todo el territorio nacional, el Congreso de la República expide el 7 de mayo de 1841, un decreto legislativo donde le concede facultades especiales al Poder Ejecutivo para "enfrentar la turbación del orden público en algunas de las provincias de la República"235.

El numeral $4^{\circ}$ de la mencionada norma le autoriza al Poder Ejecutivo, es decir, al Presidente de la República, conceder amnistías e indultos generales y particulares, con excepción de los gobernadores y caudillos responsables del alzamiento, a quienes se les podía otorgar por razones de conveniencia pública, con la condición de salir del territorio y solo volver con permiso del Congreso.

El siguiente artículo precisa que a los no exceptuados -combatientes, mandos medios, funcionarios y ciudadanos en general involucrados con la sublevación-, el Poder Ejecutivo los podría amnistiar e indultar en forma absoluta o parcial de las penas cometidas, imponiéndoles la condición de “...residir en el lugar y bajo la inspección de la autoridad que se les señale" ${ }^{236}$. En ambos casos, los amnistiados e indultados perderían el empleo público que estaban desempeñando en el momento de la rebelión.

El Presidente Pedro Alcántara Herrán expidió el 11 de julio de 1842, un decreto ejecutivo para reglamentar el otorgamiento del indulto a quienes -desde sargento primero hasta soldado raso- desertaron de las filas de cualquiera de las diferentes fuerzas del ejército nacional, con ocasión de la Guerra de los Supremos. Se debía pedir el indulto ante el gobernador de la provincia o el jefe militar del respectivo departamento y ellos mismos lo concedían. Los beneficiados quedaban libres, pero obligados a servir donde los destinaran las mencionadas autoridades, por seis años.

Indultados de todas las condiciones llegaron por cuenta de esas normas al cantón de Cartago y se involucraron en la construcción del camino del Quindío y en el manejo del presidio de Boquía, con lo cual lograban que el gobernador del Cauca

234 Gaceta De La Nueva Granada. Trimestre 38. Bogotá, 18 de abril de 1841. № 501.

235 Gaceta De La Nueva Granada. Trimestre 38. Bogotá, 9 de mayo de 1841. No 504.

236 Gaceta De La Nueva Granada. Trimestre 38. Bogotá, 9 de mayo de 1841. No 504. 
les tramitara la rebaja del tiempo de confinamiento o de destierro a que estaban sometidos.

De la documentación encontrada en archivos históricos, se evidencia el papel jugado por los gobernadores de provincia en lo relacionado con los indultos y en particular, la forma como esa política fue aprovechada en el Gobierno del Cauca, para fortalecer la fuerza laboral empleada en la reapertura del Camino del Quindío.

Un ejemplo es la forma como el gobernador Jorge Juan Hoyos Cabal aboga ante el Secretario del Interior, para que se conceda el indulto a Calixto Lazo e Ignacio Jiménez, procesados por rebelión, a cambio de seis meses de trabajo en el Quindío ${ }^{237}$.

Otra evidencia de la capacidad de maniobra del gobernador provincial, es el caso ya referenciado del indultado Ciriaco del Villar quien, como vimos en el cuarto capítulo, fue comisionado accidentalmente como director provisional del presidio de Boquía, mientras se creaba el cargo y asumía el titular; situación en la cual podría luego servir de proveedor o capataz en los trabajos del Camino del Quindío ${ }^{238}$.

Del joven sujeto habla muy bien Hoyos Cabal, debido a su buena conducta, sin importar que estaba incluido en la lista de individuos indultados durante la Guerra de los Supremos por el gobierno, con la condición de salir del territorio de la Nueva Granada $^{239}$. Se concluye que Ciriaco del Villar era de aquellos que, a pesar de haber sido líderes de la rebelión, fueron indultados por razones de conveniencia pública, con la condición de salir de la Nueva Granada; pero que por alguna razón terminó confinado en el Canton de Cartago, sin medio de subsistencia.

Los indultados, dada la calidad letrada de muchos, fueron utilizados en las obras de apertura del Camino del Quindío para ejercer responsabilidades administrativas que no eran fáciles de encomendar a personas de la zona, porque no les interesaba, tal como señalan por separado Juan Maiguashca y Uribe-Urán, o por la escasa instrucción de los "paisanos".

El 26 de julio de 1843, el Gobernador Jorge Juan Hoyos Cabal le solicita a la Secretaría del Interior y Relaciones Exteriores, autorizar el indulto solicitado por el señor Ignacio Jiménez a la Gobernación del Cauca, a cambio de trabajar en las

237 A.G.N. Sección República. Fondo Gobernaciones varias. Rollo 86. Fl. 298.

238 A.G.N. Sección República. Fondo Gobernaciones varias. Rollo 86. fl. 368.

239 Gaceta De La Nueva Granada. Trimestre 38. Bogotá, 9 de mayo de 1841. No 504. 
obras de la mencionada vía. "Este individuo merece que se le rebaje la tercera parte que le resta del tiempo que fue condenado, por haber desempeñado con honradez el destino de comprador de víveres para el presidio, asistiendo a los enfermos con el mismo esmero"240, fundamenta el mandatario provincial.

Los gobernadores debían estar atentos de la llegada de los indultados a su territorio, como lugar del confinamiento, y en caso de que no llegaran debían procurar su aprehensión. Así ocurrió en marzo de 1842 con Jesús María Caicedo, quien debió llegar a Cartago para cumplir con su confinamiento y no lo hizo. Luego de informar sobre esa situación, el gobernador Hoyos Cabal fue instruido por parte del Secretario Ospina para que procediera con él e informara al gobernador de Mariquita para que lo buscara y aprehendiera en los cantones del sur de esa provincia, donde se creía que estaba oculto. ${ }^{241}$ Posteriormente, el 19 de abril de 1844, Hoyos Cabal informaba al Secretario Ospina que había exhonerado a Jesús María Caicedo de su obligación de servir en la obra del Camino del Quindío, impuesta como condición para obtener la gracia del indulto ${ }^{242}$.

Trabajar en las obras de reapertura del camino del Quindío era la mejor carta de presentación para cualquiera que deseara acceder al indulto. Hoyos Cabal, al hablar del señor Norberto Hernández, un individuo que le solicita reconfirmar su condición de indultado y su habilitación para gozar de sus derechos ciudadanos, le dice al Secretario del Interior y Relaciones Exteriores, Mariano Ospina Hernández: "Este individuo ha observado buena conducta, está dedicado al trabajo i (sic) es uno de los que ha servido en la apertura del camino del Quindío"243.

Es claro entonces, que quienes obtenían algún beneficio por venir a la montaña del Quindío eran los involucrados en el bando rebelde y vencido en la Guerra de los Supremos, que no eran presidiarios y que lograban acortar su período de confinamiento con su colaboración en las obras del camino entre Cartago e Ibagué y en tareas administrativas y operativas en el presidio del Quindío.

Otro grupo que pudo haber contribuido al poblamiento inicial del Quindío fue el de los llamados vagos, que como se mencionó antes, constituían un problema de marca

240 A.G.N. Sección República. Fondo Gobernaciones varias. Rollo 86. Fl. 668.

241 A.G.N. Sección República. Fondo Gobernaciones varias. Rollo 86. Fl. 381.

242 A.G.N. Sección República. Fondo Gobernaciones varias. Rollo 94. Fl. 791.

243 A.G.N. Sección República. Fondo Gobernaciones varias. Rollo 94. Fl. 926. 
mayor para las autoridades de la época, tal como lo evidencia la caracterización hecha en el artículo 29 de la Ley del 3 de mayo de 1826, citada en capítulo anterior.

A comienzos de la República, la vagancia como consecuencia de la norma citada ya era un delito, pero su castigo fue considerado por muchos impracticable e inadecuado para afrontar la magnitud del problema, ya que la pena era condenar al individuo a servir en la Marina, que no existía en los primeros años del nuevo Estado $^{244}$.

Posteriormente, con la expedición de la Ley del 6 de abril de 1836, se disponen en el artículo 10, las siguientes condenas:

1. A servir en calidad de concertados con individuos particulares o de establecimientos públicos por un tiempo de dos a seis años, o al servicio de las armas... 2. A trabajar en el presidio urbano de la provincia, si lo hubiere establecido, o al de otra provincia inmediata, por el tiempo de uno a tres años con arreglo a la ley sancionada el 30 de mayo de 1835. 3. A formar nuevas poblaciones o caseríos en parajes desiertos o baldíos, a las orillas de los caminos públicos, o aumentar las poblaciones ya establecidas; proporcionándoles por cuenta de las rentas provinciales, aquellos auxilios indispensables para su establecimiento y subsistencia, según los decretos que al intento expedirán las cámaras de provincia ${ }^{245}$.

Cuando el gobierno del Presidente Pedro Alcántara Herrán decide emprender la reapertura del Camino del Quindío, no solo promueve la expedición por parte del Congreso de la República de la Ley 3 del 27 de mayo de 1842, ya mencionada. También firma el decreto ejecutivo del 15 de junio del mismo año sobre la composición y mejora de la vía en cuestión, con la cual señala a los vagos como mano de obra para esos trabajos y para el establecimiento de poblados en su área de influencia. El artículo 25 del decreto citado dice:

Todos los individuos que por vagos fueren destinados en la Provincia de Mariquita a fundar nuevas poblaciones, en virtud de lo dispuesto en el artículo $1^{\circ}$ de la Ley de 14 de junio último, lo serán en la nueva población que en el camino del Quindío debe crear la misma Provincia. Los individuos que

244 A.G.N. Sección República. Fondo Gobernaciones varias. Rollo 94. Fl. 926.

245 A.G.N. Sección República. Fondo Gobernaciones varias. Rollo 94. Fl. 926. 
en los mismos términos fueran destinados en la provincia del Cauca a nuevas poblaciones, lo serán a la del camino del Quindío en la misma provincia ${ }^{246}$.

El 31 de marzo de 1843, Herrán expidió un nuevo decreto sobre el concierto de los vagos destinados a trabajar en el Camino del Quindío, debido a dificultades presentadas para sacar el mejor provecho de esa mano de obra para la reapertura de la vía y al mismo tiempo beneficiarla con el aprendizaje de un oficio y con el hábito del trabajo ${ }^{247}$.

La norma ejecutiva autorizó al director del Camino del Quindío a recibir en concierto a los vagos para trabajar en el camino "...y en las obras y establecimientos que en él deben hacerse...” También les concede ración, vestido y atención médica en caso de enfermedad a los concertados, todo financiado con los fondos del camino.

Del mismo modo, precisa que las condiciones con las que se concerta un vago para trabajar deberán ser dejadas por escrito, subrayando como condición especial, el trabajo diario que deberá realizar para que el desempeño pueda ser juzgado por el director, que incluirá del mismo modo en el mencionado documento, "los medios coercitivos de que podrá usarse para obligar al vago a trabajar y a mantenerlo sujeto". En virtud de ese acto del ejecutivo, los gobernadores de Mariquita y el Cauca quedaron facultados para expedir los reglamentos y órdenes necesarias para el mejor aprovechamiento del trabajo de los vagos, que como vimos atrás, eran considerados por el gobernador del Cauca como un grupo de indeseables, no aptos para el cometido de abrir el Camino del Quindío y poblar la comarca aledaña.

Presidiarios, indultados y vagos, junto con los miembros de familias llegadas al Cauca de otras provincias, atraídas por los estímulos ofrecidos a cambio de manejar los tambos y tierras aledañas al camino, iniciaron a mitad del siglo XIX la aventura de poblar la montaña del Quindío. A pesar de que estaban expuestos a un medio inhóspito y al trabajo obligatorio, muchos de ellos reconstruyeron sus vidas y echaron raíces, trayendo consigo sus costumbres, sus tradiciones, sus dietas alimenticias y su manera de relacionarse con el entorno.

En la mayoría de los casos, el medio que inicialmente los recibió fue el presidio de Boquía; más que un sitio, una comunidad con grilletes que se desplazaba

246 Gaceta De La Nueva Granada. Bimestre 43. Bogotá, jueves 21 de julio de 1842 (№ 567)

247 Jaime José Grisales Otálvaro, «El Camino del Quindío en la conformación de la región» en Historia de nuestra región. La Historia del Quindio. (Armenia: Editorial La Crónica (s.f.)), 40. 
constantemente entre Cartago y la cumbre de la Cordillera Central, que era el tramo del camino del Quindío que les correspondía abrir y mantener.

\subsection{Presidio y camino: Las normas y su aplicación en la Montaña del Quindío}

Cruzar lo dispuesto por las normas de la época para los presidios, con lo reflejado por la correspondencia oficial, permite conocer la forma como se administraba el de Boquía y la vida que llevaban los reos del mismo y los indultados y vagos asociados a la apertura de la vía. El 30 de mayo de 1838, el Congreso de la Nueva Granada había expedido la Ley 4 sobre los establecimientos de castigo, que en consonancia con lo dispuesto por el código penal de la época, los clasificaba y precisaba las particularidades de cada $\mathbf{u n o}^{248}$.

Tal como lo decía la normatividad penal, los establecimientos de castigo eran: a) Trabajos forzados; b) Los de presidio; c) Las casas de reclusión, y d) Los lugares de prisión. Su ubicación la definía el Poder Ejecutivo, es decir, el Presidente de la República, que tenía en los presidios - como el de Boquía- una herramienta importante para impulsar el progreso, si nos atenemos a lo dicho en el artículo 10 de la Ley de establecimientos de castigo: "En un distrito compuesto por dos o más provincias, los reos del presidio podrán ocuparse en las obras públicas de cualquiera de ellas, pero cada una sufragará el transporte desde donde esté el presidio hasta donde debe hacerse el trabajo" ${ }^{249}$. Posteriormente, la Lei (sic) 5 del 16 de abril de 1839, en su artículo único, “...Autoriza al Poder Ejecutivo a designar las provincias y lugares donde se establezcan los trabajos forzados, los presidios, las casas de reclusión y de prisión" 250 .

También era el Presidente de la República el que decidía dónde haría los trabajos el presidio, si varias provincias de un solo distrito solicitaban el respaldo de esa mano de obra para sus obras públicas. Si la concurrencia de solicitudes se daba al interior de una provincia, era el gobernador de aquella el que definía dónde trabajarían los reos.

Del mismo modo, la ley de establecimientos de castigo en su artículo $4^{\circ}$, definía el tipo de edificios que debían escogerse para el funcionamiento de los presidios,

\footnotetext{
248 Lino De Pombo, Recopilación, 228.

249 Lino De Pombo, Recopilación, 228.

250 Lino De Pombo, Recopilación, 228.
} 
los de trabajos forzados y las casas de reclusión: a) Edificios que hubieran servido de presidio; b) Edificios del Estado, que sea necesario adecuarlos para el efecto; c) Edificios que no se les hubiera dado otra destinación; d) Conventos suprimidos que no se hubieren adjudicado o que adjudicados, no se hubieren destinado como locales para colegios o casas de educación.

\subsubsection{La vida en el presidio de Boquía.}

La norma mencionada regulaba aspectos que impactaban la forma de vida de los reclusos de los estalecimientos de castigo. En el caso de los presidiarios, el artículo 17 indicaba que estos usarían obligatoriamente el vestuario suministrado, que era de dos piezas de distinto color cada una. También determinaba que los condenados recibirían dos comidas al día y que estas podían ser contratadas con particulares, al tiempo que definía un régimen de castigos.

El artículo 18 de la Ley comentada decía que la negativa de un reo a trabajar, la insubordinación y la inobediencia (sic), serían castigadas con las siguientes penas, según la gravedad: a) Encierro solitario; b) Privación de cama; c) Cepo; d) Disminución de alimento; e) Reducción a pan y agua por un día, y f) Golpes de látigo en la espalda: dieciseis por día a los presidiarios. La última pena no podía ser aplicada por quien ordenó el castigo y su ejecución solo se podía hacer, luego de que deliberara un consejo compuesto por el director del presidio y dos empleados más designados por el Poder Ejecutivo ${ }^{251}$.

De acuerdo con la ley sobre establecimientos de castigo, la vida era muy dura para un presidiario. Los reos, por ejemplo, tenían prohibidos los pasatiempos y la recreación "que no sea inocente" y el esparcimiento estaba restringido a las horas de descanso; mientras se autorizaba la ingesta de licor en pequeñas cantidades, según el clima y los alimentos que les estuvieran suministrando (Art. 21).

En los días festivos, según la Ley (Art. 22), los presidiarios debían asistir "a los oficios divinos", si no atentan contra la seguridad: "Un sacerdote les explicará el evangelio y la doctrina cristiana, exhortándolos a la resignación, a la virtud i (sic) a toda especie de prácticas morales". Para esos días, el director del presidio tenía otra obligación (Art. 23). En compañía de los capataces, debía dar a los reos lecciones de lectura, escritura, aritmética y moral (árt. 23) ${ }^{252}$.

251 Lino De Pombo, Recopilación, 229.

252 Lino De Pombo, Recopilación, 229. 
Durante las horas de trabajo los presidiarios debían guardar silencio y también cuando fuese necesario para preservar el orden del establecimiento de castigo, propósito que hacía aconsejable, si fuese posible, mantener a los reos separados en las noches (Art. 24).

Los estabecimientos de castigo, incluyendo los presidios, tenían una estructura administrativa definida por la Ley 4 del 30 de mayo de 1838. Un director y un número de capataces, a razón de uno por cada quince presidiarios, debían encargarse de la administración del presidio (Art. 25).

Los capataces ganaban por ese trabajo entre setenta y dos y ciento veinte pesos anuales. Eran nombrados por el gobernador de la provincia, de terna presentada por el director del presidio (Art. 27). Según el inciso segundo del artículo 28 de la mencionada ley, los capataces tenían los siguientes deberes: a) Estar subordinados al director del presidio; b) Cuidar más inmediatamente de la seguridad de los presos; c) Hacer trabajar a los presidiarios en las horas debidas, y d) Mantener el orden y la mejor disciplina ${ }^{253}$.

El director del presidio, por su parte, tenía sus obligaciones definidas en el inciso primero del artículo citado, que consistían en: a) Gobernar los establecimientos como sus jefes superiores; b) Hacer que los reos cumplan las condenas según la ley y los reglamentos, y c) Cuidar de la seguridad de los presidiarios y de que el suministro de alimentos y vestuarios se hiciera oportunamente. El mencionado funcionario, de acuerdo a la lei (sic) 7 del 19 de abril de 1842, ganaba entre quinientos y mil pesos anuales.

Los gobernadores de las provincias tenían la misión de asegurar el funcionamiento adecuado de estos establecimientos de castigo. Según lo dispuesto por la ley que los regulaba, estos funcionarios debían visitar los presidios una vez al mes, si éste estuviera establecido en la capital provincial, y una vez cada seis meses si se ubicaba fuera de ella (árt. 29). De estas diligencias el gobernador debía pasar un informe detallado al Poder Ejecutivo.

Pero la ley no solo les entregaba esa responsabilidad a los gobernadores. También los jefes políticos de los cantones y los alcaldes de los distritos parroquiales tenían esa responsabilidad. Los primeros, debían practicar la visita cuando los presidios estuvieran en la cabecera del cantón o a una legua o menos del mismo y los segundos, 
cada semana o con más frecuencia si fuera posible, cuando el presidio realizara trabajos o se estableciera en su jurisdicción.

La Ley 4 del 30 de mayo de 1838 también hace precisiones sobre ciertos gastos, como en los que se incurre cuando un reo termina su condena y no tiene cómo pagar su traslado del presidio hasta su nuevo destino, o el generado por desplazamiento del presidiario prófugo que regresa al establecimiento de castigo. En la primera situación, los gastos corren por cuenta del fondo del respectivo presidio, por orden del gobernador de la provincia, y en la segunda se financia con recursos del tesoro nacional (árt. 32).

Después, con la lei (sic) 6 del 24 de mayo de 1839 se precisan los gastos y de dónde salen los recursos. De su lectura se desprende que sale del Tesoro Nacional el dinero para los alimentos, vestuarios, prisiones y herramientas para el trabajo de los reos, el salario de los empleados y la construcción de edificios. Lo mismo ocurre con los gastos de estancia de los presidiarios que pasan al hospital, que se deberán pagar también del presupuesto nacional, a razón del valor equivalente a una ración para reos y una mitad más.

La lectura de esta normatividad nos bosqueja un panorama de cómo debía ser la vida en los presidios y en particular, de cómo debía ser el día día en el de Boquía. Un cuadro que hace presentir la dureza de la vida en esos establecimientos de castigo, pero que al revisar la correspondencia oficial sobre el manejo del presidio de Boquía, se ilumina para mostrar otra realidad, quizas más cruel, que devela hasta dónde ese grupo de reos peregrinos se convirtió en el núcleo poblador de la montaña del Quindío en la mitad del siglo XIX.

\subsubsection{La penuria económica en el presidio.}

Uno de los primeros aspectos que permiten examinar la correspondencia oficial entre el gobernador del Cauca Jorge Juan Hoyos Cabal y el secretario del interior Mariano Ospina Rodríguez, es el presupuestal. Las dificultades económicas entorpecían la labor de los encargados del presidio de Boquía y por la misma razón, impedían el desarrollo adecuado de los trabajos en el camino del Quindío.

Fueron muchas las cartas que debió enviar Hoyos a Ospina pidiéndole la remisión de los recursos para el pago de la construcción de la primera casa que se construyó en Boquía para el funcionamiento del presidio, que el funcionario adelantó de sus propios recursos, debido a la urgencia de la obra. Tal como se vio atrás, entre 
Cartago y la cima de la cordillera Central no había dónde guarecerse de las difíciles condiciones climáticas.

El 11 de julio de 1843, Hoyos le escribe a Ospina:

Que los 1200 pesos valor de la casa de Boquía, debe ser pagados conforme el contrato del modo siguiente: 600 anticipados luego que se cerró el contrato i el resto cuando se le entreguen las llaves de la casa a nuestra satisfacción, el primer contado lo pagué yo, para que no hubiese demora i (sic) $2^{\circ}$, deberá ser satisfecho en el presente mes o a principios de agosto en que se entregará la casa, por lo cual he presupuestado el gasto de los mil doscientos pesos, para $\operatorname{agosto}^{254}$.

Un mes después, el gobernador del Cauca vuelve a escribirle al secretario del interior: "Ha sido imposible que los seiscientos pesos que se dieron al individuo que construye la casa de Boquía hayan sido reintegrados por la Tesorería de hacienda de esta provincia, porque hasta la fecha no se ha recibido de la general, ni un real para la obra del Camino del Quindío...” El 29 de agosto de 1843, Ospina Rodriguez ordena al margen de la carta de Hoyos:

Remítase por la Tesorería general a Cartago, los quinientos pesos que se anticiparon por el gobernador del Cauca para el pago de la casa construida en Boquía, para servicio del presidio i (sic) para que sirva de tambo en el camino. La misma se tomará de la partida destinada por lei (sic) de gastos para el camino del Quindío ${ }^{255}$.

De la lectura de la correspondencia mencionada se concluye que el gobernador Hoyos Cabal valoraba en grado sumo el papel de los peones contratados con los recursos que ingresaban por concepto del servicio personal obligatorio que desde 1843 empezó a ser pagado en dinero por las clases 1,2,3, en el avance de los trabajos del camino del Quindío. Una mano de obra a la que ponía a interactuar con los reos del presidio, para lograr los mejores resultados.

En un informe que le envía al secretario del interior el 7 de mayo desde Cartago, el gobernador precisa que:

254 A.G.N. Sección República. Fondo Gobernaciones Varias. Rollo 86. Folio 629.

255 A.G.N. Sección República. Fondo Gobernaciones Varias. Rollo 94. Folio 528. 
En el mes de abril han (sic) habido de 30 a 35 peones diarios de trabajo, i (sic) se han ocupado de abrir i desmontar los alrededores del tambo de Consotá a donde se pasó el presidio a fin de marzo, tanto para obtener mayor ventilación, como para sembrar todo el espacio descuajado: En sembrarlo de maíz i (sic) yuca, i preparar el terreno para plátanos, arracacha, batatas i papas; en hacer las casas o ranchos para cocina, i para la dirección; en recoger el empajado que por lo fuerte del invierno, i efectos de construcción, dejaba pasar el agua, en desmontar cuatro cuadras de largo i veinte varas de ancho hacia Boquía, i como seis cuadras de largo i cincuenta varas de ancho en la vega del río Consota por donde viene el camino para Cartago; en hacer dos canoas, carbón para la herrería, i refaccionar las piezas de herramienta que se han dañado ${ }^{256}$.

El mismo informe muestra la voluntad de hacer del tambo de Consota una importante estación del camino del Quindío, lo que suscita un comentario favorable del presidente de la República Pedro Alcántara Herrán, según lo dice al margen del reporte Ospina: “...Estima también (el presidente) muy oportunas las medidas de hacer una labranza en Consota que suministre varios artículos de subsistencia para sostener el establecimiento..."

Aunque la Presidencia de la República pretendía, a través de la secretaría del interior, ejercer un estricto control sobre el manejo del presidio del Quindío y su contribución a la construcción del Camino del Quindío, había muchas decisiones que legalmente podían tomarse en el ámbito local, pero que en la práctica terminaban siendo adoptadas con el concurso del gobierno central, como ocurría con la "construcción" de los vestidos de los reos del presidio de Boquía.

A instancias de Hoyos Cabal, que solicita autorización para proveer de setenta vestidos completos a los reos de Boquía, cuya entrega debió haberse realizado en marzo; el 24 de mayo de 1844, la junta de hacienda de la provincia del Cauca, reunida en Buga, acuerda que:

se fijen carteles en Buga y Cartago por el término de ochos días para provocar contratistas, i (sic) en caso de que pasado el término fijado no se presentasen posturas, se autoriza al señor gobernador para que contrate los jéneros (sic) para construcción de los vestuarios, pidiendo la cantidad necesaria a la tesorería de hacienda" 257 .

256 A.G.N. Sección República. Fondo Gobernaciones Varias. Rollo 94 Folio 846.

257 A.G.N. Sección República. Fondo Gobernaciones Varias. Rollo 94 Folio 891. 
Los vestidos se componían de calzón de manta, camisa de lienzo del país, sombrero de caña y una cobija. Tanto la camisa como el pantalón debían ser de diferente color. Meses después, por medio del oficio 49 del 30 de diciembre de 1844, el gobernador Hoyos le solicita al Secretario del Interior Mariano Ospina Rodríguez, gestionar la "construcción de setenta vestidos para el presidio del Quindío, en vista de que en Bogotá salen más baratos" 258 .

Ya para el segundo semestre del año anterior, el gobernador del Cauca había advertido esa realidad de la economía neogranadina y por tanto ya le había solicitado al secretario del interior su ayuda para conseguir un vestuario más barato. Desde Cartago, Hoyos Cabal le escribe a Ospina el 4 de julio de 1843:

(...) manifiesto a usted que es económico que se construya el vestuario de los presidiarios y vagos en Bogotá, pues aquí son los jéneros (sic) más caros. Actualmente he comprado la manta del Socorro a once pesos pieza, que es el mejor precio a que se obtiene aquí, i (sic) a este respecto el corte de un patanlón vale cinco reales y medio, su hechura vale por lo menos dos reales, fuera de la obra que importará cuatro octavos, mientras que en Bogotá, pueden conseguirse los pantalones a cinco o seis reales i no teniendo de costo una carga sino de catorce o diez y seis pesos, en la cual pueden venir doce piezas de manta o ciento sesenta pantalones, el aumento del valor de cada pantalón sería de dos cuartillos i ocho décimos ${ }^{259}$.

Agrega Hoyos que para las camisas de bayeta ha comprado ya el "jénero" "que saldrá a igual precio que el que pudiera lograrse en Bogotá i (sic) de mejor calidad por ser bayeta ecuatoriana" 260 . Del mismo modo, advierte que las frazadas deben comprarse en Tunja, pues son más económicas:

Aquí se venden a ocho reales una, cuando están más baratas, i (sic) no pueden reemplazarse sino con jerga de Pasto que costará por lo menos dos reales i (sic) medio la vara en Popayán i su conducción catorce pesos por carga, debiendo resultar aquí a tres reales por vara por lo menos i que sería nueve para cada cobija.

Al margen de la solicitud, Mariano Ospina Rodriguez ordena en 18 de julio de 1843:

258 A.G.N. Sección República. Fondo Gobernaciones Varias. Rollo 94 Folio 349.

259 A.G.N. Sección República. Fondo Gobernaciones Varias. Rollo 94 Folio 349.

260 A.G.N. Sección República. Fondo Gobernaciones Varias. Rollo 86. Folio 608. 
Encárguese a la gobernación de Bogotá que haga construir i remita a Ibagué con dirección a Cartago para el presidio del tercer distrito ochenta pantalones de manta i (sic) otras tantas frazadas. Procediendo en los términos acostumbrados para la provisión de vestidos para los presidiarios. El gasto se deducirá del fondo respectivo comprendido en la parte treceava, artículo primero de la lei (sic) de 3 de junio de 1842"

Pero es que, en la misma omisión, en cuanto a la entrega del vestuario correspondiente al mes de marzo de 1844, se había incurrido en 1843, de acuerdo con lo expresado en uno de los informes del gobernador del Cauca al secretario del interior Ospina Rodríguez, identificado con el número 52 y despachado desde Cartago el 28 de marzo del mencionado año:

Los presidiarios del tercer distrito se enuentran sin vestido i (sic) sin cama, no recibieron el $1^{\circ}$ de marzo el vestido que prescribía el reglamento; i cama, parece que nunca hubieran recibido, porque el reglamento no habla de este gasto. Creo necesario vestirlos de pantalón de manta del Socorro, i blusa de bayeta en vez de camisas. En atención al temperamento en que van a vivir i al desabrigo con que estarán frecuentemente por la noche, no pudiendo alojarse en la casa sino los meses de invierno, por la distancia de ella del lugar de trabajo, por igual causa me parece conveniente que se les dé un cuero de obeja (sic) a cada uno, una frasada, i un encerado i un costal de cabuya ${ }^{261}$.

Hoyos Cabal agrega, demostrando una gran consideración por la suerte de los reos que "No pudiendo, como he dicho, volver cada noche a la casa del presidio luego que se aleje el trabajo es necesario costear dos toldos, por lo menos que le sirvan de abrigo..."; para concluir con preocupación que "...Me encuentro en una situación penosa, sin recursos, ni aún para lo más indispensable, como son las herramientas i (sic) sin poder utilizar debidamente el trabajo de los presidiarios ni el de los habitantes de este cantón. He jusgado (sic) que esto es consecuencia de la escacez (sic) del tesoro, he esperado, pero ya me vi forzado a hablar i representarlo..."262

El 11 de abril de 1843, el secretario del interior Mariano Ospina Rodríguez, resuelve:

1. La gobernación del Cauca dictará órdenes consecuentes para que se dé a la mayor brevedad posible un vestido de pantalón de manta i blusa de

261 A.G.N. Sección República. Fondo Gobernaciones Varias. Rollo 86. Folio 388.

262 A.G.N. Sección República. Fondo Gobernaciones Varias. Rollo 86. Folio 388. 
bayeta a los reos del presidio del tercer distrito, observando para ello las reglas establecidas. En los mismos términos se les proveerá de una frasada, un sombrero de paja, un encerado i (sic) una estera i un cuero para cama. 2. La misma gobernación hará construir o comprar dos toldos, veinticinco candados, cuatro garrochas, doce carretas, cuatro limas i serruchos brasileros i cuatro ídem menores. Los libros que deberán quedarse conforme al decreto que arregla los establecimientos de castigo i los útiles de escritorio que sean absolutamente indispendables. 3. Si alguno de estos gastos se hubiese hecho por acuerdo de la junta de hacienda no se harán, sino los restantes que fuesen necesarios, en uno i otro caso se dará cuenta de su importe y se deducirá de la partida destinada para gastos de los presidios. 4. La gobernación remitirá oportunamente al gobierno sobre los gastos que en cada mes deban hacerse en el presidio ${ }^{263}$.

Otros de los conceptos que hacían parte de las partidas del presupuesto del presidio de Boquía, eran las raciones para el sustento de los reos y los sueldos de los empleados del mismo, que se financiaban de los fondos del establecimiento de castigo y del dispuesto para construcción del camino del Quindío.

Sin embargo, en algunos momentos de crisis, como la planteada por Hoyos Cabal en marzo de 1843, la junta de hacienda de la Gobernación del Cauca debió aprobar, a instancias del gobernador, gastos extraordinarios para sufragar el costo de las raciones de los reos y los sueldos de los empleados, ${ }^{264}$ y así siguió siendo después, aunque se giraba contra los recursos de los fondos nacionales destinados al mantenimiento del presidio y la construcción del camino del Quindío.

Un ejemplo de lo anterior es la relación fechada en Cartago el 7 de febrero de 1844 de gastos extraordinarios enviada por Hoyos a Ospina para su aprobación, que incluye algunos del presidio de Boquía, la construcción del camino y el poblamiento de la Montaña del Quindío:

$3^{\text {a }} \mathrm{Al}$ reo Gregorio Chilinguas, vecino del distrito parroquial de Pastal, cantón de Túquerres, provincia de Pasto, condenado por el Tribunal del Cauca en 17 de noviembre úitmo a 18 meses de presidio por el delito de hurto. En su marcha de Buga a Cartago se le ordenó racionar por los dias 20, 21 i (sic) 22 por tener una ración sobrante para el $19 \ldots 5^{\text {a }}$ Los reos Lucas Collado i 
Antonio Pedroza condenados, el primero a tres años, once meses, once días, i dos horas de presidio en el tercer distrito, por el Tribunal del Istmo el 23 de diciembre de 1843, avecindado en La Gorgona, natural de Chagres, provincia de Panamá, por injurias en público a una autoridad. El segundo, a cuatro años de igual pena en el mismo establecimiento por la Suprema Corte por el delito de inobediencia. Fueron racionados para cuatro días de marcha de Buga a Cartago i además por los días 23 i 24 que permanecieron en la cárcel de Buga... $7^{\mathrm{a}} \mathrm{Al}$ reo Francisco Nejo se mandó a racionar por nueve días de permanencia en la cárcel de Buga, condenado por el Tribunal del Cauca en 16 de diciembre último a un mes de presidio en el del tercer distrito, por el delito de hurto. Este reo fue enviado por la gobernación de Buenaventura, i no se remitió al establecimiento indicado porque en la misma cárcel de Buga cumplió su condena ${ }^{265}$.

En estos casos, el secretario del interior, por lo general, autorizaba la deducción del fondo respectivo, de acuerdo con la legislación vigente.

Otra circunstancia relevante para anotar, era que como la alimentación se le debía suministrar no solamente a los reos, sino también a sus capataces y a los vagos concertados a trabajar en el camino del Quindío o a formar poblaciones en esa comarca, una sola proveeduría la suministraba. Por esa razón,

la compra de los víveres se ha hecho provisionalmente del fondo del camino i (sic) cada seis meses se prorratean los gastos según el número de raciones suministradas para presidiarios, i capataces i vagos concertados, ordenándose en consecuencia un reintegro al fondo del camino que se hace del fondo de gastos del presidio ${ }^{266}$.

Un aspecto importante del tema de las raciones para los reos, era la forma como el precio de los mismos cambiaba según el lugar donde fueran a ser suministradas. En una comunicación enviada desde Cartago por el gobernador Hoyos a Ospina el 31 de diciembre de 1844, lo anterior se expresa con claridad: "La ración que reciben los presidiarios en el día en la montaña del Quindío, vale más de un real, contando el valor principal de los víveres, el transporte i (sic) los gastos de distribución i preparación.

A.G.N. Sección República. Fondo Gobernaciones Varias. Rollo 94. Folio 612. 
La carta mencionada tenía como propósito que Ospina aclarase si el gobernador estaba facultado para autorizar hasta un real más del valor de la ración ordinaria. Como un aporte a la conciliación de las disposiciones fiscales, Hoyos Cabal le propuso al secretario del interior que "...se haga del fondo especial del camino el gasto de víveres i (sic) su transporte, o el pago de contratas si se logran estas, i que mensualmente sea reintegrado dicho fondo por el de gastos del presidio, de un real por cada ración suministrada..." El secretario del interior contesta el 21 de enero de 1845:

El esceso (sic) sobre un real diario en la ración suministrada a los presidiarios del tercer distrito, se cubrirá del fondo señalado para gastos del camino del Quindío por el artículo $2^{\circ}$ de la lei (sic) del 3 de junio último. Al efecto la gobernación informará a que suma asciende este esceso en el año económico"267.

En cuanto a los capataces del presidio del tercer distrito (Boquía) encargados de manejar grupos de quince reos para garantizar la realización de los trabajos encomendados, su salario no sufría descuento alguno, por disposición del secretario del interior Mariano Ospina Rodríguez, quien el 20 de junio de 1843 ordenó que: "El sueldo de los capataces de los presidios del 1er y 3er distrito que trabajan en la montaña del Quindío, debe pagárseles íntegramente sin descuento alguno”268.

La decisión la anunció el alto magistrado, al margen de una comunicación del gobernador del Cauca Jorge Juan Hoyos Cabal, quien, desde Cartago, el 6 de junio del mismo año, informó por medio del oficio No 87, que había ordenado pagar sin descuentos el sueldo a los capataces del presidio de Boquía, en la misma forma como se le cancelaba el suyo al director del mencionado estableciemiento. La razón de esta medida la expone el mandatario provincial de la siguiente forma: "porque se me dificulta conseguir buenos hombres que se comprometan por menos de diez pesos, a servir este destino (el de capataz), cuando los jornaleros ganan cuatro reales diarios" Del mismo modo, le recuerda a Ospina que la consulta sobre el tema ya se la había planteado en el oficio 09 del 7 de noviembre de 1842.

Sueldos, raciones y traslado de los reos desde sus lugares de origen hasta el presidio, constituían la estructura de gastos del establecimiento de castigo del tercer distrito, que para el año económico corrido entre el $1^{\circ}$ de septiembre de 1843 y el 31 de agosto de 1844, tuvo los siguientes egresos: 
GASTOS DEL ESTABLECIMIENTO DEL PRESIDIO DEL TERCER DISTRITO EN TODO EL AÑO CORRIDO DEL $1^{\circ}$ DE SEPTIEMBRE DE 1843 A 31 DE AGOSTO DE 1844

\begin{tabular}{|c|c|}
\hline Gastos Generales & Valores \\
\hline Sueldo del director & 620,4 \\
\hline Sueldo de capataces & $287.3,1 / 2$ \\
\hline Sueldo del proveedor & 50 \\
\hline Gastos de escritorio de la dirección & 14,6 \\
\hline Raciones de los reos & $717,3,3 / 4$ \\
\hline Arrendamiento de piesa(sic) para asegurar \\
herramientas & 2,6 \\
\hline Conducción de vestuario & 7,2 \\
\hline Asistencia de reos enfermos & $617.4,1 / 4$ \\
\hline Utiles para hospital & 16,2 \\
\hline Construcción y composición de herramienta & 21,1 \\
\hline Composición de prisiones & 1,4 \\
\hline Gastos Varias & Valores \\
\hline Valor de una piezas (sic) para trabajar fragua en & 80,6 \\
\hline herreria & 2,7 \\
\hline Valor de dos angarillas y cuatro cueros de res & 2,2 \\
\hline Tote bagajes transporte de víveres y otros efectos & 12 \\
\hline Valor de una romana & 12 \\
\hline Compra de toldos & $2,466.3$ i $1 / 2$ \\
\hline
\end{tabular}

Cuadro 4. Gastos del presidio de Boquía, 1843-1844. ${ }^{269 .}$

\subsubsection{Las enfermedades en la Montaña del Quindío.}

La asistencia a los reos enfermos es uno de los gastos más elevados en el cuadro anterior, con un total de $617.4 \frac{1 / 4}{\mathrm{y}}$ coincide con que, entre diciembre de $1843 \mathrm{y}$ agosto de 1844, hay un alto número de presidiarios que aparecen internos mes a mes en el hospital del establecimiento de presidio, según lo arrojan los informes de altas y bajas que presenta la gobernación del Cauca a la secretaría del interior:

269 A.G.N. Sección República. Fondo Gobernaciones Varias. Rollo 94. Folio 368. 
REOS DEL PRESIDIO DEL TERCER DISTRITO INTERNADOS EN EL HOSPITAL ENTRE DICIEMBRE DE 1843 Y AGOSTO DE 1844

\begin{tabular}{|c|c|c|c|}
\hline AÑO & MES & TOTAL INTERNOS & $\begin{array}{c}\text { TOTAL } \\
\text { HOSPITALIZADOS }\end{array}$ \\
\hline 1843 & Diciembre & 50 & 23 \\
\hline 1844 & Enero & 65 & 36 \\
\hline & Febrero & 73 & 22 \\
\hline & Marzo & 63 & 26 \\
\hline & Abril & 68 & 33 \\
\hline & Mayo & 71 & 31 \\
\hline & Junio & 75 & 42 \\
\hline & Julio & 74 & 33 \\
\hline & Agosto & 80 & 41 \\
\hline
\end{tabular}

Cuadro 5. Reos de Boquía internados en el hospital, 1843-1844. ${ }^{270 .}$

En opinión del gobernador Hoyos Cabal, la fuente de las enfermedades es el duro clima de la Montaña del Quindío, que se agudiza o atempera según el lugar donde se encuentren los reos del presidio de Boquía.

Lo anterior se desprende de un informe fechado en Cartago el 7 de mayo de 1844, que el mandatario provincial le envía al secretario del interior para contarle los avances que hace el presidio en los alrededores del tambo de Consota. Al referirse a la salud de los reos dice:

Las enfermedades han cesado en Consota. Los fríos por lo menos han desaparecido casi totalmente. Continúan las úlseras (sic). En el hospital ha habido (sic) pocas altas i (sic) salidas en lo cual ha tenido seguramente mucho influjo la estación por los vientos húmedos, las emanaciones pantanosas i la mala calidad del agua que se toma en este tiempo.

El secretario Ospina le contesta: "El Presidente del Estado se ha complacido al saber que han disminuido notablemente las enfermedades que aquejaban a los presidiarios con su traslado a Consota i espera del cuidado del nuevo director que en lo sucesivo

270 Archivo general de la nación. Sección República. Fondo Gobernaciones varias. Rollo 94. Folio 53, 620, 675, $761,899,12,55,155$. Nota: No aparece el reporte de altas y bajas del presidio para el mes de abril de 1844 y a partir del mes de septiembre del mismo año, no se reporta el número de reos hospitalizados. 
no sucederá como se sita (sic) aquí que la mitad de los presidiarios tengan que estar en el hospital"271.

De acuerdo con lo que muestra el cuadro, las esperanzas fueron vanas y en algunos meses, los internados en el hospital del presidio superaron la mitad de los presidiarios.

Pero no solo los reos debían vérselas con las enfermedades de la Montaña del Quindío. Tambien requerían atención los militares de la guarnición encargada de la seguridad del presidio. La proporción de lo que se compraba en medicinas para los soldados era superior a la que se gastaba para los remedios de los presidiarios, de acuerdo con lo que le dice Hoyos Cabal a Ospina desde Cartago el 28 de mayo de 1844: "En medicamentos para presidiarios se consumieron en febrero cuarenta y ocho pesos, tres reales i (sic) $3 / 4$ (48 $\$ 3 \mathrm{i} 3 / 4)$; i para los militares ciento setenta i nueve pesos dos reales i cuartillo $(179 \$ 2 \mathrm{i} 1 / 4)$, de lo cual daré cuenta por medio del señor secretario de guerra" 272 .

¿Eran mejor atendidos los soldados o se enfermaban más los presidiarios?, es la pregunta que se puede formular. Los militares recibían sus medicinas a expensas del presupuesto de la Intendencia de Guerra i (sic) Marina y eran compradas en Bogotá, para evitar los costos excesivos de los mismos productos en Cartago. Ese mismo criterio usó el gobernador al solicitarle desde Cartago el 17 de diciembre de 1844 al secretario del interior, la compra de los medicamentos:

Como por la Secretaría de Guerra se ha dispuesto que se formen i (sic) remitan con la debida anticipación a la Intendencia de Guerra i Marina presupuesto de las medicinas que se consumirán en la curación de los soldados enfermos, para que sean remitidas de Bogotá i eviten de este modo los excesivos costos en ésta ciudad; i como en ellos no se comprenden los que se consumirán en la curación de los presidiarios e (sic) hecho firmar al médico del hospital el presupuesto que en copia remito a usted para que por el despacho de usted se disponga lo conveniente a fin de que se remitan con oportunidad las drogas presupuestadas ${ }^{273}$.

Previamente, el 29 de noviembre del mismo año, el facultativo mencionado por Hoyos Cabal había enviado la siguiente información:

271 A.G.N. Sección República. Fondo Gobernaciones Varias. Rollo 94. Folio 846.

272 A.G.N. Sección República. Fondo Gobernaciones Varias. Rollo 94. Folio 876

273 Archivo general de la nación. Sección República. Fondo Gobernaciones Varias. Rollo 94. Folio 317. 


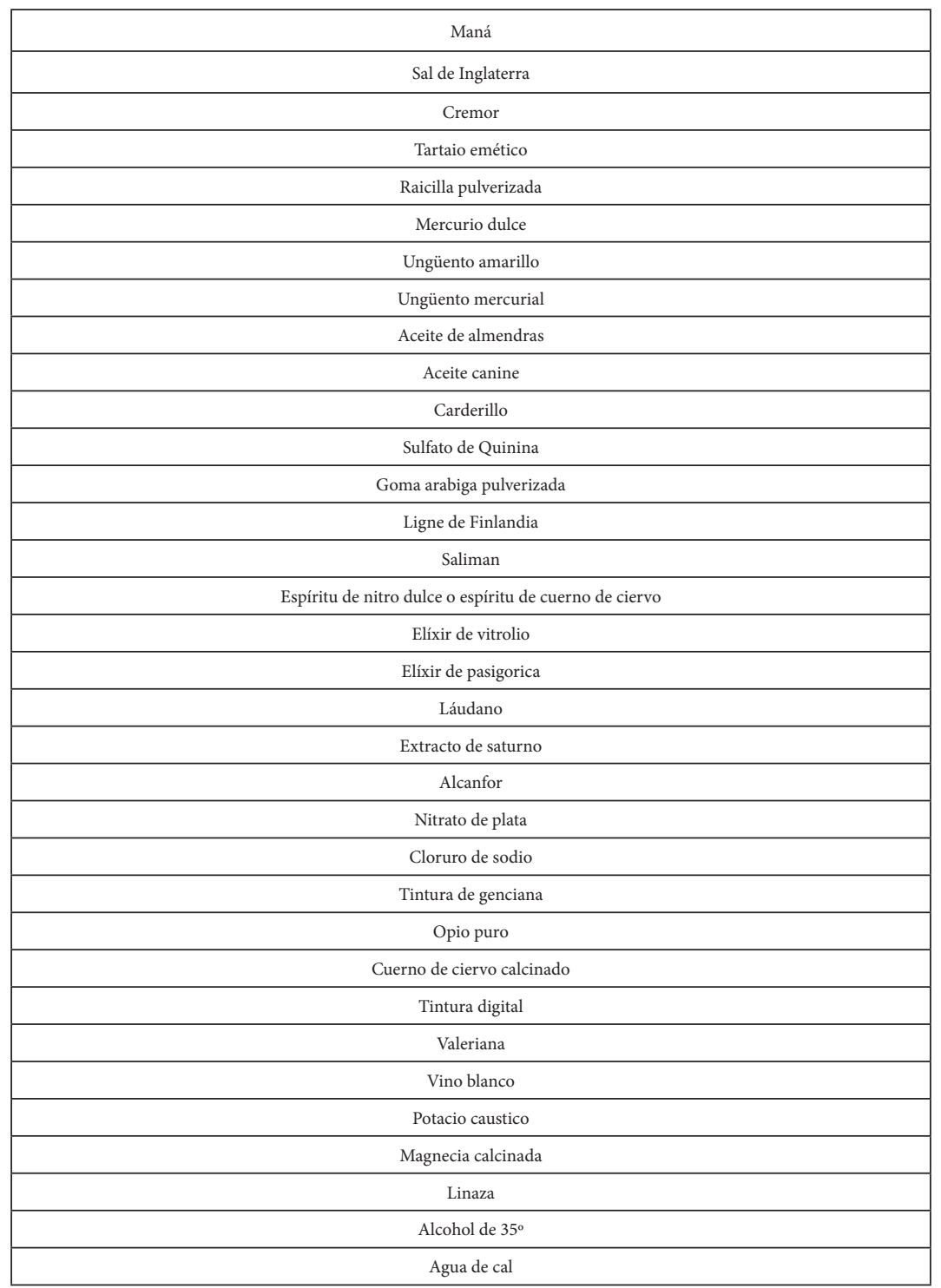

Cuadro 6. Listado de los medicamentos ${ }^{274}$

Como se dijo con anterioridad, las condiciones ambientales propiciaban las enfermedades de los presidiarios y también el régimen al que estaban sujetos los reos en el momento de efectuar los trabajos a los cuales habían sido asignados. Cada uno debía tener una prisión en una de sus piernas, pero ese elemento con

274 A.G.N. Sección República. Fondo Gobernaciones Varias. Rollo 94. Folio 328. 
el movimiento producía una frotación que traía como consecuencia la ulceración del miembro inferior y un proceso infeccioso que obligaba a remitir al individuo al hospital, donde el médico ordenaba frecuentemente que se retirara el grillete a cada interno, aunque la razón de su ingreso no se haya relacionado con lo mencionado ${ }^{275}$.

Esa situación llevó a que los reos fueran enviados a los frentes de trabajo del Camino del Quindío sin el grillete; circunstancia que parecía explicar el elevado número de fugas que se constituyó en uno de los más graves problemas que enfrentó el gobernador Jorge Juan Hoyos Cabal cuando estuvo al frente de las obras camineras.

\subsubsection{La fuga de los reos.}

De acuerdo con un informe que el propio mandatario le envió al secretario del interior el 12 de febrero de 1845, desde el primero de junio de 1839, hasta esa fecha se habían fugado 64 presidiarios; la mayoría proveniente de Buga y condenados por hurto.

Sin embargo, el gobernador identificaba otras causas para explicar el elevado número de fugas y así se lo hizo saber a Ospina Rodríguez en un oficio despachado desde Buga el 20 de septiembre de 1844:

Las verdaderas causas de la frecuente fuga son:

$1^{\text {a }}$ Que los militares no observan la disciplina con esatitud (sic); porque $1^{\circ}$ Por cualquier pretesto (sic) dejan de ir los oficiales al destacamento, fuera de que las enfermedades han contribuido a que no puedan permanecer en él. $2^{\circ}$ Por la falta de tropa ha quedado muchas veces el destacamento en poder de cabos i (sic) sarjentos (sic) que no saben ni escribir, i que viendose solos descuidan sus deberes i no exigen vigilancia de soldado. $3^{\circ}$ Alegando siempre cansancio por la continua fatiga (Esto es porque no se releva con frecuencia el destacamento) los soldados buscan las sombras, se separan de los reos, o duermen principalmente cuando el director no asiste, como por desgracia a (sic) sucedido con una parte de los que han desempeñado ese destino. $4^{\circ}$ Por que reusando (sic) siempre el soldado recibir preparado su rancho, i no dando lugar a esta reforma el estado de la disciplina, se ocupan en preparar su comida rodeado de las mujeres que los acompañan, i no en vigilar. $5^{\circ}$ Porque el oficial del destacamento pocas veces se toma el trabajo de asistir al lugar en 
que se maniobra, para dar reglas i cuidar la vijilancia (sic) de los soldados.--. $2^{\mathrm{a}} \mathrm{La}$ facilidad para ocultarse en el bosque el reo cuando al caer un árbol todos prestan atención a este suceso, el bosque es transitable en todas las direcciones, i (sic) las aguas marcan una dirección segura para marchar acia (sic) Cartago por entre ellos; el que huye elije su vía, i el que persigue no puede tomar una a su gusto, sino que debe detenerse para reconocer por los rastros que deja el prófugo. $3^{\text {a }} \mathrm{El}$ deseo de sacar provecho de los servicios de los reos para la obra que se les destina, hace que los superiores no sean suficientemente severos para establecer una subordinacón absoluta fundada en el temor i la opresión. De aquí proviene que estos establecimientos no inspiren ya miedo para los que no pueden aspirar mas que a alimentarse i vestirse ${ }^{276}$.

Indisciplina, medio ambiente hostil, carencia presupuestal y enfermedades, evidencian la cotidianidad del presidio de Boquía, que, aunque se ha visto como una institución independiente y generadora, por sí sola, del poblamiento de la Montaña del Quindío al promediar el siglo XIX, no se puede separar del proyecto que motivó su establecimiento en la frontera nororiental de la provincia del Cauca: La construcción del camino del Quindío.

\section{Decisiones desde el Cauca: la reapertura del Camino del Quindío}

Como se puede concluir de la revisión bibliográfica y de la revisión de la documentación oficial consultada en el Archivo General de la Nación, el Archivo Central del Cauca y la hemeroteca de la Biblioteca Nacional de Colombia, el camino del Quindío ha sido protagonista de la historia de lo que hoy es Colombia, desde la etapa precolombina.

El camino del Quindío fue un proyecto del interés de los gobiernos en los albores de la vida independiente de España y es un ejemplo de la forma como el proyecto de Estado unitario debió penetrar en lo ideológico, político, normativo y material, las periferias sociales y territoriales de la entonces Nueva Granada para consolidarse, con el concurso indispensable de las élites de la provincia del Cauca.

Justamente, las formas de esa penetración en lo material, lo normativo y administrativo, se hacen presentes en forma abigarrada en la documentación que 
sirve para contar cómo se dirigió la reapertura del camino del Quindío entre 1843 y 1845 y cuáles fueron los problemas que debieron afrontar las autoridades caucanas en el desarrollo del proyecto.

Para esa época, el gobierno del general Pedro Alcántara Herrán que surgía como resultado del triunfo del oficialismo durante la Guerra de los Supremos -la primera gran guerra civil de nuestra era republicana-, decide emprender el proyecto de reabrir el Camino del Quindío como una forma de integrar grandes baldíos a la economía del país y comunicar al centro y sur occidente de la república, con el valle del río Magdalena y con Bogotá.

Con ese propósito toma varias decisiones, entre las que se destaca el involucramiento de las autoridades de las provincias por las que cruzaba el camino -Cauca y Mariquita- en la dirección de la reapertura, y la utilización de mano de obra sin costo alguno que provenía de los presidios que instaló en esos territorios, de los procesos de indulto de la anterior guerra civil; de la persecusión a los vagos, mirados como delincuentes por la sociedad decimonónica neogranadina, y de la oferta de tierras baldías a campesinos pobres, en desarrollo de la política de consolidación de los nuevos Estados iberoamericanos, que el argentino Alberdi resumió con la frase "gobernar es poblar".

\subsection{El trazado del camino del Quindío}

Quizás las decisiones más importantes y que involucran, de acuerdo con la documentación, a las autoridades provinciales y en particular a la del Cauca, son las relacionadas con el trazado del camino, que entraña considerar una ruta que vaya desde Ibagué al centro geográfico del valle del río Cauca o mantener la tradicional, con la necesidad de escoger cuál de sus ramales -el de Cerrillos, el de La Trocha o el del páramo de Herveo- debía ser puesto en funcionamiento.

En diciembre 31 de 1842, el director del Camino del Quindío Vicente De la Roche le escribe desde Ibagué al gobernador del Cauca:

Doy cuenta a usted del resultado de mis exploraciones en estas montañas con el objeto de encontrar una vía más cómoda que la que actualmente ecsiste (sic) entre esta ciudad i (sic) la de Cartago y trazar el camino propuesto por el gobierno supremo del modo más ventajoso posible"277. 
Luego de hacer una extensa descripción de la geografía de la zona inspeccionada, dice el funcionario:

El orden y regularidad de las cuchillas y vertientes de este lado de la cordillera me hacia esperar que del otro lado se encontraban ventajas análogas el nuevo camino sería más ventajoso que el antiguo, i (sic) pagaría ampliamente el aumento de gastos que sería preciso hacer con la apertura; pero desgraciadamente he visto que esta dirección es del todo imposible por el desorden que reina en las caídas accidentales, sus asperidades y la forma de sus cuchillas poco propia para la empresa.

Luego concluye:

Seguramente cuando estas dos provincias llegaren a cierto grado de prosperidad (sic) que se aumenten sus intereses mercantiles se abrirá un camino por toda la cuchilla del Tambo que comunique de Ibagué con los cantones del sur del Cauca, también podrá salir de éste camino alguno de travesía para Cartago; pero un camino que comunique directamente de Ibagué a Cartago, ni ahora ni en ningún tiempo podrá ser otro que el que actualmente ecsiste (sic) ${ }^{278}$.

El gobernador del Cauca Jorge Juan Hoyos Cabal remitió desde Cartago el 15 de febrero de 1843, el informe de De la Roche al secretario del interior, con la siguiente acotación:

(...) acompaño a usted para conocimiento del P.E. copia del informe que ha dado a esta gobernación el director de la apertura del Quindío, del resultado de sus exploraciones, para buscar una cuchilla o rama de la cordillera que haga descender del páramo de Ibagué viejo a Boquía, esta empresa ha sido infructuosa pero no debemos sentir mucho, porque el plan de volver a la ruta actual del Quindío después de haber encontrado un buen ascenso al páramo por Ibagué Viejo era de perder las ventajas adquiridas. Después de estar en la cumbre de la cordillerta debe buscarse la salida al Cauca acia (sic) la Paila i (sic) no rodiar (sic) por volver a Boquía; de este modo piensa el director que se abrirá el camino en tiempos mas felices, i pienso como él, como ya lo he manifestado a usted ${ }^{279}$.

278 A.G.N. Sección República. Fondo Gobernaciones Varias. Rollo 86. Folio 307.

279 A.G.N. Sección República. Fondo Gobernaciones Varias. Rollo 86. Folio 307. 
Posteriormente, por encargo de la Secretaría del Interior y Relaciones Exteriores, el gobernador del Cauca, Jorge Juan Hoyos Cabal, se ocupa de recabar información en el propio terreno, que permita tomar las decisiones adecuadas. En cumplimiento de ese encargo escribe desde Cartago el 24 de enero de 1843 al secretario Mariano Ospina Rodríguez:

(...) me he trasladado a esta ciudad, en donde me hallo desde el 21 del presente mes. Mañana entraré a la montaña a reconocer la nueva vereda que se ofrece por el sitio de Los Cerrillos y Salina de Consota, que se une con la actual en el Roble, a media jornada de Boquía, i (sic) por el próximo correo podré informar al gobierno sobre las ventajas que en mi concepto ofrezca"280.

En un informe del 7 de febrero de 1843, despachado desde Cartago, Hoyos Cabal cumple con el encargo y empieza por señalar cuáles son los puntos que se deben resolver en relación con la apertura del camino del Quindío:

Correspondiendo a los deseos del P.E. que usted me manifestó en su nota del 21 de diciembre, número 12 de la sección primera, donde me invita a expresar mi concepto sobre la línea que debe preferirse para la construcción del camino del Quindío, esta cuestión se presenta hoy comprendiendo dos puntos diferentes. 1. Qué línea conviene preferir para abrir un camino por la Cordillera Central de los Andes que facilite la comunicación de las provincias del sur con las del centro. 2. Qué vereda se preferirá para componer el actual camino del Quindío ${ }^{281}$.

Al resolver el primer punto, reconoce los inconvenientes que ofrece el tradicional camino del Quindío, por "El aspecto físico que toma la cordillera al oriente de esta ciudad, levantándose a su mayor altura, con riscos inaccesibles", que hacen "necesario buscar hacia el sudeste por el actual camino que evite una parte de esta altura para volver después siguiendo la dirección de intrincadas corrientes y remontando frecuentemente hasta las fuentes de los arroyos que se atraviesan a buscar la ciudad de Ibagué". Atribuye a lo anterior que se alargue "la extensión natural del camino" en dos tercios y sea peligroso al subir y bajar "por cerros empinados, cuyas faldas son precipios".

280 A.G.N. Sección República. Fondo Gobernaciones Varias. Rollo 86. Folio 273.

281 A.G.N. Sección República. Fondo Gobernaciones Varias. Rollo 86. Folio 290. 
A renglón seguido, admite la conveniencia de trazar un camino que salga a La Paila, pues conserva la "dirección del camino nacional que debe ir desde la capital de la República hasta el puerto de Buenaventura", "acorta el camino para los que de las provincias de Pasto y Popayán se dirijan a la capital", ofrece de uno y otro lado terreno más propio para poblar" y "sale hacia el centro del valle del Cauca que es su parte más poblada"; para luego concluir, a favor de componer el que desde la colonia comunicó a Cartago y a Ibagué, lo siguiente:

Mas, el proyecto de abrir el camino por ella es por ahora mas grande de lo que exigen nuestras actuales necesidades; demoraría en dar principio a la obra mas de lo que conviene i ( $\sin$ ) carecerían estas provincias de un pronto auxilio que pueda contribuir mucho a su mejora i creo que por esto es preferible componer la actual vía, i dejar para mejor ocasión buscar determinar la otra ${ }^{282}$.

Hasta ahí, la posición del gobernador Hoyos Cabal coincide con la de De la Roche, en el sentido de que se debe acometer la composición del camino del Quindío, en vez de iniciar la construcción de uno nuevo; pero lo que a continuación expresa determina una postura y unas decisiones que proyectarán y convertirán en decorado de la gestión del gobierno caucano y de Hoyos Cabal en esa obra, las sombras de un conflicto colonial sobre cuál de los ramales de esa vía debe usarse y mantenerse:

Supuesto que el gobierno decida que se mejore la vía actual, resta todavía averiguar si deve (sic) conservarse la salida a Cartago por La Balsa, o si conviene que desde El Roble se tome una nueva que por la salina de Consota y la parroquia de los Cerrillos conduzca a esta ciudad; i (sic) este es el segundo punto sobre el que creo debo informar al gobierno.

He examinado personalmente una trocha que uno de los vecinos de Cartago ha abierto para ir desde la salina de Consota al sitio del Roble, con ánimo de demostrar que aquella vía es mejor que la de la Balsa.

Dicha vía va por una cuchilla o loma de montaña espaciosa, haciendo poco a poco de suerte que se puede ir a caballo a paso largo. De Cartago salí a las 9 de la mañana en mula i (sic) sin apurar el paso, he estado a las 4 de la tarde en la salina de Consota, no obstante haber unos puntos en que el lodo impide un paso regular, i desde la Salina seguí por otra cuchilla un poco más inclinada i menos espaciosa, cubierta de bosque no más espeso ni antiguo, 
parte del cual es enteramente de palmas delgadas que no han acabado de crecer i que dejan entre sus espacios libre para andar a paso largo, casi sin obstáculo: Este bosque no está abierto i entré por él en mula abriéndome paso a machete de suerte que seis horas que emplié (sic) caminando fueron suficientes para andar como dos leguas y un tercio. El paso de una quebrada, impidió continuar en mula i a pie caminando despacio me puse en tres horas en el Roble por una cuchilla igual a la anterior, cortada al pie del Roble por una pequeña quiebra de la montaña ${ }^{283}$.

Tras demostrar sus conocimientos de geodesia haciendo una descripción de la composición del terreno y de su favorabilidad para las actividades de labranza y subrayar que a la vereda comentada sale la trazada por "peones de Antioquia, que desean poblar en las cabeceras de Chinchiná” Jorge Juan Hoyos Cabal remata:

(...) Aunque pocas esperanzas de mejora me prometían esta vía antes de conocerla, después de caminarla por menos me ha parecido preferible a la de la Balsa, no obstante que es como dos leguas más largas que ella. Las razon en que fundo este concepto son las siguientes- $1^{\text {a }}$. Une por el espacio de dos leguas dos caminos, uno por Mariquita y otro por Antioquia porque la trocha abierta por los antioqueños me parece deve (sic) perfeccionarse. Esta sale a las poblaciones de Neira y Salamina, para que sirva de comunicación con la provincia de Antioquia, por ser más recta, de mejor camino, por mejor temperatura, i (sic) porque ella se pasan menos ríos, i por puntos que tienen menos agua que la que sucede por el camino actual de Ansermaviejo a Supía$2^{\mathrm{a}}$. Pasa por un terreno reconocido por más mineral que el camino de La Balsa pues hay ojos de sal en el sitio de Cartago Viejo i (sic) mas adelante en la salina de Consota en donde el Gral. Cabal essaminó (sic) una veta de oro que le pareció muy rica, según se me ha informado, i es además Cartagoviejo hay oro en abundancia que arrastran las quebradas con afluentes al río Otún, como también treinta ojos de sal que conocieron los conquistadores. En este sitio de Cartagoviejo puede florecer una población con ventajas naturales a distancia como a dos leguas de Cartago, i siendo al mismo tiempo el punto de unión de los dos caminos-3a. Hay más terreno de labor que por La Balsa, en que cosecharán frutos de paises fríos y calientes- $4^{\text {a }}$. Es más continuado el acenso (sic) regular a la cordillera, pues no se encuentra por ella ni una subida como la de Cerro Gordo, ni una hondura como la de la Vieja, ni hay qye remontar como de la Vieja a La Balsa, ni como de aquí a Buenavista, declives 
que fatigan a los hombres i a las bestias en el actual camino por el espacio de cinco leguas estando parte de una de ellas enteramente desprovisto de sombra para el verano- $5^{\text {a }}$. No se encuentran tampoco gargantas estrechas (que dicen puntesusas) como hay por la otra vía en diferentes puntos, siendo algunas tan estrechas que será necesario ancharlas para que no haya riesgos de que recostán dose una con otra la haga caer- $6^{a}$. Hay abundancia de paja para los techos, la cual no se encuentra en la cuchilla de la Trocha, ni en el sitio de la Balsa- 7a. Lo mas fácil de conducir la madera para la construcción i (sic) porque la angostura de la Trocha hace que frecuentemente se dé en faldas empinadas- $8^{\mathrm{a}}$. En el puesto de la salina de Consota que todo se compone de terreno valdío (sic), hay lomas cubiertas ya de grama, que a poca costa se conbertirán (sic) en dehesas- $9^{a}$. Pasándose el río la Vieja por el borde de la ciudad habrá más competencia para el remate de los derechos de pasaje y peaje, i más comodidades para el manejo de las cargas, porque el paso que dará al principio o fin de una jornada, i no hacia la mitad como sucede en Piedras de Moler- 10ª . Se presenta como una legua de camino hasta los Cerrillos, que no necesita de más composición que una i otra zanja para dar cause a las aguas, mientras que la otra vía comenzará la composición desde donde se dejan las calles de la ciudad ${ }^{284}$.

Los argumentos que expone Hoyos Cabal no solo evidencian que para la época el camino del Quindío operaba en el ramal conocido como la Trocha, que salía de Cartago, cruzaba Piedrademoler, luego a la población de La Balsa y se conectaba con El Roble. También muestran que un antiguo ramal, el que conducía a la Cartago fundada por el Mariscal Jorge Robledo durante la Conquista, seguía siendo utilizado y por tanto ofrecía mejores oportunidades, cuando de componer la vía se hablaba. Pero, sobre todo, refleja una vieja pugna entre quienes preferían escoger el camino por los Cerrillos, al de la Trocha que pasaba por La Balsa.

Larry Vito Larrichio y Víctor Zuluaga en sus obras reseñadas en el balance historiográfico de esta investigación, cuentan de ese enfrentamiento entre Cartago e Ibagué en el siglo XVII, cuando la primera intrigaba para que el camino fuera reactivado por la Trocha y la segunda quería que fuera por los "Serrillos de Pindaná".

Larrichio le pone nombre al enfrentamiento: 
Ignacio Nicolás Buenaventura, encargado de la apertura del camino, entre la cima de la cordillera Central e Ibagué, “....apoyó la ruta de Serrillos, que era parte del camino antiguo que pasaba por Cartago Viejo y que había sido abandonado en 1690 .... Por su parte, “...Pedro Zerezo (el director de la parte que va desde Cartago hasta la cúspide de la cordillera) prefirió La Trocha (que pasaba por el actual Finlandia) porque era más corta. Hubo testimonios de tratantes vecinos que apoyaron la ruta de Zerrillos, pero también hubo testimonios apoyando a Zerezo, confirmando que la Trocha era mucho mejor. Los tratantes estuvieron en desacuerdo reflejando igualmente la división de los dos cabildos ${ }^{285}$.

Víctor Zuluaga Gómez, por su parte, comenta sobre Buenaventura y un documento que él escribió al respecto:

Al hablar sobre la característica de La Trocha, dice que lo más penoso de esta ruta consiste en las muchas bajadas y subidas, así como la gran cantidad de guaduales que hacen bien difícil el tránsito. Por todo ellos recomienda "abrir el antiguo (camino) de los Cerritos; que oy (sic) igualmente se transita”. El documento, finalmente recomienda que se abra el camino con 12 varas de ancho, que se empale en algunos sitios en donde las lagunas son permanentes y también que se busque la manera de abrir potreros para poder suministrar alimentos a las recuas que transitaban por el camino ${ }^{286}$.

De otra parte, no habilitar La Trocha significaba condenar a La Balsa, población que aún no existía cuando se enfrentaron los cartagüeños e ibaguereños por el trazado en el siglo XVII, y que para la década del 40 del Siglo XIX tenía una población ínfima y en descenso y en la que su fortalecimiento podría ser del interés del propio Vicente De la Roche -director del camino del Quindío-, en tanto que él descendía de la unión entre una de las herederas de la casa señorial de Mar y Sanzena que fundó a finales del siglo XVIII ese asentamiento, con el nombre de San Sebastián de la Balsa, y el francés Gabriel Ambrosio De la Roche, uno de los primeros cartógrafos al servicio de la nueva república.

La fundación misma había sido el fruto de la fuerza de voluntad, por no llamar terquedad, de Sebastián de Sanzena, tal como lo explica Zuluaga Gómez:

285 Larry Vito Larrichio, «La arquitectura del paisaje».

286 Víctor Zuluaga Gómez, El camino del Quindío y las guerras civiles. Cartago, Boquía, Salento, Ibagué. (Pereira: Gráficas Buda, 2010), 39. 
A finales del siglo XVIII... don Sebastián de Sanzena, hijo de don Thomás Sanzena, escribano real de la ciudad de Cartago, solicitó autorización para que se le permitiera actuar como juez poblador de una aldea ubicada precisamente entre Cartago y El Roble, a orillas del camino del Quindío. Dicha aldea sería llamada San Sebastián de la Balsa... Todo indica que don Sebastián reunió a varios vecinos de Cartago y ofreció repartirles tierras y apoyarlos en la construcción de viviendas y herramientas necesarias para el desmonte de bosques. Quienes aceptaran las condiciones, se comprometían a pagarle a plazos la deuda contraida. Resultaba entonces que si alguien decidía regresar a Cartago y abandonar la colonización de la aldea, Sanzena lo obligaba a retornar, acudiendo a la justicia ${ }^{287}$.

San Sebastián de la Balsa era la gran incógnita a despejar para tomar la decisión de habilitar el ramal de los Cerrillos y no el de la Trocha y de eso era consciente el gobernador Hoyos Cabal, quien en su informe a Ospina Rodríguez dice lo siguiente:

En contravía de esta vía se presenta una objeción fuerte, i (sic) es que en la Balsa hay una población que quedará abandonada si se abandona aquella vía, éste es para mí el principal obstáculo que ofrece la variación, pues aunque los vecinos no pasan de ciento, éste número es el mayor al que pueda aspirarse en una nueva población de montaña ${ }^{288}$.

La argumentación sobre la conveniencia de componer el ramal de los Cerrillos para la reapertura del Camino del Quindío, la completó con un mapa de la zona de influencia de la vía y sus ramales levantado por él mismo, con base en otro del puño del mismísimo Gabriel Ambrosio De la Roche y que amablemente le facilitó al mandatario. (Ver mapa 4)

Se observan en el mapa, con gran precisión, ríos, quebradas y montañas y punteado lo que en la época se llamaba la vereda de los Cerrillos o el ramal de los Cerrillos del Camino del Quindío.

287 Víctor Zuluaga Gómez, El camino del Quindío, 99.

288 A.G.N. Sección República. Fondo Gobernaciones Varias. Rollo 86. Folio 290. 
El despliegue del Estado en el poblamiento de la Montaña del Quindío y la fundación de Santa Rosa de Cabal, $1840-1845$

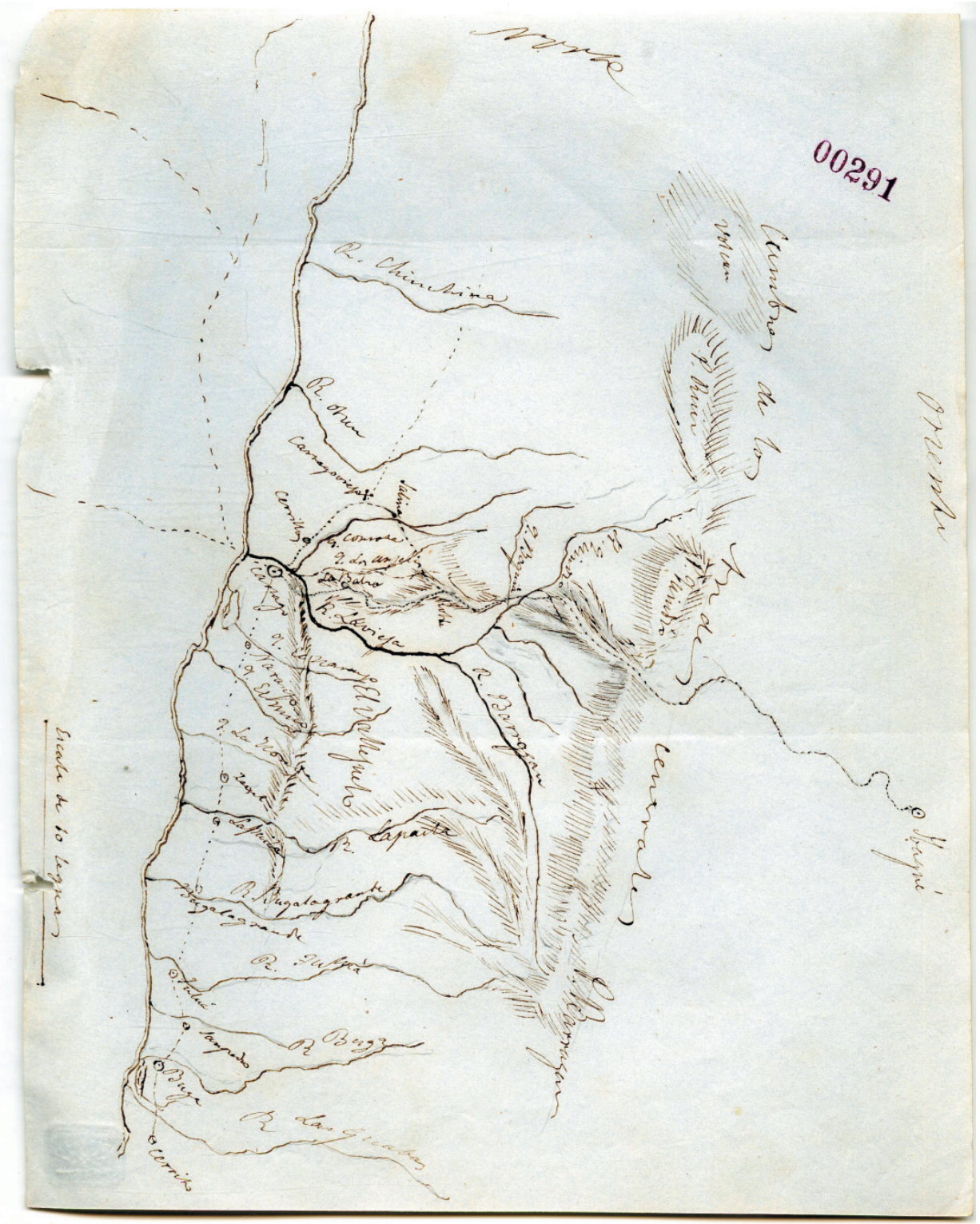

Mapa 4. Zona de influencia del Camino del Quindío289. 
El ejecutivo central recogió los argumentos de Hoyos Cabal y al margen del mismo informe del gobernador, el secretario del interior Mariano Ospina Rodríguez le contesta el 29 de marzo de 1843 que "El P.E. estima preferible, según los datos que suministra este informe, la vía de los Cerrillos a la de la Balsa; y es por la... que debe emprenderse la construcción del camino"; pero deja abierta la posibilidad que la ruta no escogida, pueda serlo en un futuro, al decir que, "no obstante si la gobernación encontrare que se presenta de nuevo un grave inconveniente en que esta vía sea preferida, y aparece alguna nueva ventaja que no se haya tenido en cuenta y que pareciera ser mejor la de la Balsa, suspenderá los trabajos por la vía de los Cerrillos y propondrá lo que convenga", y advierte: "El que se hayan hecho algunas reparaciones para hacer ahora transitable la senda de la Balsa, será razón suficiente para ser ésta la vía preferida" ${ }^{290}$.

\subsection{La resistencia del pasado}

Triunfó la tesis de Hoyos Cabal y se dio inicio a los trabajos por la vía de Cerrillos, afrontando infinidad de dificultades; entre ellas una muy mala relación entre el gobernador y el director del Camino del Quindío, Vicente De la Roche y una aparente resistencia a los trabajos por el ramal escogido, que se pone de presente en la correspondencia oficial revisada para esta investigación:

- En la carta del 24 de enero de 1843, en la cual el gobernador informa a Ospina que ya está en Cartago listo para entrar a la montaña a inspeccionar si la vía de Cerrillos puede ser la mejor, informa también que no tiene noticias del director del camino del Quindío. ${ }^{291}$

- En una comunicación del 13 de enero de 1844, Hoyos le dice a Ospina: “... He excitado al señor director de la composición del camino del Quindío para que ya que no le es posible estar en esta provincia, fije por lo menos reglas generales bajos las cuales admitirá vagos como concertados para trabajar en la obra, no he logrado ni contestación y me he visto precisado a destinarlos i (sic) admitirlos sin conocimiento del director" ${ }^{292}$.

- En julio de 1844, el gobernador Jorge Juan Hoyos Cabal presenta renuncia de su cargo ante el secretario del interior Mariano Ospina Rodriguez, al saber que

290 A.G.N. Sección República. Fondo Gobernaciones Varias. Rollo 86. Folio 291.

291 A.G.N. Sección República. Fondo Gobernaciones Varias. Rollo 86. Folio 273.

292 A.G.N. Sección República. Fondo Gobernaciones Varias. Rollo 94. Folio 568. 
ha sido acusado por parte de salineros de Zipaquirá de incidir en la decisión del gobierno de abrir el camino del Quindío por la vereda de los Cerrillos y no por la Balsa, para favorecer la explotación que extranjeros hacen de la salina de Consota. ${ }^{293}$

- Al quejarse de los problemas que ha tenido la obra del camino del Quindío, por falta de dirección y personal capacitado, el mandatario provincial le dice el 25 de octubre de 1844 a Ospina Rodríguez, que “...la dirección general de la obra no ha contribuido hasta ahora sino a desalentar en su ejecución por haber sido opuesto el director general a que se llevase el camino por Pindanar de los Cerrillos mas que por la Balsa"294.

Queda clara la tensión existente entre quienes querían que la nueva composisión del camino se hubiera hecho por la Trocha -entre ellos el propio director de la obra- y los que lograron que los trabajos se hicieran en el ramal de Cerrillos.

Sin embargo, no se puede asegurar que Hoyos Cabal quisiera sepultar las posibilidades de San Sebastían de la Balsa. Cuando Hoyos Cabal ya no era gobernador del Cauca, su sucesor, Laureano Mosquera, dio a conocer desde Buga el 22 de septiembre de 1845 a la secretaría del interior, el remate irregular del paso de Piedrasdemoler hecho por el primero para beneficiar a la mencionada población, en los siguienes términos:

Cuando se pretendió en el presente año hacer el remate del paso principal de Piedrasdemoler en el río la Vieja en la montaña del Quindío, no hubo quien quisiera celebrarlo por una cantidad que llegara siquiera a la cuatro quintas partes del remate anterior, que es el mínimo que la Cámara Provincial por su decreto del 4 de octubre de 1840, ha señalado para ser admisibles los remates de peaje, pasaje y pontazgo en los caminos provinciales, habiendo sido la cantidad que se ofreció, menos de la tercera parte de la cantidad del remate anterior. Mi antecesor prefieriendo a la pérdida total de la cantidad en que por menos debió rematarse aquel derecho, el aprovechamiento de una parte suya, por haber comenzado el citado paso a quedar sin uso alguno a consecuencia de la composición del Camino del Quindío por los Cerrillo, declaró admisible dicha propuesta ${ }^{295}$. 
De otro lado, la conducta contumaz de Vicente De la Roche no tenía como blanco exclusivo a Jorge Juan Hoyos Cabal. Lo anterior se desprende de una comunicación que proyectó el gobernador Laureano Mosquera el 21 de octubre de 1845 para Ospina Rodríguez, que decía: "Hasta hoi (sic) no ha aparecido nel señor Vicente De la Roche a hacerse cargo de la dirección del Camino del Quindío"296. La misiva nunca se envió pues el 4 de noviembre De la Roche llegó al mencionado cantón. Lo anterior evidencia las tensiones que se vivieron en los primeros años de la década del 40 en relación con la reapertura del Camino del Quindío y que hacen parte del cúmulo de decisiones que las autoridades de la época debieron tomar para solucionar problemas, en desarrollo de la penetración normativa, ideológica, política y material en la periferia territorial que configuraba esa montaña.

\subsection{La mano de obra}

Otra de las dificultades que debieron afrontar las autoridades fue el tema de la mano de obra calificada para que los trabajos rindieran lo esperado. Según reiterados señalamientos del gobernador Jorge Juan Hoyos Cabal, referenciados en otros apartes de la presente investigación, ese aspecto fue un verdadero dolor de cabeza, pues para el mandatario, ni los reos del presidio del tercer distrito, ni los vagos servían para esas labores. Tampoco la fuerza laboral que llegaba gracias al gravamen del servicio personal obligatorio, pues consideraba poco dispuestos para el trabajo a los habitantes de la región.

Solo cuando empezó a hacer efectivo el servicio personal obligatorio en dinero para las clases $1^{\mathrm{a}}, 2^{\mathrm{a}} \mathrm{y}$ aún $3^{\mathrm{a}} \mathrm{y}$ no con trabajo en la obra del Camino, pudo el mandatario contratar peones de Ibagué y Supía, "porque en este cantón no los ai (sic) buenos para el trabajo en la montaña" ${ }^{\prime 297}$.

El anterior comentario se lo hizo Hoyos Cabal a Ospina Rodríguez, cuando le pidió desde Cartago el 7 de abril de 1843, que hiciera extensiva para el tramo del Camino del Quindío correspondiente al Cauca, una modificación del decreto del 15 de julio de 1842 que autorizaba a la Gobernación de Mariquita, responsable del otro tramo de la vía, a recibir dinero como equivalente del servicio personal obligatorio. El secretario del interior contestó el 25 de abril desde Bogotá: "Hacerle estensivas (sic) las disposiciones del decreto del 7 de marzo último que reformó el del 15 de julio

\footnotetext{
296 A.G.N. Sección República. Fondo Gobernaciones Varias. Tomo 1. Carpeta 104. Folio 69.

297 A.G.N. Sección República. Fondo Gobernaciones Varias. Rollo 86. Folio 400.
} 
pasado, sobre los aportes a la obra del camino que corresponde a la provincia del Cauca" ${ }^{298}$.

Lo anterior es una muestra de la forma como las instituciones del Estado expedían y modificaban normas que permiten el desarrollo de las obras del camino del Quindío y por supuesto, enraizar la presencia oficial en la periferia territorial, a través de lo que Juan Maiguasca denomina la penetración ideológico normativa.

\subsection{La autoridad provincial en acción.}

Ese tipo de penetración se logra gracias a la interacción del Poder Ejecutivo en Bogotá y los gobernadores de las provincias de Mariquita y Cauca. En la revisión de la correspondencia entre el mandatario de la última entidad territorial mencionada y el secretaro del Interior y de Relaciones Exteriores Mariano Ospina Rodríguez, se evidencia que muchas de las decisiones tomadas desde Bogotá son la respuesta a las sugerencias, pedidos y descripciones que el gobernante provincial formula y envía a la capital.

Así ocurrió por ejemplo, cuando el Gobernador Jorge Juan Hoyos Cabal le informa a Ospina Rodríguez el 25 de julio de 1843 que, como debe en septiembre ausentarse del cantón de Cartago, donde por disposición legal debe permanecer para dirigir los trabajos de apertura del camino, para asistir a las sesiones de la Cámara Provincial en Buga, "es consiguiente dejar encargado aquí al jefe político de todos aquellos deberes que ahora incumben personalmente al gobernador respecto de la obra del Quindío"

El secretario del Interior da la orden al margen del oficio de la referencia, de contestar lo siguiente:

Los jefes políticos de Ibagué y Cartago, ejercerán durante la ausencia de los gobernadores de Mariquita y el Cauca las funciones que estos deberían ejercer relativamente a las operaciones del camino del Quindío i (sic) de lo que es anexo. Dichos gobernadores darán al efecto las instrucciones convenientes a aquellos empleados ${ }^{299}$.

298 A.G.N. Sección República. Fondo Gobernaciones Varias. Rollo 86. Folio 400

299 A.G.N. Sección República. Fondo Gobernaciones Varias. Rollo 86. Folio 657. 
En consecuencia, desde Cartago, el 31 de agosto del mismo año, Hoyos Cabal expide una completa reglamentación sobre las funciones que deberá asumir el jefe político del mencionado cantón y otros funcionarios, cuando el gobernador se ausente de la dirección de los trabajos en el Camino del Quindío y que encabeza de la siguiente manera:

Debiendo ausentarme de esta ciudad para dar cumplimiento a las disposiciones legales que me previenen hacer la visita en la provincia e intervenir en la formación i (sic) sanción de los actos de la cámara provincial de acuerdo con la orden particular del presidente del Estado comunicada por la secretaría del Interior el 10 de agosto $\mathrm{N}^{\circ} 58$ de la sección $2^{\text {a }}$, he acordado el siguiente reglamento de los deberes i funciones del jefe político, alcalde parroquial, administración de recaudación, director de presidio i proveedores relacionados con la obra del camino del Quindío i con la inversión i cuenta de sus fondos ${ }^{300}$.

Con relación con algunas de las responsabilidades del jefe político del cantón de Cartago, el reglamento dispone en su primera parte:

JEFE POLÍTICO: Artículo $1^{\circ}$. El Jefe Político queda encargado inmediatamente del cumplimiento de las órdenes del gobernador i (sic) i de la gobernación, relativas a la obra del Quindío. - 2². Contratará por sí mismo o por medio de las personas que tenga a bien los víveres que se necesiten para el presidio cerciorándose de su calidad, peso, valor de ellos, i dispondrá todo lo conveniente para su conducción. La compra de víveres solamente tendrá lugar, cuando no haya celebrado alguna contrata para suministrarlos con arreglo al decreto del Presidente del Estado de 15 de julio de $1842 \ldots$ Artículo 17. El jefe político llevará el apunte del número de peones que prestan personalmente o por medio de otros peones la contribución para el camino, expresando el número de días que haya trabajado cada uno ${ }^{301}$.

También el tema de los vagos, que siempre fue un dolor de cabeza para Hoyos Cabal, demandó de la facultad reglamentaria del Gobernador del Cauca, cuando el 12 de enero de 1844 en Buga, expidió un reglamento sobre la forma como debían ser concertados para trabajar en las obras del camino del Quindío y el poblamiento de esa comarca y que le dio a conocer al secretario Ospina en un oficio expedido en la misma ciudad al dia siguiente de su creación.

300 A.G.N. Sección República. Fondo Gobernaciones Varias. Rollo 86. Folio 806.

301 A.G.N. Sección República. Fondo Gobernaciones Varias. Rollo 86. Folio 806. 
El contenido del reglamento refleja en primer lugar, el rechazo de la sociedad neogranadina a las personas que eran clasificadas como vagos, en virtud de la legislación analizada anteriormente, y en segundo, la desconfianza del gobernador del Cauca al personal que llegaba a la Montaña del Quindío por estar en esa condición, hasta al punto de equipararlos en su tratamiento con los reos del presidio de Boquía:

Art. $1^{\circ}$. Los vagos que sean destinados a trabajar en calidad de concertados en la obra del Quindío estarán a cargo del director del establecimiento del tercer distrito del presidio, tanto para su custodia, sujesión (sic) i (sic) mantenimiento, como para el cumplimiento del concierto... Art. $6^{\circ}$. Los vagos quedarán sujetos por el concierto a las condiciones siguientes, sin perjuicio de las demás que puedan establecerse en cada caso o que se hayan impuesto por la condena: $1^{\circ}$. Trabajar por el tiempo de la condena sujeto a órdenes del director del Camino, del director y capataces del presidio, i de los demás superiores que haya en la obra del camino, i que señale la gobernación a los directores. $2^{\circ}$. Están sujetos al mismo sistema de corrección que los presidiarios, pudiéndose aplicar por el superior a cuyo cargo estén, el máximo del castigo cuando fuere necesario a su juicio. $3^{\circ}$. Si se fugan o pretenden hacerlo serán apremiados a permanecer cumpliendo con el concierto del mismo modo i con las mismas seguridades que los presidiarios, conforme al decreto del Presidente del Estado de 31 de marzo de $1843^{302}$.

\subsection{Los reportes de Hoyos Cabal}

Las penetraciones ideológico normativa y material que se alcanzan con especial éxito en la Montaña del Quindío, se manifiesta también en la forma como el gobernador del Cauca mantiene al gobierno central permanentemente informado sobre los avances de los trabajos del camino y sobre los dineros invertidos en el proyecto, hasta el punto de que con la correspondencia entre Hoyos Cabal y Ospina Rodríguez, se puede conocer cómo la vía se va acondicionando y también todos los problemas que hubo que enfrentar:

- Arrancando desde los Cerrillos: el 15 de agosto de 1843 el gobernador del Cauca le escribe desde Cartago al Secretario del Interior y Relaciones Exteriores: "Desde el 22 de mayo, día en que traslado el presidio a los Cerrillos hasta el 31 de julio, se ha abierto una legua de camino (de sesenta y dos y 
media cuadra de a cien varas) i ( sic) con el ancho desde 30 a 50 varas según la naturaleza del terreno ${ }^{303}$, por entre un bosque de más espeso i antiguo que ofrece la montaña hasta Boquía. Dos tercios de esta extensión han sido abiertos por el presidio, i el resto pagados con el producto de la contribución personal" 304 .

- Los problemas con el personal: Desde Cartago, el 3 de abril de 1844, el gobernador del Cauca le escribe a Ospina Rodriguez: "Luego de que llegué a esta ciudad fui a visitar los trabajos y encontré que, por ineptitud de los directores i (sic) falta de eficacia en los jefes políticos, desde que yo me ausenté se había descuidado quemar el bosque destrozado, menos en una pequeña parte, no obstante, varias prevenciones de la gobernación. Suspendí el derroque de bosque, i destiné los peones, a limpiar la abundante maleza, que había crecido entre los troncos y ramas destrozadas, a amontonar estos i quemarlos, trabajo que se ejecutó al mismo tiempo por los contribuyentes del servicio personal i ha concluido ya... Desde septiembre dejé construyendo otro tambo en Consota, en lugar que promete ser bien sano, con órdenes de que pasara el presidio a él inmediatamente. Ninguna cooperación encontré para ello, ni en las jefaturas políticas, ni en los jefes de los establecimientos. Durante mi ausencia se difirió la traslación sin motivo... concluido el tambo, se le abandonó, de suerte que cuando yo regresé encontré que por no haberlo habitado, o por no haberle puesto humo, se le dañó la mayor parte de la paja... En la parte de la montaña, el trabajo que hai (sic) que hacer es destruir el bosque. El terreno es tan cómodo que con él solo se obtendrá un buen camino. Haré construir un puente en la quebrada Consota, que es la primera de consideración que se encuentra. Su caudal es como el del río San Francisco en Bogotá"305.

- Más avances del camino: el 13 de agosto de 1844, desde Cartago, otro informe de Hoyos Cabal a Ospina Rodríguez habla de los adelantos de la obra, en un

303 "La legua (proveniente del latín leuca) es una antigua unidad de longitud que expresa la distancia que una persona, a pie, o en cabalgadura, puede andar durante una hora; es decir, es una medida itineraria (del latín, iter: camino, periodo de marcha). Dado que una persona recorre normalmente a pie una gama de distancias, la legua se mantiene en esa gama, pero según el tipo de terreno predominante en cada país o según la conveniencia estatal, la palabra legua abarca normalmente distancias que van de los 4 a los $7 \mathrm{~km}$ ". En el siglo XIX se aplicaba en el territorio de la actual Colombia, la legua granadina que es equivalente a 5 kilómetros. La vara es una medida de longitud equivalente a 83,5 centímetros. 
lapso de más de un año: “...desde el mes de junio de 1843 hasta el 3 de julio pasado, se ha abierto una estensión (sic) de Camino de Quindñio de trescientas veintiseis cuadras de largo con el ancho de treinta a cincuenta varas la mitad de ellas, i las otras con el de 25 varas, el número de varas descuajadas es de un millón setenta i un mil quinientas. Por el centro del descuaje se ha abierto una carrera de tres varas de ancho, andable libremente pues se ha cuidado de remover los troncos y raíces..."306

- Culminación del desmonte: con fecha del 5 de febrero de 1845, Hoyos Cabal le informa a Ospina Rodríguez la culminación del trabajo de desmonte del Camino del Quindío, en el tramo correspondiente a la provincia del Cauca: “... Desde el $1^{\circ}$ de agosto de 1844 hasta el 31 de enero de 1845 se han abierto en el Quindío 47.064 varas de camino a lo largo, que por tener el ancho de 25 varas forman un área de 1'176.600 varas cuadradas... No existe ya parte alguna del camino en que haya que desmontar, sino aquellos puntos en convenga anchar el camino por alguna circunstancia..." 307

- Informe sobre los gastos: el siguiente cuadro recoge lo que Hoyos Cabal informa sobre lo gastado en la labor de desmonte del camino del Quindío hasta el 31 de enero de 1845:

\begin{tabular}{|c|c|}
\hline Concepto & Valor \\
\hline Gasto del presidio & $7.456,3$ \\
\hline Valor contribución servicio persona & $2.181,72 / 4$ \\
\hline Gastos fondo especial Camino & $4.574,13 / 4$ \\
\hline Otros gastos de fondo especial Camino & 517,8 \\
\hline Total & 15.729 " $1 / 4$ \\
\hline
\end{tabular}

Cuadro 7. Gastos obras de desmonte del Camino del Quindío entre el $1^{\circ}$ de agosto de 1844 y el 31 de enero de 1845308

El gobernador Jorge Juan Hoyos Cabal advierte en el mencionado informe, que en los gastos del presidio incluyó una pequeña cantidad con la cual dio herramientas a algunos pobladores y sentencia: "En lo sucesivo procuraré dar cuenta separadamente

\footnotetext{
306 A.G.N. Sección República. Fondo Gobernaciones Varias. Rollo 94. Folio 58.

307 A.G.N. Sección República. Fondo Gobernaciones Varias. Orden 1844. Carpeta/legajo 104. Folio 231-232.

308 A.G.N. Sección República. Fondo Gobernaciones Varias. Orden 1844. Carpeta/legajo 104. Folio 231-232.
} 
de este gasto pues espero que las medidas que he tomado para establecer la población de Quindío corresponderán a mis deseos i (sic) entonces será de consideración el gasto que se haga en herramienta". Luego concluye que "La formación de esta población ha sido mirada con entusiasmo por los vecinos de este cantón, i contando por el señor Manuel Ibáñez han ofrecido entre varios ciudadanos cerca de cuarenta cabezas de ganado vacuno para ausiliar (sic) a los pobladores" ${ }^{309}$.

Después, el 12 de marzo de 1845, Hoyos Cabal envió a su enlace con el gobierno nacional, una lista con los nombres de las personas que contribuyeron voluntariamente a la formación de un "deposito de bacas" (sic), con un total de 52 semovientes. Entre los donantes se destacan, el mismo gobernador del Cauca, con una res; Pedro Murgueitio con dos; Manuel José Etayo y Manuel Morales con una; el padre Remigio Antonio Cañarte con una y el también presbítero Fulgencio Castillo con una. ${ }^{310}$

\subsection{Una población en la Montaña del Quindío}

Este último clérigo fue el que le hizo cambiar la mala opinión que Hoyos Cabal tenía sobre la posibilidad y conveniencia de fundar una población en el Quindío, a pesar de que la estrategia de la apertura del camino contemplaba la fundación de poblaciones a mitad de los tramos correspondientes a las provincias del Cauca y Mariquita.

El 27 de febrero de 1844, el gobernador del Cauca le dice a Ospina Rodriguez desde Cartago:

(..) aunque es importante el fomento de una población en el Quindío, en esta provincia; i (sic) aún en las vegas del río Quindío i en las tendidas faldas que se hayan entre Consota i el Roble, cabe muy bien una población que producirá frutos del temperamento templado, creo por ahora no puede pretenderse con su realización, i que es suficiente para conservar el camino i hacerlo cómodo favorecer el establecimiento de labradores a lo largo de él. La población es muy escaza (sic) en esta provincia, esto porque sus habitantes son sedentarios, i se hayan adormecidos en la aparente abundancia de que gozan; tienen algunas de las orillas del Cauca i no afectan terrenos donde el plátano no crecerá robusto, i que sus bacas (sic) i marranos no encuentran fácil alimento. No

309 A.G.N. Sección República. Fondo Gobernaciones Varias. Orden 1844. Carpeta/legajo 104. Folio 231-232.

310 A.G.N. Sección República. Fondo Gobernaciones Varias. Orden 1844. Carpeta/legajo 104. Folio 398. 
será pues posible poblar con jentes (sic) de esta provincia, mientras que de las demás solo Antioquia y el Socorro se presentan a ofrecer pobladores... Eso se conseguiría después de cinco años de constancia, mientras que ahora lo que más importa es proporcionar recursos a los pasajeros en la montaña, i hacer que el camino sea transitado inmediatamente ${ }^{311}$.

Esta posición del mandatario cambió radicalmente y él mismo se lo explicó a Ospina Rodríguez el 18 de enero de 1845 en una carta enviada desde Cartago:

Yo no he creido conveniente activar antes el establecimiento de esta población porque no contaba con otros pobladores que los vagos, ni con otros auxiliares que escasa (sic) fuerza. Habíame propuesto poblar el camino, pero no hacer pueblo. Más ahora, concibo esperanzas de llevar a cabo los deseos del Gobierno porque he encontrado lo que pocas veces se encuentra, un hombre ${ }^{312}$.

Se trata del cura Fulgencio Castillo, a quien el gobernador presenta así, en el encabezado de su misiva:

El presbítero Fulgencio Castillo, naturaly vecino de esta ciudad, ha manifestado a esta gobernación que se halla dispuesto a consagrarse a fomentar una nueva población a orillas del río Quindío, o de aguas tributarias suyas, siempre que el gobierno coopere a aquella empresa, i (sic) en el concepto de que los auxilios acordados por la legislatura por su auto del 18 de junio de 1844 comprendan a dicha población. La Gobernación ha aceptado sus patrióticos ofrecimientos; pero no ha podido asegurarle que el decreto legislativo citado comprende a la población que se intenta.

Por esa misma razón, el mandatario solicita: "del gobierno que declare si la población Quindío tendrá los auxilios que conforme al decreto legislativo del 18 de junio parecen que se han ofrecido a la población Velazquinal", y plantea una alternativa ante la posibilidad de una respuesta negativa:

En caso de que sea negativa la declaración, pido que del fondo especial del camino se asigne un sueldo al Presbítero Fulgencio Castillo, para que con el permiso Diocesano administre los sacramentos i (sic) celebre misa en Quindío, siendo al mismo tiempo un ajente (sic) de la Gobernación para el

311 A.G.N. Sección República. Fondo Gobernaciones Varias. Rollo 94. Folio 639.

312 A.G.N. Sección República. Fondo Gobernaciones Varias. Carpeta 104. Folio 180. 
establecimiento de la población, sin perjuicio de solicitar del Congreso que se estienda (sic) a la población Quindío las gracias concedidas por el decreto de 18 de junio ya citado ${ }^{313}$.

Como al margen del mismo documento Ospina Rodríguez autoriza la contratación del levita, se debe concluir que el gobierno nacional consideró que el alcance de la norma mencionada no cubría la fundación de poblaciones en el marco de la apertura del Camino del Quindío, que estaba sujeta a una reglamentación especial.

Posteriormente, el 13 de abril de 1845, Hoyos Cabal le informa desde Buga a Ospina Rodríguez, sobre el descontento de los habitantes de Cartago, con la noticia sobre la imposibilidad de fundar una población en el Quindío y también, sobre la imposibilidad de nombrar un cura con fondos del camino, ya que propone modificar una resolución que amparentemente lo impide.

La modificación del acto administrativo permitiría, según el gobernador, nombrar un cura que se traslade de Pindaná o de Cartago a la zona, para celebrar misa cada quince días y servir de agente de la administración provincial en la población; circunstancia que favorecería el poblamiento con la gente de Antioquia: "No necesita más que pagar el cura, porque aquellas jentes (sic) es lo que piden, i (sic) hacerles lijeras (sic) anticipaciones para la primera cosecha que ellos pagarán en servicios en el camino" 314 .

De esta misma situación dio cuenta el sucesor de Hoyos Cabal en la gobernación del Cauca, Laureano Mosquera, en el informe que entregó a la Cámara provincial de Buga, el 15 de diciembre de 1845, cuando dijo que la fundación de la población Quindío no pudo prosperar, pese a la adecuada ubicación, su clima y la abundancia de sus aguas; al tiempo que mostraba cómo los interesados podrían aprovechar las otras garantías que disponía la ley, para quienes decidieran poblar el camino del Quindío: "los pobladores de aquel punto tienen el derecho que la lei (sic) ha dado a los simples pobladores de un nuevo camino, i (sic) si el ajente (sic) del gobierno de la provincia los proteje (sic) abiertamente, creo que podrán prosperar"315.

313 A.G.N. Sección República. Fondo Gobernaciones Varias. Carpeta 104. Folio 180.

314 A.G.N. Sección República. Fondo Gobernaciones Varias. Carpeta 104. Folio 427.

315 A.G.N. Sección República. Fondo Gobernaciones Varias. Carpeta 104. Orden 1844. Folios 38-39. 


\section{La fundación de Santa Rosa de Cabal}

En ese mismo informe, Mosquera también hablaba sobre la evolución de la población de Cabal, creada en 1844, durante el período de Hoyos Cabal, en forma expedita por el gobierno de la Nueva Granada, en las orillas del río San Eugenio, en la parte más nororiental de la provincia del Cauca, y pensada como un artículador en la ruta que se pretendía abrir por la margen derecha del Cauca hacia las nuevas poblaciones fundadas en el sur de Antioquia y hacia Medellín, y como un centro de acopio de mano de obra antioqueña para la reapertura y mantenimiento del camino del Quindío, proyecto estratégico del Estado neogranadino, que tenía como una de sus herramientas normativas, la fundación de una población entre Cartago y la cima de la cordillera Central y otra entre esa cúspide e Ibagué.

El gobernador recién posesionado decía de Cabal, posteriormente llamada Santa Rosa de Cabal: "Aún no se ha hecho la demarcación precisa del punto donde deba fundarse, ni el señalamiento del lugar destinado a la plaza, de modo que los pocos habitantes que hai (sic) en ella están dispersos en seis chosas (sic). Será una de las primera cosas que haré cuando me traslade a Cartago, lo que ejecutaré cuando concluya la reunión de la Cámara”316.

Lo que, al tenor de lo reportado por el funcionario, podía parecer un proceso inconcluso, fue sin duda la expresión de lo que Reboratti calificó como la frontera estatal -diferente a todo lo que hasta ese momento había pasado en el suroriente antioqueño-, la evidencia de la penetración del Estado andino en la periferia territorial planteada por Maihguasca, y una prueba irrefutable de que la llegada de los "paisas" al Cauca, fue impulsada por la élite política y empresarial de esa provincia, interesada en el poblamiento con familias laboriosas, blancas, extensas y católicas y en la mano de obra que estas aportarían para la construcción y mantenimiento del camino del Quindío y la conexión con la vecina provincia del norte.

Desde que el gobernador Hoyos Cabal supo de las pretensiones de los antioqueños asentados entre los ríos Chinchiná y Consota a comienzos del decenio de los cuarenta del siglo XIX, Fermín López y sus asociados tuvieron un aliado en el propósito de ser beneficiados con la concesión de baldíos que entregaba el Estado a quienes fundaban poblaciones. 
De acuerdo con los archivos consultados, el mencionado funcionario se da cuenta de la presencia de los antioqueños en las inmediaciones del río San Eugenio, cuando conoce una representación de aquellos en la que solicitan el establecimiento de una nueva población en el norte del cantón de Cartago, en la falda de la cordillera central de los Andes, en arreglo con lo dispuesto por la Ley del 6 de mayo de 1834, que concede baldíos a quienes vayan a fundar nuevos asentamientos.

La mencionada solicitud, dirigida al jefe político del cantón de Cartago, está fechada el $1^{\circ}$ de octubre de 1842 y firmada en esa ciudad por Fermín López. El 12 de octubre, se da orden que se le dé traslado al gobernador del Cauca para que resuelva sobre el asunto.

De acuerdo al registro de sus despachos oficiales en el Archivo General de la Nación, Jorge Juan Hoyos Cabal se posesionó como Gobernador del Cauca, en ese mismo mes y año, y solo conoció de la representación de Fermín López, cuando viajó a Cartago a ponerse al frente de los trabajos de reapertura del camino del Quindío.

Hoyos Cabal remite la petición al secretario del Interior Mariano Ospina Rodríguez el 14 de marzo de 1843. El alto dignatario capitalino responde que para que el Poder Ejecutivo otorgue las excepciones y conceda las tierras baldías a los pobladores del paraje desierto, se necesita saber el número de individuos y las verdaderas posibilidades de que el poblado prospere; información que no hace parte del documento elevado por los interesados. ${ }^{317}$

Con el propósito de subsanar lo anterior, con fecha del 18 de junio del mismo año y fechada en Santa Rosa, Fermín López y sus asociados envían, a través del gobernador del Cauca, una nueva representación donde hablan del elevado número de personas interesadas en poblar las "orillas del río Chinchiná en el norte de la provincia" y sembrar en sus diferentes climas los productos que son del interés del mercado de Cartago y que llegarán con mayor recurrencia y rapidez, luego de que ellos mismos perfeccionen el camino, "que ahora nos sirve apenas en estado de trocha"318.

En el oficio remisorio que acompaña la nueva petición de Fermín López y sus colonos, Jorge Juan Hoyos Cabal expresa su opinión favorable:

Yo juzgo importante esta población como lo he manifestado ya; la posibilidad de llevar a efecto la empresa se deduce de la experiencia a cerca del modo como

317 A.G.N. Sección República. Fondo Gobernaciones Varias. Rollo 86. Folio 360.

318 A.G.N. Sección República. Fondo Gobernaciones Varias. Rollo 86. Folio 642. 
se ha formado otra de las poblaciones de las nuevas. El carácter laborioso i (sic) constitución robusta de los habitantes de la provincia de Antioquia, son una garantía adicional para el buen éxito de la población ${ }^{319}$.

Sobre el tema no se vuelve a cruzar ningún otro documento entre Hoyos y Ospina, hasta el 3 de abril de 1844, cuando el gobernador le remite una nueva representación de los colonos. En el oficio que lleva la nueva solicitud, el funcionario argumenta a favor del pedido: "Reitero a usted las consideraciones manifestadas por mis comunicaciones de 14 de marzo de 1843, número 41 i (sic) de 12 de julio último, número 19". Refuerza su alegato, trayendo a cuento el papel de la nueva población en la ruta que una al Cauca con Neira y Salamina y lo que implica para el comercio con la provincia de Antioquia y trae otro elemento a favor de la fundación de Santa Rosa: "La afluencia de éstas personas hacia (sic) aquel sitio, producirá entre otras ventajas, la de obtener buenos peones que trabajarán gustosos en los ulteriores trabajos necesarios para la conservación del camino del Quindío"320. Amarra la posibilidad de que se funde el poblado a uno de los proyectos más importantes de la República de la Nueva Granada y de la provincia del Cauca.

La petición mencionada es firmada en Santa Rosa el 22 de marzo de 1844 y ubica el lugar donde se pretende establecer la población: “...El paraje decierto (sic) valdío (sic) que hemos elegido para planear la nueva población, es a propósito para el efecto, cercano al río denominado Otún, i (sic) sobre la nueva vía de comunicación entre Cartago i Medellín por la parroquia de Salamina, el dista poco del camino del Quindío, que recientemente se está abriendo quedando hacia (sic) el norte de él".

En cuanto al número de individuos que harán parte del poblamiento y que es información importante a la luz de la ley respectiva, la representación dice: "De los que representamos, cincuenta i (sic) siete somos cavesas (sic) de familia y muchos más somos miembros de otras parentelas, todas estando actualmente en Santa Rosa, con el deliverado (sic) ánimo de radicarse inmediatamente".

Además, la demanda trae el ofrecimiento de una contraprestación muy útil:

Como prueba de nuestro buen deseo i intención de ejercer nuestra industria en provecho público nos comprometemos desde ahora solemnemente a establecer cuando seamos pocesionados (sic) en Santa Rosa, posadas o 
mesones, de a dos leguas en dos leguas en el indicado camino de Medellín desde donde se separa desde Quindío hasta un mencionado sitio de Santa Rosa, ofreciendo además establecer otras posadas en el mismo camino que de aquí va para Salamina, luego que se le dé la dirección que se han propuesto los esploradores (sic) $)^{321}$.

En el mismo legajo, aparecen otros dos documentos:

- Un concepto emitido por un señor Borda, dirigido al parecer al Secretario del Interior y Relaciones Exteriores Mariano Ospina Rodríguez, que dice: "Parece que debieran concedersele todos los privilegios y esenciones (sic) que permite tal lei (sic), i que al efecto procediera autorizando al gobernador como mejor impuesto en este negocio para conceder al establecimiento de la nueva población, el número de fanegadas de tierras valdía (sic) que estime conveniente i que no pase de 12.000 , que es el máximo señalado en el artículo primero de dicha lei: que el gobernador quede autorizado para asignar a cada cabeza de familia hasta 60 fanegadas bajo las condiciones señaladas en los artn por la fertilidad de la tierra i salubridad del paraje, esistencia (sic) de minas o de otros medios de 60 fanegadas bajo las ículos $4^{\circ}$ i $5^{\circ}$ de la lei citada" 322 .

- Una nota de Ospina Rodríguez al margen de la carta del 3 de abril, fechada el 25 de abril de 1844 y despachada el $1^{\circ}$ de mayo, que ordena al Gobernador del Cauca iniciar los trámites que permitan conocer si las tierras pretendidas por Fermín López y sus asociados son realmente baldías y determinar el punto más conveniente para establecer la población, de manera que ofrezca las mayores ventajas en relación a unos objetos señalados a renglón seguido por el alto dignatario: “...crecimiento i (sic) conservación de la población por la fertilidad de la tierra i salubridad del paraje, esistencia (sic) de minas o de otros medios de industria, abertura i conservación del camino que debe unir las dos provincias para lo cual debe atenderse que la población quede en un punto por donde debe pasar el camino, sin desviarse de la línea más conveniente i que la población quede en la mediación del desierto que separa los puntos poblados más inmediatos de las dos provincias por aquella parte; facilidad de poblar por la existencia de los elementos necesarios para los edificios" ${ }^{\text {"23 }}$.

En cumplimiento de esas instrucciones, Hoyos Cabal hizo tres cosas:

321 A.G.N. Sección República. Fondo Gobernaciones Varias. Rollo 94. Folio 751.

322 A.G.N. Sección República. Fondo Gobernaciones Varias. Rollo 94. Folio 751.

323 A.G.N. Sección República. Fondo Gobernaciones Varias. Rollo 94. Folio 751. 
- Fijó en un lugar público una invitación para que los que creyesen que tenían algún derecho de dominio o posesión en el “...territorio comprendido desde el río Chinchiná al norte, hasta el Consota i (sic) la Vieja al sur, i desde el Cauca en el poniente hasta la cumbre de las montañas que dividen esta provincia de las de Mariquita...", lo demostraran presentando sus títulos o alegando sus derechos antes del $1^{\circ}$ de julio de 1844324 .

- Citó a declarar a unos ciudadanos que pudiesen testificar sobre la condición de baldíos de los terrenos pedidos por los antioqueños en el río San Eugenio325.

- Viajó al punto de Santa Rosa los últimos días de julio, para absolver personalmente los interrogantes planteados por el Secretario del Interior y Relaciones Exteriores326.

Como en los archivos consultados no aparece ninguna manifestación sobre los terrenos solicitados por Fermín López y sus asociados, con ocasión de la invitación pública y la adjudicación posterior de los mismos, se concluye que nadie alegó ningún tipo de interés en el negocio.

Las comparecencias de los testigos citados, se verificaron el 3, 4 y 6 de agosto de 1843. Los citados, Alfonso López Hoyos, José María Palomeque y Ramón Gómez de Lasprilla, debieron contestar las siguientes preguntas:

1. ¿Tiene usted o a (sic) pretendido alguna vez tener derecho alguno sobre las tierras que en este cantón se encierran entre los ríos Chinchiná i (sic) Otún i desde la cumbre de la cordillera oriental de éste valle hasta el río Cauca? 2. ¿Sabe usted o a (sic) oído decir que alguna persona tenga o haya pretendido tener derecho a las mismas tierras? 3 . ¿Le consta a usted que dichas tierras han permanecido constantemente incultas, i aun olvidadas del hombre hasta que algunos individuos procedentes de la provincia de Antioquia han penetrado en ellas i hecho rocerías, con el ánimo de poblar aquel desierto? 4. ¿Le consta a usted que han sido reputadas siempre como tierras valdías (sic), i como tales se tienen i reputan hasta ahora? ${ }^{327}$.

El gobernador Jorge Juan Hoyos Cabal presentó el 7 de agosto de 1844 a Ospina Rodríguez, un reporte minucioso de su visita a los terrenos identificados por los

\footnotetext{
324 A.G.N. Sección República. Fondo Gobernaciones Varias. Rollo 94. Folio 46.

325 A.G.N. Sección República. Fondo Gobernaciones Varias. Rollo 94. Folio 751.

326 A.G.N. Sección República. Fondo Gobernaciones Varias. Rollo 94. Folio 751.

327 A.G.N. Sección República. Fondo Gobernaciones Varias. Rollo 94. Folio 751.
} 
antioqueños como Santa Rosa, absolvió todas las inquietudes de la Secretaría del Interior y verificó el cumplimiento de los requisitos legales; así como estableció lo oportuno que sería establecer una población en ese punto, como enlace en la ruta hacia el sur de Antioquia y adjuntó un croquis para fortalecer su argumentación. El reporte estaba acompañado por un mapa que detalla las condiciones del terreno solicitado.

Al respecto dijo el mandatario provincial: "La situación es ventajosa para la fundación del pueblo tanto porque se halla en un punto cuasi equidistante de Cartago y de Neira, como porque su temperamento medio, la fertilidad del terreno i (sic) lo fácil de descuajar los bosques convidan para cultivar la tierra..." Por esa misma razón propone la adjudicación de doce mil fanegadas, la cantidad más grande de baldíos permitida por la ley.

Al relacionar el territorio con eventuales adelantos en materia de la industria agrícola y la minería, el funcionario dice que el sitio donde se debe asentar la población es "digno de llevar el nombre de un filósofo granadino, de un humanista, de un patriota excelso, sacrificado por nuestros opresores, de un químico cuyo nombre se cita con respeto en Europa, del ilustre general José María Cabal, Cabal es el nombre que propongo para esta población, en honor al modesto y valiente procer de la independencia" 328 . (Ver mapa 5)

El 21 de agosto de 1844, el secretario del Interior, en nota al margen del oficio anterior, ordena expedir el decreto adjudicando el número de fanegadas de tierras baldías recomendado por Hoyos Cabal.

El decreto fue expedido siete días después, el 28 de agosto del mismo año y fue publicado en la Gaceta de la Nueva Granada el $1^{\circ}$ de septiembre de 1844. En él se establece que la población se llamará Cabal y las demás instrucciones que se deberán observar para el establecimiento de la población y la adjudicación de doce mil fanegadas baldíos a los colonos antioqueños asentados a orillas del San Eugenio y a los que vendrían después ${ }^{329}$.

328 A.G.N. Sección República. Fondo Gobernaciones Varias. Rollo 94. Folio 751.

329 Gaceta de la Nueva Granada. № 700. Domingo 1º de septiembre de 1844. Biblioteca Nacional de Colombia. 
El despliegue del Estado en el poblamiento de la Montaña del Quindío y la fundación de Santa Rosa de Cabal, $1840-1845$

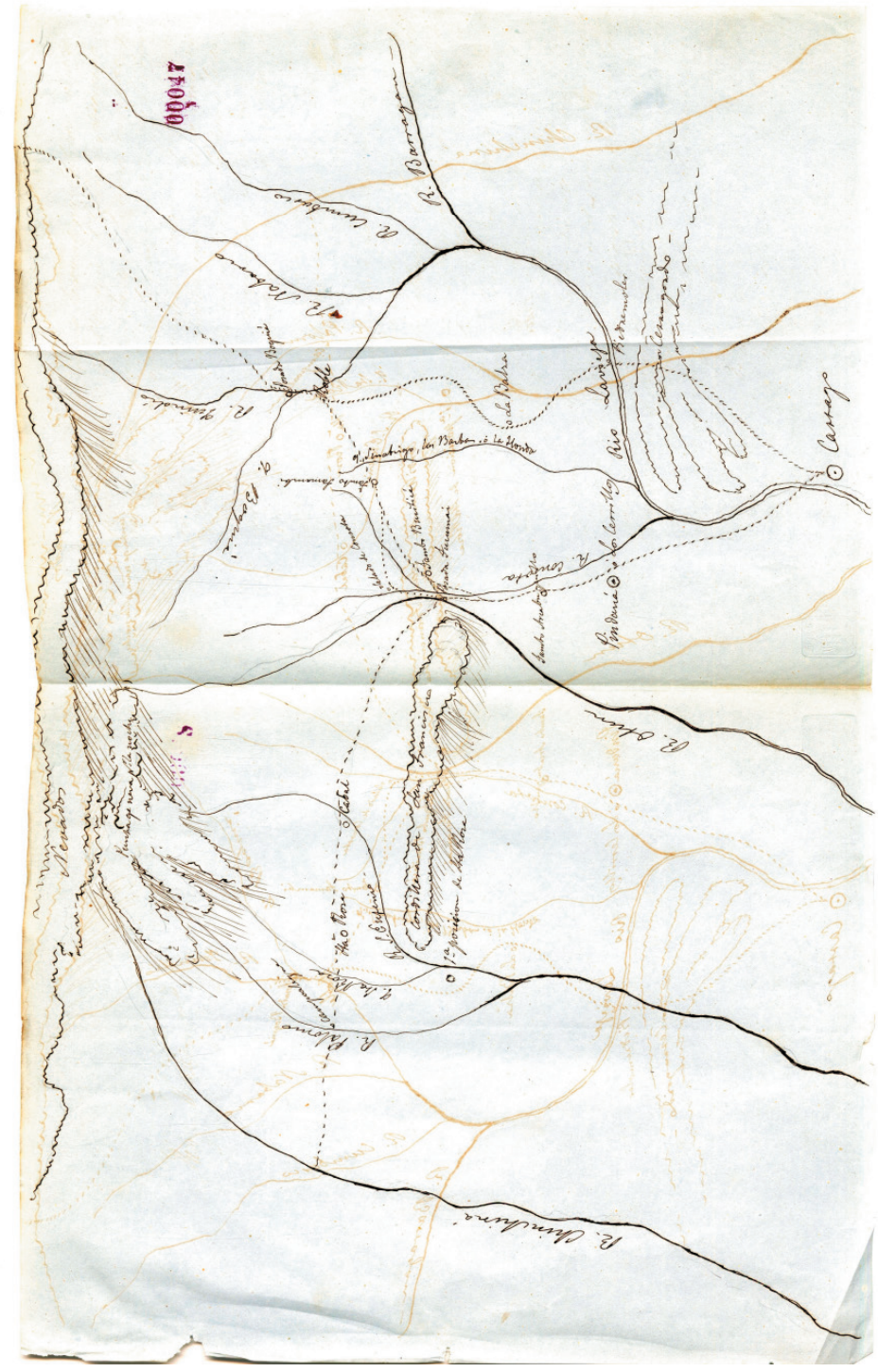

Mapa 5. Croquis que ilustra la conveniencia de fundar a Santa Rosa de Cabal ${ }^{330}$

330 Croquis que el Gobernador Jorge Juan Hoyos Cabal envió al Secrerario del Interior y Relaciones Exteriores Mariano Ospina Rodríguez, para ilustrar la conveniencia de fundar una población con los colonos antioqueños llegados a los parajes limitados por los ríos Chinchiná y Otún. Debajo de la cordillera de San Francisco, se observa una leyenda que dice: "1a posición de Santa Rosa”, en referencia al lugar al que llegaron Fermín López y sus amigos en 1837. Archivo General de la Nación. Sección República. Fondo Gobernaciones Varias. Rollo 94. Folio 47. 
El 14 de septiembre del mismo año, Hoyos Cabal envía copia del decreto al comisario de Santa Rosa, con lo que se concluye que, a nivel del cantón de Cartago, se había dispuesto de un funcionario que se encargara de los asuntos públicos en la zona de colonización. Este agente oficial tenía la misión de dar a conocer el contenido de la disposición del gobierno nacional; cometido que solo llevó a cabo el 13 de octubre. ${ }^{331}$

Entre tanto, la Cámara Provincial del Cauca expidió una ordenanza el 29 de septiembre, para reglamentar la forma como debían distribuirse las doce mil fanegadas adjudicadas ${ }^{332}$.

De la forma descrita, se le dio vida legal a lo que hoy es el municipio de Santa Rosa de Cabal, la primera población antioqueña asentada en el norte del Cauca y gracias a la actividad de sus impulsores de lado y lado: Fermín López y sus amigos de Sonsón y Salamina y las autoridades de la República de la Nueva Granada; en especial el gobernador Jorge Juan Hoyos Cabal.

Esa actividad refleja una institucionalidad que, con todas sus falencias y escases de recursos, funcionó para aplicar una normatividad pensada para ampliar la frontera interna del joven Estado y en especial, el nororiente de la entonces provincia del Cauca. También dio resultado la figura jurídica colonial de la representación y todos los demás mecanismos normativos y burocraticos dispuestos para que los ciudadanos hicieran solicitudes a los mandatarios.

En lo que se refiere al acceso a la tierra, el proceso se inició el 18 de agosto de 1838, cuando los antioqueños recién llegados a Cartago, luego de su travesía por las soledades delimitadas por los ríos Chinchiná y Otún, se avecinan en ese cantón, con el deliberado propósito de beneficiarse de las políticas de estímulo al poblamiento. Para la prueba, se puede transcribir un aparte del acta de avecindamiento suscrita ante testigos e interesados por el alcalde parroquial Tomás Osorio: "Por presentado admítanse como vecinos de esta parroquia a los peticionarios; y en efecto prestaron el juramento de sujetarse a las cargas de vecinos y estar dispuestos ir a poblar deciertos (sic) se les concederán privilegios y títulos" ${ }^{\prime 33}$.

En el caso de las representaciones de Fermín López con relación a la creación de la población y la adjudicación de tierras, se puede sospechar que su trámite positivo

331 Archivo Del Municipio De Santa Rosa De Cabal.

332 Archivo Del Municipio De Santa Rosa De Cabal.

333 Luís Enrique Valencia R. Historia de Santa Rosa de Cabal, 39. 
fue favorecido por la presencia del Gobernador del Cauca en Cartago, a raíz de las obras de reapertura del Camino del Quindío. Un proyecto que para Hoyos Cabal podía ser favorecido con la mano de obra antioqueña aportada por los colonos de Santa Rosa, que igualmente permitiría la conexión vial entre Cartago, Neira y Salamina, por la margen derecha del Cauca.

Si a esta actividad estatal, entendida como la relación ciudadanos-instituciones del Estado, se suma la que, en la misma época, en forma a veces paralela, pero con los mismos propósitos se lleva a cabo en el presidio de Boquía y el camino del Quindío, se debe revalorar el papel del poder público neogranadino al promediar el siglo XIX y en especial, el que jugó en los procesos de colonización. Lo que se ve es un Estado actuante, un proceso de colonización impulsado por este y un interés de los caucanos influyentes por poblar con antioqueños. 


\section{CONCLUSIONES}

Lo arrojado por el balance historiográfico, no permite llegar a afirmaciones concluyentes sobre el tratamiento que al concepto de frontera le han dado historiadores e investigadores nacionales o extranjeros, diferentes a las adelantadas por el vallecaucano Jaime Londoño Motta cuando analiza la recepción y aplicación de la obra de James J. Parsons en Colombia ${ }^{334}$.

Son excepciones las obras de Catherine LeGrand ${ }^{335}$ y Hermes Tovar Pinzón ${ }^{336}$, únicas dentro de los denominados trabajos "clásicos", en plantear por separado modelos alternativos al turneriano latente en Parsons.

También pretende serlo, dentro de las obras de historia regional, la investigación de Luis Javier Ortiz y Oscar Almario ${ }^{337}$, quienes rechazan enérgicamente las críticas de Jaime Londoño y proponen un modelo que supera al turneriano, emparentado con el "patrón de archipiélago" de Richard Morse, propuesto por el mismo Londoño como alternativa al de Parsons, y sustentado en unas regiones bosquejadas con anterioridad por el historiador Ricardo de los Ríos Tobón, para entender cómo emerge Caldas a comienzos del siglo XX, en un trabajo que hace parte del balance precedente ${ }^{338}$.

\footnotetext{
334 Londoño Motta, El modelo de colonización, 190.

335 LeGrand, Colonización y protesta, 20.

336 Tovar Pinzón, Que nos tengan en cuenta, 15.

337 Almario, Oscar. Ortiz, Luís Javier. Caldas: una región nueva, 22.

338 De Los Ríos Tobón, Orígenes.
} 
Se merece una mención especial lo planteado por Jaime Lopera Gutiérrez, cuyo trabajo sobre la colonización del Quindío fue incorporado al balance historiográfico en el compartimiento de la historia regional ${ }^{339}$. El investigador califica la colonización del oriente antioqueño como "un proceso centrífugo", similar a lo que ocurre en la región de frontera sobre la que habla Londoño para explicar el sentido de aplicar el modelo de "patrón de archipiélago" a la expansión de la frontera en Colombia a partir del siglo XIX.

Igualmente, hay que anotar que no todos los trabajos incluidos en el balance provenían del plexo histórico y no todos se plantearon como problema la caracterización de la frontera y su diferencia con la colonización; tarea inacabada, incluso en aquellos trabajos que tienen el propósito de definir y deslindar los términos.

Otro tanto ocurre con el tema de la colonización y en particular, de la colonización estatal. En muchas de las obras denominadas, la amplitud de su foco impide observar los detalles de la interveción del Estado en la colonización y el interés por los sucesos posteriores a 1850 hacen que el mismo enfoque deje por fuera acontecimientos relevantes en la frontera, distintos a los conflictos por la tierra entre los concesionarios y los colonos en el sur y sur oriente de Antioquia en la primera mitad del siglo XIX, de cuyo relato se ocupa toda la historiografía sobre la materia. Sin embargo, el trabajo de Fabio Zambrano y Olivier Bernard ${ }^{340}$, valora el papel del Estado al decir que fue el animador de la colonización del Quindío, con medidas diferentes a la simple titularización de los baldíos en la década de 1840, ámbito temporal de la presente investigación.

Cuando se empiezan a analizar las obras de historia regional, el papel del Estado se visibiliza como protagonista. Así lo califica Olga Cadena Corrales al hablar de la colonización del Quindío hasta 1874, año en que hay un cambio sustancial en la política de poblamiento ${ }^{341}$.

La tendencia se acentúa cuando se abordan los textos que hablan de referentes históricos como la apertura del camino del Quindío, el establecimiento del presidio de Boquía y la fundación de Santa Rosa de Cabal - focos de esta investigación-, sin que la descripción de la voluntad y quehacer del Estado lleve a concluir que hubo

\footnotetext{
339 Jaime Lopera Gutiérrez, La colonización del Quindio, 56.

340 Zambrano Bernard y Olivier, Fabio. Ciudad y Territorio, 150.

341 Cadena, Procesos de colonización, 15.
} 
una colonización de corte estatal. Todo lo anterior aparece como la ínfima reacción del Estado al desbordamiento de los antioqueños.

Pero hay un trabajo de los etiquetados con el rótulo de historia regional, que muestra el camino hacia la identificación de un papel mucho más consistente de los niveles nacional y territorial del Estado en el proceso de colonización del norte del Cauca al promediar el siglo XIX. Se trata de la obra de Nancy P. Appelbaum ${ }^{342}$, que muestra cómo el proceso de colonizacion antioqueña del norte del Cauca, era la expresión de una política racialista de las élites de esa provincia y que en consecuencia con ella, se tomaron medidas oficiales para favorecer el poblamiento paisa en la llamada Montaña del Quindío. El aporte de la canadiense estriba en que, desde esa visión, la colonización más al sur del río Chinchiná no es el resultado exclusivo de la imparable y ejemplarizante avalancha de los laboriosos paisas, frente a la inactividad y desidia de las élites caucanas, copadas por el fenómeno migratorio o, lo que es peor, absolutamente desinteresadas en lo que pasaba en esa parte del territorio. Por el contrario, es la expresión de una visión racialista del poblamiento y del desarrollo territorial; la puesta en marcha de una política de la provincia del Cauca para su frontera con Antioquia.

De esta forma, entra como protagonista de la colonización de vertiente del siglo XIX, el Cauca y su élite. Un actor -invisible hasta el momento- con necesidades e intereses muy diferentes a los agenciados por los colonos, empresarios territoriales y gobernantes antioqueños $\mathrm{y}$, al menos en lo que tiene que ver con el lapso corrido entre 1840 y 1845, una provincia del Cauca muy diferente a la que, en términos de entidad territorial, ha sido referenciada por la historiografía nacional. Con límites y problemas particulares y un centro de impulsión política diferente a Popayán, esa provincia contribuye a la construcción de nación y de Estado, teniendo como escenario su frontera norte.

Simultáneamente, se abre ante los ojos de la investigación una veta conceptual y fáctica para extraer material útil a la discusión en torno a la frontera y a su presencia en el fenómeno colonizador decimonónico. ¿Qué tipo de frontera es la que surge del espontáneo o deliberado encuentro de dos entidades socioculturales tan caracterizadas y diferentes como eran Cauca y Antioquia? ¿Es suficiente la noción turneriana para entender la frontera que separaba a esos dos países?

En términos generales, es paradójico que las autoridades del Cauca operativicen una serie de decisiones de carácter estatal -leyes, decretos legislativos, decretos

342 Appelbaum, Dos plazas y una nación, 91. 
ejecutivos y resoluciones-, que son tan solo una pequeña parte de los muchos actos expedidos por las ramas del poder público de la Nueva Granada, en desarrollo de unas políticas sobre baldíos y poblamiento, que fueron evolucionando de acuerdo con las necesidades, aciertos, errores y coyunturas propias de una joven república; sin que esa circunstancia, que también la vivió Antioquia, haya merecido considerar la posibilidad de hablar de una colonización estatal.

Quizas lo anterior lo puedan explicar algunas de las conclusiones arrojadas por el balance y que tienden a decir que es imposible una caracterización absoluta y excluyente de la actividad colonizadora, ya que la iniciativa espontánea de los colonizadores individuales, los esfuerzos de los grupos que buscaron acceder a la tierra vía el establecimiento de poblaciones y la inversión de los empresarios territoriales, no habría sido posible sin el concurso del Estado. Un Estado que no es visible en su nivel territorial. Para la mayoría de los historiadores incluidos en el estado del arte, el Cauca es el mismo a lo largo del siglo XIX y quienes mencionan algunos de los actores institucionales no profundizan en el hecho de que aparezcan nuevos centros de impulsión política.

En ese sentido, se trae a colación la afirmación de Roberto Luis Jaramillo en su ensayo sobre la colonización antioqueña, en el sentido de que ese fenómeno incluyó en forma simultánea las modalidades de colonización espontánea y de colonización planeada, entendida esta última como la liderada por los empresarios que jalaban los hilos del Estado. ${ }^{343}$

También es útil la aplicación a los casos concretos de la apertura del camino del Quindío, el asentamiento del presidio de Boquía y la fundación de Santa Rosa de Cabal, las definiciones sobre colonización y frontera y los modelos explicativos de las mismas que ofrecen Jaime Londoño y Carlos Reboratti; así como una caracterización de la provincia del Cauca de la época y un repaso a las normas expedidas por el Congreso y el poder ejecutivo de ese entonces, en torno al poblamiento.

De la lectura de Londoño y Reboratti en el segundo capítulo, se debe concluir que la discusión sobre la frontera, asociada al tema de la colonización del siglo XIX no ha llegado a la etapa de las definiciones, aunque el cruce entre lo categorizado por el argentino y lo encontrado en la bibliografía y en los documentos de archivo, ayuda a conocer en forma ejemplar las fases asociadas a esos conceptos y, lo que es más importante, a ver con mayor claridad el papel de las instituciones del Estado en el poblamiento del nororiente del Cauca en la mitad del siglo XIX. 
Sus funcionarios, como veremos en el caso del Cauca, expidieron en su órbita, regulaciones para mejorar las condiciones de ejecución de la obra de apertura del Camino del Quindío, que imponía enormes retos y entrañaba grandes obstáculos. Decretos y resoluciones, redactadas e implementadas por el gobernador Jorge Juan Hoyos Cabal, con el visto bueno del secretario de Estado del Interior y de Relaciones exteriores, completaron un corpus normativo propio de un proceso de colonización estatal. La República continuó expidiendo normas que permitieran el cumplimiento de los propósitos fijados en el decreto del 15 de julio de 1842. Una de ellas, también recogida en la Recopilación Granadina, es la lei (sic) 5 de junio 18 de 1844, que apropia fondos para la iglesia, el párroco y el culto de una nueva parroquia en la montaña del Quindío.

Aún con las precariedades que desde la actualidad se pueden advertir en el ejercicio normativo de las ramas ejecutiva y legislativa de la Nueva Granada en la mitad del siglo XIX, las leyes y decretos expedidos eran actos administrativos complejos, que exigían conocimiento de los territorios y la voluntad de planificar la forma de utilizar importantes recursos, como lo eran en su momento los baldíos; tal como lo demanda, al decir de Carlos Reboratti, la constitución de una frontera planificada desde el Estado y una colonización estatal.

En el cuarto capítulo se ve cómo la frontera nororiental de la provincia del Cauca es la periferia territorial y social que el Estado debe penetrar de diversas formas, para consolidar su proyecto centralista y republicano, en alianza con facciones de élites regionales y locales, que comparten con las bogotanas visiones racialistas comunes y que explican la decisión de promover el poblamiento con antioqueños.

Un aspecto importante es el papel jugado por el proyecto de reapertura del camino del Quindío como dinamizador de la presencia del Estado en esa frontera y en su poblamiento, dado lo vital de los asentamientos para el mantenimiento de la vía, el el apoyo a los viajeros y comerciantes. Es quizás el aspecto que determina el poder decir que en el tiempo y en el espacio del trabajo investigativo, la colonización fue un proyecto estatal.

Esa presencia estatal modela la región y determina su demografía; al tiempo que las decisiones adoptadas son el reflejo de las visiones y maneras como entienden el mundo las élites nacionales y locales.

Si a esta actividad estatal, entendida como la relación ciudadanos-instituciones del Estado, se suma la que, en la misma época, en forma a veces paralela, pero con los 
mismos propósitos se lleva a cabo en el presidio de Boquía y el camino del Quindío, se debe revalorar el papel del poder público neogranadino al promediar el siglo XIX y en especial, el que jugó en los procesos de colonización. Lo que se ve es un Estado actuante, un proceso de colonización impulsado por este y un interés de los caucanos influyentes por poblar con antioqueños. 


\section{BIBLIOGRAFÍA}

ALMARIO, Óscar y ORTIZ, Luis Javier. Caldas: una región nueva, moderna y nacional. Medellín: Universidad Nacional. Sede Medellín, noviembre de 2007.

APPELBAUM, Nancy P. Dos plazas y una nación: raza y colonización en Riosucio, Caldas, 1846-1948. Bogotá: Universidad de los Andes, Universidad del Rosario e ICANH, octubre de 2007.

APRIL, Jacques. La ciudad colombiana. Siglo XIX y Siglo XX. Bogotá: Banco Popular, 1992.

ARANGO CANO, Jesús. Origen y desarrollo del Camino del Quindío. Armenia: Óptima Gráfica Ltda., 2003.

BOTERO JARAMILLO, Natalia. El problema de los excluidos. Las leyes contra la vagancia en Colombia durante las décadas de 1820 a 1840. En: Anuario Colombiano de Historia Social y de la Cultura. Vol. 39. No 2 -Jul-Dic 2012.

CADENA CORRALES, Olga y PÉREZ BRAVO, José Manuel. Colonización del Quindío. En: Historia de Nuestra Región. La Historia del Quindío. La Crónica. Armenia.

CADENA CORRALES, Olga. Procesos de colonización en el Quindío: El Caso Burila. Tesis. Bogotá: Universidad Nacional de Colombia, 1988. 
CAMARGO BONILLA, Álvaro Hernando. El camino del Quindío y la cambiante biodiversidad en la provincia Quimbaya. En: Ensayos de Historia Quindiana. Volumen 2. Biblioteca de Autores Quindianos. Armenia: Centro de Publicaciones de la Universidad del Quindío, 2011.

CHRISTIE, Keith H. Oligarcas, campesinos y política en Colombia: Aspectos de la historia socio-política de la frontera antioqueña. Trad. Fernan González. Ciudad: Editorial, año.

DE LOS RÍOS TOBÓN, Ricardo. Orígenes y colonización hasta 1850. Manizales: Biblioteca de Escritores Caldenses. Imprenta Departamental, 1983.

DE POMBO, Lino. Recopilación de leyes de la Nueva Granada. Bogotá, 1845. GARCÍA NOSSA, Antonio. Geografía Económica de Caldas. 2a Edición. Bogotá: Banco de la República, 1978.

GÓMEZ VALDERRAMA, Francisco. Historia de Santa Rosa de Cabal. Pereira: Editorial Papiro, 1994.

GÓMEZ, Diego M. Apuntes para la Historia de Santa Rosa de Cabal. Pereira: Tipografía Santander, 1926.

GRISALES OTÁLVARO, Jaime José. El camino del Quindío en la conformación de la región. En: Historia de Nuestra Región. La Historia del Quindío. La Crónica. Armenia, (s.f.).

JARAMILLO, Roberto Luis. La Colonización Antioqueña, p. 190. En: Historia de Antioquia. Ed. Jorge Orlando Melo. Medellín: Suramericana de Seguros, 1988

LARRICHIO, Larry Vito. La arquitectura del paisaje topográfico-ecológico y adaptación cultural en el Eje Cafetero. En: Policromías de una región. Procesos históricos y construcción del pasado local en el Eje Caferero. Pereira: Universidad Autónoma de San Luis Potosí, Red Alma Mater, 2008.

LEGRAND, Catehrine. Colonización y protesta campesina en Colombia 1850-1950. Bogotá: Universidad Nacional de Colombia, 1988.

LONDOÑO MOTA, Jaime. La frontera: un concepto en construcción. En: Fronteras. Territorio y Metáforas. GARCÍA, Clara Inés (Comp.). Medellín: Hombre Nuevo Editores, Instituto de Estudios Generales Universidad de Antioquia. 
LONDOÑO, Jaime. El Modelo de Colonización Antioqueña de James Parsons. Un balance historiográfico. En: Revista Frontera de la historia.

LOPERA GUTIÉRREZ, Jaime. La colonización del Quindío. Apuntes para una monografía del Quindío y Calarcá. Bogotá: Banco de la República, 1986.

LÓPEZ, Alejandro. Problemas Colombianos. París. Editorial París-América, 1927.

LÓPEZ, Juan Bautista. Biografía de Fermín López. En: Santa Rosa: Primer Centenario/Dirección: Rafael Lema Echeverry/Administrador: Enrique Valencia. 1944.

MAIGUASHCA, Juan. Dirigentes políticos y burócratas: el Estado como institución en los países andinos, entre 1830 y 1890. En: Historia de América Andina. Creación de las repúblicas y formación de la nación. Vol. 5. Maiguashca, Juan, edit. Quito: Universidad Andina Simón Bolívar, 2003.

ORTIZ MESA, Luis Javier y ALMARIO GARCÍA, Oscar. Caldas: Una región nueva, moderna y nacional. Bogotá: Universidad Nacional de Colombia Sede Medellín, 1990.

PARSONS, James P. La Colonización Antioqueña en el Occidente de Colombia. Medellín, 1950.

PARSONS, James J. La Geografía como exploración y descubrimiento. Traducido de Annals of the Assocation of American Geographers, Vol. 67, No 1, marzo de 1977, pp. 1-16. Versión española de Dr. H. F. Rucinque en: Trimestre Geográfico, Vol. 1, marzo 1980. En: Las regiones tropicales americanas: visión geográfica de James J. Parsons. Bogotá: Fondo FEN Colombia, 1992, p. 27.

PEÑA PIÑEIRO, Heliodoro. Geografía e historia de la Provincia del Quindío (Departamento del Cauca) 1892. 2a edición. Pereira: Instituto de Cultura de Pereira, 2003.

PÉREZ GUZMÁN, Gonzalo Alberto. Juan Bautista Alberdi: Padre Constitucional Argentino. Monografías.com

REBORATTI, Carlos E. Fronteras agrarias en América Latina. Cuadernos Críticos de Geografía Humana. Universidad de Barcelona. Año XV. No 87. Mayo de 1990. 
RESTREPO M. José M. El explorador manizaleño Fermín López. En: Archivo Historial. Manizales, Imprenta departamental, 1923, 2a Ed. Col. Órgano del Centro de Estudios Históricos de Manizales. "Obras Históricas" No 3. Manizales: Academia Caldense de Historia, 2006.

RESTREPO PIEDRAHÍTA, Carlos. Constituciones políticas nacionales de Colombia. Bogotá: Universidad Externado de Colombia, 1995, p. 176.

RUIZ, Liliana Fabiola. El Estado y el concierto de los hijos de los esclavos. En: Reflexión Política, vol. 3, núm. 5, enero-juni, 2001. Bucaramanga: Universidad Autónoma de Bucaramanga.

SANTA, Eduardo. Colonización antioqueña. Una empresa de caminos. Bogotá: TM Editores, 1993.

TASCÓN, Tulio Enrique. Historia de Buga en la Colonia. Colección de Autores Bugueños. Alcaldía de Buga, p. 170.

TOVAR PINZÓN, Hermes. Que nos tengan en cuenta. Colonos, empresarios y aldeas: Colombia 1800-1900. Bogotá: Tercer Mundo Editores, 1995.

URIBE-URÁN, Víctor M. Vidas honorables. Abogados, familia y política en Colombia. 1780-1850. Medellín: Fondo Editorial Universidad EAFIT, coedición Banco de la República, 2008.

VALENCIA LLANO, Albeiro. Colonización. Fundaciones y conflictos agrarios. Segunda edición. Manizales: Artes gráficas Tizan, 2001.

VALENCIA LLANO, Alonso. Empresarios y políticos en el Estado Soberano del Cauca 1860-1895. Universidad del Valle- Facultad de Humanidades, Fundación para la promoción de la investigación y la tecnología, Banco de la República. Santiago de Cali, agosto de 1993.

VALENCIA R. Luis Enrique. Historia de Santa Rosa de Cabal. Volumen I. Manizales: Imprenta Departamental de Caldas, 1984.

VALENCIA RAMÍREZ, Enrique. Santa Rosa de Cabal y sus fundadores. Alcaldía Municipal de Santa Rosa de Cabal, 1980. 
VALENCIA ZAPATA, Alfonso. Quindío histórico. Monografía de Armenia. Armenia, 1963.

VILLEGAS ARANGO, Jorge. Colombia: Colonización de Vertiente en el Siglo 19. Medellín: Centro de Investigaciones Económicas. Universidad de Antioquia, 1977.

ZAMBRANO, Fabio y BERNARD, Olivier. Ciudad y territorio. El proceso de poblamiento en Colombia. Bogotá: Academia de Historia de Bogotá e Instituto Francés de Estudios Andinos, 1993.

ZULUAGA GÓMEZ, Víctor. El camino del Quindío y las guerras civiles. Cartago, Boquía, Salento, Ibagué. Pereira: Gráficas Buda, 2010.

LEYES I DECRETOS Espedidos por el Congreso Constitucional de la Nueva Granada en el año de 1842 págs. 13 i 14. En: Geografía y censos en el siglo XIX.

\section{Sitios Web}

Archivo General de la Nación «Sección República. Fondo Libros y manuscritos y leyes originales de la República Libro No. 120», www.negrosyesclavos.archivogeneral.gov. co

Archivo General de la Nación «Fondo Negros y esclavos». Acceso febrero de 2018. http://negrosyesclavos.archivogeneral.gov.co

GACETA DE LA NUEVA GRANADA. Trimestre 38. Bogotá, 18 de abril de 1841. No 501. Acceso febrero de 2018, http://bibliotecanacional.gov.co

GACETA DE LA NUEVA GRANADA. Trimestre 38. Bogotá, 9 de mayo de 1841. No 504. Acceso febrero de 2018, http://bibliotecanacional.gov.co

Concepto de legua. Disponible en: https://es.wikipedia.org/wiki/Legua\#Colombia 
Este libro terminó de imprimirse en Febrero de 2019, en los talleres gráficos de Publiprint, bajo el cuidado de los autores.

Pereira, Risaralda, Colombia. 
Se ha asumido que sucesos como el poblamiento de Montaña del Quindío y la fundación de Santa Rosa de Cabal, hacen parte de la llamada Colonización Antioqueña, espontánea y menesterosa, aunque las instituciones del Estado expiden leyes y decretos, asignan competencias, planean asentamientos y arbitran recursos del presupuesto de la Nación y de provincias como la del Cauca.

El presente trabajo precisa el papel del Estado en sus niveles nacional y territorial, en el poblamiento del noriente de la provincia del Cauca entre 1840 y 1845 ; lustro en que se asienta el presidio del tercer distrito en Boquía para reabrir el Camino del Quindío y se funda la población que hoy conocemos como Santa Rosa de Cabal.

Para esto se rastrean diversas caracterizaciones sobre la frontera y la colonización, se hace un gran balance historiográfico relacionado con las anteriores categorías y los sucesos objeto de estudio y se revisa la normatividad de entonces, para luego contrastar con los contenidos de fuentes primarias halladas en diversos archivos históricos del país.

elSBN: 978-958-722-530-3

ISBN: 978-958-722-336-1

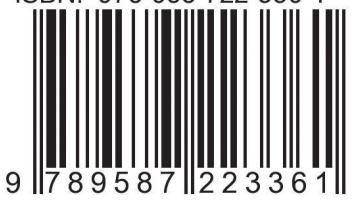

Universidad Tecnológica de Pereira 